\title{
IN-SERVICE PERFORMANCE AND BEHAVIOR CHARACTERIZATION OF THE HYBRID- COMPOSITE BRIDGE SYSTEM
}

\author{
A Thesis \\ Presented to \\ the faculty of the School of Engineering and Applied Science \\ University of Virginia \\ in partial fulfillment \\ of the requirements for the degree \\ Master of Science \\ by \\ John M Civitillo Jr
}

May

2014 
APPROVAL SHEET

The thesis

is submitted in partial fulfillment of the requirements

for the degree of

Master of Science

John M Civitillo Jr

AUTHOR

The thesis has been read and approved by the examining committee:

\begin{tabular}{c} 
Dr. Devin Harris \\
\hline Advisor \\
Dr. Michael Brown \\
\hline Dr. Thomas Baber \\
\hline
\end{tabular}

Accepted for the School of Engineering and Applied Science:

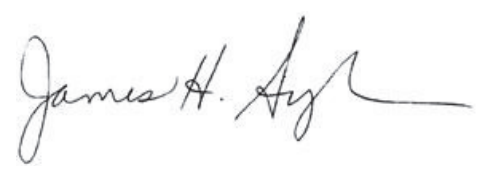

Dean, School of Engineering and Applied Science

May

2014 


\section{ACKNOWLEDGEMENTS}

The author would like to thank the following for their support and contributions to this work;

- Dr. Devin Harris, for taking me on as an advisee and being understanding as you guided me through the difficulties of graduate work, as well as supporting me as I grew as an engineer. In addition, it was a pleasure getting to know you, whether boating on Lake Anna or finding good food and beer or the nearest ski resort to fill down town time on instrumentation trips.

- Dr. Michael Brown, for serving on my committee, but also for overseeing this project and providing useful insight into instrumentation plans and the like. Also thanks are in order for taking me on as an undergraduate researcher. The work I did with under your guidance has significantly contributed to my progress and helped to lead me to where I am today.

- Dr. Thomas Baber, for serving on my committee, as well as being around during my entire engineering education to teach me the fundamentals of structural engineering principles with enthusiasm and gusto.

- Dr. Stephen Chase, for lending your NDE expertise to assist me in evaluating methods of inspection for $\mathrm{HCBs}$

- Dr. Bernard Kassner, for all of your help with the load testing and bridge insight. It was a pleasure working with you.

- Amir Gheitasi, for you continual assistance with my research, especially getting me up to speed rapidly on the steep ANSYS learning curve, as well as your help with the bridge instrumentation and load test. 
- Muhammad Sherif, for the numerous hours and patience you spent teaching me finite element modeling. That, and your friendship are sincerely appreciated and won't be forgotten.

- Mark Saliba, for taking charge of an entire data acquisition system for the load test. It was a relief to have one less thing to worry about, knowing you had things under control. As a great friend, your perpetual optimism in the office and your willingness to take breaks kept me sane.

- Victoria Tsamis, I am incredibly lucky to have you in my life. You are a truly awesome person and never fail to make me smile. Thanks for being there for me through the stressful times. I really look forward to things to come.

- To the rest of my graduate friends \& peers, including Mohamad Amine, Levon Hoomes, Sherif 'Whatever' Daghash, Jonathan Tanks, Lauren Bolton, and Jamie Johnston, your support and encouragement were more helpful than I'm sure you realize, and of course the many deep laughs we shared made my two years here an exceptionally memorable experience. I will miss you all.

- To my parents, John and Elaine Civitillo, your unconditional love and support has allowed me the opportunity to achieve each new goal I set for myself and I can't express my gratitude for all that you have done for me. To my sister, Alicia Civitillo, you're my oldest friend and have always been there for me when I needed you most. I wish only the best for you. 


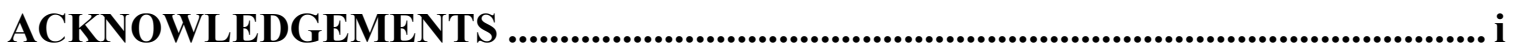

LIST OF FIGURES ……..................................................................................................

LIST OF TABLES ................................................................................................................ vii

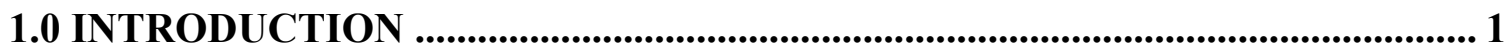

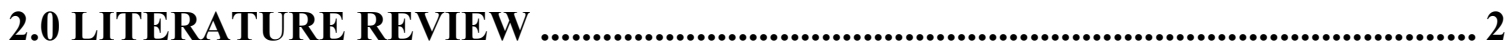

2.1 HCB Theory ......................................................................................................................

2.2 Benefits, Drawbacks \& Unknowns ....................................................................................

2.3 Previous Applications and Investigations ................................................................................11

3.0 SYTHESIS OF HCB BEHAVIOR FOR SUBMISSION TO THE ASCE JOURNAL FOR COMPOSITES IN CONSTRUCTION .......................................... 15

Abstract ...............................................................................................................................15

3.1 Introduction ..........................................................................................................................16

3.1.1 Background \& Research Significance ……………………………………………....16

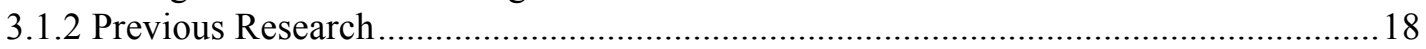

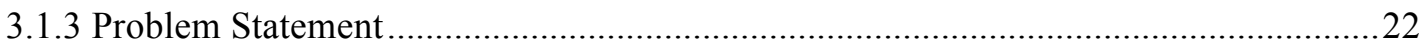

3.2 Tides Mill Stream - Route 205 Bridge ..................................................................................23

3.2.1 Instrumentation \& Experimental Setup …………………………………….....24

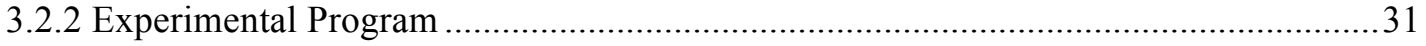

3.3 Finite Element Model \& Analysis ..............................................................................38

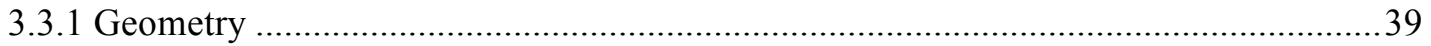

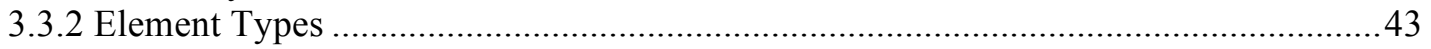

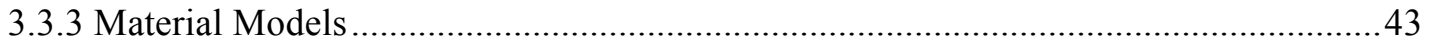

3.3.4 Loading \& Boundary Conditions..............................................................................4

3.4 Discussion of Results .................................................................................................................46

3.4.1 Finite Element Model Validation of Virginia Tech Study ………………………….....46

3.4.1 Flexural Lateral Load Distribution Behavior.................................................................47

3.4.2 Element Load Sharing Behavior...............................................................................56

3.4.3 Dynamic Load Allowance ……………………………….........................................63

3.5 Conclusions ..................................................................................................................................65

4.0 EVALUATION OF LONG-TERM INSPECTION TECHNIQUES ..................... 67

4.1 Reinforced Concrete Deck Inspection ...............................................................................68

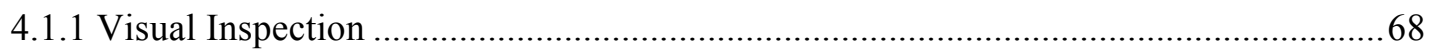

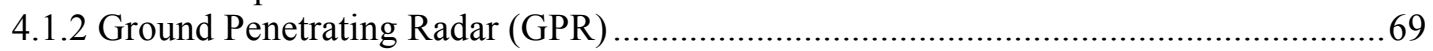

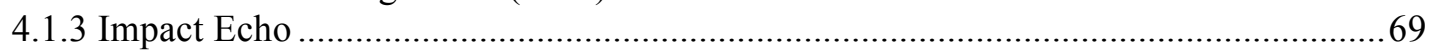

4.2 Steel Strand Inspection ...................................................................................................70

4.2.1 Magnetic Flux Leakage Inspection (MFL) …………………………………..... 70

4.2.2 Eddy Current Inspection ....................................................................................72

4.2.3 Impact Echo/Mechanical Sounding .......................................................................74

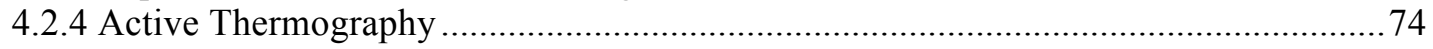

4.2.6 Visual Inspection for Local FRP Bulging...............................................................75

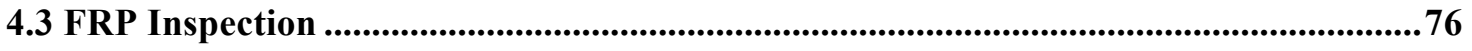

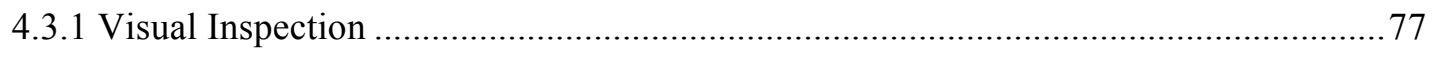




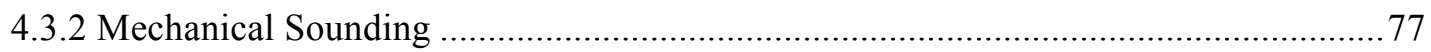

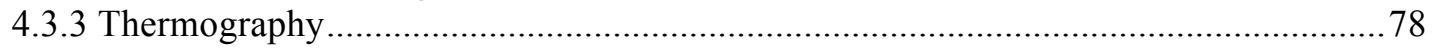

4.4 Inspection of HCB Interior for Moisture Content .............................................................78

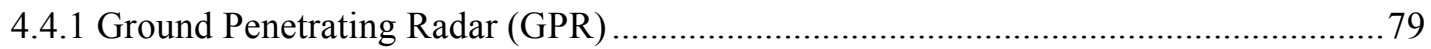

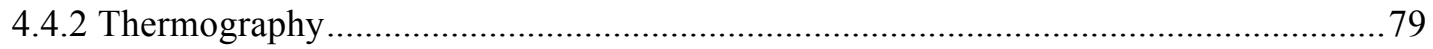

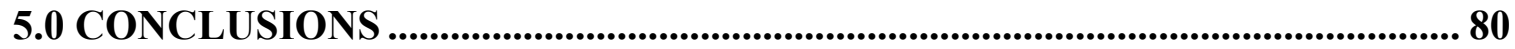

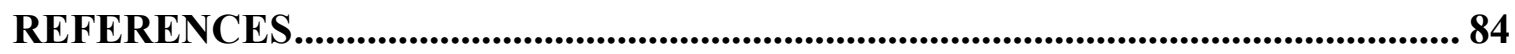

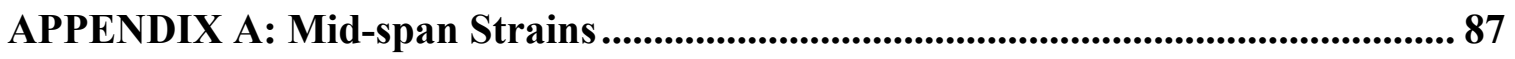

APPENDIX B: Quarter-span Strains ............................................................................... 103

APPENDIX C: Barrier Strains........................................................................................ 119

APPENDIX D: Mid-span Strain Profiles ............................................................................ 123

APPENDIX E: Quarter-span Strain Profiles.................................................................. 131

APPENDIX F: Dynamic Amplification .................................................................. 139 


\section{LIST OF FIGURES}

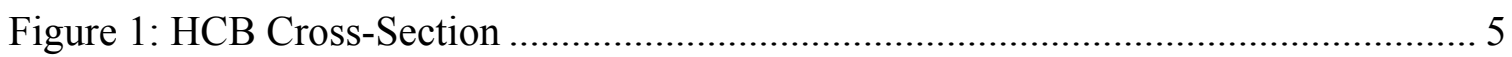

Figure 2: Hybrid Composite Beam Design (Hillman 2008) ............................................ 17

Figure 3: Thin Arch Local Bending Hypothesis (Adapted from Ahsan, 2012)................ 21

Figure 4: Instrumentation Overview in Plan View ……………………………....... 24

Figure 5: Vibrating Wire Gauge Locations through the Depth ...................................... 26

Figure 6: Mid-span Cross-Sectional Instrumentation Layout and Test Truck Loading

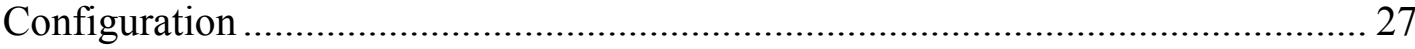

Figure 7: Internal VWG Placement at Tension Level (Left) and FRP Shell After Resin Infusion (Right).................................................................................. 28

Figure 8: Concrete Arch VWG Stacked Frame at Mid-span (Left) and Additional Rosette

Configuration at Eighth-span (Right) ............................................................ 29

Figure 9: Finished FRP Box Shell Being Filled with SCC............................................ 30

Figure 10: Instrumenting Bridge Underside ............................................................. 31

Figure 11: Bottom Flange External Strain Gauge Placement............................................ 32

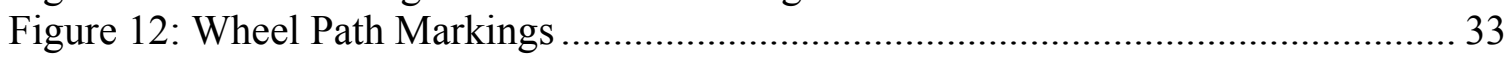

Figure 13: Wireless BDI Nodes (Left) and Cardboard 'Igloo' (Right) ............................. 34

Figure 14: Campbell Scientific Data Loggers Setup ...................................................... 35

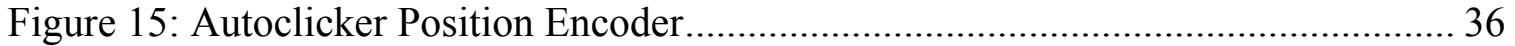

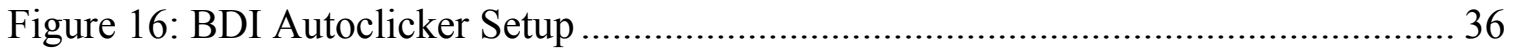

Figure 17: Guiding Load Truck for Quasi-Static Testing............................................. 38

Figure 18: Internal Arch Concrete Geometry \& Mesh ..................................................... 40

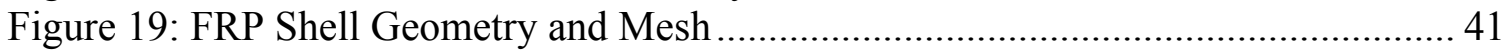

Figure 20: Full-Scale Skewed HCB Bridge Model ........................................................ 42

Figure 21: Boundary Condition Validation by Strain Distibution................................... 45

Figure 22: Transverse Distribution of Mid-span Tension Flange Strain versus Girder

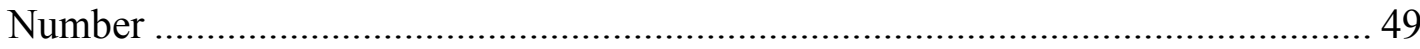

Figure 23: Transverse Distribution of Quarter-span Tension Flange Strain Versus Girder

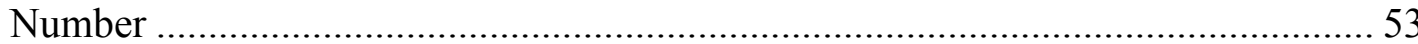

Figure 24: Simplified Representation of Possible Separation of Steel and FRP Under

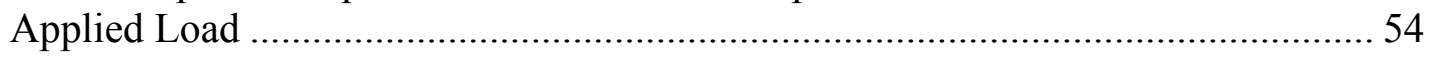

Figure 25: Load Case 'A' Longitudinal Strain Response .................................................. 55

Figure 26: Strain Profiles Through Mid-span Depth of Truck Locations F Through H... 57 Figure 27: Strain Profiles Through Quarter-span Depth of Truck Locations F Through H

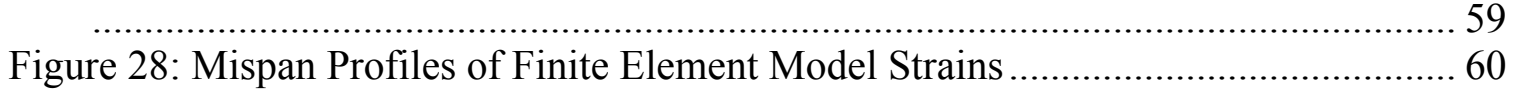

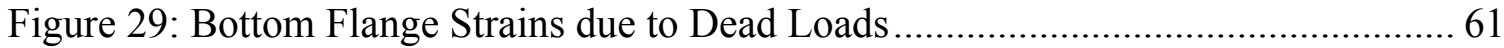

Figure 30: Concrete Arch Strains due to Dead Loads ..................................................... 62

Figure 31: Representative Mid-span Time-Lapse Strain Comparison

Girder 8 Response for Load Case H, Run 1

Figure 32: Maximum Dynamic Amplification Response Under Load Case 'B' (Left) and

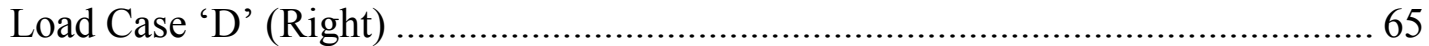

Figure 33: Magnetic Flux Leakage Theory (Chase, 2013) ............................................... 71 
Figure 34: Example of Automated Magnetic Flux Leakage Inspection (Ghorbanpoor,

Borchelt, Edwards \& Abdel Salam, 2002)....................................................... 71

Figure 35: Mutual Inductance Theory - Magnetically induced current in conductive surface creates secondary magnetic fields that in turn influence the current feedback

in coil (Collaboration for Non-Destructive Testing, 2014) ................................. 73

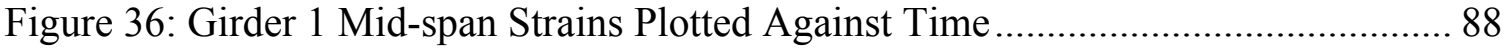

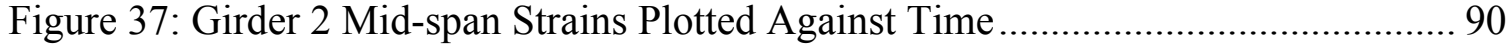

Figure 38: Girder 3 Mid-span Strains Plotted Against Time ......................................... 92

Figure 39: Girder 4 Mid-span Strains Plotted Against Time .......................................... 94

Figure 40: Girder 5 Mid-span Strains Plotted Against Time ......................................... 96

Figure 41: Girder 6 Mid-span Strains Plotted Against Time ........................................ 98

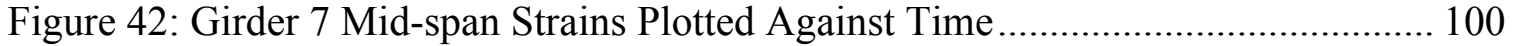

Figure 43: Girder 8 Mid-span Strains Plotted Against Time ..................................... 102

Figure 44: Girder 1 Quarter-span Strains Plotted Against Time .................................. 104

Figure 45: Girder 2 Quarter-span Strains Plotted Against Time ................................. 106

Figure 46: Girder 3 Quarter-span Strains Plotted Against Time ................................. 108

Figure 47: Girder 4 Quarter-span Strains Plotted Against Time ................................ 110

Figure 48: Girder 5 Quarter-span Strains Plotted Against Time ................................. 112

Figure 49: Girder 6 Quarter-span Strains Plotted Against Time ................................ 114

Figure 50: Girder 7 Quarter-span Strains Plotted Against Time .................................. 116

Figure 51: Girder 8 Quarter-span Strains Plotted Against Time .................................. 118

Figure 52: North Barrier Strains (Maximum Influence on Girder 1) ............................ 120

Figure 53: South Barrier Strains (Maximum Influence on Girder 8) ........................... 122

Figure 54: Load Case 'A' Mid-span Strain Profiles .................................................... 123

Figure 55: Load Case 'B' Mid-span Strain Profiles ..................................................... 124

Figure 56: Load Case 'C' Mid-span Strain Profiles .................................................... 125

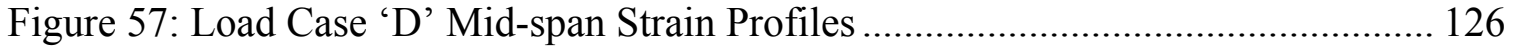

Figure 58: Load Case 'E' Mid-span Strain Profiles...................................................... 127

Figure 59: Load Case 'F' Mid-span Strain Profiles....................................................... 128

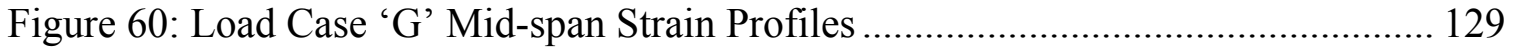

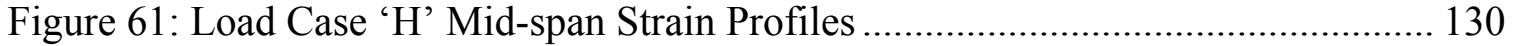

Figure 62: Load Case 'A' Quarter-span Strain Profiles.............................................. 131

Figure 63: Load Case 'B' Quarter-span Strain Profiles............................................... 132

Figure 64: Load Case 'C' Quarter-span Strain Profiles.............................................. 133

Figure 65: Load Case 'D’ Quarter-span Strain Profiles.................................................. 134

Figure 66: Load Case 'E' Quarter-span Strain Profiles .............................................. 135

Figure 67: Load Case 'F' Quarter-span Strain Profiles ............................................... 136

Figure 68: Load Case 'G' Quarter-span Strain Profiles............................................. 137

Figure 69: Load Case 'H’ Quarter-span Strain Profiles............................................. 138 


\section{LIST OF TABLES}

Table 1: Vibrating Wire Gauge Instrumentation Location Matrix ................................ 26

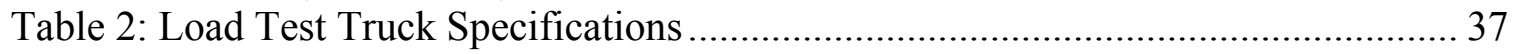

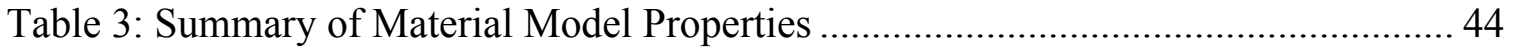

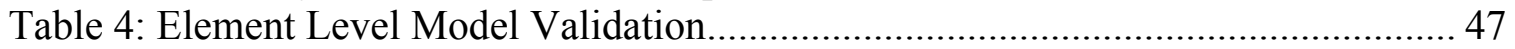

Table 5: Summary of Mid-span Flexural Distribution Factors..................................... 51

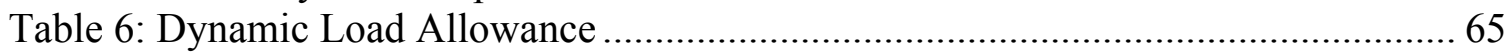

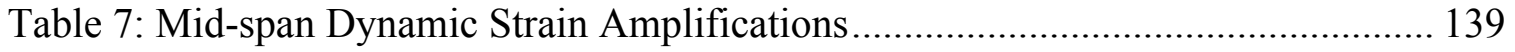

Table 8: Quarter-span Dynamic Strain Amplifications ............................................. 139 


\subsection{INTRODUCTION}

A relatively new technology in the field of structural engineering, hybrid composite beams $(\mathrm{HCB})$ have begun to show their worth as attractive alternatives to traditional bridge members such as concrete and steel. The HCBs are lighter in weight allowing for smaller cranes for construction, and corrosion resistant, potentially offering an extended lifespan over conventional girders.

This study was conducted as a means of evaluating the HCB girders for use in a skewed bridge construction project in Colonial Beach, Virginia. Previously, testing and applications have been limited to straight bridges, and the Virginia Department of Transportation (VDOT) wished to gather more information on the behavior of these complicated HCBs in a skewed configuration. The goal was to understand how the loads are transmitted and how the structure should be inspected in the future to ensure the beams are healthy, despite the inability to visually inspect the crucial load carrying components encased in the fiberglass shell.

This research was the second phase of the project, and done as a follow up to Ahsan's (2012) laboratory work that was conducted on three identical HCBs in the laboratory at Virginia Tech prior to construction of the bridge. The research presented here is the result of an extensive in-service load test, finite element model validation of results, and an evaluation of non-destructive evaluation techniques for inspecting the condition of the girders in the future. 
Chapter 2 follows, and presents a summary and review of the literature relevant to this study. This chapter includes background information on the design and mechanics of the HCB system, as well as the differences that set it apart from the conventional steel and concrete girders it is proposed to replace. Finally, this section offers a summary of pertinent past research and highlights the results that are of interest to this study. Chapter 3 is a comprehensive section that is presented in a manner similar to that required for submission to the American Society of Civil Engineers (ASCE) Journal of Composites for Construction. The section contains all relevant data and discussions for completeness, but was trimmed down to adhere to journal constraints for submission. It is intended to serve as itself, a standalone document, and thus contains its own introductory material and conclusions. Therefore, parts of this document will seem repetitive, but chapter 3 also serves as the meat of the research, offering the majority of the data and discussion of results. A chapter four follows, serving to propose directions for future research in the area of standardization of non-destructive evaluation methods for long-term HCB inspection \& monitoring. Lastly, chapter 5 summarizes the work done and concludes the proceedings of this research.

\subsection{LITERATURE REVIEW}

The idea of hybrid-composite beam technology made its debut into a bridge construction application as a prototype railroad bridge in 2007 , making it extremely young for a civil engineering technology. Since the prototype testing at the Transportation Technology Center, Inc. (TTCI) in Pueblo, Colorado, HCBs have been used in another railroad project in Colorado as well as highway projects in Illinois, New Jersey, Maine, and several projects in Missouri, although many of these instances have not performed field 
testing. Accordingly, there is only a small amount of literature available on these beams and their limited applications. While HCB is continually being used in more and more applications, not all construction projects involve accompanying research, and several have yet to be published.

The earliest studies focus on the design and behavior of individual beams and how they behave as a tied-arch system under self-weight and non-composite dead loads. The strength and serviceability were tested to confirm the design assumptions and substantiate the technology as a legitimate system. The purpose of these beams as an efficient configuration of strong materials for lightweight and accelerated construction is also evaluated in the incipient stages of research. Feasibility studies were performed to compare the cost and lifecycle of these HCBs against conventional girder technologies across a variety of bridge spans (Hillman, 2002).

As HCBs were used in more mainstream bridge applications, some research focus was allocated towards investigating the behavior of beams when acting as a bridge unit. Specifically, the relative behavior of the beams within a unit was of interest, and the global behavior of HCB bridge systems.

\subsection{HCB Theory}

Just as many great civil engineering advancements start with a simple concept, John Hillman of the HC Bridge Company recognized the application for the one of the strongest structural shapes in bridge construction. The arch has been used as a structural support for thousands of years, but never within a beam itself. Hillman speculated that the 
arch shape could be used within a bridge girder to carry the compression zone loads generated during flexural loading, and conserve excess concrete materials that offer little load resistance in the tension zone. Hillman's vision was completed with the combination of 3 well-known civil engineering materials in a configuration that makes use of each material's strongest asset. FRP is stronger than steel, but more flexible. The contribution of the concrete carrying compression loads and steel carrying tensile loads is comparable to traditional reinforced concrete theory and counteracts the flexibility of the system.

A single beam consists of a parabolic concrete arch tied in the tension zone by steel, carbon fiber, or glass fiber prestressing strand. Under bending, the beam distributes loads from the top of the beam through axial compression of the arch down to the supports, where the tension strand restrains the supports. The entire arch system is contained within a glass fiber-reinforced polymer (FRP) box shell that protects the main load carrying components and contributes additional shear resistance and shear capacity in certain primary fiber directions during flexure. Figure 1 offers a visual representation of the orientation of each of the aforementioned materials. 


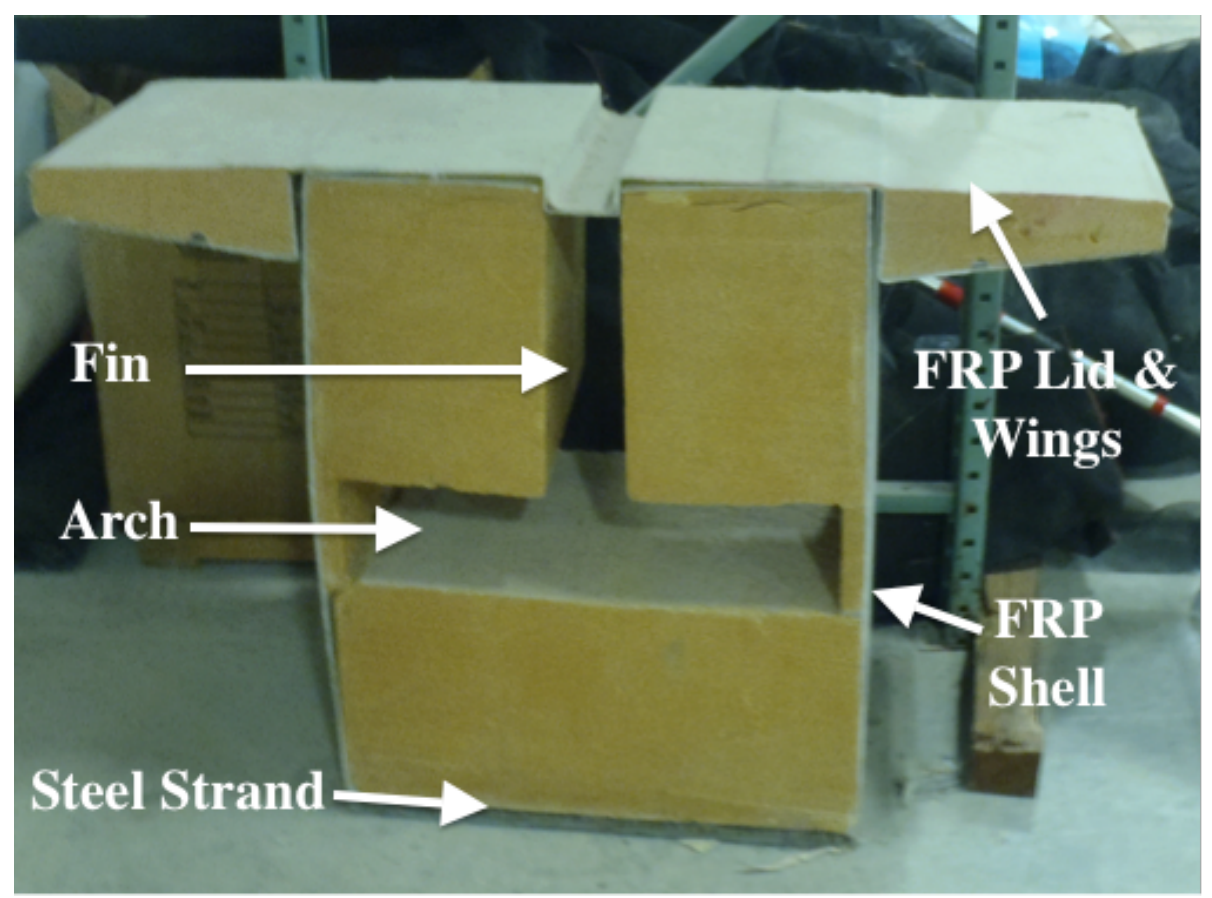

Figure 1: HCB Cross-Section

For the FRP shell, a quad-weave fiber fabric is used in order to avoid custom alignment of fiber orientations for each application. In this fabric, 45 percent of the fibers are orientated in the longitudinal direction, while 25 percent runs in both a positive and negative 45-degree orientation. The remaining 30 percent of the fibers run in the direction perpendicular to the length of the beam (Hillman, 2002). During fabrication of the beam, several layers of the fiberglass fabric are laid in the box formwork. The tension zone reinforcement is laid in the base of the beam formwork and covered with a single additional fiberglass sheet prior to the resin infusion process. Considerations for the tension reinforcement include carbon fiber, glass fiber prestressing strands, as well as traditional steel strands and a welded steel wire mesh. While each is a valid option, steel remains the most cost effective (Hillman, 2002). The core formwork, cut of polyisocyanurate foam, is laid in the mold next, filling the void space of the box while retaining the arch-shaped formwork for the concrete to be filled in the beam at a later 
time. See Figure 1 for a cross-sectional representation of the foam placement within the beam. The height of the voided concrete formwork varies parabolically over the length of the beam to create the arch shape.

The beam is then infused with a vinyl ester resin through a closed-mold vacuum-assisted resin transfer method (VARTM) that creates a monolithic unit of FRP, steel and foam (Hillman \& Otter, 2008). During this process, the foam supports the beam shape during the vacuum application, and maintains the arch profile. While not structurally significant, the foam offers some lateral stability to the beam, improves the elastic buckling capacity of the FRP webs, and helps to distribute the load to the rest of the beam beneath the concrete arch (Hillman, 2002).

The FRP lid and wings are manufactured separately from the rest of the beam, but glued together prior to placement of the arch concrete. Inclined shear connectors, consisting of conventional steel rebar are inserted through holes drilled in the middle of the lid and fed down through the vertical concrete 'fin' (Figure 1) to the concrete arch and serve to enforce composite action between the deck concrete and the HCB. Once the shear connectors are in place, a highly workable concrete mixture, typically self-consolidating concrete (SCC) is fed into the beam to fill the voided conduits. The concrete is vibrated to ensure that all void spaces are filled entirely.

The geometry of these beams is complicated relative to a conventionally reinforced concrete beam, but John Hillman devised a design methodology that includes simplifying design assumptions that allow for use of traditional beam theory. These include 
assumptions that all materials are assumed to act linearly elastically under service loads, and that plane sections remain plane during flexure. A transformed section approach is used, converting steel and concrete sections to equivalent FRP sections (Hillman, 2003). Section properties including centroid and moment of inertia are generated for the tenth points of the beam. Design loading values are drawn from AASHTO, including distribution factors and dynamic load amplifications for an HL-93 design truck, and applied at the $10^{\text {th }}$ points to determine the controlling moment and shears (Hillman, 2011).

The strength limit state for flexure is checked by a comparison of the strains at mid-span to ultimate strain values for each material. A linear strain profile is assumed for this purpose. The shear strength calculations were limited to the shear stress capacity of the FRP webs, which was determined to be $7.5 \mathrm{ksi}$. Due to the inclined profile of the arch in compression, the vertical component of the axial load is considered to contribute to the shear resistance, but not the area of the concrete arch or fin. The shear is taken this way to ensure a conservative calculation for the FRP capacity, despite the area of the fin being greatest at the location of maximum shear (Hillman, 2003).

The stiffness of the beam varies over the length, and thus the moment-area method for calculating deflection is used. The deflections are calculated for the non-composite section with no compressive contribution from the deck, and these deflections are used as the camber built into the formwork for the FRP layup. Because the beam is deflectioncontrolled, additional steel is required to satisfy serviceability, making the beam over- 
reinforced. This means that unlike reinforced concrete beams, the failure mode will not be ductile, but rather a brittle failure of the deck via crushing before the tension steel ever yields (Hillman, 2002).

\subsection{Benefits, Drawbacks \& Unknowns}

A topic of interest to some of the preliminary HCB studies (Hillman, 2002) was the feasibility of the system as a viable alternative to existing structural bridge members. There are quite a few features of HCBs that make them attractive to use in both new construction and bridge superstructure replacement projects, but there are also some drawbacks to be considered. Additionally, there are some unknown factors regarding the performance and behavior of the girders that still need to be quantified.

Through use of the concrete arch, a significant quantity of material is saved, which is beneficial both from a constructability and environmental standpoint. The minimization of concrete makes the girders much lighter than ordinary prestressed girders typically required for comparable spans, in some cases as much as $10-20 \%$ reduction in weight (Otter \& Doe, 2009). Due to the lighter weight of the girders, shipping costs may be reduced since there will be fewer shipments required. Shipping weight may be drastically reduced if the beams are shipped empty and filled with concrete on site. From an environmental standpoint, the production of cement releases large quantities of carbon dioxide into the atmosphere, so any reduction in concrete consumption is better for the environment. Additionally, the lighter shipping weight and fewer shipments require less fuel consumption. 
The light weight of the girders also allows for the reuse of existing abutments in many bridge superstructure replacement projects. Large cranes will not be necessary to move the girders into place, and as the girders are self-supporting both under self-weight and the dead weight of uncured concrete, the girders may be placed on the abutments without being filled with arch concrete and eliminate the need for any shoring or deck formwork as the girders themselves serve this purpose (Hillman, 2002). Also of importance is the similarity to other bridge construction methods. Once the girders have been fabricated, they resemble a traditional prestressed concrete girder, and require a very low learning curve for installation.

HCBs are also well suited for accelerated bridge construction (ABC) projects as the girders are self-contained, prefabricated units. If the arch concrete is placed within the girder just off-site with adequate curing time, shipping weight will still be conserved, yet the girders can be installed in a minimal amount of time thus minimizing the disruption to traffic flow or railway deliveries (Hillman, 2008).

Of the few negatives associated with HCB use, an important one is the over-reinforced nature of the beams. As mentioned previously, the girders are flexible and require steel beyond the strength requirement to meet serviceability requirements. Because of this, the failure mode for this type of girder is a brittle one. On the other hand, there is a significant amount of reserve strength, in some cases as much as four times the design strength (Hillman, 2002). The HCBs tend to be slightly deeper than their prestressed 
counterparts due to the nature of the arch and may be of concern to certain users constrained by depth limitations.

The cost of HCBs is higher due to the materials and the labor involved in manufacturing the FRP shell. There is a lack of continuity in the manufacturing process as the FRP shells have to be laid up by hand and the shell manufacturing process has yet to be automated (Hillman, 2002). That being said, as the beams continue to be used in projects and gain traction, the economy of scale should allow for more streamlined manufacturing processes and reduced costs. Still, cost analyses show that the beams are feasible for railway applications in the range of 40 to $60 \mathrm{ft}$ spans, as concrete beams are too heavy for existing rail cranes, but steel is too costly for these spans (Otter \& Tunna, 2011). Similarly, when taking into account the lifecycle cost of the beams, it has been shown that $\mathrm{HCBs}$ are cost-competitive in the 30 to $50 \mathrm{ft}$ span range because the higher cost may be distributed over a longer projected service life (Hillman, 2002).

The projected service life of these girders is expected to be around 100 years versus the projected 75-year lifespan of concrete girders. It is expected that the FRP shell will provide protection for the internal load carrying components, however it has yet to be shown that this holds true for long periods of time. The fiberglass is impervious to water and chlorides, thus there is little chance for corrosion of the steel or degrading concrete reactions. Furthermore, the FRP weathers well in marine environments, but is susceptible to degradation from ultraviolet rays. The concrete bridge deck should provide adequate protection from sunlight, however. Other questions that have been raised include the fire 
resistance of the girders, and the lateral stability in the case of a vehicular collision (Otter \& Doe, 2009).

\subsection{Previous Applications and Investigations}

The first investigation of hybrid composite girders was sponsored by the Transportation Research Board as part of the Innovations Deserving Exploratory Analysis (IDEA) program. The program involved several phases of investigation and was intended to serve first as a feasibility study for HCB application in the bridge market, and second to test prototype beams to determine the reliability of the design philosophy and gather information on the behavior of the complicated beam systems.

The first phase of this IDEA program was a feasibility study in which John Hillman investigated the cost of producing beams for varying span lengths. Current railway bridge replacement projects became the focus and led to short and medium span bridge applications. The girders were found to be less costly than steel, but more costly than concrete. Hillman (2003) indicated the life cycle costs could still be competitive.

A single $20 \mathrm{ft}$ prototype beam was constructed in 2003 for testing at the University of Delaware as the second phase of the program. The girder was 12 in wide by 24 in deep and did not include a composite deck. The beam was simply supported, and loaded in 9 load cases by four actuators distributing load over the span with spreaders. Heavy instrumentation included linear strain gauges throughout the interior of the beam to measure bending stresses and maximum stresses in each material, and deflections were recorded with string potentiometers. The load cases included varying loads across the 
span, mimicking dead loads of a completed rail structure, live loads produced by a Cooper E-80 rail car with impact factors applied, as well as locations of maximum shear and moment. A cyclical load was applied for 100,000 cycles and then the beam was tested for fatigue damage. On the final loading, the beam was tested to failure, sustaining almost 60 kips of load and measuring a deflection just over 2 inches. The deflections were found to be greater than predicted by design, but the overall design methodology was confirmed by the load tests. The linearly elastic assumptions held true until just near ultimate loading. An interesting outcome of the study was the discovery that the system acts like a tied arch close to mid-span, but not at the supports. Near the beam ends, concrete and steel loads diminished, as the FRP webs distributed the loads to the supports at these locations through shear (Hillman, 2003).

The next phase of research was conducted at the Transportation Technology Center, Inc. (TTCI) in Pueblo, Colorado. This instance of HCB was for a complete railway bridge structure to replace an existing structure. The bridge, which weighed just $57 \%$ of the one it replaced, consisted of $8 \mathrm{HCBs}$, each 20 inches wide by 28 inches deep, and bolted sideby-side through their webs into two four-girder groupings (Hillman, 2008). A 4-inch composite deck was included, along with ballast curbs and ballast for the rail. The bridge occurred on a curved portion of track and thus experienced a slightly inclined loading from the inclined rail and centripetal motion of the train. Instrumentation for this test included strain gauges, deflection sensors and linear variable distance transducers (LVDT). The loading program consisted of running heavily loaded freight cars over the 
bridge, first at static locations to produce maximum shear and moment, then at increasingly rapid dynamic speeds.

The results of this test also found that the structure acted predictably and within AREMA code limits (Hillman, 2008). LVDT measurements confirmed that there was indeed full composite action between the deck and girders. All stresses measured were well within the ultimate capacities of each respective material. Limited damage was discovered in the deck concrete, but was concluded to be shear cracking due to the eccentricity of the load and not due to any HCB deficiencies. It was noted that the exterior girders, which supported the ballast curbs always experienced less deflection and strain due to the added stiffness contributed by the curbs.

A large-scale project was undertaken in 2010 in Boothbay, ME to construct an eight span HCB bridge spanning a total of $540 \mathrm{ft}$ (Snape, 2009). This time testing took place prior to construction at the Advanced Structures and Composites Center at the University of Maine. A single beam was tested for service and fatigue loads both with and without the addition of a composite deck, and finally loaded to failure. These girders were 33 in deep with 42 steel strands of .5 in diameter, spaced at $4 \mathrm{ft}$ center-to-center such that FRP wings were integrated with the lid to serve as formwork for the deck in the interstitial space of the beams. Instrumentation included strain gauges internally and externally, LVDTs, string potentiometers, load cells and a 3D digital imaging system to capture surface strains. Instrumentation was primarily concentrated to mid-span, quarter-spans and the supports. 
The beam was first tested without the presence of a deck, and was subjected to four point bending to simulate an HL-93 truck loading. First service shear and moments were determined from static loading, followed by a fatigue loading of 2,000,000 cycles with interim flexural tests to investigate any damage accumulated. The deck was then added to the beam and a similar loading scheme was prescribed. In both cases the beam behaved as predicted, although the beam was even stiffer than predicted, eventually attributed to the contribution of the FRP wings that were neglected in design calculations (Snape, 2009). In addition, there was elastic buckling observed in the FRP lid of the beam during the test prior to addition of the deck, but this behavior was eliminated when constrained by the deck. The last loading cycle took the beam to ultimate, and proved that the beam behaved linearly elastic through failure.

Preliminary work was performed by Ahsan (2012) at Virginia Tech as a lead-in to the construction of the Tides Mill Stream Bridge and load testing program and research that is the topic of this paper. A description of the research performed and its relevance to the results obtained in this project are presented in section 3.1.2 and should be referenced as an exploratory program aimed at mimicking many features of the as-built Route 205 Bridge.

Chapter 3 follows as a comprehensive research document in its own right. It is intended to serve as the groundwork for a journal submission, and therefore includes introductory and conclusive material within the overarching paper. This chapter synthesizes the data 
collected and research performed to draw conclusions regarding the behavior of the HCB system constructed over the Tides Mill Stream.

\title{
3.0 SYTHESIS OF HCB BEHAVIOR FOR SUBMISSION TO THE ASCE JOURNAL FOR COMPOSITES IN CONSTRUCTION
}

\begin{abstract}
The Hybrid Composite Beam (HCB) system is an innovative structural technology that has been recently used in bridge construction within the U.S. transportation network. In this system, the superstructure consists of a conventional reinforced concrete deck supported by Hybrid Composite Beams. Each beam is comprised of a glass-fiber reinforced polymer (FRP) box shell containing a tied parabolic concrete arch. Inclined stirrups provide shear integrity and enforce composite action between the HCBs and the concrete deck. This investigation focuses on evaluating the in-service performance of a newly constructed HCB bridge superstructure located on Route 205 in Colonial Beach, Virginia. A live load test was conducted using tandem axle dump trucks under both quasi-static and dynamic conditions. Results obtained from the experimental investigation were used to determine three key behavior characteristics, which were validated by a finite element model. Dynamic amplification and lateral load distribution were found to be acceptable in comparison to the assumed design values. The testing program also included internal and external measurement systems to help characterize the load sharing behavior of the HCB on an element level. It was confirmed that the main load carrying elements are the deck in compression and the steel ties in tension, and it was found that the FRP shell did not act compositely with the internal components due to local bending effects of the thin arch, and de-bonding of the steel and FRP interface.
\end{abstract}




\subsection{Introduction}

The state of bridges in the United States is one of disrepair. According to the ASCE infrastructure report card (2013), about one third of the nation's bridges by square footage are rated as structurally deficient. More than $30 \%$ of bridges have surpassed their 50-year design, but remain in service (ASCE 2013). As bridge engineers attempt to mitigate this problem, alternative bridge designs and construction practices have been developed. Accelerated bridge construction $(\mathrm{ABC})$ is one such method in which major bridge components are constructed off site and simply dropped in place, minimizing the cost and time associated with the disruption of traffic flow, and freeing resources that may be directed to bridge rehabilitation efforts elsewhere. The Hybrid Composite (HCB) system offers an attractive mix of conventional civil engineering materials and an efficient arrangement of these materials to produce a self-contained, lightweight girder that may be used in $\mathrm{ABC}$ and offers the potential for extending the service life of such bridges.

\subsubsection{Background \& Research Significance}

The Hybrid Composite Beam (HCB) system, as shown in Figure 2, consists of a glass fiber reinforced polymer (FRP) box shell that encases a passively tied concrete arch. The tie reinforcement is unstressed prestressing strand that is integrated into the shell fabrication, while the arch is typically made of self-consolidating concrete that is able to fill the $100 \mathrm{~mm}$ (4 in) thick arch profile created with foam inserts (Hillman 2008). Within the design, the concrete arch resists the internal compression forces due to self-weight and additional construction loads, while the steel is intended to tie the arch together and carry internal tensile forces. Reinforcing bars oriented at $45^{\circ}$ from vertical and anchored 
within the arch section are distributed along the beam to provide composite action between the beam and a conventionally reinforced concrete deck. In this configuration, when the bridge is under service loads, the major load resisting components are the deck in compression and the steel in tension (Van Nosdall et al. 2013).

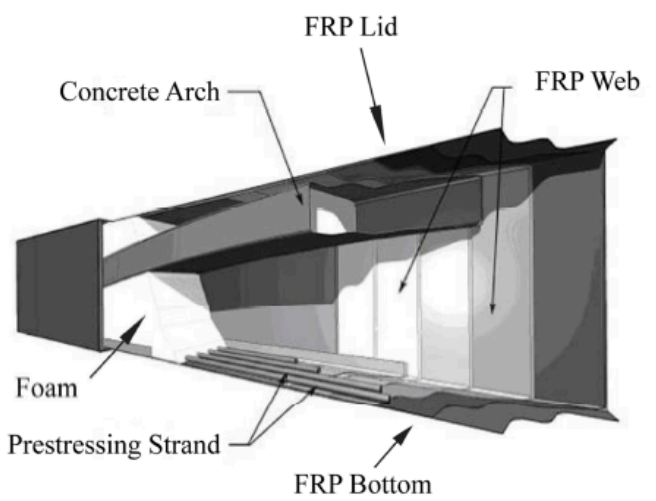

Figure 2: Hybrid Composite Beam Design (Hillman 2008)

The efficient use of materials, lightweight design, corrosion resistance, and application in accelerated construction applications are some of the advantages that make the HCB system an attractive alternative to conventional bridge designs (Hillman 2008). As this innovative structural system is quite new to the bridge industry and has been used in very few previous applications, it is necessary to understand the behavior and response under standard in-situ loading scenarios. This study provides a foundation for understanding the structural characteristics of the HCB system, which is crucial to confirm the design methodology and promote further applications in the North American transportation network. Furthermore, this bridge technology was designed for a longer than average life span, but doesn't have a long enough in-service history to provide a comprehensive understanding of its behavior over the lifespan. 


\subsubsection{Previous Research}

This project is the culmination of a multi-phase research project designed and funded by the Virginia Department of Transportation (VDOT) to investigate the HCB system for use in Virginia. As the first application of $\mathrm{HCB}$ in the state was slated to undergo construction in 2013 over the Tides Mill Stream in Colonial Beach, it was of interest to the owner to have a better understanding of the system's behavior. Virginia Tech was tasked with the investigation of the HCB system in a laboratory setting, focusing on the element-level behavior and load path generated between the concrete arch and FRP shell, at various phases throughout the construction of the system and a variety of loading scenarios. Of particular interest was a confirmation of the flexural design methodology, which currently uses a transformed sections approach (Van Nosdall et al. 2012). The research presented in this paper, however, focused on the in-service behavior the particular application of the HCB girders and provides insight into some element level behavior under service loads, but also global behaviors of this system.

In the Virginia Tech study, three $\mathrm{HCB}$ were built for testing according to the specifications used for the construction of the Tides Mill Stream Bridge. An extensive research plan was devised to test the beams throughout the fabrication, and ultimately test a three-girder, fully composite bridge superstructure that would mimic that of the eightgirder bridge design to cross the Tides Mill Stream. The work done on these girders can be separated into three distinct phases. First, the empty FRP box shell (including tension steel) was tested. After placement and curing of the self-consolidating concrete within the arch formwork additional tests were performed to investigate the behavior of the tied arch 
subjected to construction loads. Lastly, a skewed, three-girder mockup of the Rt. 205 bridge configuration was tested, including a composite deck (Ahsan 2012).

An extensive instrumentation plan was devised to test the beams at each phase. Strain gauges were mounted externally on the FRP at multiple locations on the webs, top and bottom flanges, and internally on the tension steel. Vibrating wire gauges (VWGs) were embedded in the arch concrete, also yielding strain measurements. Photogrammetry was employed to allow for complex measures of deflection and subsequent derivations of strain on the face of the FRP web. These measurements were confirmed by traditional deflection measurements, including string potentiometers and linear variable differential transformers (LVDTs). Load cells were also used at the bearings to provide a measure of the shear through the beams at the supports.

For testing of the empty FRP box, the lid and wings were placed on top of the shell, but not glued down, such that its dead weight would be contributed, but not add to the flexural rigidity of the box. These beams were tested in a non-skewed configuration, with the same clear span as the Rt. 205 Bridge. The loading of the shell was performed using weighted angles spaced closely along the length of the beam. It was found that the FRP behaves in a linear elastic manner (Ahsan, 2012).

The next phase that was tested was the completed HCB. At this point, the FRP lid and wings were glued on, and the arch concrete was pumped throughout the voided formwork within the beam and allowed to cure. These beams were also tested in a straight 
configuration with the same clear span. The two loading scenarios for these beams involved a single load point of 15 kips at mid-span, and two third-point loads of 12.5 kips. The FRP is not intended to contribute significantly to the flexural strength of the overall beam, and this test confirmed that in the non-composite case, the tied concrete arch carries approximately $80 \%$ of the total flexural load, leaving the shell to carry the remaining $20 \%$. It was found through a comparison of the strain registered on the steel itself and the FRP surrounding the steel that there is relatively good strain compatibility in the tension zone (Van Nosdall et al. 2012).

The last phase of research conducted in the laboratory was the three-girder mockup of the fully composite HCB system as would be put in-service at Colonial Beach. It is important to note, however, that the bridge mockup did not include any parapet walls, which would prove to provide a significant level of stiffening to the exterior girders and alter the distribution of load throughout the system. Additionally, there was no way to enforce the fixity caused by an integral abutment, thus the boundary conditions differ from the actual configuration. The loading used was a simulated truck loading using HL-93 design truck estimates for axle loads, including an assumed 1.33 impact factor for including dynamic loads in a static test. Several simulated wheel paths were tested to induce moment and shear distribution throughout the system. Once the beams become composite with the deck, the neutral axis moves up within the deck, thus the HCB ceases to act as a tied arch, and the concrete arch contributes little to the strength of the system. It was found that the FRP shell and tension steel combine to provide $80 \%$ of the total moment resistance 
calculated from the integration of stress diagrams at mid-span, while the deck accounts for the last 20\% (Van Nosdall et al. 2012).

Of particular interest for use in this project was the discovery that the concrete arch does not act compositely with the rest of the HCB system. Ahsan (2012) hypothesized the existence of a local bending phenomenon of this thin arch that is accentuated at the unsupported quarter-spans. The tension strains registered in the bottom of the arch are not compatible, but quite exaggerated compared to the strains read from the external FRP strain gauges, indicating the existence of this phenomenon. Further, there exists a discrepancy between the upper and lower strain readings in the arch also indicating flexure within the arch. Figure 3 shows Ahsan's (2012) representation of this phenomenon. In this theory, the mid-span of the arch is treated as being supported by a stiff spring, as an $8 \mathrm{ft}$ FRP sheet connects the two FRP webs directly beneath the arch conduit. The purpose of this sheet was to provide a rigid surface to protect the foam formwork from the force of the concrete placed at this location, and preserve the shape of the arch. Following this theory, it is easy to see how flexure could be induced throughout the length of the arch, but especially at the unsupported quarter points.

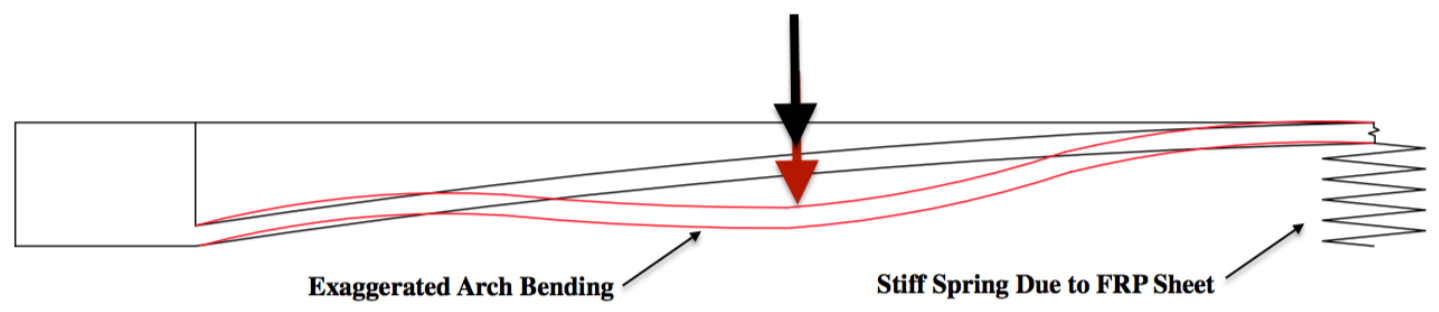

Figure 3: Thin Arch Local Bending Hypothesis (Adapted from Ahsan, 2012)

The tensile strains registered in the bottom of the arch were found to be well above that necessary to induce cracking in this concrete, yet there clearly exists a means to carry this 
level of strain. This seems to indicate that the two steel strands laid out in the bottom of the arch profile for construction purposes may indeed provide tensile resistance within the $\operatorname{arch}($ Ahsan 2012).

Other important findings from the study include a confirmation of the current design methodology of transformed sections. The approach is effective, although slightly conservative. Van Nosdall et al. (2012) also noted the importance of including the FRP wings and the concrete fin in design and analysis of the beam since they both contribute to the flexural resistance.

Ahsan (2012) included an analysis of both moment and shear distribution factors from the limited load configurations performed on the three-girder system and provides a comparison to the assumed AASHTO values. While the design for this bridge is conservative and does not include skew corrections, Ahsan includes lever rule corrections in his calculations and found the exterior girder shear and moment distribution factors to be within AASHTO regulations. Interior distribution factors were less conservative as compared to the AASHTO values.

\subsubsection{Problem Statement}

The purpose of this study was to quantify some unknown structural behavior of the HCB system and to validate the design assumptions used in construction of this particular application. The Virginia Department of Transportation (VDOT) was interested in using this design technology in a bridge replacement project, but required instrumentation throughout the bridge and its components to quantify the behavior of this skewed bridge 
and compare that against existing applications of $\mathrm{HCB}$ with no skew. Of particular interest was the flexural lateral load distribution behavior, the element load sharing behavior, and the dynamic load amplification of this skewed HCB application.

Additionally, a finite element (FE) model was proposed after conducting the load test to quantify some of the subtler load distribution behaviors of the HCB system that were not captured by the existing instrumentation. Both the results from Ahsan's (2012) laboratory study and the in-situ load test would be used to validate the model's accuracy.

\subsection{Tides Mill Stream - Route 205 Bridge}

This load test examined the initial in-service behavior of a recently constructed HCB structure located on Route 205 over the Tides Mill Stream in Colonial Beach, VA. The previous concrete girders and deck were replaced with eight HCBs spanning 13.5 meters (44 ft) over a small creek and supporting a $19.5 \mathrm{~cm}$ (7.5 in) deep conventionally reinforced, cast-in-place concrete deck, while maintaining the existing substructure. Each HCB girder was $53 \mathrm{~cm}$ (21 in) deep by $61 \mathrm{~cm}$ (24 in) wide and contained inclined shear connectors that serve to enforce composite action with the deck. The girders were spaced

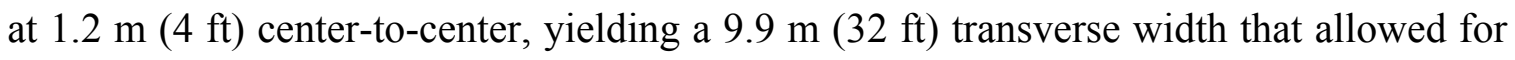

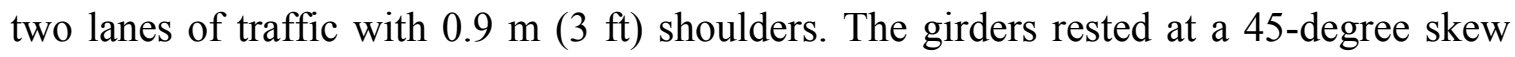
across two parallel abutments, and were made integral with the abutments by encasing the end sections of the beams in the abutment concrete. The in-service behavior of the system was evaluated through live load testing. 


\subsubsection{Instrumentation \& Experimental Setup}

The bridge across the Tides Mill Stream was constructed on abutments skewed at 45degree angles to the roadway (Figure 4) with integral abutments. The girders cross the waterway with a very low clearance of approximately $6 \mathrm{ft}$ at low tide, making access for instrumentation a challenge. The stream feeds to the Potomac River, which flows to the North of the bridge site. To keep the instrumentation systems organized, a numbering system was used for girders where the northernmost girder was labeled number 1 (alternatively girder A), and the numbers progressed sequentially to the eighth southernmost girder, labeled girder $8(\mathrm{H})$.

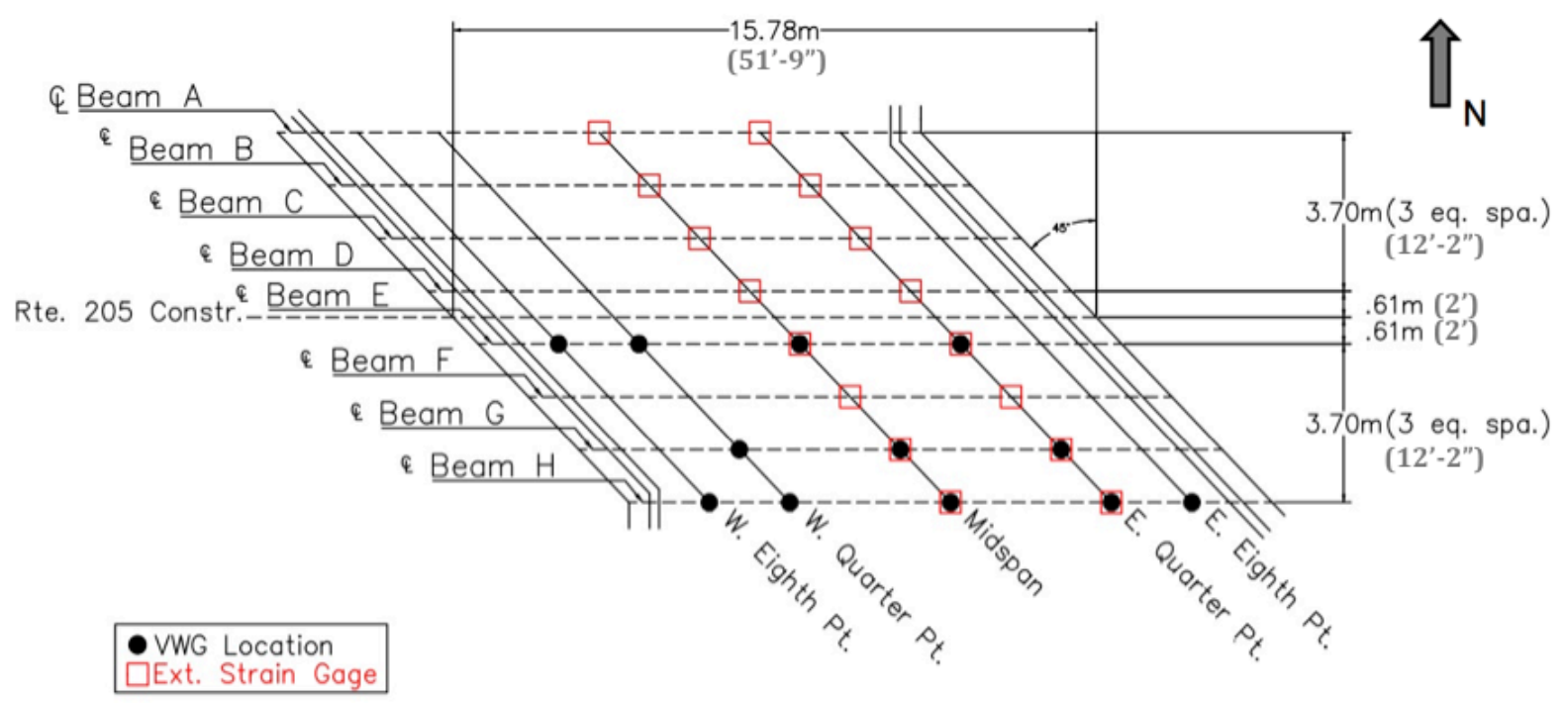

Figure 4: Instrumentation Overview in Plan View

The focus of this investigation was the initial in-service performance of this particular HCB bridge however, the instrumentation program that was implemented was chosen to serve two purposes: 1) to yield measured responses during load testing, and 2) provide long-term monitoring capabilities for the HCB bridge system. To accomplish these functions, a series of different, yet complimentary data acquisition systems were used, including multiple types of sensors. 
The first data acquisition plan involved a series of Geokon 4200 series embeddable vibrating wire gauges (VWGs) that were installed throughout the fabrication and construction process of the girders and bridge deck so as to capture the strains internal to the bridge. Two datalogging systems were devised using Campbell Scientific Inc. (CSI) modules to monitor these gauges. The first was designed for long-term monitoring of the internal state of strain of the bridge, and was able to capture up to 48 VWGs. While this type of sensor has been typically intended for static, low-frequency measurements, the second unit used a module recently developed by CSI that is capable of measuring the embedded VWGs dynamically.

The second data acquisition system was a rapidly deployable wireless field-testing setup by Bridge Diagnostics Inc. (BDI) that consisted primarily of externally mounted strain gauges. Both the VWGs and BDI strain gauges were intended to be used during loadtesting, but only the CSI system was intended for long-term monitoring due to the durability of the VWGs and the protection offered by embedment.

The locations of vibrating wire gauges were determined in collaboration with VDOT in order to capture enough of the desired behavior while remaining reasonably economical. These VWGs were installed in three of the eight girders so as to minimize the interference with the construction of the girders. Symmetry of the bridge made this instrumentation plan feasible, as it was still possible to capture both an acute and obtuse corner of the skew. Figure 5 and Table 1 indicate the interior placement of VWGs within 
the HCB. Figure 6 represents the instrumentation configuration at mid-span and overlays the loading truck schemes. Figure 4 shows the overall lateral and longitudinal locations of the two types of gauges in plan view and where they overlap for congruence. Along the length of the beam gauges were installed at mid-span to yield the maximum flexural responses of these select girders, and at both quarter-span locations to accommodate the effect of the skew. Additional gauges were installed at select eighth-span points on these three girders to measure shear response.

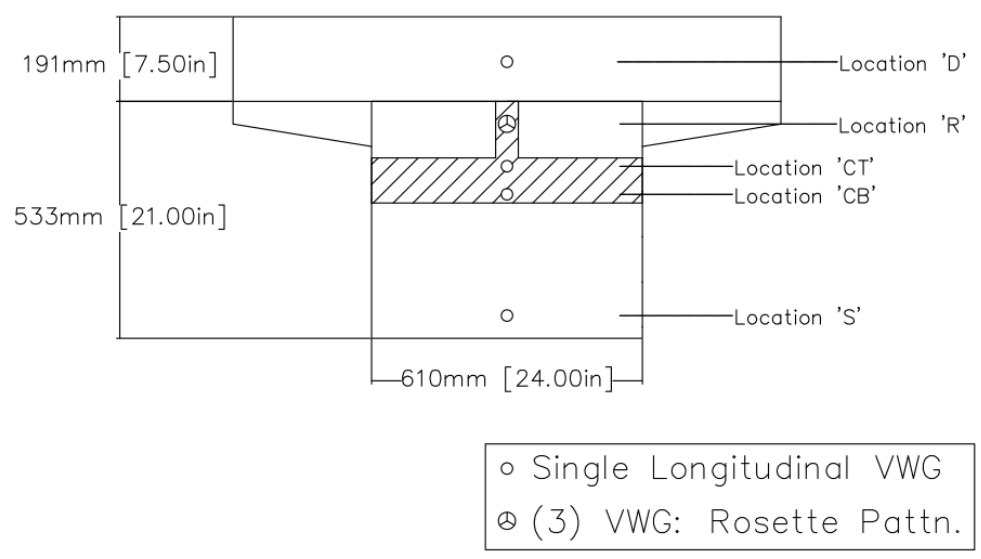

Figure 5: Vibrating Wire Gauge Locations through the Depth

Table 1: Vibrating Wire Gauge Instrumentation Location Matrix

\begin{tabular}{lccc}
\hline & Girder 5 & Girder 7 & Girder 8 \\
\hline \hline East Eighthspan & & & $R, C T, C B$ \\
East Quarter-span & $D, C T, C B, S$ & $D, C T, C B, S$ & $D, C T, C B, S$ \\
Mid-span & $D, C T, C B, S$ & $D, C T, C B, S$ & $D, C T, C B, S$ \\
West Quarter- & $D, C T, C B, S$ & $D, C T, C B, S$ & $D, C T, C B, S$ \\
span & $R, C T, C B$ & & $R, C T, C B$ \\
West Eighthspan & & & \\
\hline
\end{tabular}

Construction took place for the bridge in a series of stages. The HCBs were fabricated off site, at Harbor Technologies in Brunswick, ME where the box shells were laid up with 
fiberglass, high-strength passive steel strand and foam formwork, then infused with resin. In this manner, eight lightweight, self-supporting, monolithic box shells were created and shipped to Coastal Precast concrete plant in Virginia, where they were filled with selfconsolidating concrete and allowed to cure, forming a fully functional, composite HCB girder. These girders were placed on the existing abutments that were being reused and cast integrally with the abutments. From that point, the steel mat for the deck was constructed, and construction began to take the form of a conventional bridge project.

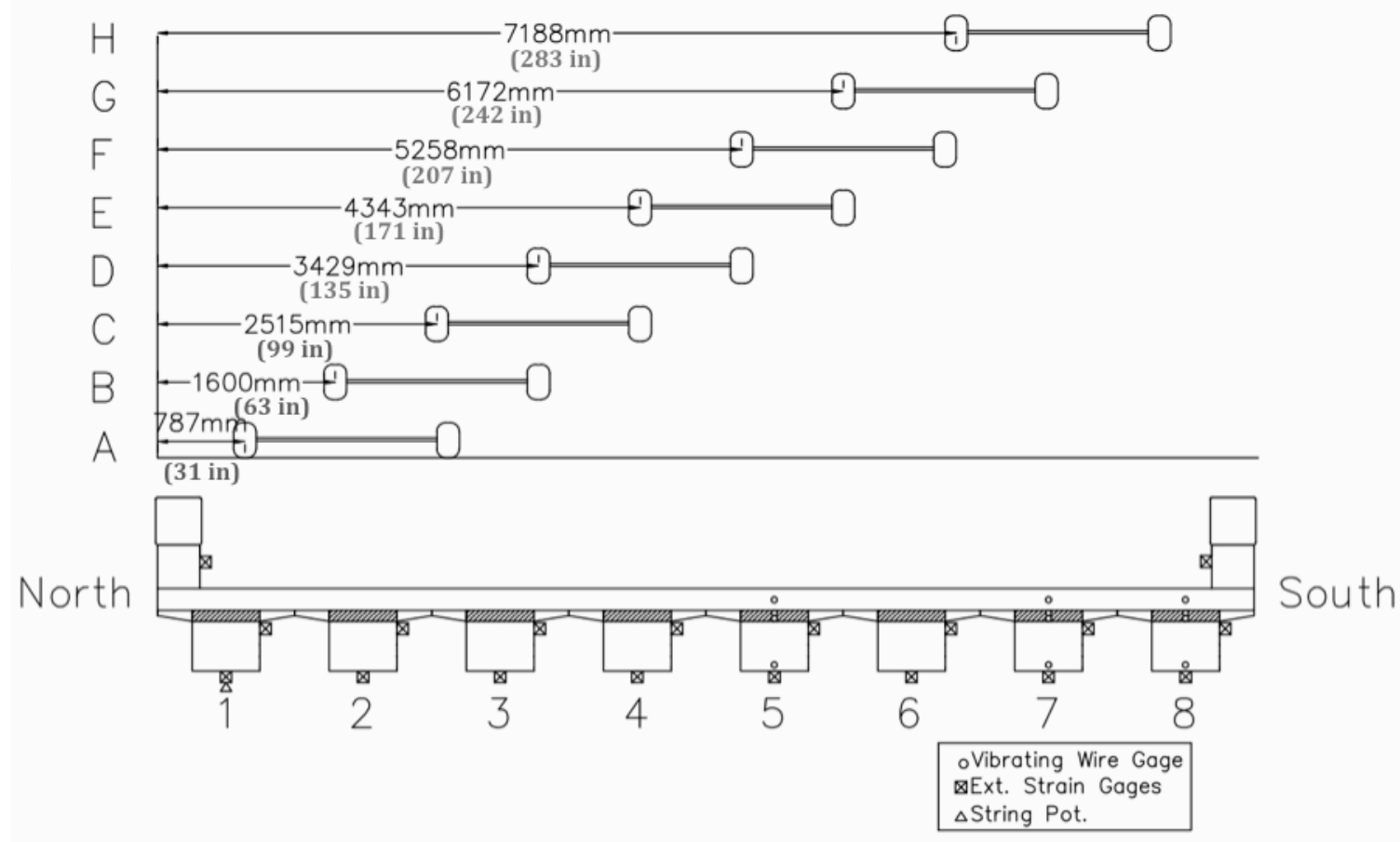

Figure 6: Mid-span Cross-Sectional Instrumentation Layout and Test Truck Loading Configuration During the first phase of construction of the HCBs, the fabrication of the FRP box shell, a VWG was installed at each of the nine proposed mid-span and quarter-span locations at the level of the steel strand. This involved tying the VWG parallel to a strand as close to the middle of the girder as possible during the layup of the fiberglass sheets and highstrength steel strand (Figure 7). Just as concrete transfers strain to a VWG through the 
movement of concrete perpendicular to the end discs, it was theorized that when cured, the resin would offer the same transfer of strain to the gauge and an accurate reading would be provided for the particular cross-sectional depth to neutral axis.

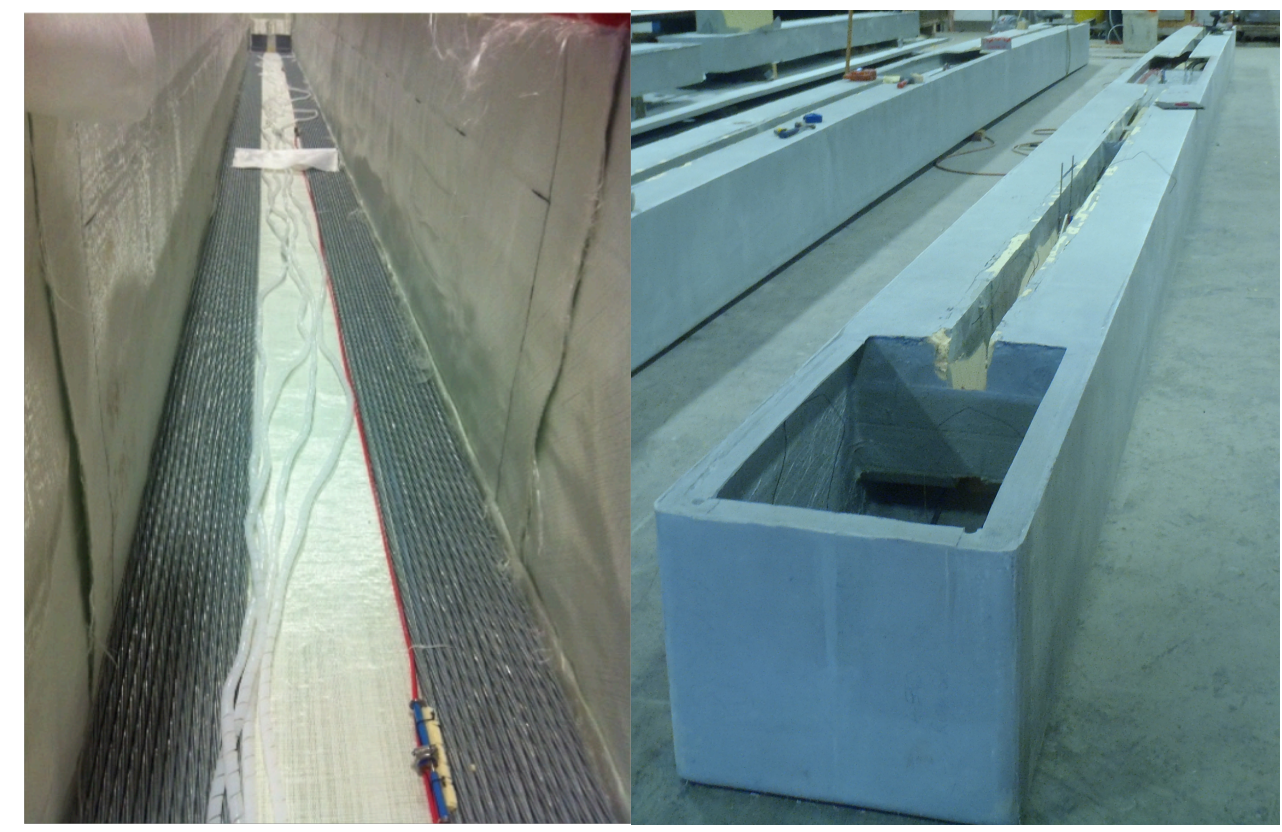

Figure 7: Internal VWG Placement at Tension Level (Left) and FRP Shell After Resin Infusion (Right) After infusion of the FRP shell took place, the remainder of the VWGs internal to the HCB itself were installed. A series of non-corroding, acrylonitrile butadiene styrene, 3Dprinted frames were designed to hold the VWGs in place at the desired location within the voided conduits that would later be filled with self-consolidating concrete (SCC). Again, nine frames were placed at the proposed mid-span and quarter-span locations with two VWGs stacked two inches apart. Each frame was then inserted through the void for the concrete fin (Figure 8) down to the level of the arch void and inserted into the existing foam formwork such that the VWGs were aligned longitudinally with the beam, not following the profile of the arch. Note that the exact cross-sectional depth of these gauges differed by location due to the varying profile of the parabolic arch. At the three designated eighth point locations, a frame identical to the one devised for the other arch 
locations was used in conjunction with an additional frame, linked by two stainless steel threaded rods that would allow the whole assembly to be lowered into the deeper eighthspan locations (Figure 8). The additional frame on top consisted of three VWGs arranged in a pattern at 60 degrees to one another; the rosette was designed to measure the shear in the fin at the eighth-span near the point of maximum shear and where the fin is deepest.

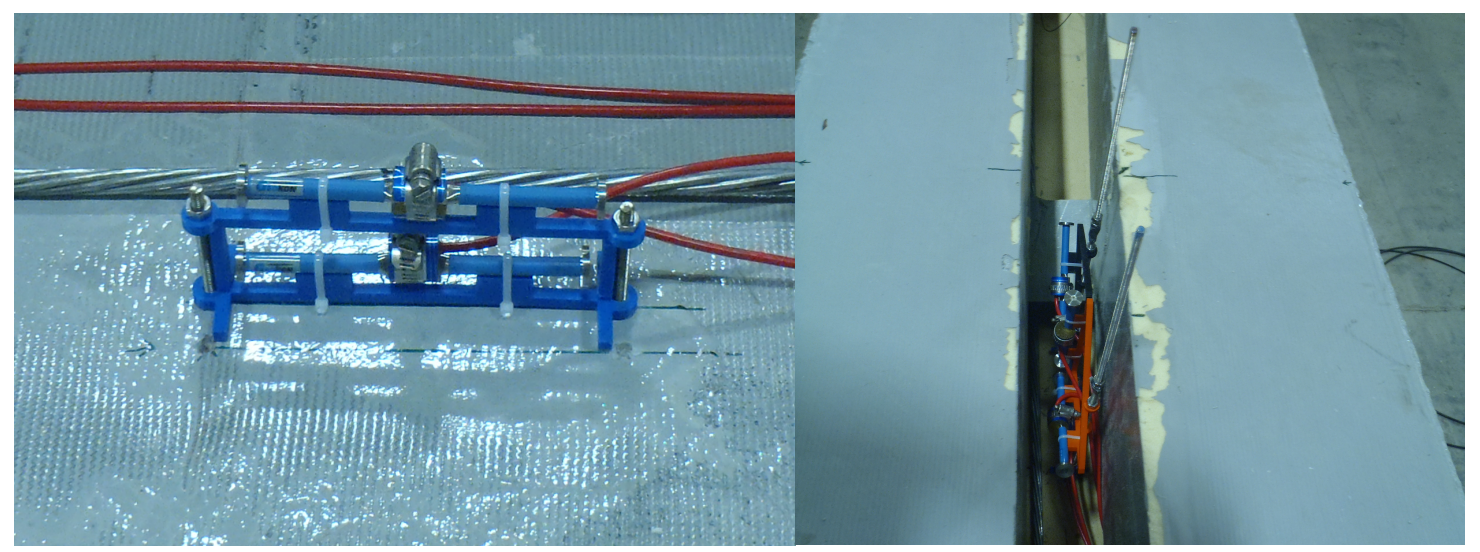

Figure 8: Concrete Arch VWG Stacked Frame at Mid-span (Left) and Additional Rosette Configuration at Eighth-span (Right)

The next steps in the HCB fabrication process were to secure the FRP lid to the box, install the inclined shear connectors and fill the beams with SCC (Figure 9). Once the beams were completed, they were placed on site, and the deck reinforcement mat was laid out. Nine additional gauges were longitudinally affixed to the mat $102 \mathrm{~mm}$ (4 in) deep at companion locations to the mid-span and quarter-span locations of the three selected girders prior to placement of the deck concrete. The resulting system of gauges provided a more comprehensive measure of the overall internal system behavior including the neutral axis location and level of composite action between the deck and girders. 


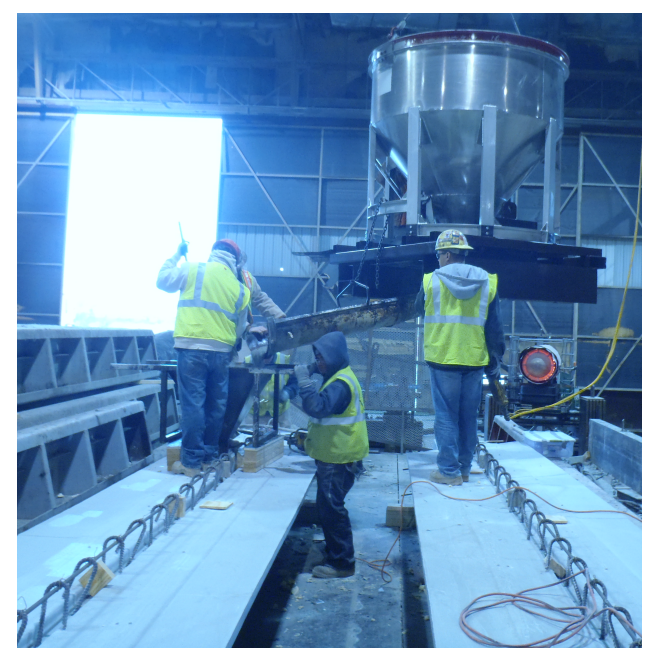

Figure 9: Finished FRP Box Shell Being Filled with SCC

On the day of the load test, external BDI strain gauges were placed in conjunction with the internal VWGs in order to mirror the strain locations and provide a comparison between the internal strains and the strains experienced by the external FRP shell (Figures $5 \& 6$ ). These external gauges were mounted on the bottom flange of each girder at mid-span and the East quarter-span to capture distribution behavior laterally across the eight girders. Additional gauges were mounted on the web of the girders at these locations as close to the arch position as possible, though the depth of the wings made this somewhat challenging at mid-span. These web gauges were used to create an external strain profile that could be matched against the internal strain profiles and contribute to the evaluation of the load sharing behavior of the individual HCB elements.

Lastly, two additional external BDI strain gauges were placed on the parapet at mid-span such that any strains registered could give an indication of the level of stiffening provided by the barriers to the bridge system. A BDI string pot was also hooked to the BDI acquisition system to measure deflection for a single exterior girder, however, it was later surmised that the wire used to tie off to the anchor was too stiff to be adequately 
tensioned by the resisting spring force of the string pot itself, as the results from this instrument were insignificant other than noise. Deflection was not of primary concern for this study, and the string pot was in place simply to correlate the displacement readings of an additional digital image correlation system that was being tested.

\subsubsection{Experimental Program}

The load test was performed in August 2013 over a span of two days. The first day consisted mostly of setup and prep work and the second day included final preparation and carrying out the load test runs. It was a function of the bridge site that the clearance of the waterway was already shallow, but also fluctuated with the rising tides. This was a concern that had to be factored into the schedule of the load test, and dictated when certain tasks could be performed underneath. This factor determined the need to carry out the load test over two days. The depth of the waterway varied, and as such, a combination of small jon boats and researchers in waders was used for access to attach the sensors beneath the bridge (Figure 10).

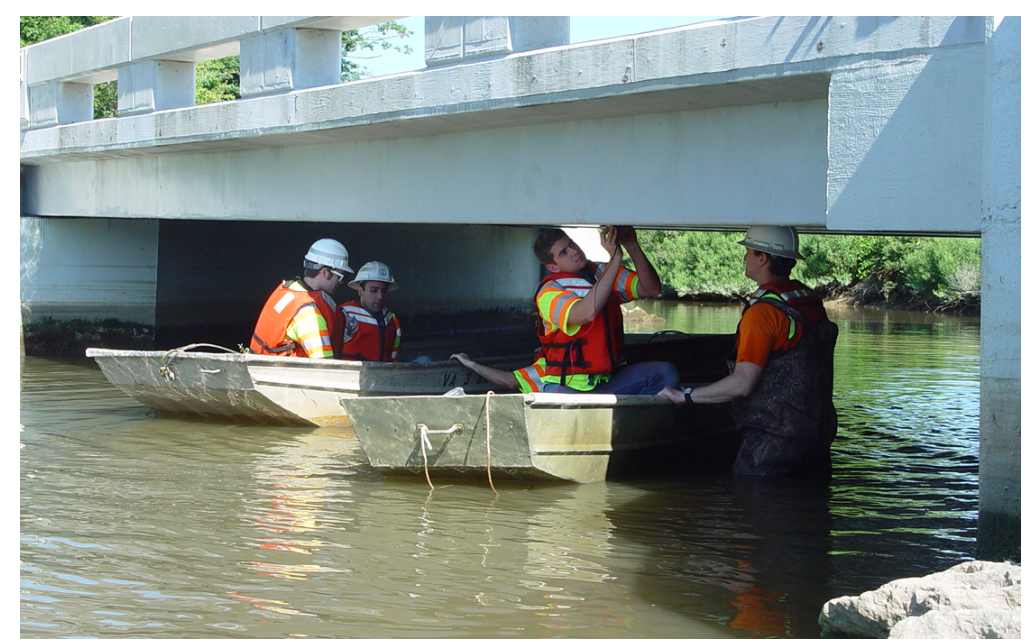

Figure 10: Instrumenting Bridge Underside 
On the morning of August 5, two teams were deployed to accomplish multiple tasks. One team headed beneath the bridge to begin marking mid and quarter-span locations. These measurements were taken from the clearspan distance, and a chalk line was dropped across all eight girders, along the skew to mark these locations on each beam. Next, BDI strain gauge sensors were glued to the bottom flange of each girder at the two specified locations, taking care to maintain the gauge longitudinally along the beam's length, and remain centered in the beam's width. Using a carpenter's square, the same chalk lines were extended up the South-facing web and additional gauges were glued at each longitudinal location at a uniform 1.5 in beneath the wing edge.

In order to keep the sensor lead wires organized and dry, conduit clamps were glued along the girders and the lead wires were sequentially zip-tied off to the clamps, channeling the groupings out the South end of the bridge where they were bundled and bagged to keep moisture out overnight. This concept is shown in Figure 11. These bundles were then hung on conduit clamps on the first interior web, or rested on the abutment face to remain out of sight.

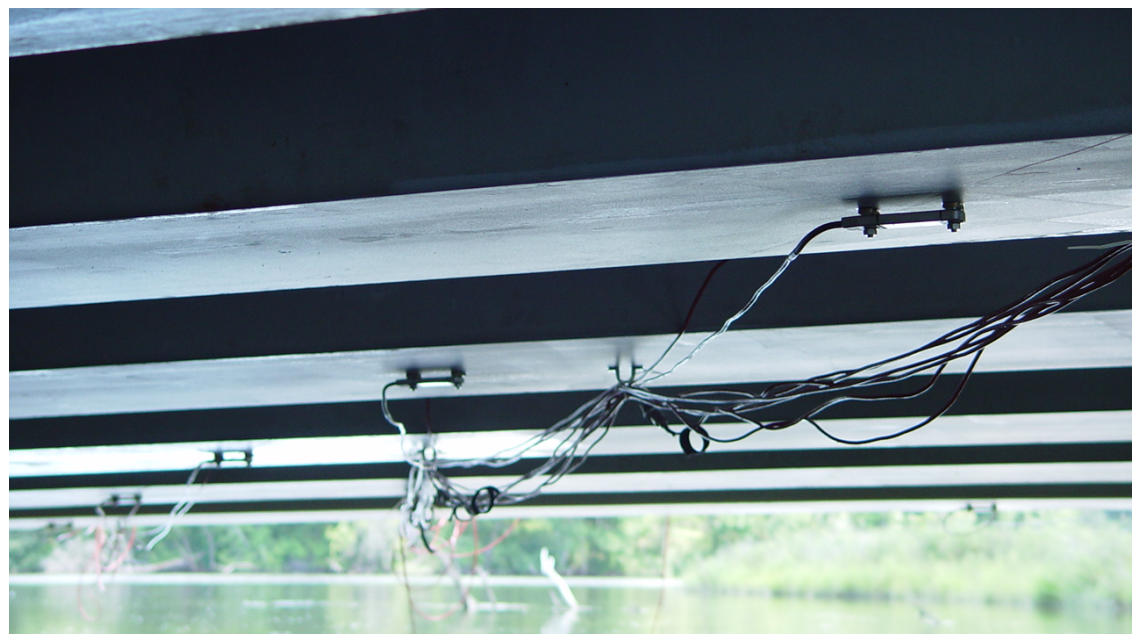

Figure 11: Bottom Flange External Strain Gauge Placement 
Meanwhile, a second team stayed on top of the bridge and took care of marking the wheel path lines for the various pre-determined load cases (Figure 12), as well as handing down groupings of strain gauges based on the plan. It was important to place specifically labeled gauges at the predetermined locations for data analysis, however the BDI system does not require one to plug in the gauges in any particular order. In other words, the system recognized the gauge from a signal sent through the plug, called an intelliducer, as seen in Figure 13.

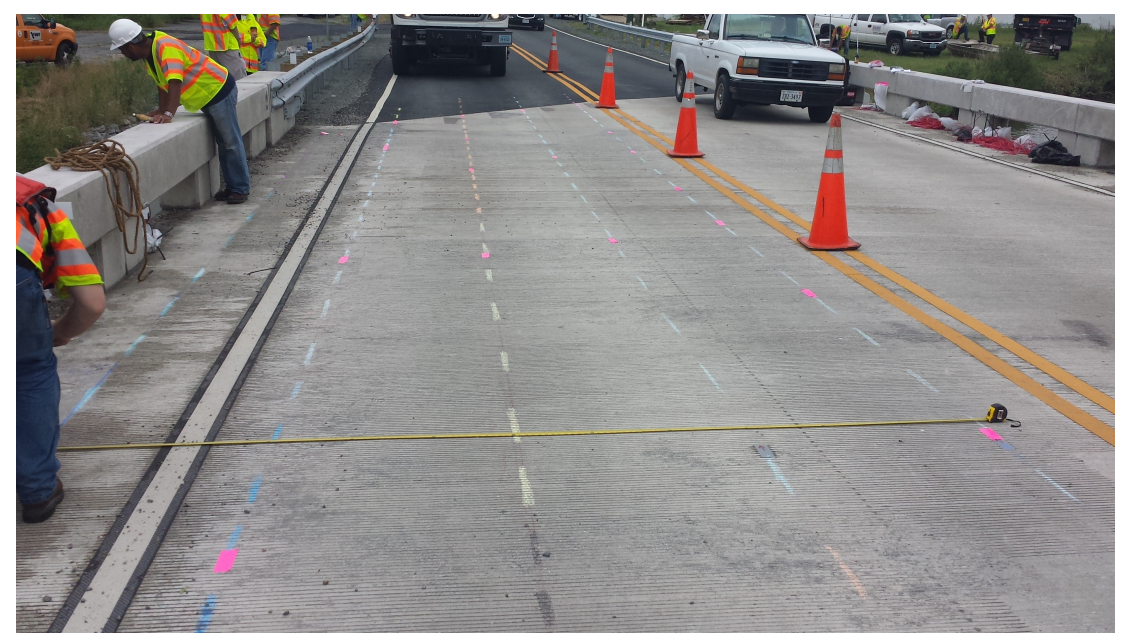

Figure 12: Wheel Path Markings

The following morning, August 6, final preparations began by retrieving the BDI wire leads from under the bridge and connecting them to wireless BDI nodes and connecting nodes to the base station and computer monitor. While underneath, pre-made cardboard 'igloos' were taped over the externally mounted strain gauges to block wind, as these gauges have been known to have a sensitivity to air currents. Figure 13 shows this BDI system setup. 


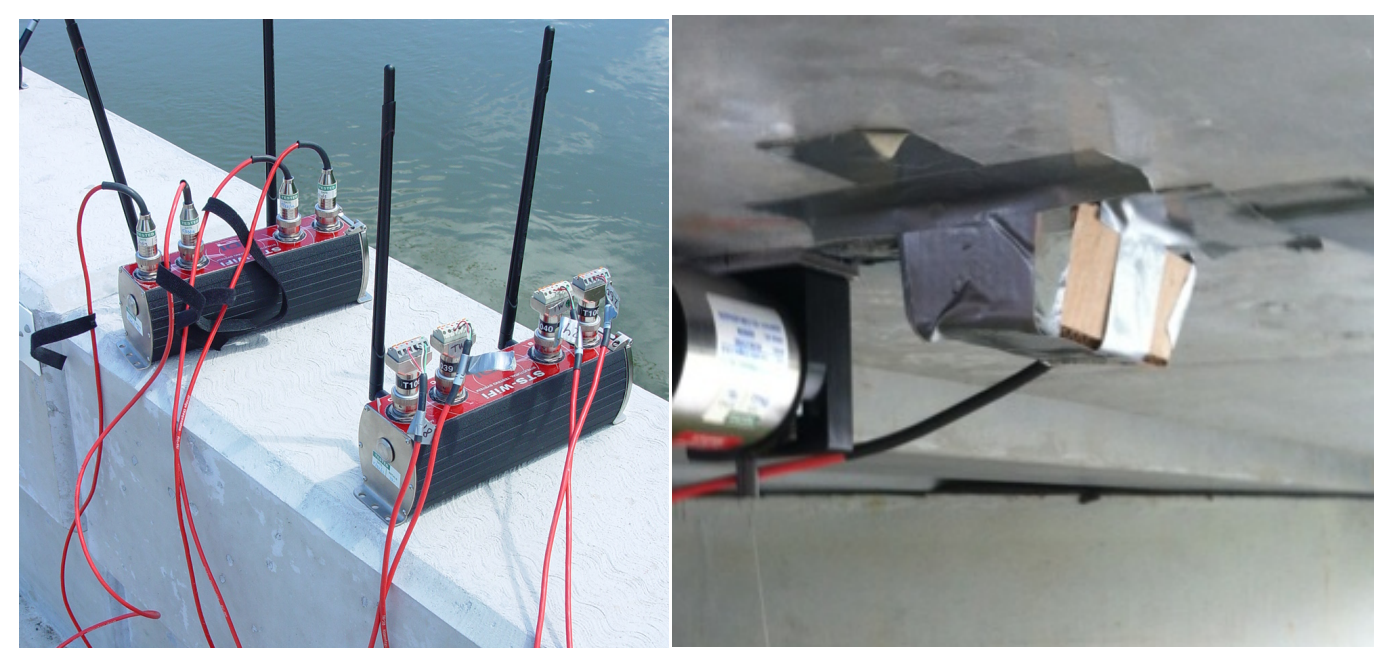

Figure 13: Wireless BDI Nodes (Left) and Cardboard 'Igloo' (Right)

The lead wires from the internally mounted VWGs were pre-connected to a CSI data logger for periodic measurements, and it was necessary to disconnect the 16 select gauges to be measured dynamically and set up the dynamic CSI system (Figure 14). As the longterm monitoring system measures the gauges sequentially, rather than simultaneously, the most rapid frequency of measurement for any given gauge possible was around one reading per 60 seconds. The program was modified to this frequency with the intent of the load truck to pause during select runs for one minute and to capture a true static reading of the remainder of the gauges not being measured dynamically. 


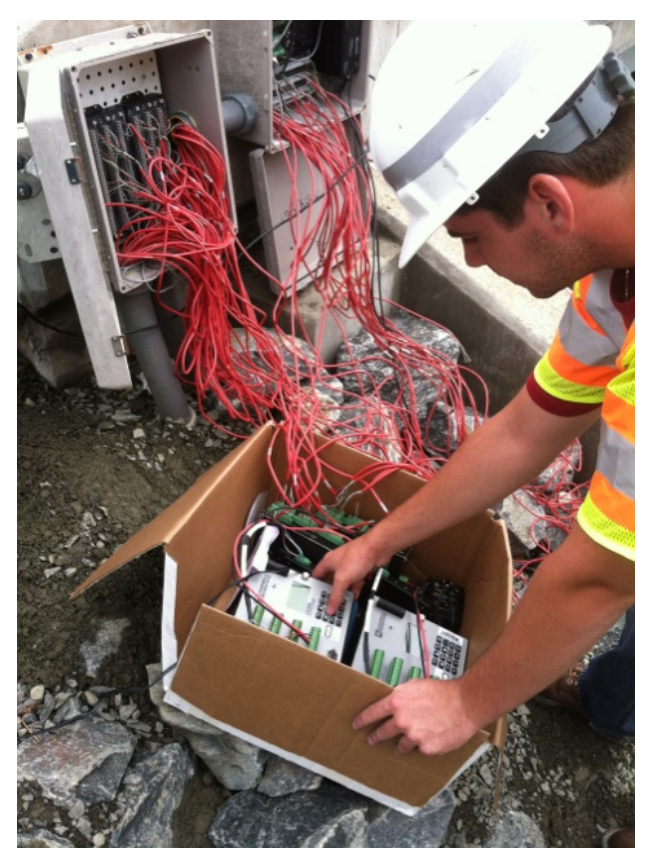

Figure 14: Campbell Scientific Data Loggers Setup

A BDI product called an Autoclicker was attached to the wheel well of the load test truck in order to track the position of the truck as it crossed the bridge (Figure 16). A vice grip with a reflective paddle was attached to the wheel rim and a lens on a flexible arm was positioned over the paddle such that each time the wheel made a complete rotation, the Autoclicker would recognize the paddle and provide a 'click' or instantaneous, timestamped unit value. Knowing the distance that the truck travels in one rotation of the wheel as given in Table 2, one can decipher the position of the truck longitudinally at each click. This progress is plotted versus clicker count in Figure 15. 


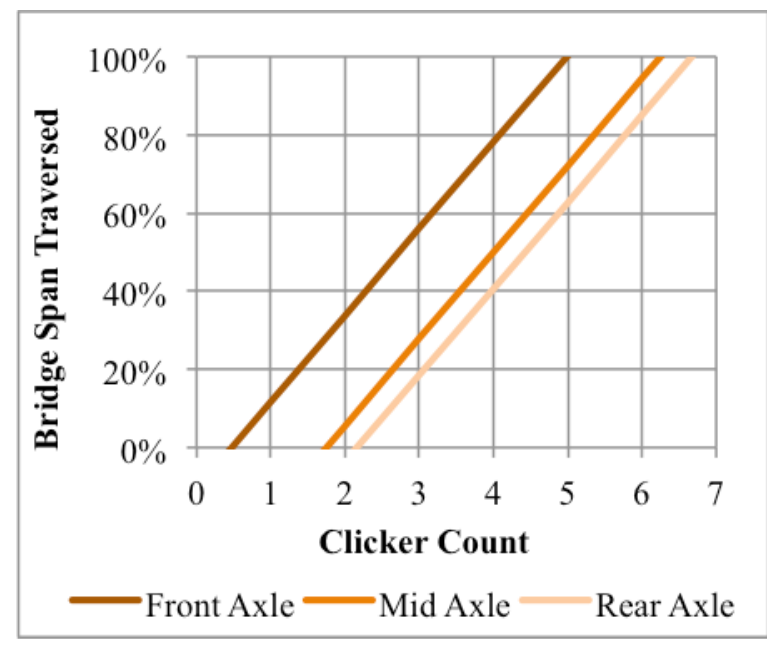

Figure 15: Autoclicker Position Encoder

Each time the truck pulled up to the start of the bridge deck, the reflective clicker tab would manually be reset to the 'zero' position on the wheel, where the Autoclicker would clock a click very close to the start of the truck motion. The locations have been divided for each of the three axles (reference Table 2 for axle loads).

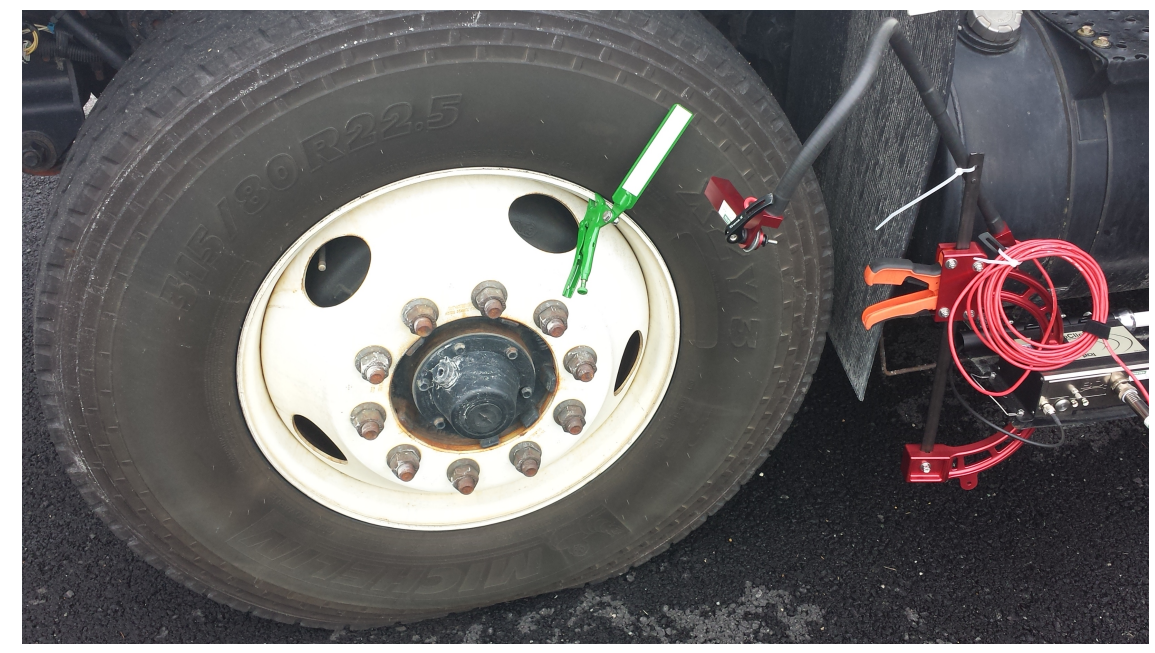

Figure 16: BDI Autoclicker Setup

The load test was performed in the afternoon of August 6 by driving the load vehicle East to West across the bridge at predetermined transverse positions as shown in Figure 5. The load trucks that were used were VDOT tandem-axle dump trucks loaded with gravel. Different load vehicles were used for the quasi-static tests and the dynamic tests, and the 
specifications for each may be found in Table 2. During quasi-static testing, the truck was positioned in each of the eight different transverse locations in order to elicit a maximum response from each of the eight girders. In each scenario, the truck driver was guided by a researcher (Figure 17) who would ensure the passenger's side wheel path aligned with the designated paths marked on the bridge deck and proceeded along the bridge at a slow speed $(<8 \mathrm{kph}$ or $5 \mathrm{mph})$. Each transverse run was performed a total of three times, always pausing on the third run for 60 seconds at a pre-designated longitudinal location close to the mid-span of the girder nearest the driver's side wheel path. This pause was intended to allow the remaining non-dynamically monitored VWGs to collect a true static picture of the loaded configuration. These static tests provided critical information regarding the system-level load sharing behavior as well as internal composite load sharing behavior of the HCB system.

Table 2: Load Test Truck Specifications

\begin{tabular}{|c|c|c|}
\hline & $\begin{array}{l}\text { Truck RO6187 (Quasi- } \\
\text { Static) }\end{array}$ & $\begin{array}{l}\text { Truck RO9185 } \\
\text { (Dynamic) }\end{array}$ \\
\hline Front Axle Weight & 80.9 kN (18.12 kip) & $77.0 \mathrm{kN}$ (17.32 kip) \\
\hline Rear Axle Weight & 151.2 kN (33.98 kip) & $147.7 \mathrm{kN}$ (33.20 kip) \\
\hline Total Truck Weight & 231.8 kN (52.10 kip) & 224.7 kN (50.52 kip) \\
\hline Front Axle Width (center-to-center of tires) & 2080 mm (82 in) & $2005 \mathrm{~mm}$ (79 in) \\
\hline Rear Axle Width (center-to-center of tires) & 1850 mm (73 in) & $1855 \mathrm{~mm}$ (73 in) \\
\hline Tire Width & $250 \mathrm{~mm}(10 \mathrm{in})$ & $255 \mathrm{~mm}$ (10 in) \\
\hline Front Axle Span & $4190 \mathrm{~mm}$ (165 in) & $4115 \mathrm{~mm}$ (162 in) \\
\hline Rear Axle Span & 1345 mm (53 in) & 1395 mm (55 in) \\
\hline Single Tire Rotation Travel Distance & $3275 \mathrm{~mm}$ (129 in) & -- \\
\hline
\end{tabular}

It was planned to perform several additional static tests, namely several dual load truck configurations where the two load trucks would proceed across the bridge in a side-byside manner. However, on the last loading scenario, 'H', the truck traveled too closely to the guardrail and damaged part of a wheel. This, along with the diminishing daylight and rising tide prompted the researchers to skip ahead to the dynamic testing. As the heavier 
truck had left the site for repairs, the lighter truck was now used for the dynamic testing. As such, it was necessary to gather a couple of baseline quasi-static runs to establish a baseline for comparison of the dynamic amplification. These baseline runs, as well as the dynamic runs were performed at the same quasi-static locations designated ' $\mathrm{B}$ ' and ' $\mathrm{D}$ '. These positions were selected because of the ease of traveling at the posted speed limit and maintaining the proper travel path. For this reason, the wheel paths for these locations were transposed to the driver's side-wheel path and highlighted for ease of picking up the line from a distance as the truck gathered speed. At each of the two locations, 2-3 dynamic runs were performed near the posted speed limit (between 55 and $72 \mathrm{kph}$ or 35-45 mph).

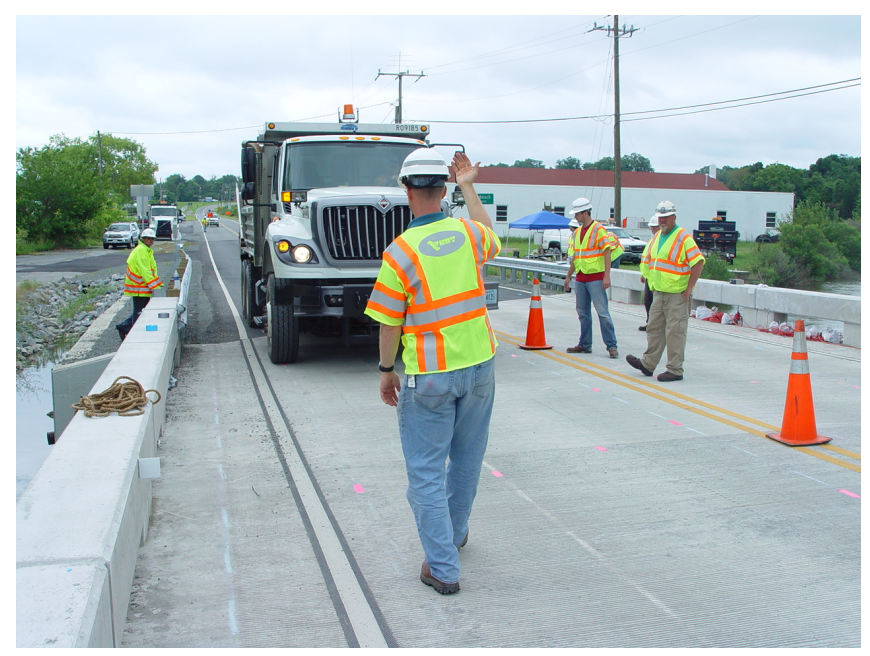

Figure 17: Guiding Load Truck for Quasi-Static Testing

\subsection{Finite Element Model \& Analysis}

This study used ANSYS (2010), a commercial finite element program to validate the laboratory results found by Ahsan (2012) and field results as well as fill in some gaps in the data that researchers were not able to collect. A summary of the modeling work 
performed is broken down into element level (single girder) and system level, and may be found in the following sections.

\subsubsection{Geometry}

The goal in setting out to model the HCB structure over the Tides Mill Stream was to be as realistic as possible. For this reason, it was necessary to create the geometry as close to the construction dimensions as possible.

\subsubsection{Element Level Generation}

Due to the complicated nature of the beam geometry, the beams were first generated using AutoCAD Civil 3D and imported into ANSYS as a series of volumetric regions. The internal concrete regions were generated using the design plans for these specific girders, including the concrete chimneys at the beam ends, the parabolic arch leveling out at mid-span, and the fin that serves as housing for the shear connectors between the arch and the deck (Figure 18). The shear connectors were not modeled in this instance because composite action was assumed from previous experiments (Hillman, 2008) and can be enforced by merging of nodes at the locations where the fin and deck surfaces align. 


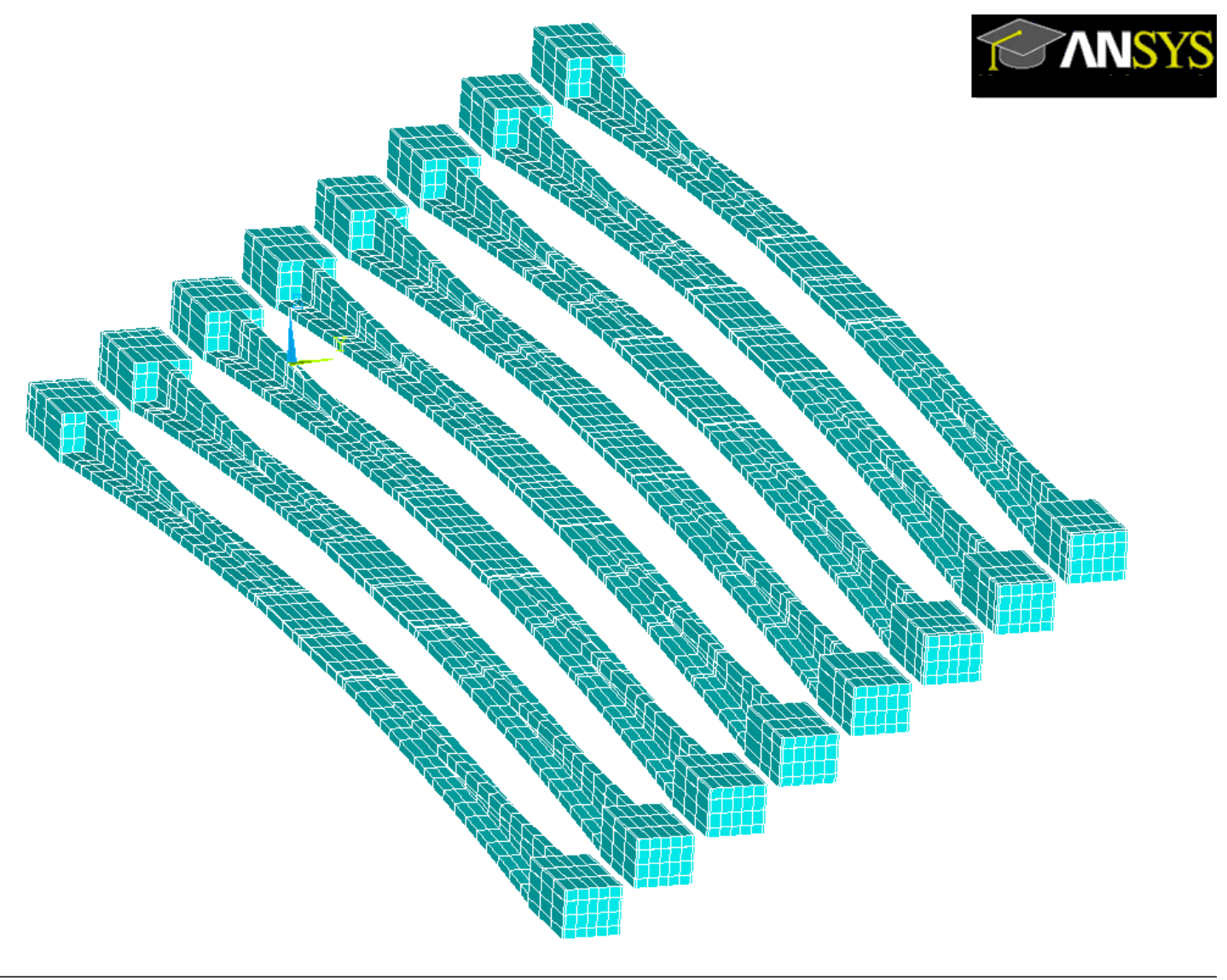

Figure 18: Internal Arch Concrete Geometry \& Mesh

Modeling of the FRP shell was fairly straightforward, as it involved applying thin solid sheets around the beam with a thickness of $1.83 \mathrm{~mm}(0.072 \mathrm{in})$ and can be seen in Figure 19. The wings were included in the model as they were found to contribute a nonnegligible stiffness to the beam behavior (Van Nosdall et al. 2013). It was also decided to include the FRP sheet beneath the mid-span concrete arch due to its predicted influence on the local bending phenomenon proposed by Ahsan (2012). 


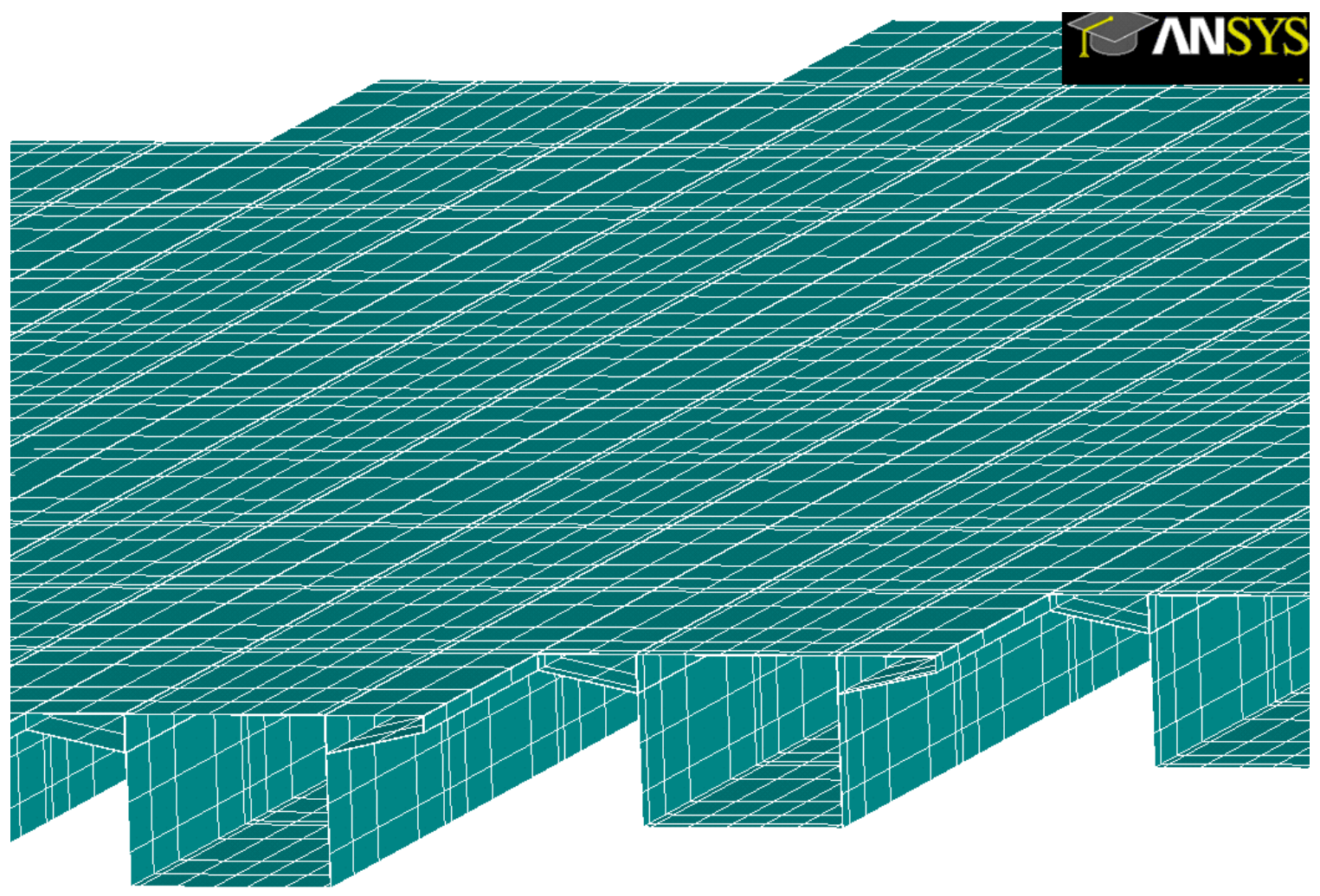

Figure 19: FRP Shell Geometry and Mesh

At first a single girder was modeled to validate against testing performed in the laboratory by Ahsan (2012). Only the natural divisions enforced by the geometric connections of the various $\mathrm{HCB}$ components were included in the original geometry in order to make the subsequent meshed elements compatible in ANSYS. The tension steel elements were included as link elements once the volumes were meshed, and were simply connected node-to-node in the bottom flange of FRP. While the beam called for 28 strands, it was assumed that two equivalent strands on either side of the girder would be sufficient to model the global behavior. This model was validated by the results as presented in section 3.4.1. 


\subsubsection{System Level Model Generation}

When the single beam model was confirmed, efforts were directed towards combining copies of the girder to create a model of the full 8 -girder bridge on a 45 -degree skew (Figure 20). Dividing the beams along the length proved to be a challenge as the natural divisions required by the concrete chimneys and arch profiles were of irregular length. It was necessary to align all the girders on a skew and divide all neighboring girders at the same locations. This created a significant number of divisions along the length, such that it was not necessary to mesh the beam in the longitudinal direction.

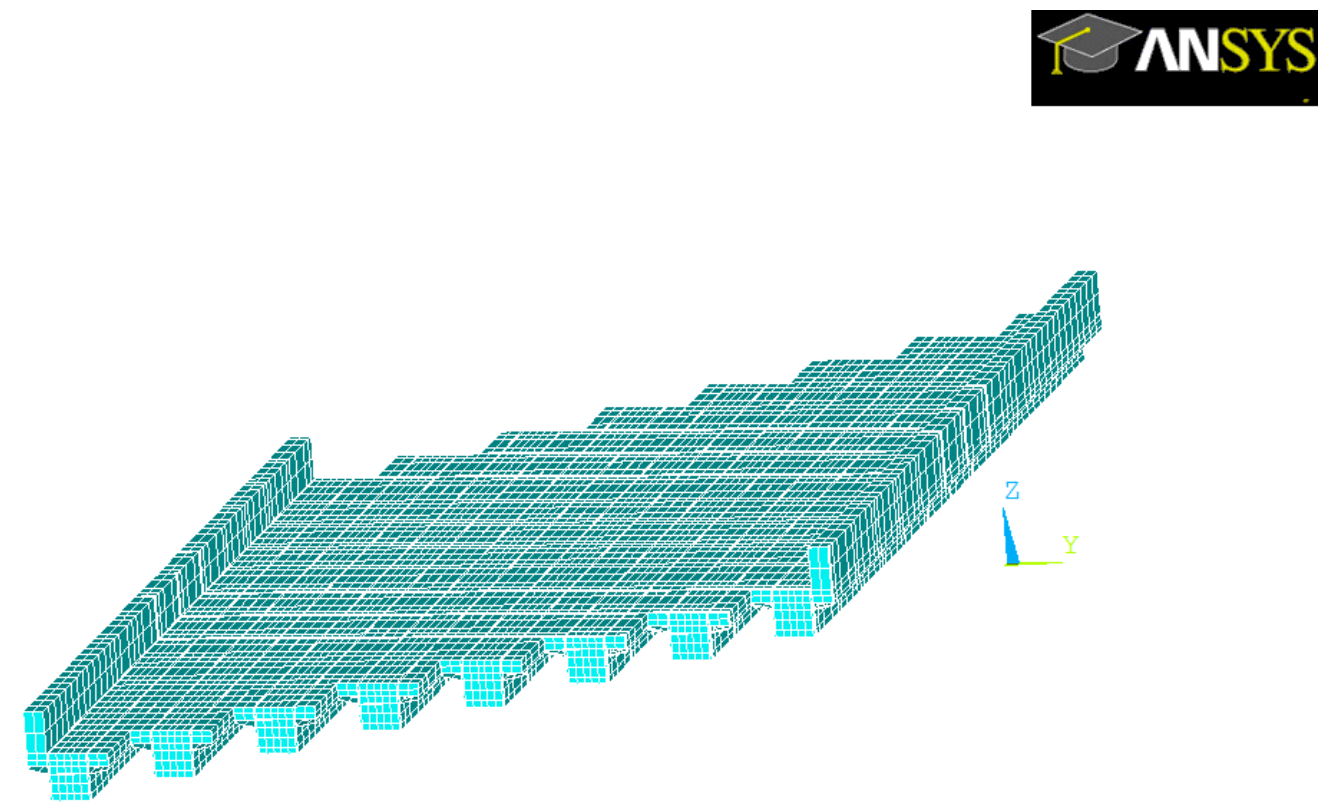

Figure 20: Full-Scale Skewed HCB Bridge Model

The concrete deck was created by copying keypoints at the end of a beam in the positive $\mathrm{Z}$ direction and drawing in areas that could be extruded along the existing longitudinal 
lines of the beam to each subsequent keypoint, and meshed into two layers of elements. Parapet walls were added to the wings of the exterior girders in order to capture the stiffening effect of the existing walls. The Kansas Corrals in place include a square concrete beam supported by posts. For the purpose of this model, the posts were ignored as they likely do not contribute to the stiffness of the bridge, but instead a rectangular section was determined at the level of the deck with an equivalent moment of inertia for the area and location of the rail. Lastly, the real constant of the external girder's tension elements were adjusted to account for the additional steel in these fascia girders.

\subsubsection{Element Types}

The standard element used for concrete, solid 65 , was used for all concrete elements in this model. These 8-node, full integration elements allow for embeddable features such as cracking, crushing and plastic deformations. The tension reinforcement was modeled discretely with link 180 elements, as uniaxial tension elements. It was chosen to make use of solid 185 elements for the FRP shell because of the apparent degree of freedom incompatibility between the concrete solid elements and shell elements.

\subsubsection{Material Models}

Material properties were taken directly from the design calculations performed by John Hillman (2011). A summary of material properties is shown in Table 3. Just as in the design process, all materials were assumed to act linearly elastic, as the loading scenarios would mimic service loads only. For the FRP, biaxial properties were input for elastic modulus and Poisson's ratio using two primary axes. A separate concrete model was applied for the arch concrete and deck concrete because they are varying mixes with different 28-day design strengths. The deck concrete model was used for the parapet 
walls, but since the parapet contained expansion joints and did not offer continuous stiffness, the elastic modulus was reduced to yield more accurate results.

Table 3: Summary of Material Model Properties

\begin{tabular}{lcccc}
\hline Element Type & Model & Elastic Modulus & Poisson's Ratio & Shear Modulus \\
\hline \hline Arch Concrete & Linear Isotropic & $30,440 \mathrm{MPa}(4,415 \mathrm{ksi})$ & 0.3 & -- \\
FRP (xy) & Linear Orthotropic & $213,740 \mathrm{MPa}(31,000 \mathrm{ksi})$ & 0.3 & $6.8 \mathrm{MPa}(850 \mathrm{ksi})$ \\
FRP (yz) & Linear Isotropic & $149,480 \mathrm{MPa}(21,680 \mathrm{ksi})$ & 0.26 & $6.8 \mathrm{MPa}(850 \mathrm{ksi})$ \\
Steel Strand & Linear Isotropic & $26,370 \mathrm{MPa}(27,824 \mathrm{ksi})$ & 0.3 & - \\
Deck Concrete & & 0.3 & - \\
& & & \\
& & & & \\
\hline
\end{tabular}

\subsubsection{Loading \& Boundary Conditions}

The boundary conditions of the Rt. 205 Bridge involved integral abutments. To obtain this condition, the beams were dropped in place on the existing abutments prior to placement of the abutment concrete and were encased in the abutment concrete. The abutment runs at a 45-degree angle, matching the substructure. In order to model this case, it was assumed that the exterior nodes of the FRP shell that fall behind the boundary should be fixed in the $\mathrm{X}, \mathrm{Y}$ and $\mathrm{Z}$ directions. This boundary was selected after a comparison of different levels of fixity (Figure 21). It was found that a fully constrained model with all nodes behind the skewed abutment fixed in all three ordinates was too stiff and didn't allow for enough distribution across the bridge compared to the actual distribution. Next, a simply supported condition was assumed where a single strip of nodes was fixed along the skewed support and fixed in the $\mathrm{X}, \mathrm{Y}$, and $\mathrm{Z}$ direction on the West end and a corresponding strip fixed in $\mathrm{Y}$ and $\mathrm{Z}$ on the East end. This boundary appears to be too flexible. It was necessary to find a combination of the two boundary conditions to adequately satisfy the mid-span strain distribution comparison. As such, it was decided to fix only the elements associated with FRP behind the skewed boundary in the $\mathrm{X}, \mathrm{Y}$ and $\mathrm{Z}$ on the West end, and the corresponding FRP nodes in $\mathrm{Y}$ and $\mathrm{Z}$ on the East. 
This condition was assumed as a test case presumed to fall somewhere in between the two extreme fixities, as the FRP is actually the material in contact with the abutment concrete at the time of casting, and there is likely at least some wiggle room in the longitudinal direction when considering thermal expansion and contraction of materials.

Regarding figure 21 , three load cases were selected to act as comparison cases for distribution factors generated under differing boundary conditions imposed. These three load cases are the two exterior load cases and one of the two load cases that straddle the centerline of the bridge. In this legend, $\mathrm{BC} 2$ is representative of the fully-constrained boundary, BC 3 is the simply supported condition, and $\mathrm{BC} 1$ is the assumed mixed boundary. While the $\mathrm{BCl}$ is not exact by any means, it is the most consistent in representing the actual load test distributions in all three load cases. This mixed boundary condition is the most accurate prediction for five out of eight girders in load case 'A' and similary four of eight and 6 of eight for load cases ' $D$ ' and ' $H$ ' respectively. This represents the majority of the distribution factors, and thus the mixed boundary condition was selected as the most appropriate representation.

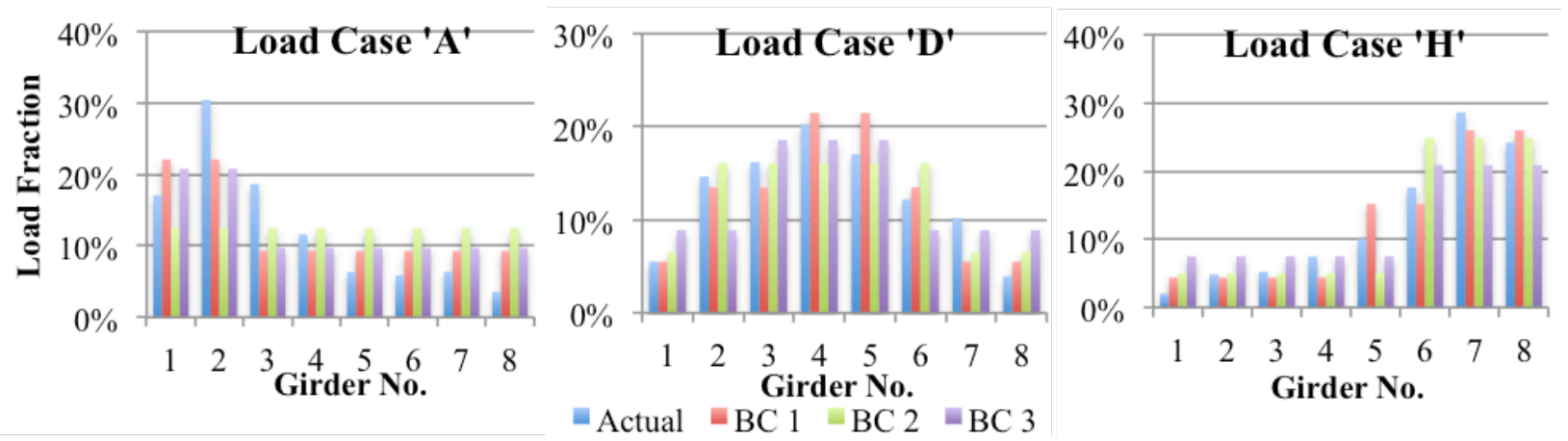

Figure 21: Boundary Condition Validation by Strain Distibution

The bridge was loaded with an algorithm that splits the wheel loads into a series of point loads distributed over the existing nodes found within a 10 in by 20 in patch surrounding 
the load coordinates on the top of the deck surface. The physical dimensions and axle loads of the load truck, measured on the day of the load test, were incorporated into this algorithm and the bridge was loaded accordingly. The lateral truck locations were fixed to match the predetermined wheel paths used in the load test, while the longitudinal locations of the truck were varied to maximize bridge response. Interpolating between data collected from the Autoclicker and quasi-static strain data, it was possible to assume the truck location for maximum response from the actual load test data. Additional load cases were run in either direction in close proximity to the selected location of maximum response until the maximum response was obtained.

\subsection{Discussion of Results}

\subsubsection{Finite Element Model Validation of Virginia Tech Study}

A single HCB model was created first to validate the generated geometry before extending the material model to a complete bridge model. In the study done by Ahsan (2012), single girder tests were conducted prior to construction of the three-beam bridge system. These tests were performed using idealized pinned-roller boundary conditions set

to match the clear span of the Rt. 205 bridge, and loaded in two variations. One 15-kip load was applied at mid-span for the first load case, while two 12.5-kip loads were applied at the quarter-span locations for the second case.

It was necessary to match the deflection data generated by Ahsan (2012) to validate the model approach, and thus the single beam model was loaded with a single strip of nodes across the width at mid-span and constrained by a single strip of nodes on the bottom of the FRP at the boundary conditions. Table 4 shows the mid-span load case to be in 
excellent accordance with the laboratory result, registering 1.47 in of deflection compared to the 1.59 in average for all tests. The quarter-span load case yielded an increased laboratory deflection of 1.77 in and the model deflection when loaded in this manner yielded a deflection of 1.74 in. Both values indicate a high level of agreement with the laboratory study and inspired confidence that the girder model was accurate.

Table 4: Element Level Model Validation

\begin{tabular}{lcc}
\hline & Mid-span Load & $\begin{array}{c}\text { Quarter-span } \\
\text { Loads }\end{array}$ \\
\hline \hline $\begin{array}{c}\text { Ahsan (2012) 7 Girder } \\
\text { Average Deflection }\end{array}$ & $40.4 \mathrm{~mm}(1.59 \mathrm{in})$ & $44.9 \mathrm{~mm}(1.77 \mathrm{in})$ \\
Model Deflection & $37.3 \mathrm{~mm}(1.47 \mathrm{in})$ & $44.2 \mathrm{~mm}(1.74 \mathrm{in})$ \\
Error & $7.5 \%$ & $1.7 \%$ \\
\hline
\end{tabular}

\subsubsection{Flexural Lateral Load Distribution Behavior}

Flexural lateral load distribution describes the relative load sharing phenomena that occurs in a complex bridge system or the fraction of live load that is resisted by an individual member in a girder bridge system. The fractional representation is generally considered a simplification of complex two-way bridge system interactions down to a one-way behavior representation and is typically used for member design. In this study, the flexural lateral load distribution behavior was analyzed to help evaluate the in-service behavior of the HCB bridge because such in-situ performance is critical to the end user and there are very few HCB bridges currently in use.

Figure 22 illustrates the transverse longitudinal strain profiles at mid-span for each of the load configurations. As would be expected in a typical load test, the girders directly under the load truck experience the greatest strain response, while the deformation diminishes 
over the neighboring girders. It would be expected that an exterior girder might exhibit greater strain because it is unable to distribute load to a more exterior member, but in fact the strains in the exterior girder are always less than the most heavily loaded interior girder. It can also be seen that in each case where the load truck is near the barriers (cases 'A', 'B', 'G', and ' $H$ '), the maximum strain response occurs not in the nearest exterior girder, but rather in the first interior girder. This behavior indicates a significant stiffening influence provided by the barriers to these outer girders. In a companion study by Ahsan (2012) that evaluated a full-scale, three girder HCB bridge of similar design, a similar distribution response was observed for the interior girder, but the exterior stiffening effects were not present due to the lack of parapets in their tests.

Referring to the series of figures within Appendix C, the strains are shown for the gauge located at mid-span on the Northern parapet wall. The magnitude of these strains progressively increase as the load truck moves transversely across the bridge. Load cases that place the truck over the more Southern girders produce little strain in the North parapet wall, yet load case ' $\mathrm{H}$ ' induces as 35 microstrain in the North parapet. Conversely, the opposite trend can be seen in the South parapet wall, where there is a maximum of 30 microstrain experienced, occuring during load case ' $\mathrm{A}$ ' and most likely accounts for the reduced strain exhibited by girder 1 . While this strain occurs in the overhang and thus cannot be combined in a strain profile, it can be inferred that the parapet wall takes a non-negligible fraction of the compression load away from these exterior girders and is the cause for the dip in strains evident in the strain profiles (Figure 22). 

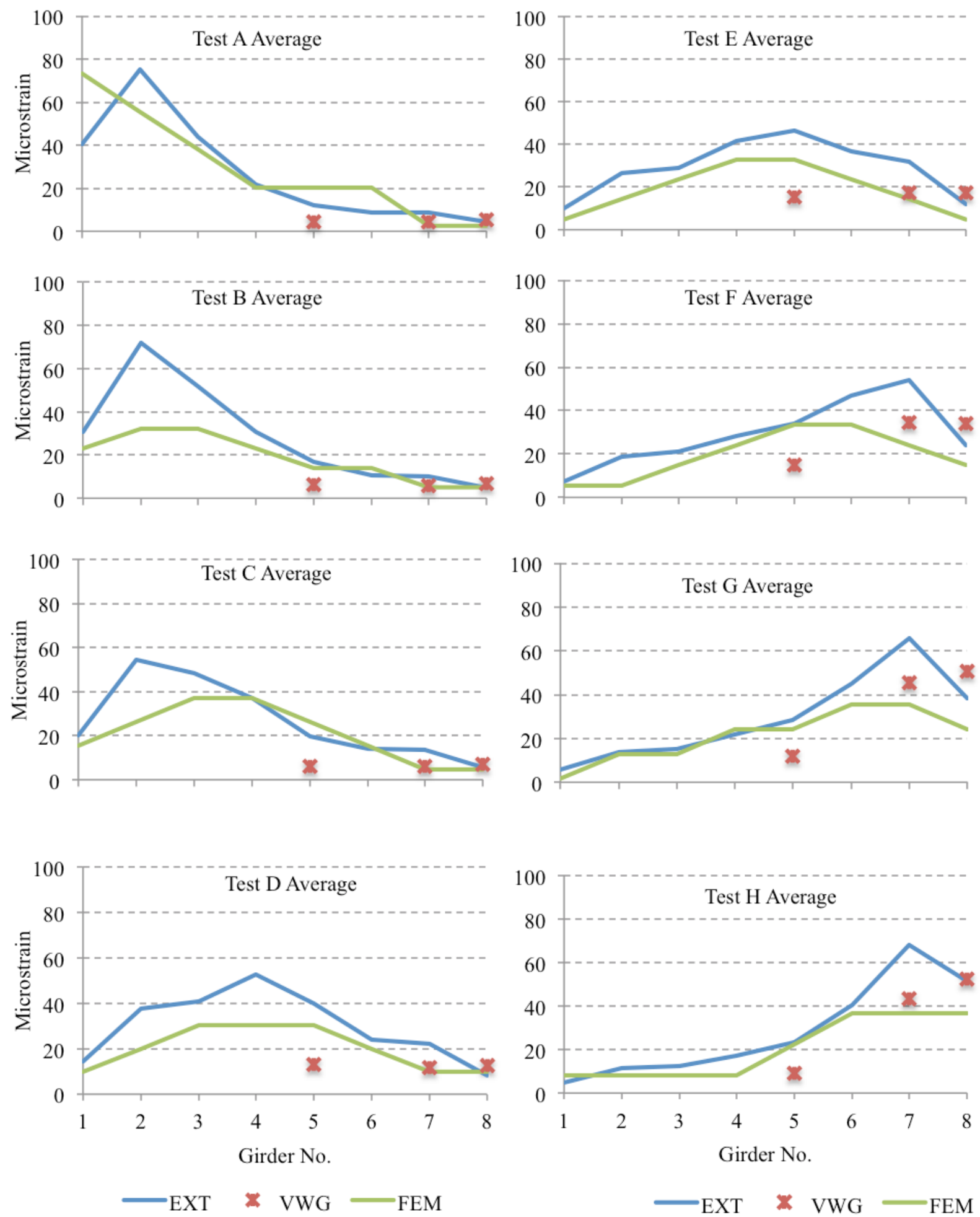

Figure 22: Transverse Distribution of Mid-span Tension Flange Strain versus Girder Number 
Additionally, the exterior girders are identical geometrically to the six interior girders, but contain $25 \%$ more steel, and are therefore inherently stiffer than the interior girders. This is why there is a sharp change in curvature in load sharing behavior at the exterior girder. The stiffness of the parapet contributes the most to the exterior girder, but also affects the nearest neighboring interior girders, while the increased stiffness of the beam itself affects only the exterior girders.

Equation 1, below, is commonly used to describe the flexural lateral load distribution response, where strains at mid-span are the measured inputs. The average distribution factor for each of the load configurations are presented in Table 5. Observe that the controlling distribution factor for the exterior girder occurred for load case ' $\mathrm{H}$ ', while the load case ' $A$ ' controlled for the interior girder. The interior distribution factors from the field test are slightly lower than the results from the study by Ahsan (2012), indicating a more uniform load sharing phenomenon than was found in the full-scale laboratory testing. Furthermore, the measured exterior distribution factors are significantly lower than the laboratory values, most likely due to the absence of the parapet walls in the preliminary study. It should be emphasized that the AASHTO LRFD and the AASHTO Standard Specification do not contain provisions for this type of system, but when considering the anticipated HCB element behavior, it would be expected that the system behavior might mimic that of a conventional slab-girder bridge system such as a concrete deck on reinforced concrete girders (AASHTO Type A) or a concrete deck on box girders (AASHTO Type B). When comparing the measured distribution behavior to these systems that include code-specified adjustments for skew, Type A and Type B 
designations yield conservative estimates for exterior girders, while only the Type A design value is conservative for the controlling interior distribution factor.

[1] $\quad \mathrm{DF}_{\mathrm{i}}=\frac{\varepsilon_{\text {maxi }}}{\sum_{\mathrm{i}=1}^{\# \text { girders }} \varepsilon_{\operatorname{maxi}}} \cdot(\#$ of Trucks $)$

Table 5: Summary of Mid-span Flexural Distribution Factors

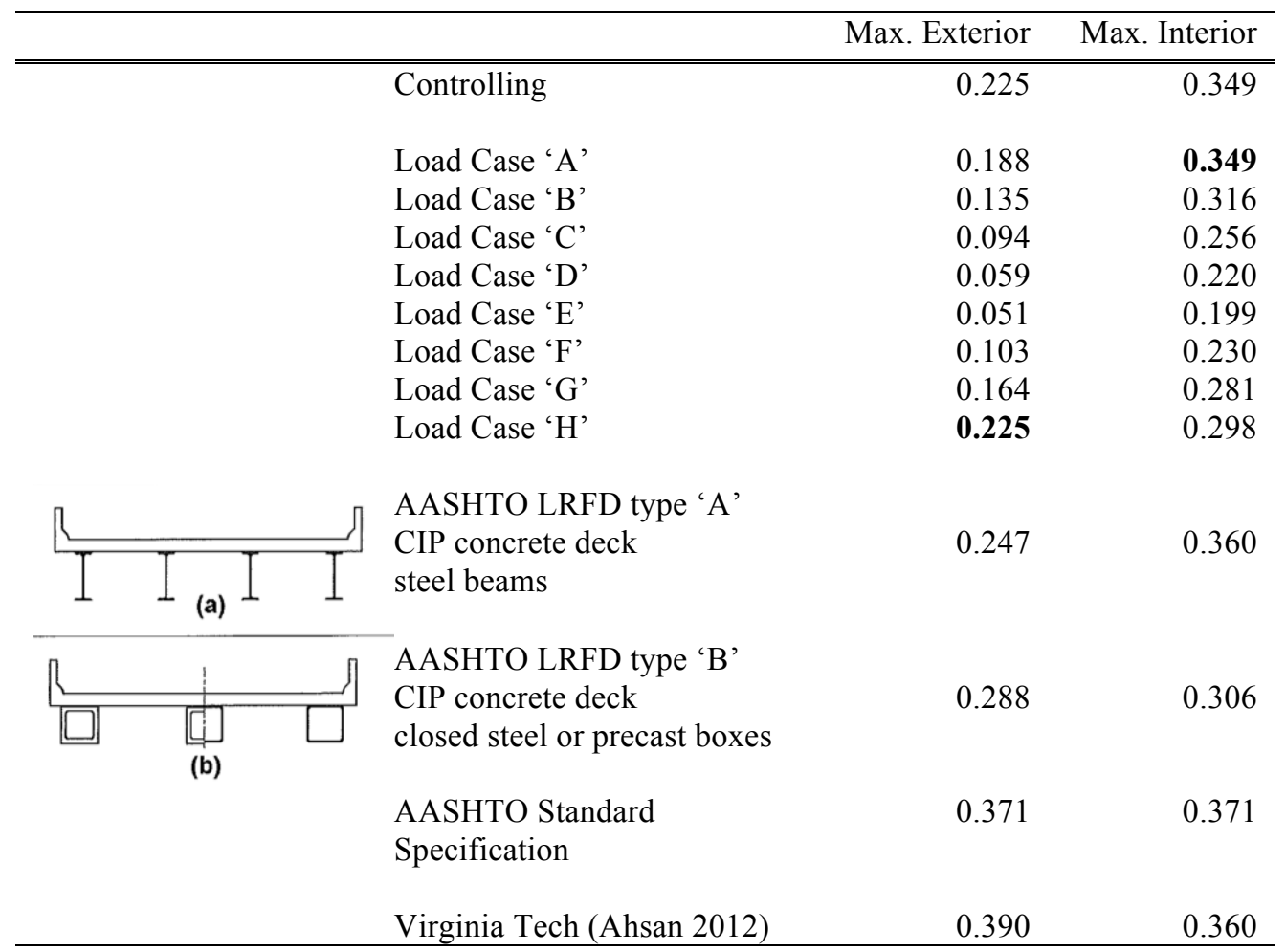

Figure 22 displays the numerical strains carried by each girder and not the traditional distribution factor in percentage of total load. This was done intentionally in order to incorporate the internal VWG strain readings at the level of the strands for the selected girders instrumented internally. These internal strains show some agreement with the external FRP strain readings at lower strain values, but show less agreement at higher strain values. This response from the internal gauges seems to contradict the measurements from the external gauges because of the lack of response from the edge 
stiffness due to the parapet walls. Each of the tests from load cases 'E' through ' $\mathrm{H}$ ' show that the internal strain readings are higher than the strains in the first interior beam, while the external FRP strains are lower in the fascia girder versus the first interior member.

The VWG strains do not consistently match the trend or magnitude of strain. The internal strain readings are consistently lower than the external FRP strains, with the exception of the fascia girder number 8 . It is important to note that the main tension load-carrying component is the internal tension steel, yet the distribution behavior has been derived from the external FRP strain readings, and may not represent the distribution behavior in the primary load resisting component. The cause of this non-correspondence is unknown, but may be attributed to the non-composite behavior of the HCB components, as discussed below. This is reinforced by an observation of the strains near the exterior of the bridge near the parapet walls where there is a lower stiffening effect on the internal tension strands than the FRP shell.

The quarter-span load sharing behavior is illustrated in Figure 23, detailing the strain distribution across each girder as the load truck moved from side to side. It should be noted that the strain gauge on the external flange of girder 4 malfunctioned and data could not be included for the purpose of this representation. As such, a linear fit was used between girders 3 and 5 and may give a good approximation of the value at girder 4 , as the slope indicating rate of change in the strain is not significantly disrupted from the neighboring girders. Generally the quarter-span tension strains exhibit similar 
distributions across the eight girders when compared to mid-span, although magnitudes of strain are lower for obvious reasons.
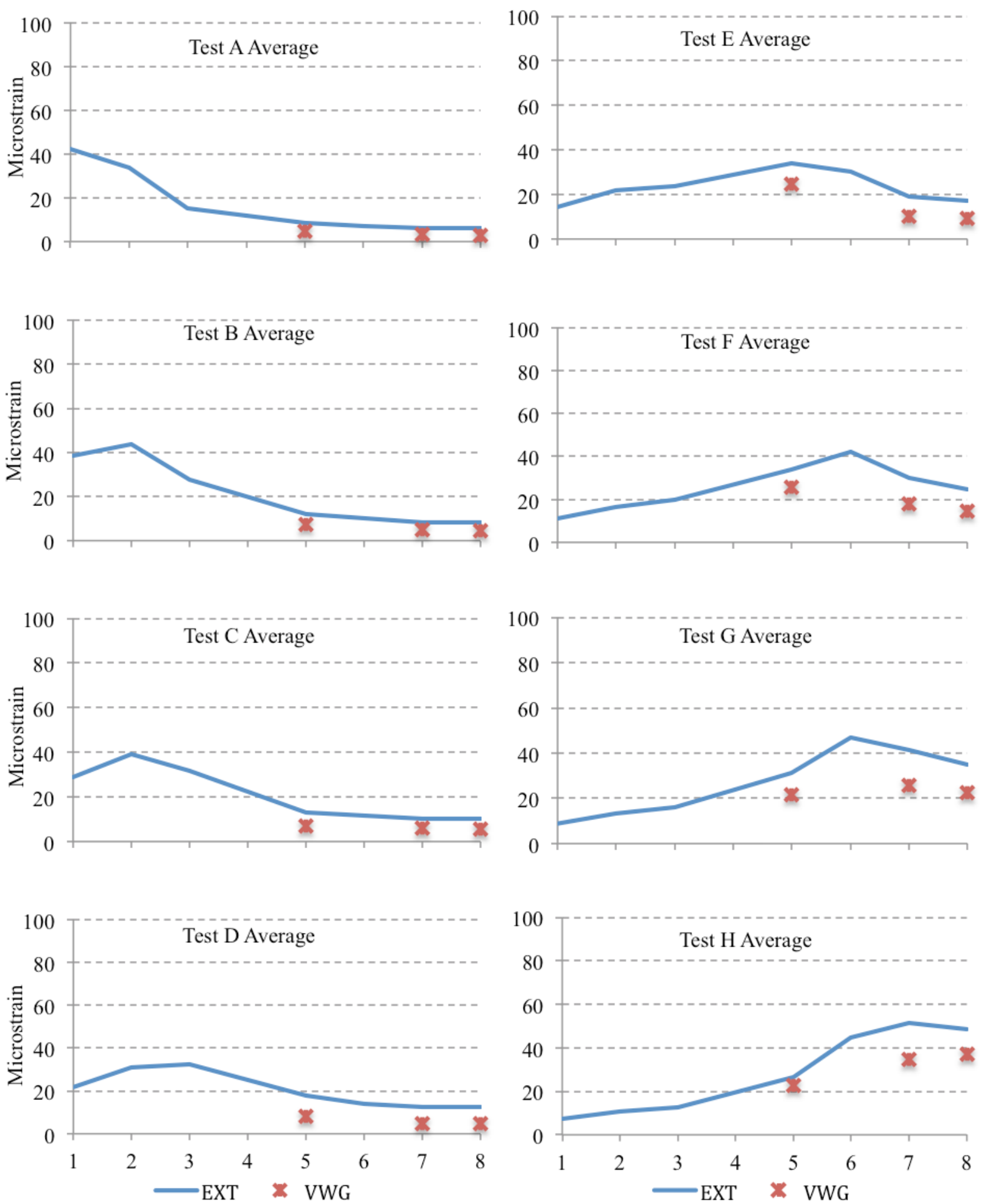

Figure 23: Transverse Distribution of Quarter-span Tension Flange Strain Versus Girder Number 
In the quarter-span case, the internal VWGs track the external strains much more closely than at the mid-span locations. While the internal strains still tend to be slightly lower than the external values, the discrepancy between the two gauges is seldom more than a few microstrain, indicating that there is not as much slippage between the internal steel and external FRP shell. The cause of this phenomenon is also unknown, as the load carrying elements are self-contained within the shell and not readily available for inspection, but one possible theory is that the tension steel pulls away from the FRP shell because of the lack of support provided by the foam at mid-span. In other words, as the beam generates curvature in flexure, the tension steel may pull away from the FRP shell to remain as linear as possible in tension, while the curvature of the bottom flange of the FRP is enforced by the stiffness of the side webs tying into the remainder of the system and the curvature of the deck. A simplified diagram depicts this phenomenon in Figure 24.

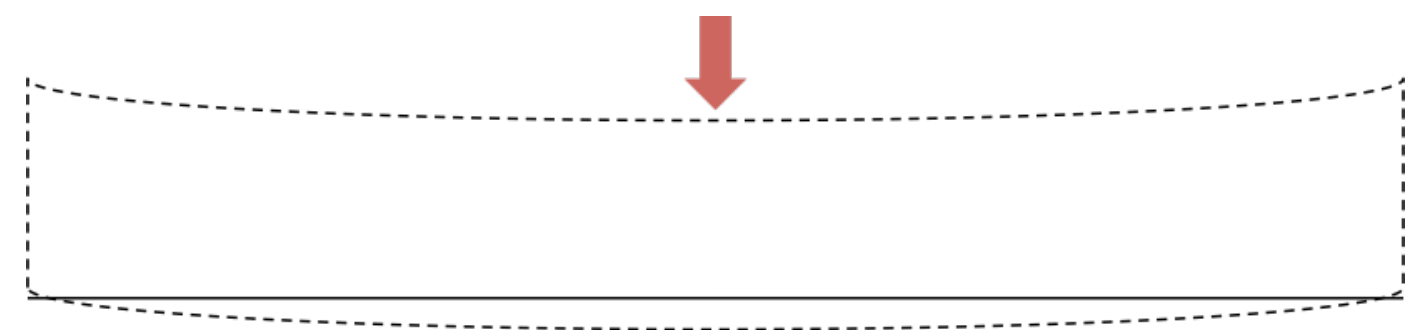

Figure 24: Simplified Representation of Possible Separation of Steel and FRP Under Applied Load The dashed line represents the deflected beam shape, originating in the deck and enforced by the rigidity of the enclosed FRP box. The solid line represents the tensile steel that may not follow the curvature of the beam due to lack of restraint. While the steel is embedded in the FRP, it is not restrained above by anything but a single layer of FRP and foam. A single extreme loading event may be enough to separate the steel from the FRP, 
and each subsequent loading would exhibit this effect. Such a phenomenon would surely be accentuated at mid-span, where curvature of a traditional beam is maximized.

Also included in Figure 22 is the distribution of strains across eight girders resulting from the analytical model. These strains cannot give quite an exact distribution due to the format of results presentation in ANSYS. The output of a simulation yields a range of strains, where a single color indicates the presence of values spanning the range. Figure 25 shows test $A$ as an example of how these strain ranges are generated. Despite this, the strain profiles still yield reasonable results that let one conclude that the model has some validity.

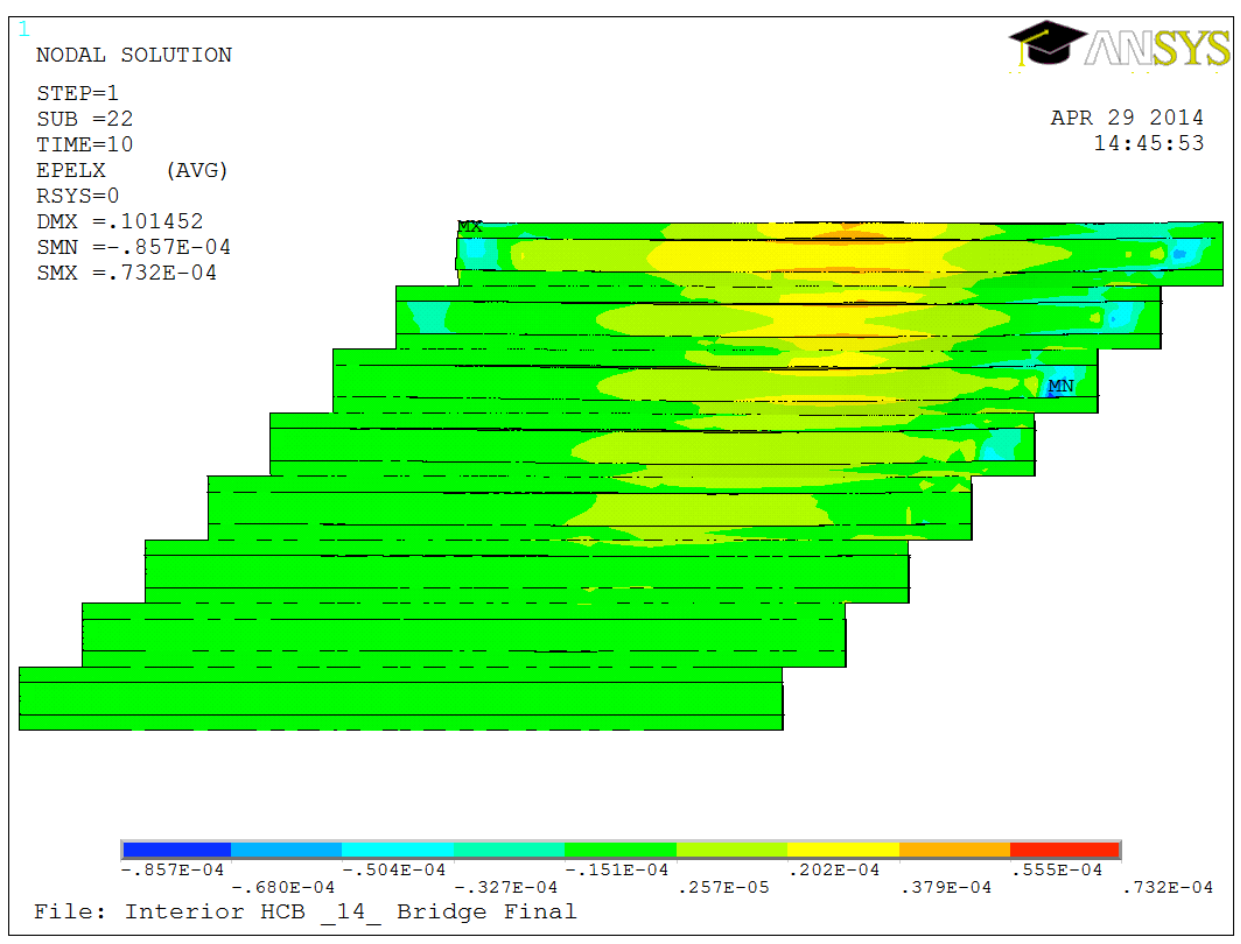

Figure 25: Load Case 'A' Longitudinal Strain Response

In general, the distribution trends mirror that of the externally measured FRP strain distributions with a few exceptions. Take load case ' $\mathrm{B}$ ' for instance, which does not peak at the first interior girder, as is the case with the external strains. Furthermore, the 
analytically generated strains are consistently lower than the external strains just as the internal VWGs tend to be. One reason for this result could be the modeling constraints. The tension steel elements linked each node of the FRP longitudinally, enforcing exact congruence in the response of the steel and FRP. This modeling assumption may not be reasonable, as it has been seen that there is likely some slippage between the FRP and steel, or there is also the possibility that the top layer of fiberglass debonds and leaves the steel unconstrained without any means to deflect the steel, as described earlier.

Strain distributions retrieved from the finite element model reveal the presence of parapet stiffening, although the phenomenon is not as pronounced as in the external strain gauges. In none of the load cases does the exterior girder exhibit the maximum strain. While there is not a significant drop in strain from the first interior girder to the fascia girder, there is at least a reduction in slope to a level distribution.

\subsubsection{Element Load Sharing Behavior}

The HCB system is a composite system that is constructed in multiple stages and as a result, an understanding of the internal element level load sharing behavior is critical. An understanding of this internal load sharing behavior is also essential for maintenance and decision-making processes as the system ages. The internal and external instrumentation allowed for the measurement of the strain profile through the depth of girders 5,7 , and 8 during loading. The data provided critical information on the load sharing behavior between the concrete arch, FRP shell, and reinforcing steel, as well as the location of the neutral axis of the composite cross-section. One critical note is that while the HCB is designed as a tied arch system, once the deck is cast, the neutral axis occurs in the deck. 
Thus, the entire HCB is in tension at mid-span under superimposed dead load (Van Nosdall et al. 2013). Figure 26 illustrates the mid-span strain profiles through the depths of girders 5,7, and 8 for load cases 'F', 'G', and ' $\mathrm{H}$ '. These load cases were selected because the load truck was in close proximity to the three girders that maintained both internal and external instrumentation, and thus yielded the most relevant results. The strain profiles for all load cases and all girders may be found for both mid-span and quarter-span in Appendices D \& E.
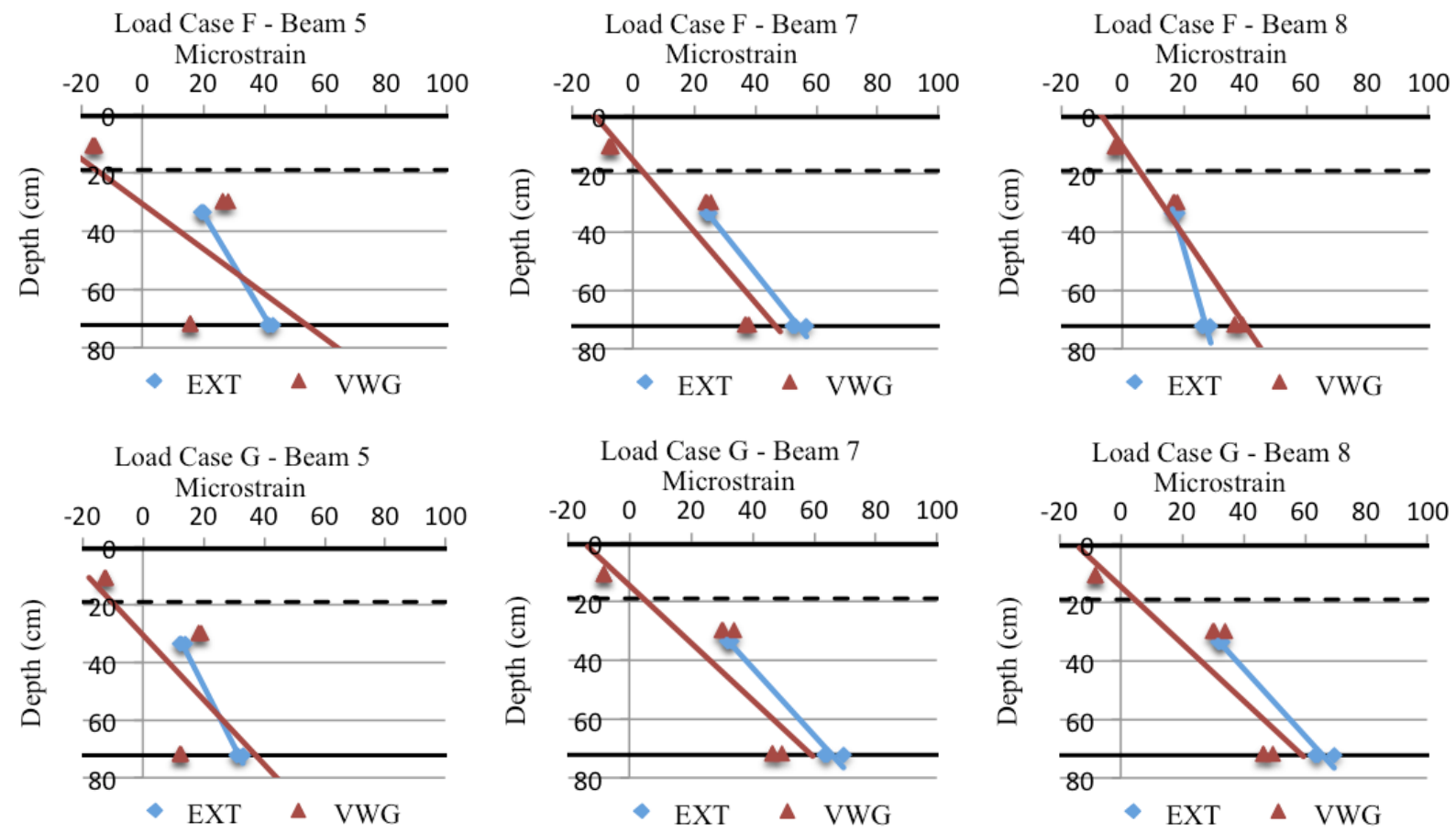

Load Case H - Beam 5
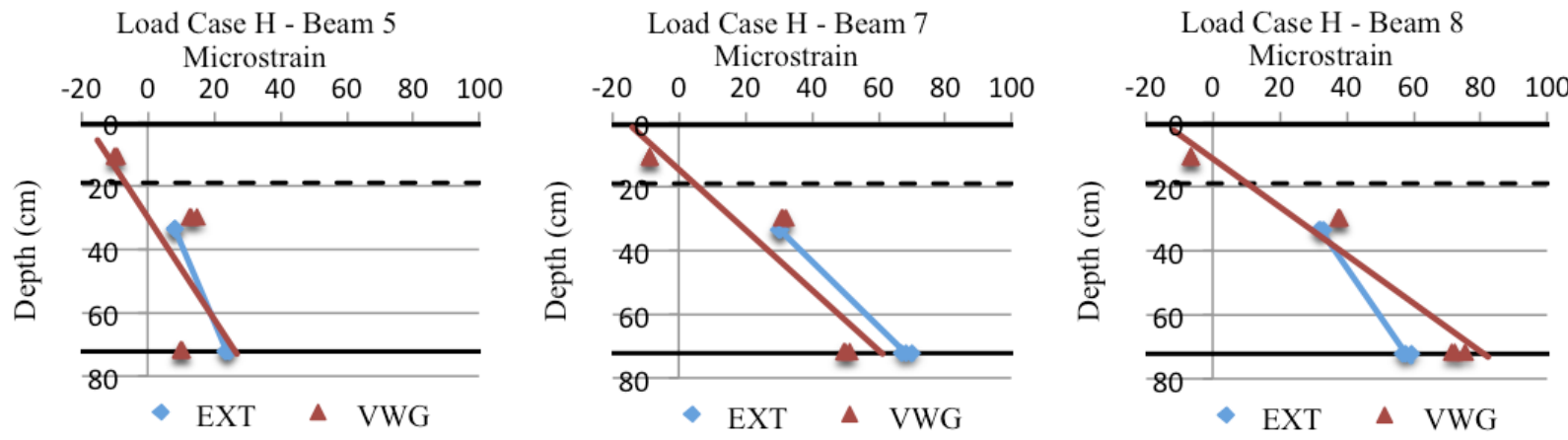

Figure 26: Strain Profiles Through Mid-span Depth of Truck Locations F Through H 
These through-depth strain profiles show that the average strain profile of the VWGs yield locations for the neutral axis as the strains transition from tension in the HCB to compression in the concrete deck. While there appears to be some level of composite action with the deck, it is evident that the strain profile through the depth is not consistently linear as might be expected for full composite action. As an example, the tensile strains in the arch section of girder 5 exceed those in the tensile strand level. At first it was surmised that the higher concentrations of strain were due to service load tensile cracking in the unreinforced arch concrete, solely intended for support during construction (Van Nosdall et al. 2013). However, after further reflection and investigation of the quarter-span strain profiles, it seems that the two steel strands in the bottom of the arch profile may be carrying significant levels of tension, despite their absence in design calculations. The VWG arch strains seen in the quarter-span plots (Figure 27) are in significant tension, well beyond the cracking strain of the arch concrete, yet the arch continues to carry the strain.

Rather than cracking in the arch, Ahsan (2012) hypothesized that there exists a local bending phenomenon in this thin concrete arch. Returning to Figure 3, one can see how the arch would be able to experience bending, especially at higher levels of overall HCB curvature where the arch begins to flatten out. Ahsan also proposed that this effect is dampened at mid-span due to the 8 foot sheet of FRP that serves as formwork for the arch, but also likely provides significant stiffening to the arch. This FRP sheet that forms an enclosure for the arch at this location also connects to either FRP web and thus enforces greater congruence with the FRP curvature and overall HCB response at mid- 
span. The data collected in this experimental program aligns with the theory, as the quarter-span arch gauges of beams 5 and 7 experience uncharacteristically high levels of tensile strain, often greater than the maximum tensile strain in the bottom flange of midspan girders. Beam 8 does not show such an accentuated trend for reasons that will be discussed later.
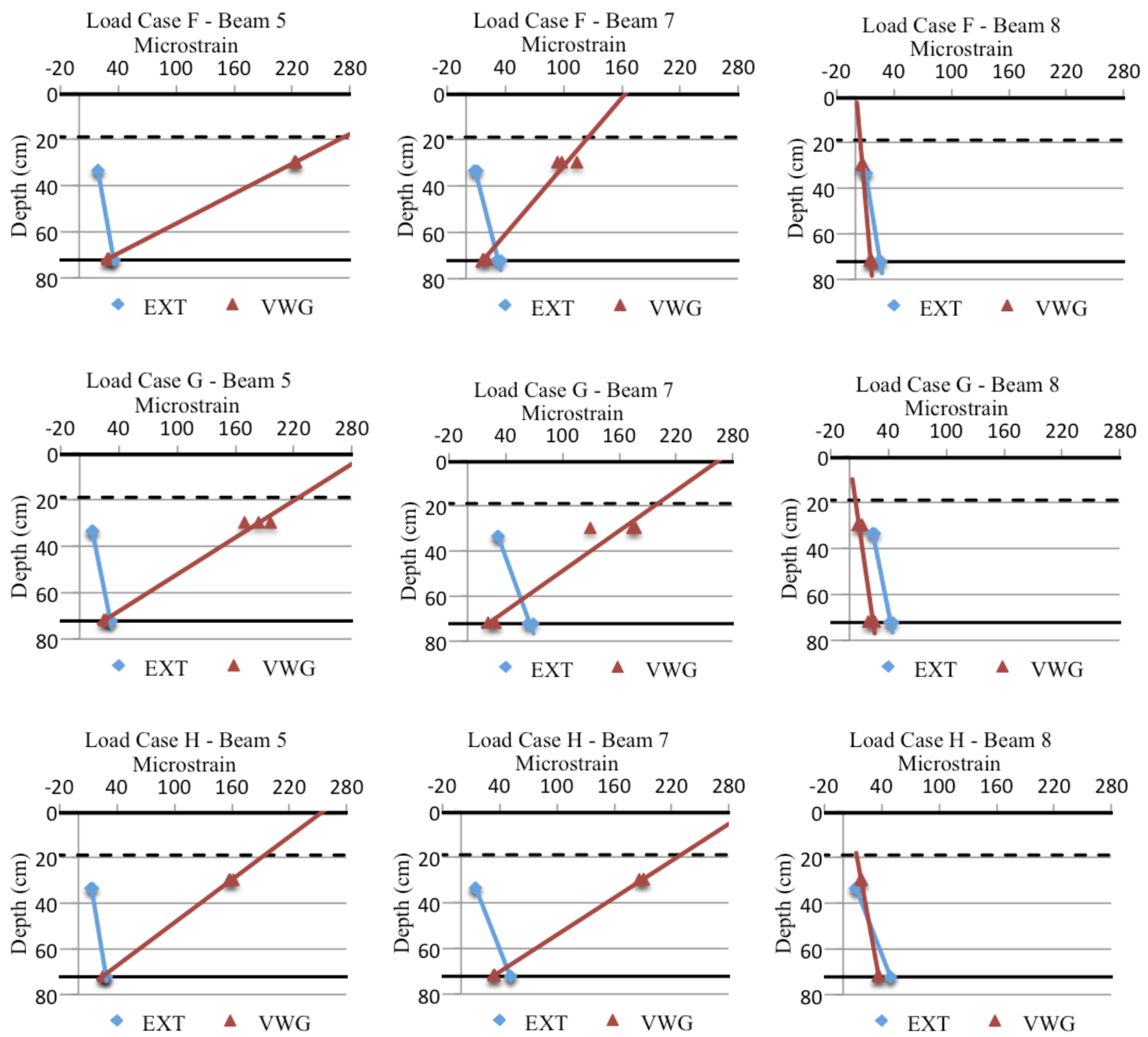

Figure 27: Strain Profiles Through Quarter-span Depth of Truck Locations F Through H

In both the mid-span case and the quarter-span case, the non-composite arch tensile strains are extremely pronounced in girders 5 and 7 , yet in girder 8 the strain profiles are 
the closest to linear. This is best explained by they the previously discussed edge stiffening effects from the parapet, in combination with the doubled quantity of steel in the tension zone of the exterior girders. These exterior beams are likely stiff enough to minimize beam curvature, and the local bending effects in the arch are therefore not as evident.

Mid-span strain profiles for girders 5, 7 and 8 are plotted in Figure 28 below for the three companion load cases for comparison with Figure 22 above. From these figures it is clear that the analytical model confirms the local bending of the arch at mid-span. Tension strains and deck strains are comparable to those recorded during the load test, but here all bottom arch locations exhibit strain higher even than the tension steel, meaning that the local arch bending generated by the model is slightly exaggerated at mid-span. The added benefit of the finite element model is the ability to compare the strains at the top and bottom of the concrete arch. In each case below, there is a swing of as much as 25 microstrain over a depth of only four inches when compared to the entire beam varying by $40-60$ microstrain over a depth of 29 inches. This is a strong indicator that there is in fact flexural behavior occurring in the arch.
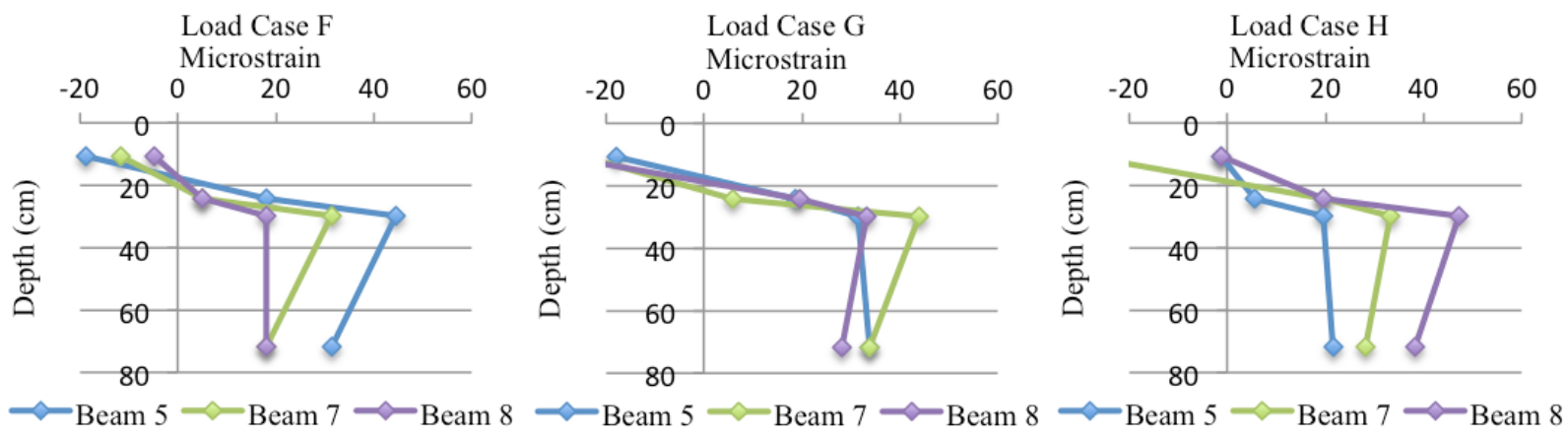

Figure 28: Mispan Profiles of Finite Element Model Strains 
The strains generated by the ANSYS model are all delta strains, in other words, the strains due only to the additional load of the load truck with no effects from the dead load. It was also desirable to gather the strains generated by the dead loads to give a complete picture of the net strain. Figures 29 and 30 show the strains due to the dead load of the girders and concrete deck for the bottom FRP flange and underside of the concrete arch, respectively. Both the FRP tension flange and concrete arch register strains on the order of 50 microstrain in tension. This means that the arch is already under tension under dead loads, thus the net strain under superimposed live loads will be further in tension. Additionally, as the highest delta strains registered in the steel strand was around 80 microstrain, the maximum total tensile strain is thus on the order of 130 microstrain.

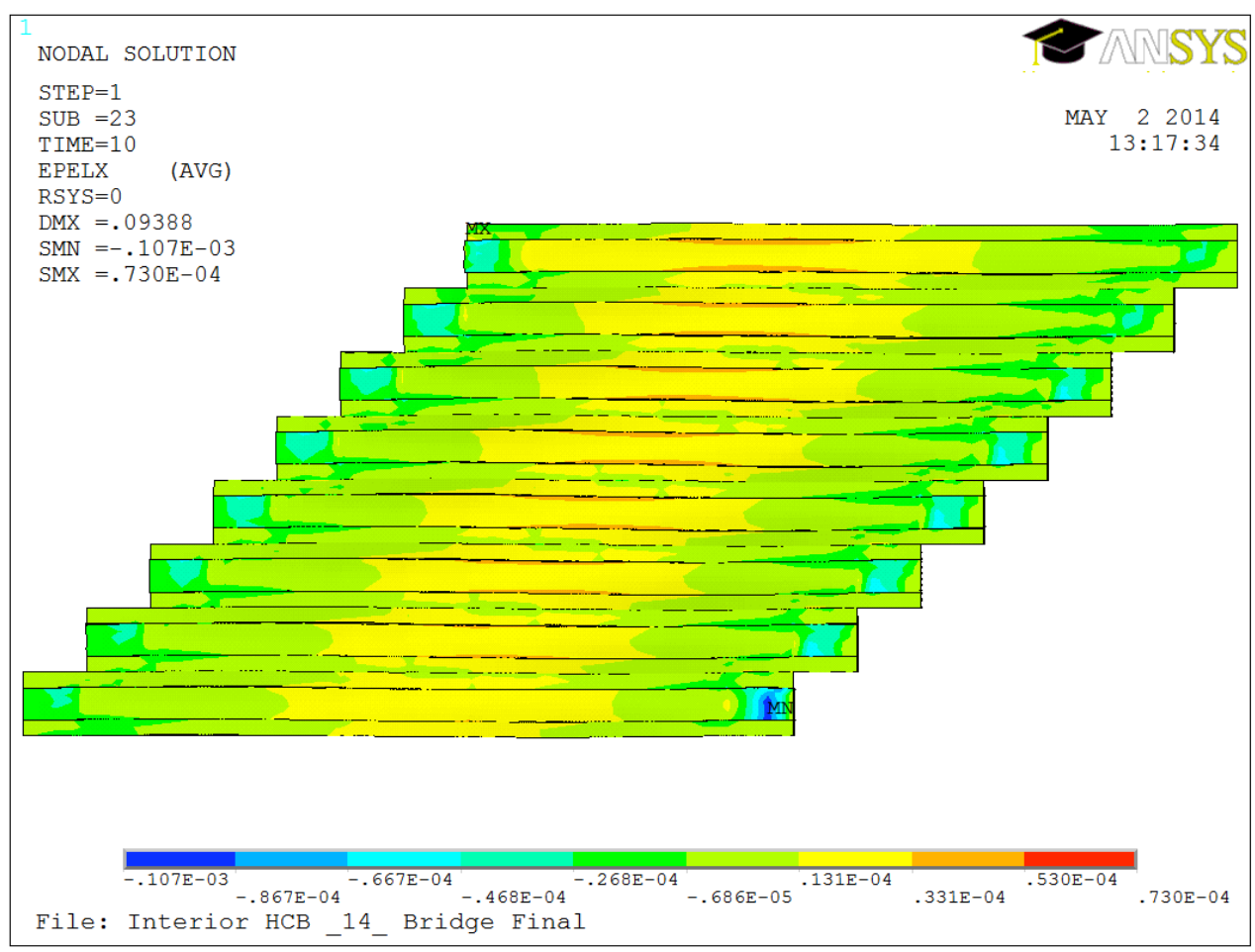

Figure 29: Bottom Flange Strains due to Dead Loads 


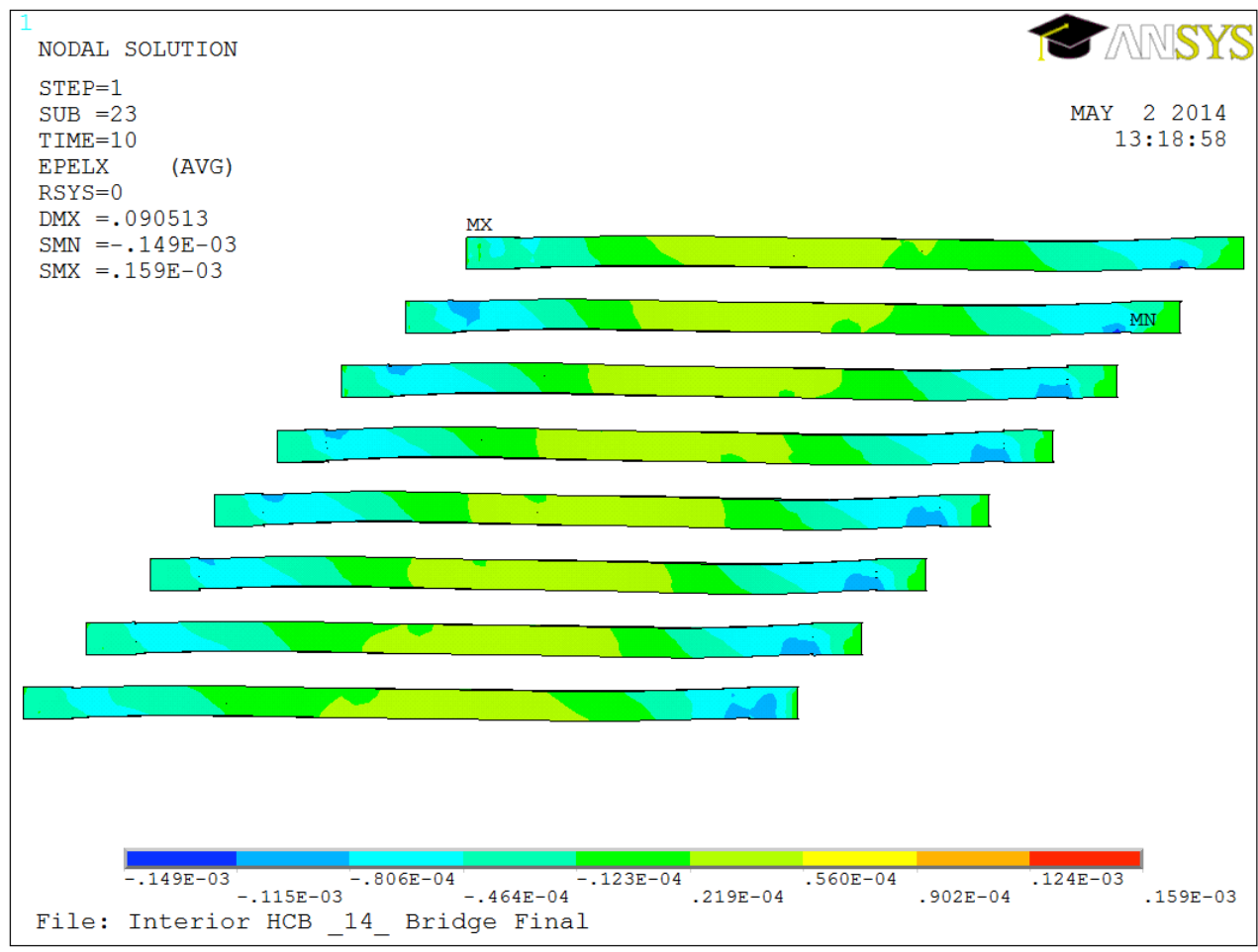

Figure 30: Concrete Arch Strains due to Dead Loads

A representative time-lapse plot of strains through the depth of a girder is shown in Figure 29 and shows that the two companion locations show some agreement. Both the arch level gauges and tension level gauges track in trend, but not magnitude. This is apparent in Figure 26, and again suggests the FRP shell is acting non-compositely with the internal load carrying components. It is also interesting to note the significant dip in strain in the arch gauges before reaching their peak strain. The cause of this phenomenon is the distribution of weight of the load truck over a front and rear axle set. Influence lines allow one to understand that as the lighter front axle passes the location of maximum response for the particular gauge, a small peak is registered. In between the two axles is a dip in the response as both axles are near to the maximum influence location. Later, as the heavier set of rear axles pass this maximum influence location, a greater peak is 
recorded. Again, the arch gauges show a slight secondary dip in this maximum peak as there are two axles closely spaced in the rear.

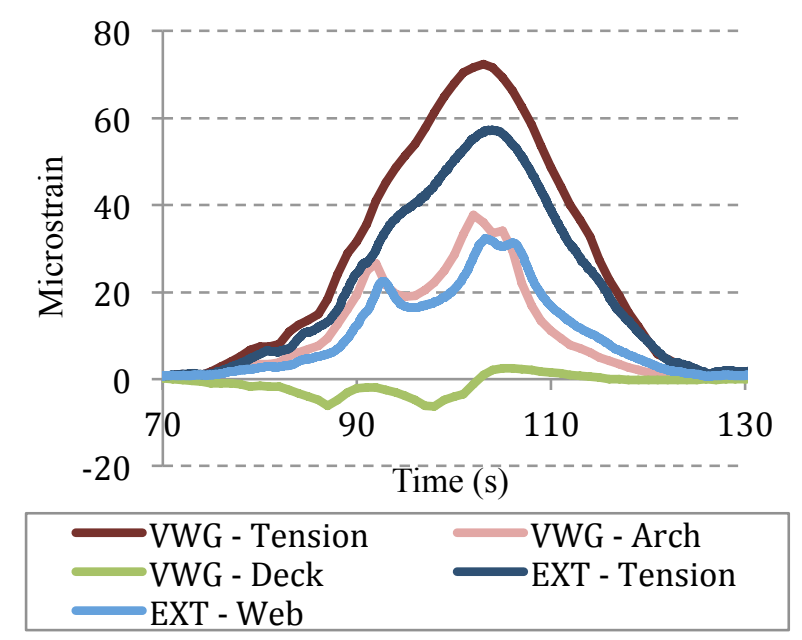

Figure 31: Representative Mid-span Time-Lapse Strain Comparison Girder 8 Response for Load Case H, Run 1

It is also of interest to note the effects of skew on the response of the system. There is a definite lag in response from one girder to another due to the alignment of corresponding locations. As a vehicle enters the bridge longitudinally, the driver's side wheel path will cross onto the bridge prior to the passenger's side, similarly reaching quarter-span and mid-span of the supporting girder prior to the same locations on the girder supporting the passenger's wheels. To demonstrate this lag, see Figure 26 and recognize that the two wheel lines of load case $\mathrm{H}$ pass over girders 6 and 8 . Referring to appendix A to compare the response of gauges on girders 6 and 8 for load case $\mathrm{H}$, it becomes clear that the peak of each gauge on girder 6 occurs nearly 10 seconds in advance of the same locations on girder 8 .

\subsubsection{Dynamic Load Allowance}

The dynamic load allowance (DLA) or impact factor accounts for the amplification of the design static live load due to a moving vehicle crossing a bridge. This amplification is 
influenced by a number of factors, including bridge mass and flexibility, vehicle mass and suspension, roadway roughness, and vehicle speed. The dynamic amplification inherent to the HCB is critical because the system is relatively lightweight and more compliant than a traditional concrete or steel girder system. Load test results from a static load case and the corresponding dynamic load test were used to determine the dynamic load allowance for load cases 'B' and 'D' with the relationship presented in Equation 2. These cases were selected to align with results from the static load cases, but also allow for safe travel of the load trucks across the bridge at speed. The original test plan included efforts to measure the VWGs dynamically, however, this effort proved unsuccessful and only external response was recorded. The amplification can be observed from the superposition of strains observed during the static and dynamic tests (Figure 30).

[2] DLA $=\frac{\varepsilon_{\text {dynamic }}-\varepsilon_{\text {static }}}{\varepsilon_{\text {static }}} \cdot 100 \%$

The maximum dynamic amplification response for each of the two load truck positions tested under dynamic conditions is presented in Table 6 along with the design values from the AASHTO LRFD and Standard Specification (AASHTO 2002 and 2012). These measured values represent the amplification observed in the most heavily loaded girders for the respective load cases. From the results it is evident that the average dynamic amplification is comparable to those prescribed for design, but there is the potential for larger amplification as demonstrated by the maximum responses observed in the most heavily loaded girders. In the maximum dynamic amplification cases below, the maximum response registered in girder 4 for load case 'B' was $46 \%$, while a response of $33 \%$ was registered in girder 7 for load case ' $\mathrm{D}$ '. 
Table 6: Dynamic Load Allowance

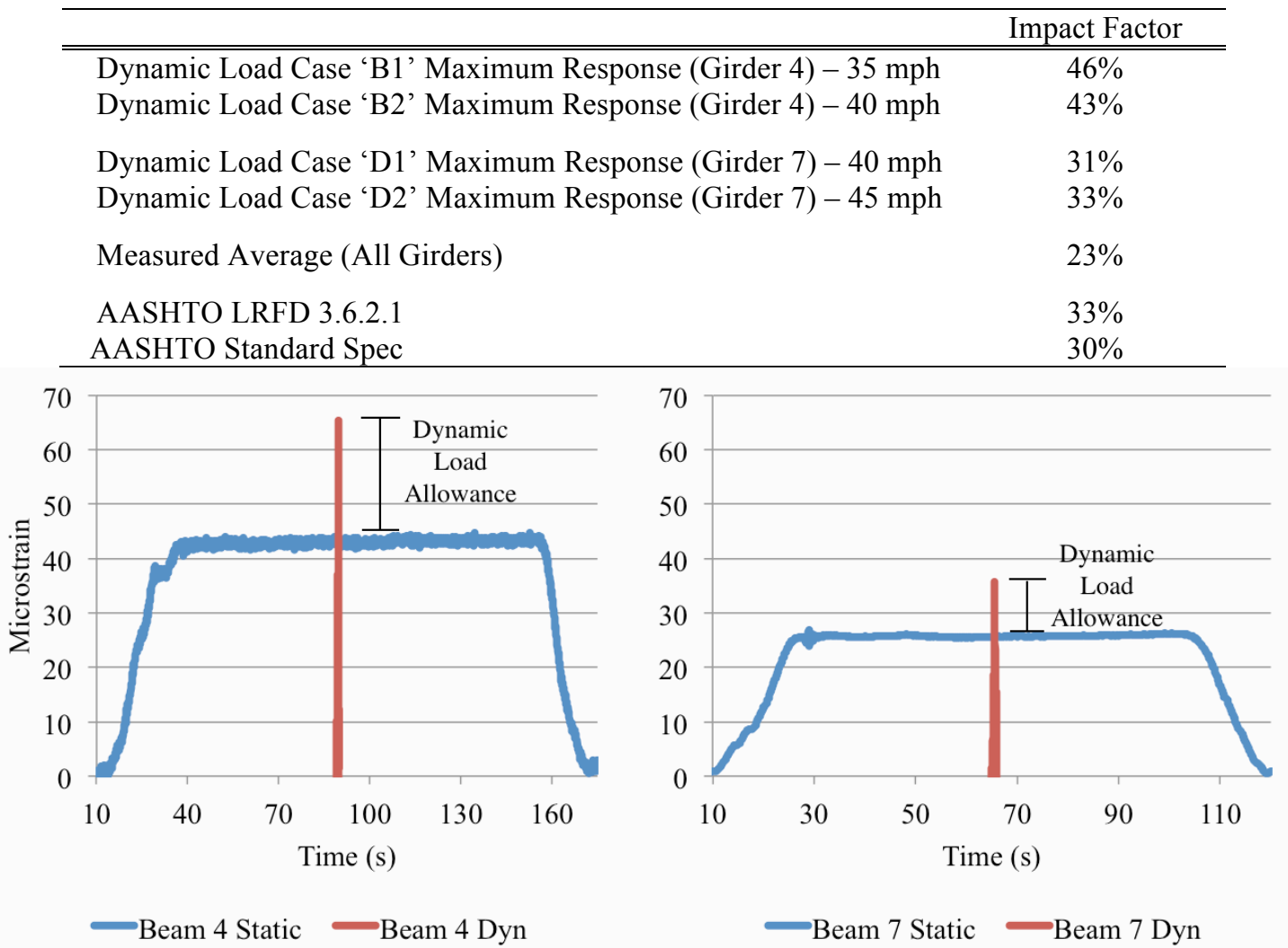

Figure 32: Maximum Dynamic Amplification Response Under Load Case 'B' (Left) and Load Case 'D' (Right)

\subsection{Conclusions}

This study was comprised of an in-service live load test of a HCB bridge system skewed at $45^{\circ}$ over a $13.5 \mathrm{~m}$ clear span. This test was conducted to validate the results of a companion laboratory study performed by Ahsan (2012), and focused on three critical bridge behavior characteristics; lateral load distribution, dynamic load allowance, and internal load sharing behavior of all HCB components. This was accomplished through an extensive instrumentation program that embedded VWGs through the depth of the composite section at various lateral and transverse locations, as well as externally mounted strain gauges at companion locations. The load test included both quasi-static and dynamic testing, and varying the transverse position of the load vehicle yielded 
sufficient data to characterize the bridge behavior. Quasi-static results were further validated through the generation of a finite element model.

The findings of the study may be summarized as follows;

- Distribution behavior determined from the externally mounted strain gauges was consistent with expected trends. The highest strains were registered directly under the load vehicle, and dissipated elsewhere. The parapet walls offered a significant stiffening contribution to the fascia girders. The controlling experimental distribution factors confirmed Ahsan's (2012) laboratory work, and were conservative compared to traditional AASHTO steel girder bridge values, where the maximum load fraction for each load case reached, but did not exceed $97 \%$ of the allowable value. The controlling interior distribution factor exceeded the AASHTO type 'b' value, but the average maximum load fraction across all load cases for interior and exterior girders was only $70 \%$ of the most conservative allowable code value.

- It was found that the typical dynamic load allowance registered was on par with the assumed design values, producing an average across all girders within $2 \%$ of both AASHTO LRFD and Standard Spec. Several instances of large amplifications (as much as $66 \%$ more than average) indicate that the system is compliant, but despite this and the observation of high levels of apparent compliance on the day of the load test, the typical behavior of the system is conservative and acceptable. 
- The internal strain profiles confirm the assumed neutral axis, but showed a nonlinear trend. It was concluded that the FRP shell does not act compositely with the internal HCB components. It was shown that the arch does not act compositely with the system and the plane sections remain plane assumption is not valid for HCB. In fact, the arch exhibits local flexural bending within the girder that is especially apparent at the quarter-spans, but subdued at mid-span due to an additional FRP shell layer beneath the arch that provides additional stiffness.

- There was also an observed disparity between the bottom flange strains and the strains in the tension steel, which could be explained by slippage of the steel within the FRP flange, though this occurrence has not been experimentally verified. Another way to look at this phenomenon is debonding of the top layer of FRP due to the vertical force applied by the steel during flexure. If the steel were to separate from the outer layers of FRP, there exists insufficient vertical restraint to enforce curvature in the steel during bending, and thus the steel would experience the pure tensile strain associated with a tied arch. The FRP shell would experience the curvature of the deck through the rigidity of the FRP webs and also higher strains than the steel.

\subsection{EVALUATION OF LONG-TERM INSPECTION TECHNIQUES}

Due to the nature of being a new structural system in the well-established field of bridge engineering, there is a lack of strategy for inspection of the HCBs, especially when considering the encasement of the critical load-bearing elements of the system. These components are not readily available for visual inspection, so the following section presents a summary of non-destructive evaluation (NDE) techniques and their feasibility 
for accomplishing specific inspection tasks. The chapter begins by discussing the evaluation of components beginning with the deck and working down to the beam level, which is broken up into internal and external components.

\subsection{Reinforced Concrete Deck Inspection}

The 191-mm (7.5-in) concrete slab deck is reinforced according to traditional design practices. Thus, it does not vary significantly from a conventional reinforced concrete slab-on-girder bridge. Conventional concrete deck inspection methods apply here and will not be discussed in depth, but one should consider the methods that follow.

\subsubsection{Visual Inspection}

Visual inspection is a very efficient method for investigating large deck surfaces quickly and economically. This type of investigation is effective in identifying significant surface defects that include, but are not limited to cracking, localized depressions and staining. While only surface defects may be detected, taking note of their characteristics may be indicative of internal concrete conditions and that of embedded rebar. Rust staining, for instance, is a good indicator of deterioration of internal steel. A visual inspection should include the orientation, width and if possible, depth of cracks (International Atomic Energy Agency, 2002). The beauty of this method is the low cost associated with visual inspection. Only very basic tools are required, unless access becomes a problem and heavy equipment is needed to provide an inspector a vantage point to capture the condition of the whole deck. Another consideration to be made when relying on visual inspection is the subjectivity of inspectors. Each inspector may not have the same visual acuity for detecting small cracks, and one inspector may rate surface defects to be more or less critical based on their background. For this reason it is important to use as many 
standardized forms of measurement as possible to quantify the deterioration. Visual inspection is a good way to identify problem areas that can be inspected further with localized NDE methods.

\subsubsection{Ground Penetrating Radar (GPR)}

The inspection method of ground penetrating radar (GPR) is one of the more popular NDE methods for investigating the location and condition of embedded steel. GPR uses a near-field investigation of electromagnetic (EM) waves that have a wavelength greater than concrete aggregates and therefore pass through the non-homogenous material with ease. These waves interact with boundaries that have disparate dielectric constants and the reflections and refractions are recorded and analyzed.

Concrete attenuates these EM waves after a depth of about $2 \mathrm{ft}$, making GPR ideal for concrete deck interrogation. Units have been manufactured that allow automation of the process, making short work of B-scans, and even three-dimensional C-scans. Successful applications have been developed where an array of GPR units mounted on a vehicle moving at highway speeds collect data from a bridge deck. It should be noted that this method is on the expensive side of the NDE inspection methods. Additionally, the dielectric disparity between concrete and steel is so high that the entire EM wave is reflected at these steel boundaries, and it is not possible to see the slab beneath these boundaries (Geophysical Survey Systems, Inc. 2006).

\subsubsection{Impact Echo}

The mechanics of the impact echo inspection method are discussed in section 4.2.3. The stress wave produced by an impact is ideal for detecting delamination, voids and 
honeycombing of a concrete deck. Impact echo is reliably accurate at detecting the location and depth of these sorts of defects. As will be discussed later, it is an efficient method when automated, but may be costly to implement (Sansalone, 1997).

\subsection{Steel Strand Inspection}

As the high-strength steel strand is embedded within several layers of the glass FRP shell, it is not available for visual inspection, yet there is still a great interest in the condition of the steel just as would be the case with a conventional prestressed or reinforced concrete girder. Of particular interest with respect to the condition of the passive steel strand is the presence of any deterioration, be it corrosion or yielding/breakage of the strands. Some of the methods that would be used to inspect steel embedded in concrete are applicable here, however there are some key differences. Notably the near-field presence of the steel in FRP is much less than the cover depths required in concrete. Additionally, the FRP exhibits material properties that differ significantly from concrete and affect readings differently. Additionally, as this type of inspection is not regulated by any codes and many of these NDE inspection readings are also affected by discontinuities outside of the scope of the steel investigation, it will be necessary to research this particular application of these NDE methods and provide standardized inspection guidelines.

\subsubsection{Magnetic Flux Leakage Inspection (MFL)}

This inspection method provides a quantitative analysis of potential discontinuities of steel. The benefit of this method is the ability of a magnetic field to penetrate materials that are not ferromagnetic. Magnetic flux leakage inspection involves saturating the strand with a magnetic field that would flow longitudinally with steel that exhibits no defects or flaws. The theory behind the method is that any defects, be it cracks or 
corrosion, will cause a disturbance in the magnetic field, requiring that the magnetic flux detour around the defect. If the flaw is significant enough, the magnetic field will protrude beyond the boundaries of the steel, and in this case, even the FRP coating. Hall sensors are able to pick up and quantify these signals (Figure 31).

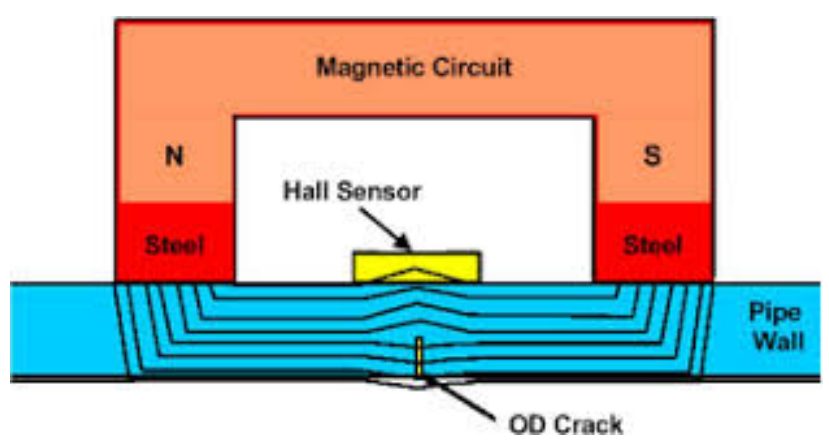

Figure 33: Magnetic Flux Leakage Theory (Chase, 2013)

A great advantage to this method is the ability to devise a unit with a position encoder that can interrogate an entire flange sequentially in a minimal time period. One such example can be seen in Figure 32.

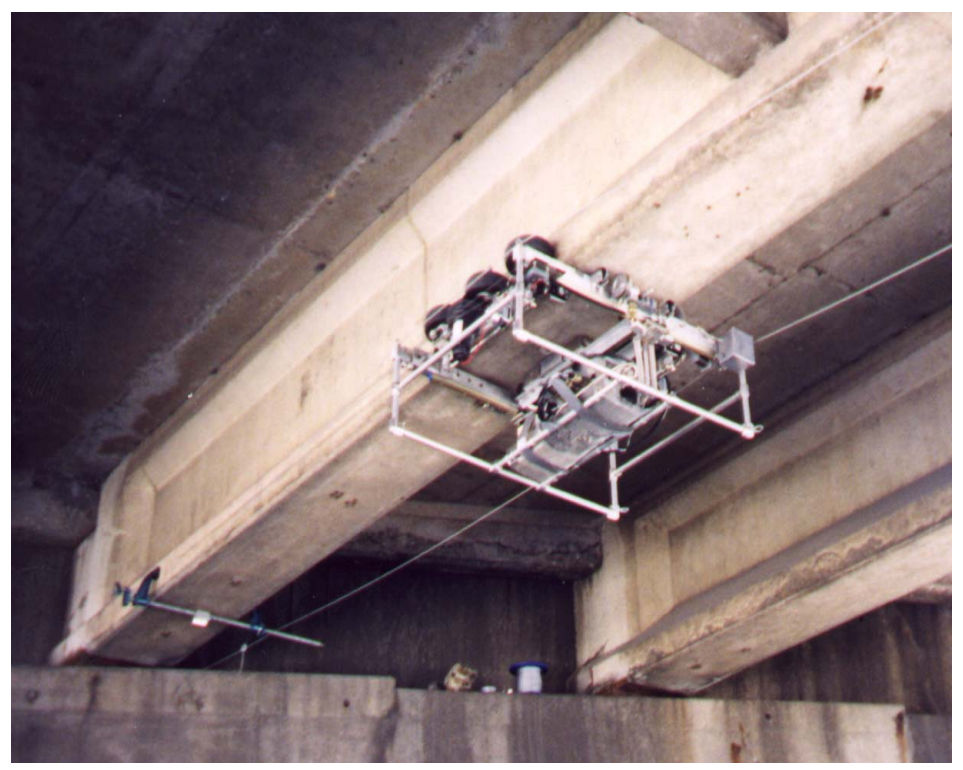

Figure 34: Example of Automated Magnetic Flux Leakage Inspection (Ghorbanpoor, Borchelt, Edwards \& Abdel Salam, 2002) 
It should be noted that as is the case with any of these methods, the working area under this particular HCB application is limited by the stream clearance, and the current tidal situation. One significant drawback to this method of inspection is the high relative cost of the equipment. This is mostly due to the difficulty of saturating larger quantities of steel. The method is, however, able to detect very minute surface discontinuities and may be quantified in volume and depth. Magnetic testing has been used in a variety of applications and has been standardized. ASTM standards E570-09 and STP371 provide the inspection guidelines for effective implementation of this method.

\subsubsection{Eddy Current Inspection}

This inspection method also provides quantitative data for discontinuities within steel. It is also similar to MFL in use of electromagnetic theory for operation. A probe consisting of a coil of wire is fed current, therefore inducing a magnetic field around the probe. When in the vicinity of a conductive object the magnetic field generated by the probe will induce a current in the conductor (Figure 33). As a result, the current in the conductor will have its own magnetic field associated with it. The interaction between the two is known as mutual inductance, and changes in this inductance can be detected by the probe as a result of the dependence of the two systems. Differences in material properties and defects will cause a change in the current, and thus the impedance as well in the test subject, and will register a change relative to a baseline reading. As the readings are relative and dependent on several factors, the results may be challenging to interpret. 


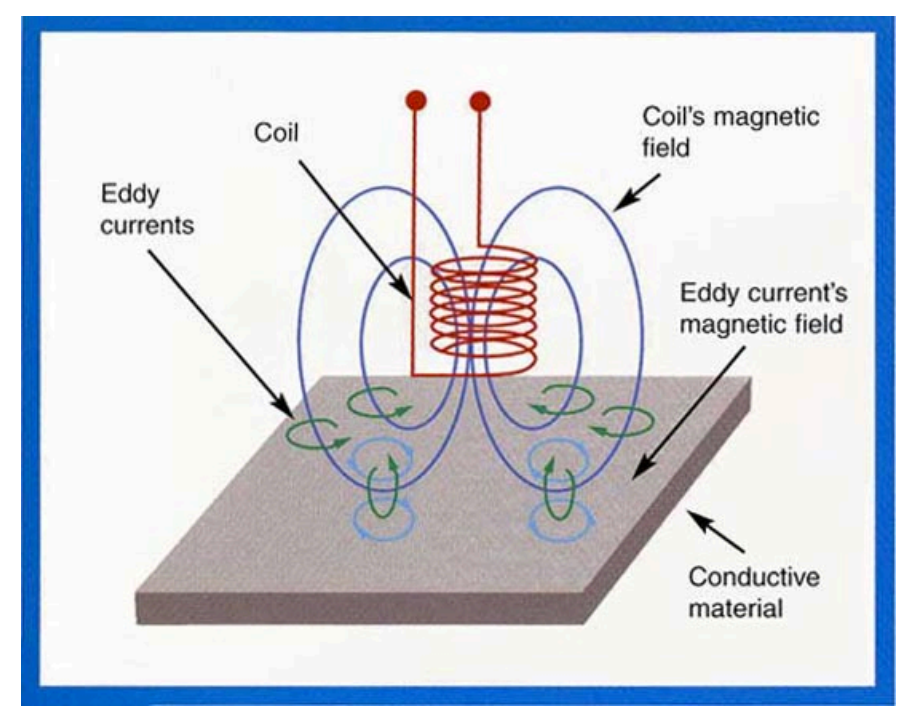

Figure 35: Mutual Inductance Theory - Magnetically induced current in conductive surface creates secondary magnetic fields that in turn influence the current feedback in coil (Collaboration for Non-

Destructive Testing, 2014)

One important drawback to the eddy current method is the idea of liftoff. While magnetic fields are able to penetrate non-conductive materials such as FRP without inducing current, the strength of the signal produced by mutual inductance is diminished by the square of the distance. The thickness of the FRP is not great, but this is also of concern because a slight variance in the thickness of the resin matrix at any location may register a significant disparity that could easily be interpreted as a reduction in steel conductivity at that location. Another important consideration to be made is the restriction of this method to local investigations. As a single probe reading a single point in the plane of the bottom flange, it would take significant man-hours and effort to take readings both longitudinally and transversely, and depending on the density of readings, it would be quite easy to neglect a significant portion of the steel. The technology is, however, relatively inexpensive with respect to MFL inspection, and may be of use for local inspections of questionable areas as identified from visual inspection (see item ' $\mathrm{e}$ ' below). Eddy current inspection is a fairly well established investigation method, and one should refer to the ISO 15549:2008 Eddy Current testing general principles standard. 


\subsubsection{Impact Echo/Mechanical Sounding}

This method provides yet another means of obtaining quantitative data, although results obtained may be hard to interpret. The theory behind impact echo testing is to impart a transient point impact that causes an elastic displacement wave throughout the material. This wave propagates spherically through the material and interacts with boundaries and interfaces causing reflections and translations depending on the acoustic impedance of the materials. The reflected signals will return to the surface and may be recorded. While this type of investigation is ideal for concrete structures, it is also widely applicable to thin materials such as FRP. While it would be most adept at detecting delamination (see item 4.3.2 below), it is also possible that the reflections off the FRP/steel interface would provide a characteristic signal that would vary with the presence of corrosion or cracking. Just as in MFL inspection, a device may be designed with a position encoder to travel longitudinally along the beam and impart an impact at close intervals and record the response along the length. This makes the method more attractive than a local inspection method; however, the technology is also relatively costly compared to other inspection methods (Sansalone, 1997). The impact echo method has been standardized for use with concrete, and ASTM C1383-04(2010) should be referenced.

\subsubsection{Active Thermography}

Thermal investigations rely on the thermal emission of all materials at a temperature greater than 0 Kelvin. The cameras designed for this type of testing pick up the infrared signals that quantify the amount of heat energy radiating from a body at any given time. Each material exhibits its own thermal emissivity and thermal conductivity properties that make one material unique from the next. Thermography is often used to search for 
voids or delamination in concrete because the thermal properties of air are quite disparate from those of concrete. This type of NDE testing will be discussed in section 4.3 .3 below in regards to potential delamination of the FRP shell (Washer, Fenwick \& Nelson, 2013).

As the high-strength steel strand and the FRP also have different thermal properties, an infrared camera should be able to pick up the thermal emissions of the steel through the thin layer of FRP. It may not be easy to differentiate between individual bars, as they are spaced somewhat closely. Furthermore, section loss or deterioration will not be significantly evident as the thermal signals showing through the FRP will likely not be precise. For this reason, it is suggested that active thermography be applied by artificially heating one end of the beam's steel. As the strand heats and creates a temperature differential over the length of the beam, the thermal conductivity of steel will allow heat to flow along the beam. This flow should be tracked over time. If any section loss or breakage of the strand has taken place, this would alter the rate of heat flow through this reduced cross-section, and the damaged strand could easily be identified relative to its neighbors. This method should also be able to identify the location of deterioration based on the spot in which the reduction in heat flow occurs. ASTM method D4788-03 is already set in place and should act as the groundwork for establishing thermography for use in $\mathrm{HCB}$ inspection.

\subsubsection{Visual Inspection for Local FRP Bulging}

It would be prudent to note any local bulging or out of plane deformation in the bottom FRP flange in basic visual inspections of the HCBs. Any significant level of bulging should be evident to the naked eye; however, subtler bulges should be noted with a 
straight edge. While any such imperfections may indeed be induced in the manufacturing process, they should be noted nonetheless, as these locations should be investigated further using additional NDE methods. The theory here is that corrosion products produced from steel degradation require more volume than pristine steel. If any significant corrosion of the steel internal to the FRP shell exists, it is possible that the corrosion products would force the bottom layer of FRP outwards. This method has not been investigated in a laboratory setting and thus should not be relied upon exclusively. It is possible that these corrosion products may not be significant enough to force the bottom layers of FRP noticeably outwards. There is only a single layer of FRP above the steel, followed by the poly-iso foam, which are collectively likely much less stiff than the lower FRP, and may be more likely to compress or deflect than the lower FRP. Further investigation of this method should be performed in order to incorporate it as a standardized addition to visual inspection of HCB.

\subsection{FRP Inspection}

The FRP shell is not a main load-carrying component of the HCB; however, its condition is still of interest as the shell provides protection for the interior system components from the surrounding environment and potential penetration of moisture, chlorides or other detrimental elements that may cause corrosion of the steel or deterioration of the concrete. While the FRP is expected to remain linearly elastic in the range of service loads, extreme loading events may cause microcracking of the shell that would cause the FRP to absorb moisture. This is disconcerting as the steel is embedded within the FRP and this phenomenon would capture and retain moisture and other contaminants in direct contact with the steel. Other than cracking or tearing at a macro level, FRP damages of 
interest include blistering, delamination and potential creep of the resin. While certain aspects of this type of inspection are performed with respect to the condition of the steel, many of the FRP inspection methods are comparable to other well-established methods. Additional information may be found in NCHRP report 564, Field Inspection of InService FRP Bridge Decks, and Hillman's (2012) HCB Design \& Maintenance Manual.

\subsubsection{Visual Inspection}

As noted earlier, visual inspection is a basic, cost-efficient method of initial investigation into the condition of a bridge. In this section, the focus of visual inspection is the quality of the FRP encasement. As the shell is intended to protect the structural components internal to it, the health of the shell itself should be a good indicator of the level of protection it is providing to the steel and concrete within. Degradation of the FRP shell is an indicator of potential problem spots within, and thus further NDE testing should be performed at these locations to determine overall HCB health. Surface defects of interest include; cracks, voids, blistering, discoloration, and delamination. Individual beams should be rated following as closely and objectively as possible using the rating system from 0-9 provided by Hillman (2012) in section 5.2.

\subsubsection{Mechanical Sounding}

Similar to the impact echo inspection process, a mechanical sounding method such as an instrumented hammer tap test or Schmidt hammer test applies a localized impact to the surface. Rather than measuring the interaction of the stress wave throughout the material these methods simply measure the overall energy transfer between the material and device through things such as rebound or acoustic emission. The purpose of this type of FRP evaluation is two-fold. Most importantly, the presence of moisture adsorbed within 
any FRP micro-cracks would alter the acoustic impedance of the FRP at that location. Any such change in response due to the presence of water would indicate a threat to the embedded steel at that location. Furthermore, the acoustic impedance of the FRP would be altered with delamination of the glass fiber sheets. This is less critical than the presence of micro-cracks that open vertically and allow access to the steel, yet were a delaminated area to intersect micro-cracks, it could serve as a collection space for moisture within the FRP.

\subsubsection{Thermography}

Thermography, as mentioned in section 4.2 .4 , is adept at locating concrete voids and delamination because of the different thermal properties exhibited by concrete and air. In the case of voids or delamination, a layer of air will act as an insulator, preventing thermal conduction of energy from one mass of concrete to another. If the insulated bit of concrete happens to fall at or near the surface, the emissivity of concrete will cause this concrete to lose heat at a greater rate to the atmosphere.

This theory is also applicable to the FRP used in construction of these HCBs, as several layers of glass FRP sheets are overlaid in various orientations and then vacuum-infused with a resin that binds the system monolithically. If, however, there were to emerge separation between two layers of FRP, thermography would apply well to detect this separation, just as in concrete delamination.

\subsection{Inspection of HCB Interior for Moisture Content}

Also of interest is the presence of moisture within the FRP shell. While the steel is embedded in the FRP, moisture that is able to penetrate the shell and foam will likely 
settle to the bottom of the beam, only separated by the steel with a single layer of FRP. The arch concrete would also be directly exposed to any contaminants. Under service loading, the location of the arch in a traditional beam would be in tension and thus not provide great load resistance, however, it has been seen that the arch likely acts as a flexural member at certain locations relative to certain local loads. These inspection methods are preliminary and would also need to be researched and standardized for use in HCB inspection in the future.

\subsubsection{Ground Penetrating Radar (GPR)}

The low frequency electromagnetic waves emitted from a GPR unit as described in section 4.1.2 embody differing wave speeds depending on the material dielectric properties. This theory can be used to an advantage when investigating the moisture content of the internal foam. The presence of water within the interior of the beam would no doubt alter the dielectric properties of the foam, and would therefore produce differing wave speeds and the wave would reflect off the back FRP flange and return to the transducer at specific time stamps. One would be able to scan vertically along the HCB flange and identify any gradients in dielectric constant, as any water within would tend to settle towards the bottom of the beam. Such a dielectric constant gradient would indicate that there is likely moisture present. It would be important to keep in mind the composition of the beam interior and note the location of the concrete arch and fin, where the wave would travel a shorter distance before returning to the transducer.

\subsubsection{Thermography}

Thermography has been discussed in 4.2.4 and 4.3.3 as using the varying thermal properties of materials to capture the infrared radiation from a specimen, allowing one to 
discern features of the specimen that are not visible to the naked eye. As water has a very high specific heat, it should show up quite readily in a thermographic scan. If moisture were to penetrate the FRP shell and infiltrate the internal foam, it would absolutely alter the thermal properties of the foam, and a vertical thermal scan should indicate a thermal gradient as the water settles to the bottom of the beam.

\subsection{CONCLUSIONS}

This investigation was performed as part of a VDOT-sponsored project to quantify the behavior of HCB girders for use in a newly constructed skewed bridge in Colonial Beach, VA. The work presented here is a continuation of the work done at Virginia Tech laboratory and is intended to validate those results and provide additional recommendations for investigation in future $\mathrm{HCB}$ condition assessments. The study involved an in-service live load test of the bridge spanning $13.5 \mathrm{~m}$ on a 45 -degree skew that was geared towards determining the lateral distribution of flexural loads across the bridge as well as determining the dynamic load amplification of a load truck driven at the posted speed limit, and an analysis of the distribution of loads within individual HCB beam components. An extensive instrumentation plan was put into place to capture these properties and behaviors. Vibrating wire gauges were embedded throughout the depth of the bridge at mid-span and quarter-span on select girders, while externally mounted strain gauges were placed on the tension flange and webs of all eight girders at mid-span and quarter-span. Quasi-static testing was implemented for eight transverse load truck positions to provide a strain history for all possible longitudinal locations of the truck and to ensure the maximum response was elicited for each girder. Dynamic testing was also 
performed at select transverse locations. A finite element model of the bridge was generated in addition to validate the load test results. Lastly, an evaluation of commonly applied non-destructive evaluation methods for civil engineering applications was performed to assess the applicability of these methods for inspecting the condition of the encased load carrying components of the HCB.

It was found that the distribution of flexural loads across the width of the bridge behaves just as expected. The highest strains are exhibited in the girders directly beneath the load truck tires and dissipate among the neighboring girders. Fascia girders, however, do not experience the highest strain when the load truck is at the outermost positions despite having fewer neighboring girders to which load may be distributed. This leads to the conclusion that the parapet walls, combined with the $25 \%$ extra steel in the exterior girders provide additional stiffness to the exterior girders. The distribution factors gathered confirm those of Ahsan's (2012) study and are comparable to the AASHTO design factors that were assumed for the design of these HCBs. In addition, dynamic load amplification factors were calculated and found to be within the acceptable AASHTO code limits, despite the flexibility of the system.

Additionally, it was concluded that the strain profiles throughout the depth of the bridge are not linear as assumed in the strength limit state for design, but the deflectioncontrolled nature of the beams results in excess reserve capacity, thus the non-linearity should not be an issue, but a consideration during the design phase. This nonlinearity in the strain profiles, however, leads one to conclude that the $\mathrm{HCB}$ components do not act compositely. There is a clear disparity between the tension level strains internal and 
external to the FRP flange, indicating that there is slippage of the steel within the resin matrix, or more probably the tension steel and FRP debond during extreme loading events. This may occur when the vertical component of the harped steel in flexure is enough to rupture the resin bond, and the two components would not be required to act compositely. An additional non-linearity in the strain profile occurs in the arch locations, where it has been concluded that a local bending phenomenon takes place, particularly at the quarter-span locations. The arch at mid-span is supported by an $8 \mathrm{ft}$ sheet of FRP that is tied into the webs of the box shell and thus act as a stiff spring, hence reducing this bending phenomenon. This indicates that plane sections do not remain plane during flexure.

Through an evaluation of common non-destructive evaluation techniques for the application of inspecting the interior HCB load-carrying components after the FRP box has been sealed, several critical factors should be investigated. Of high importance is the condition of the tension steel. Several NDE techniques may be applicable in this instance. Namely, magnetic flux leakage, eddy current testing, impact echo, thermography and visual inspection for FRP bulging have been considered. Of these methods, visual inspection is the most cost-effective, while it is surmised that magnetic flux leakage may provide the most reliable and useful results and eddy current testing is limited by the range of a single probe. Each of these methods relies on the altered material properties of steel strands that have either been corroded or cracked/fractured.

The condition of the FRP shell is also of interest as it carries a significant amount of the beam's shear and also protects the internal components from environmental conditions. 
Microcracking in the FRP may lead to the absorption of water, which could be detrimental to the health of the steel. As the FRP shell is visible to the inspector's eye, the most obvious method of choice is visual inspection as a speedy yet cost-effective method. When additional testing is required for microcracks undetectable by the naked eye, one should consider mechanical sounding and thermography to indicate any delamination.

Each of these methods has yet to be applied to HCB inspection, and thus further research is required to validate the recommendations provided here and standardize the inspection method application for HCB. 


\section{REFERENCES}

Ahsan, S. (2012). Evaluation of Hybrid-Composite Beam for Use in Tides Mill Bridge. M.S. Thesis, Civil \& Environmental Engineering, Virginia Tech, Blacksburg, VA.

American Association of State Highway and Transportation Officials (2012). AASHTO LRFD bridge design specifications, 6th edition, Washington, D.C.

American Association of State Highway Transportation Officials (2002). Standard specifications for highway bridges, 17th edition, Washington, D.C.

ANSYS (2010). “ANSYS User's Manual Revision 13.0.” ANSYS, Inc., Canonsburg, PA, USA.

ASTM Standard E570-09 (2009). Standard Practice for Flux Leakage Examination of Ferromagnetic Steel Tubular Products, ASTM International, West Conshohocken, PA, DOI: 10.1520/E0570-09.

ASTM Standard STP371 (1964). Magnetic Testing - Theory and Nomenclature, ASTM International, West Conshohocken, PA, DOI: 10.1520/STP371-EB

ASTM Standard D4788-03 (2007). Standard Test Method for Detecting Delaminations in Bridge Decks Using Infrared Thermography, ASTM International, West Conshohocken, PA.

Chase, S. (2013). Magnetic Flux Leakage Inspection. Personal Collection of Stephen Chase, University of Virginia School of Enginering and Applied Sciences Civil Engineering Department, Charlottesville, VA.

Civitillo, J.M., Harris, D.K., Gheitasi, A., Saliba, M., Kassner, B.L. (2014). In-Service Performance and Behavior Characterization of the Hybrid Composite Bridge System A Case Study. Short and Medium Span Bridge Conference, Alberta, CA

Collaboration for Non-Destructive Testing. (2014). NDT Method Summary, Retrieved from http://www.ndt-ed.org/GeneralResources/MethodSummary/MethodSummary.htm

Ghorbanpoor, A., Borchelt, R., Edwards, M. and Abdel Salam, E. (2000). Magnetic- 
Based NDE of Prestressed and Post-Tensioned Concrete Members - The MFL System, Final Report No. FHWA-RD-00-026, Federal Highway Administration, U.S.

Department of Transportation

Geophysical Survey Systems, Inc. (2006). GSSI Handbook for RADAR Inspection of Concrete, Published by Geophysical Survey Systems, Inc. (GSSI), Salem, NH.

Hellier, C.J. (2013). Handbook of Nondestructive Evaluation, Second Edition. United States of America: McGraw-Hill Companies, Inc.

Hillman, J.R. (2002). Investigation of a Hybrid-Composite Beam System. High Speed Rail IDEA Report HSR-23, Transportation Research Board, Washington, D.C.

Hillman, J.R. (2008). Product Application of a Hybrid-Composite Beam System. IDEA Program Final Report. HSR-IDEA 43, Transportation Research Board, Washington, D.C.

Hillman, J.R., Otter, D. (2008). Testing of a Prototype Hybrid-Composite Beam Span under Railroad Loadings. Proceedings AREMA Annual Technical Conference, Salt Lake City, Utah.

Hillman, J.R. (2011). “HCB Design Spreadsheet.” Microsoft Excel.

Hillman, J.R. (2012). Hybrid-Composite Beam (HCB) Design \& Maintenance Manual: Bridge No. BO439 - MO 76 Over Beaver Creek

International Atomic Energy Agency. (2002). Guidebook on Non-Destructive Testing of Concrete Structures, Training Course Series No. 17, Vienna, Austria.

Mascaro, M.G., Moen, C.D. (2012). Out-of-Plane Web Deformation and Relative Arch Movement of Hybrid-Composite Beams Based on Photogrammetry (Master's Thesis). Report No. CE/VPI-ST-12/08.

Otter, D., Doe, B. (2009). Testing of a Prototype Hybrid-Composite Beam Span at FAST. Technology Digest TD-09-019, Association of American Railroads, Transportation Technology Center, Inc., Pueblo, Colorado. 
Otter, D., Tunna, L. (2011). Second Generation Hybrid Composite Beam Span:

Preliminary Assessment at Facility for Accelerated Service Testing. Technology Digest TD-11-038, Association of American Railroads, Transportation Technology Center, Inc., Pueblo, Colorado.

Sansalone, M. (1997). Impact Echo: The Complete Story, ACI Structural Journal, Title No. 94-S71.

Snape, T., Lindyberg, R. (2009). Test Results: HC Beam for the Knickerbocker Bridge. AEWC Report 10-16, Project 671, University of Maine.

Telang, N.M., Dumlao, C., Mehrabi, A.B., Ciolko, A.T., Gutierrez, J. (2006). Field Inspection of In-Service FRP Bridge Decks. NCHRP Report 564, Washington, D.C.

U.S. Department of Transportation, Federal Highway Administration [FHWA] (2001). "Reliability of visual inspection for highway bridges, volume I: final report." Publication No. FHWA-RD-01-020, Washington D.C.

U.S. Department of Transportation, Federal Highway Administration [FHWA] (2006). "Bridge inspector's reference manual - BIRM." Publication No. FHWA-NHI-03001/002, Washington D.C.

Van Nosdall, S., Moen, C.D., Cousins, T.E., Wollman-Roberts, C.L. (2013). Experiments on a Hybrid-Composite Beam for Bridge Applications. Journal of the Transportation Research Board, 2(2332): 43-52.

Washer, G., Fenwick, R., Nelson, S. (2013). Guidelines for Thermographic Inspection of Concrete Bridge Components in Shaded Conditions, $92^{\text {nd }}$ Annual Meeting of the Transportation Research Board, Washington, D.C. 


\section{APPENDIX A: Mid-span Strains}
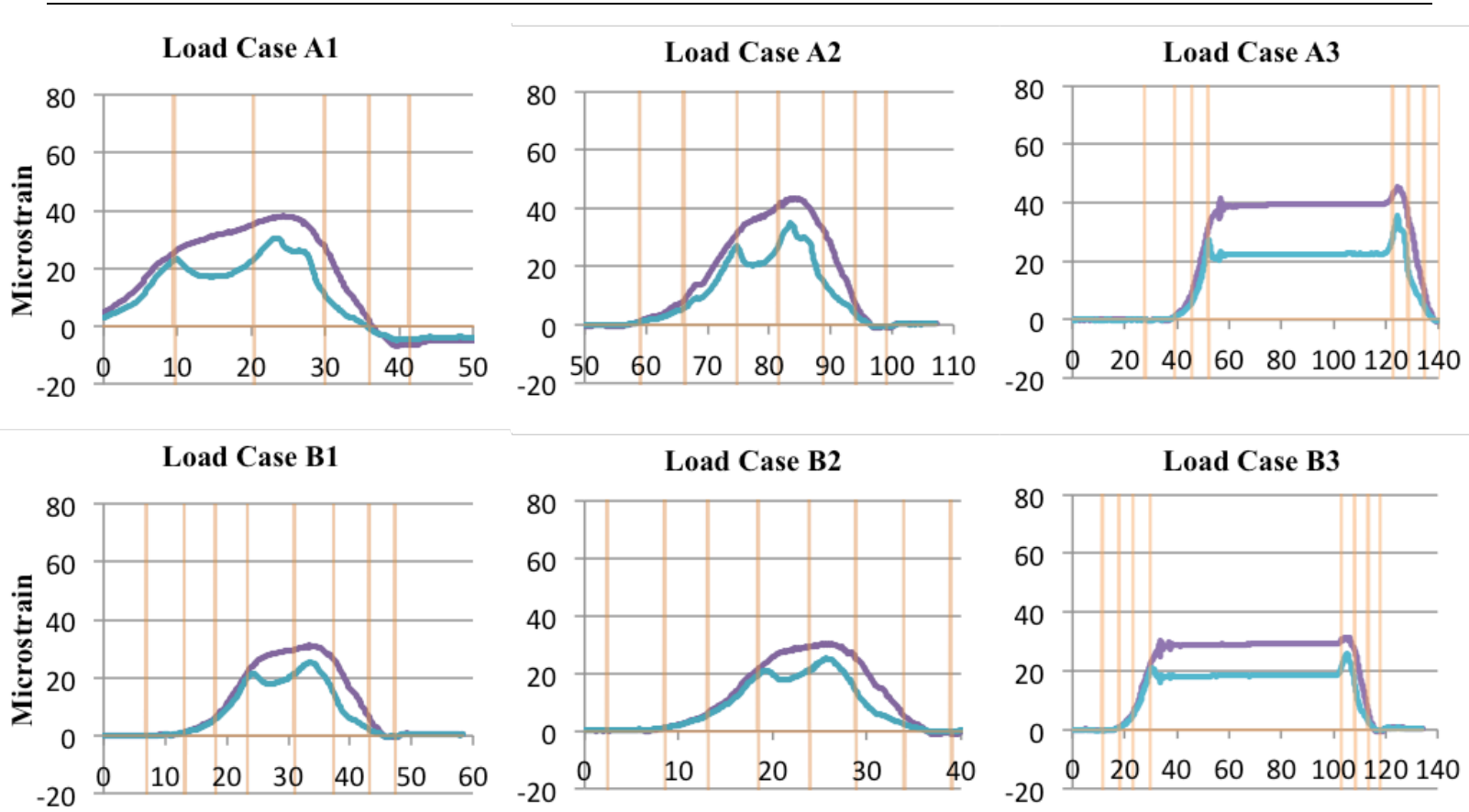

\section{Load Case C1}

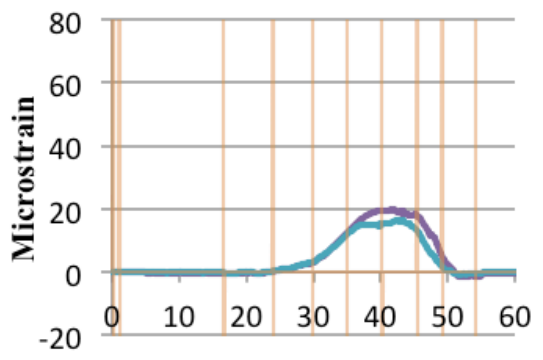

Load Case D1

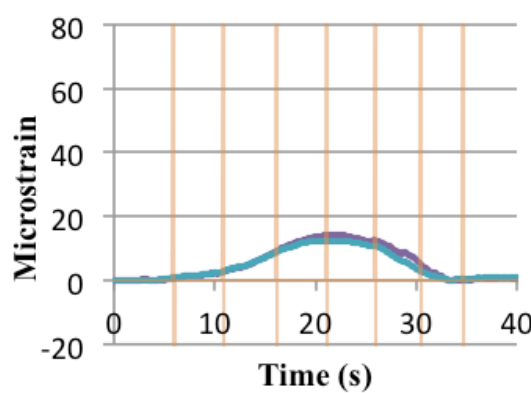

Load Case C2

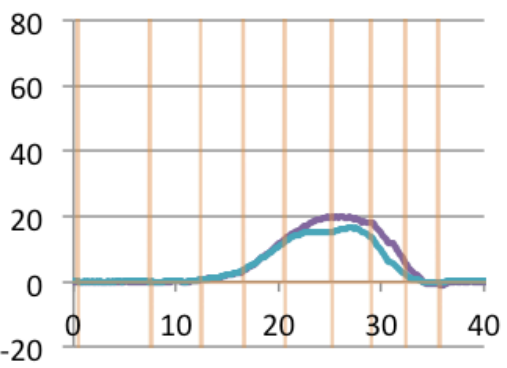

Load Case D2

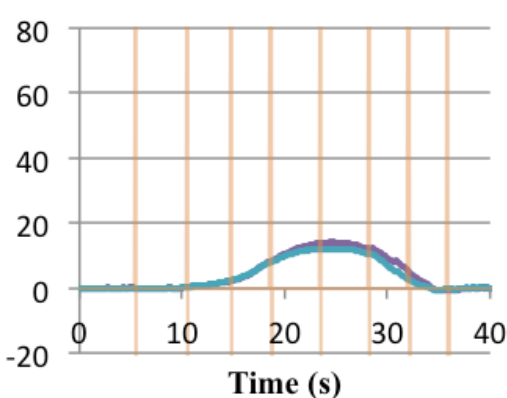

Time (s)

\section{Load Case C3}

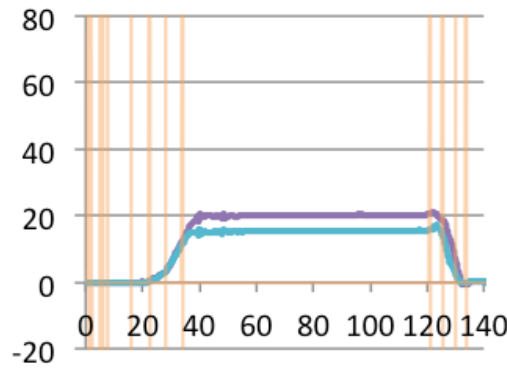

Load Case D3

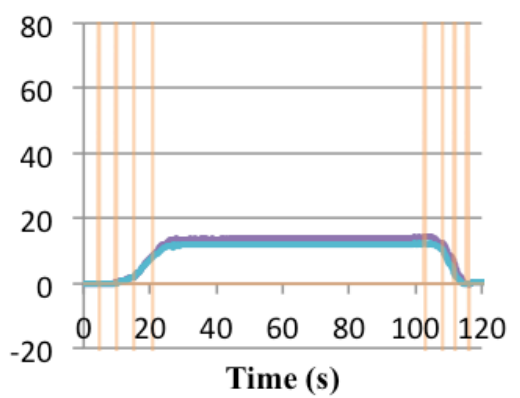

Clicker 
Load Case E1

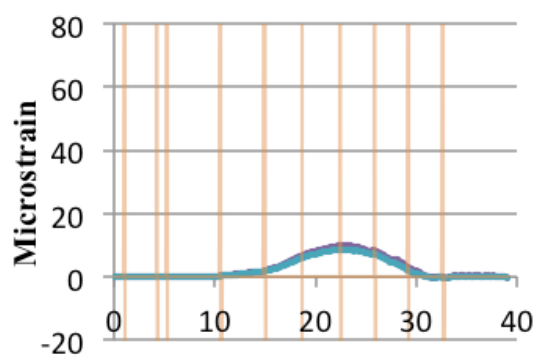

Load Case F1

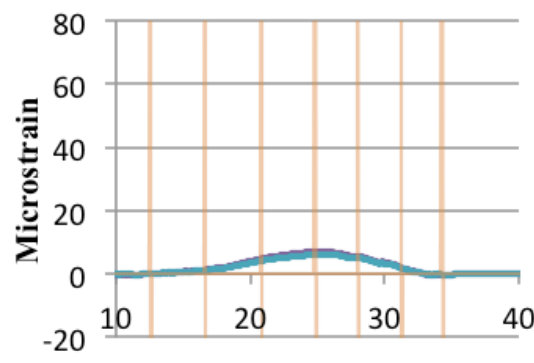

Load Case G1

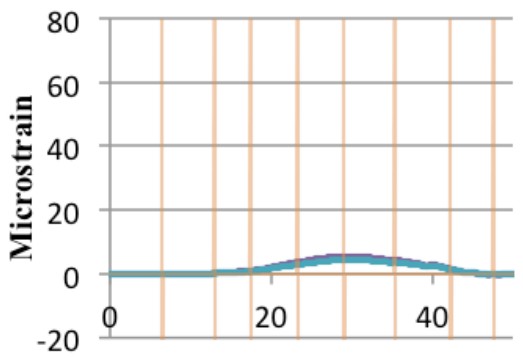

Load Case H1

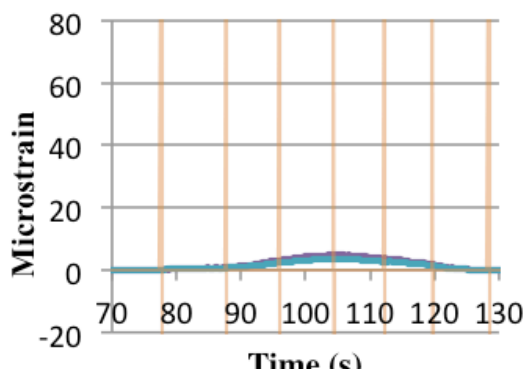

Time (s)
Load Case E2

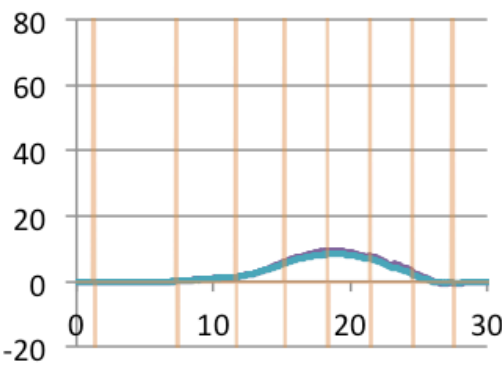

Load Case F2

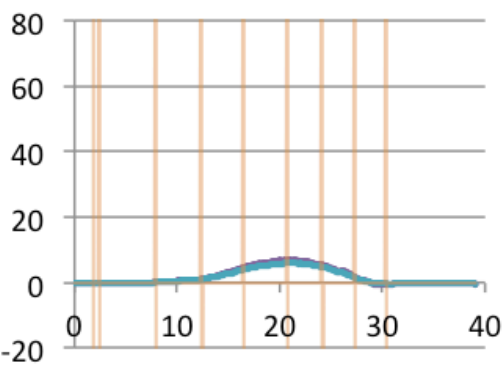

Load Case G2

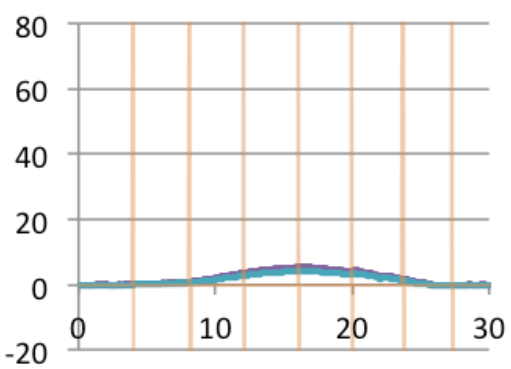

Load Case $\mathrm{H} 2$

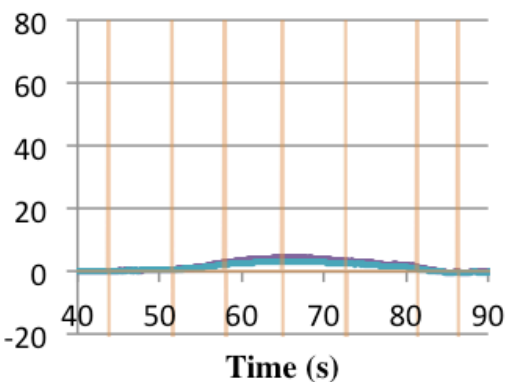

Time (s)
Load Case E3

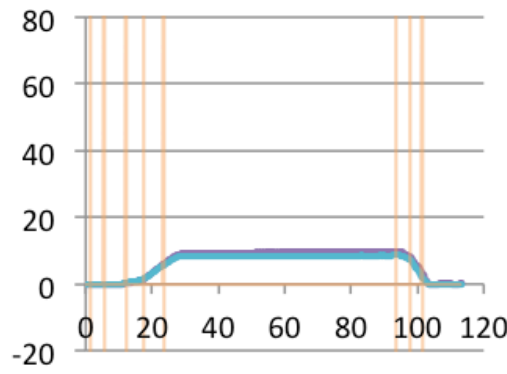

Load Case F3

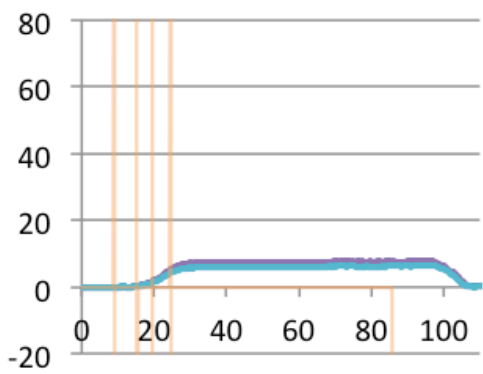

Load Case G3

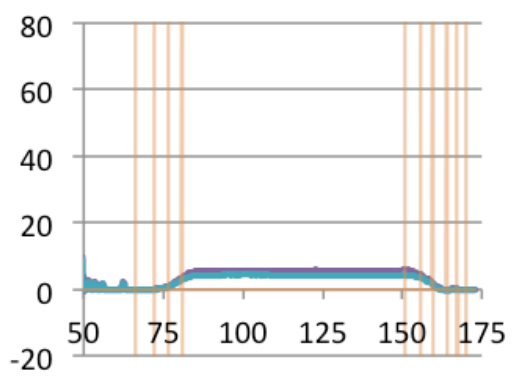

Load Case H3

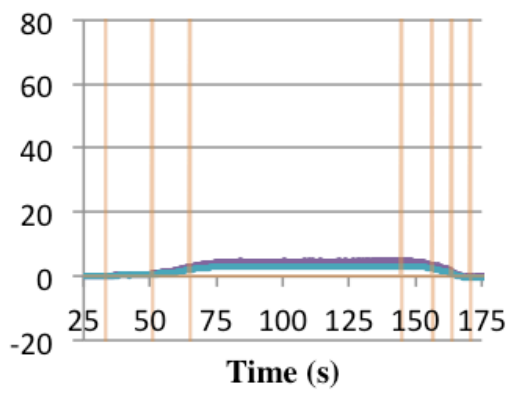

Clicker

Figure 36: Girder 1 Mid-span Strains Plotted Against Time 


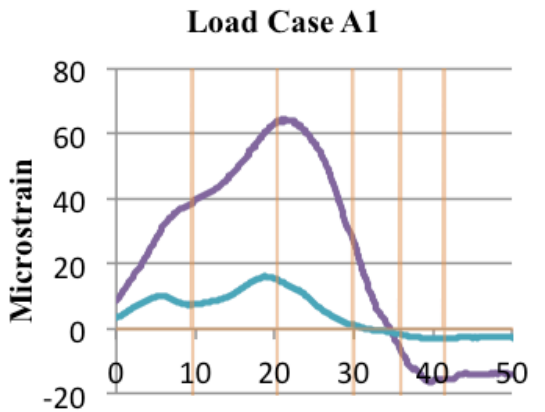

Load Case B1

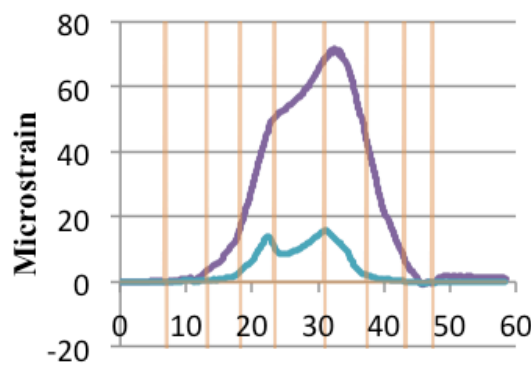

Load Case C1

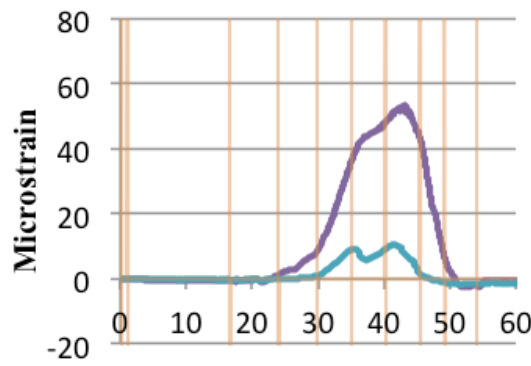

Load Case D1

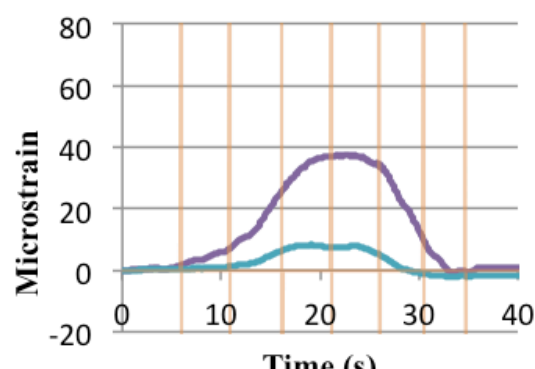

Time (s)
Load Case A2

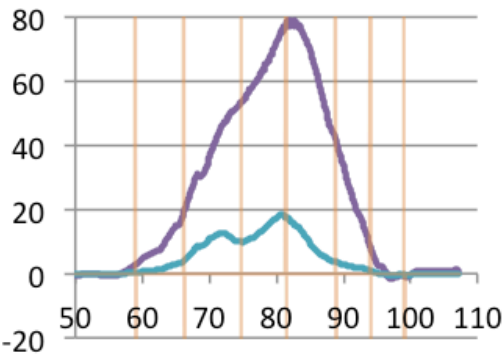

Load Case B2

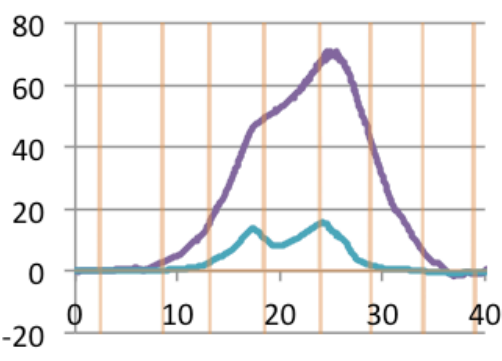

Load Case C2

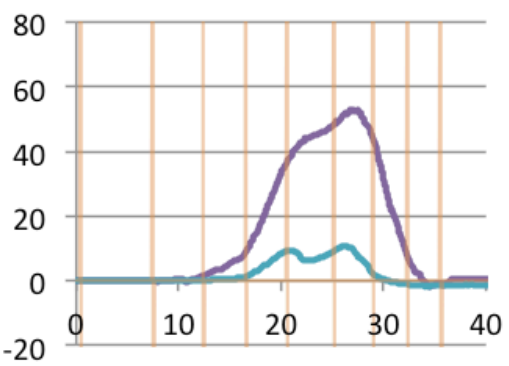

Load Case D2

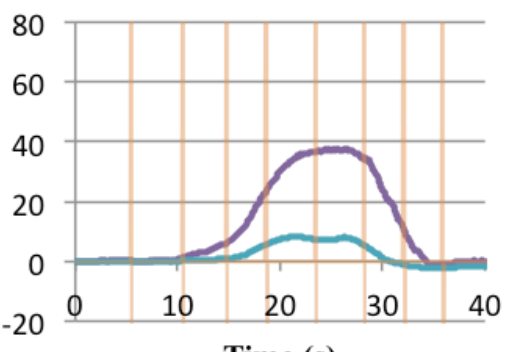

Time (s)
Load Case A3

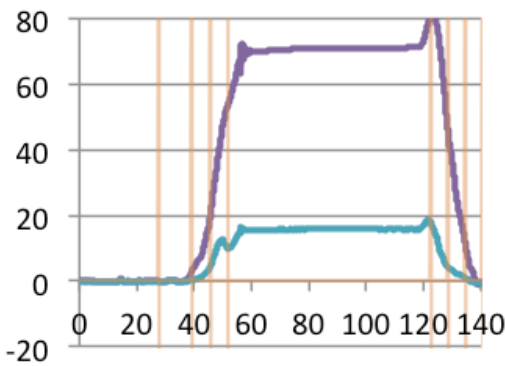

Load Case B3

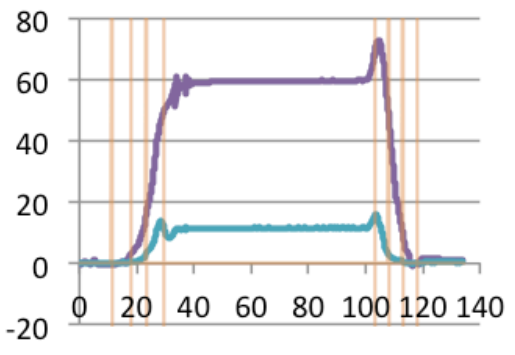

Load Case C3

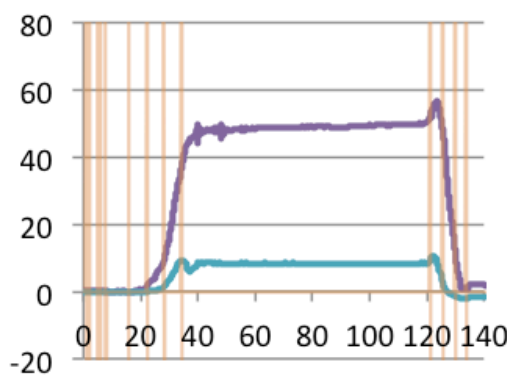

Load Case D3

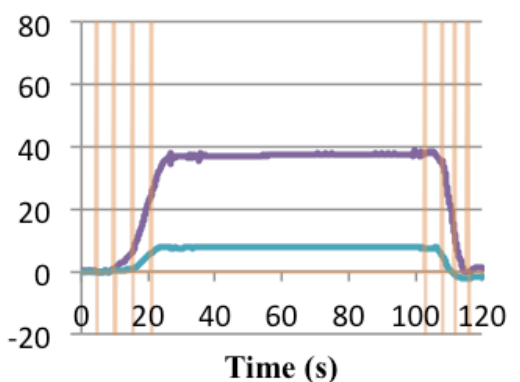

Clicker 
Load Case E1

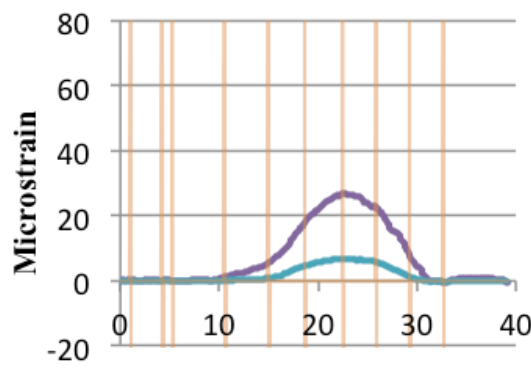

Load Case F1

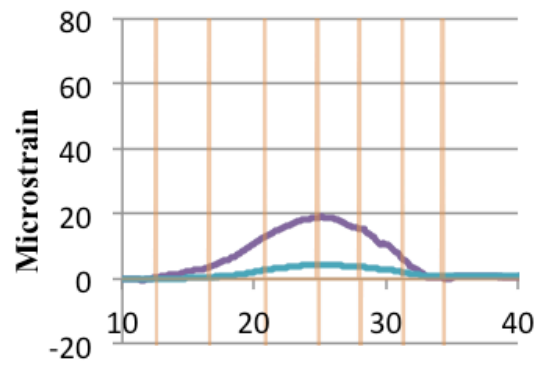

Load Case G1

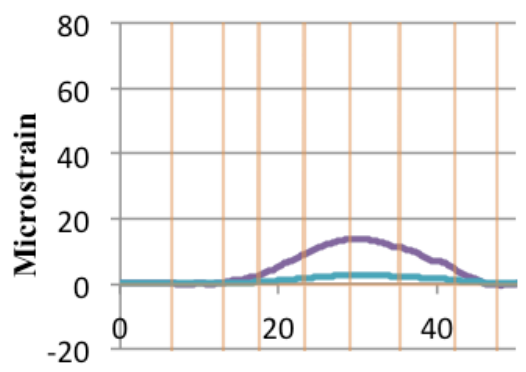

Load Case H1

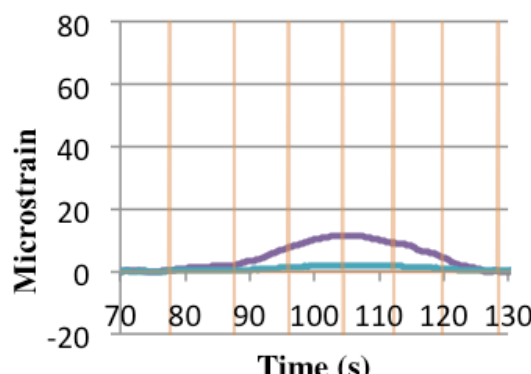

Time (s)
Load Case E2

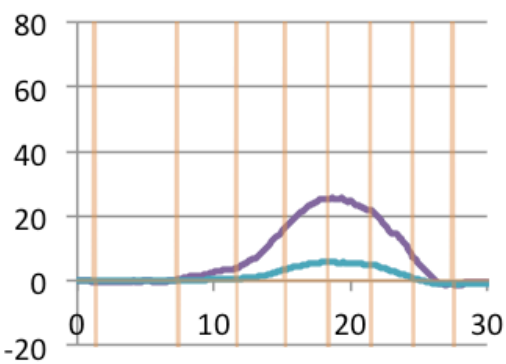

Load Case F2

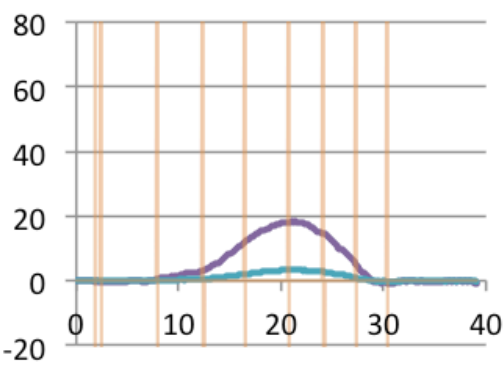

Load Case G2

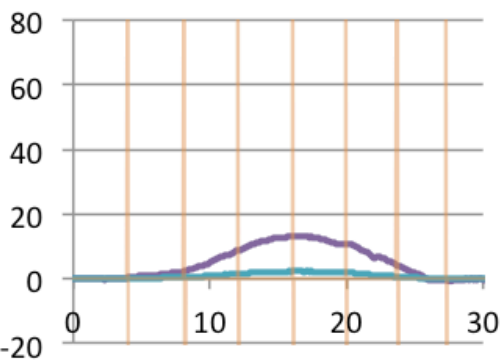

Load Case H2

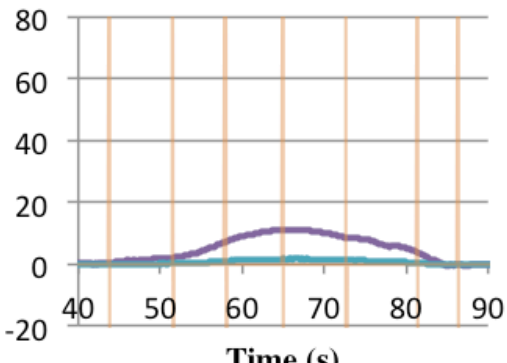

Time (s)
Load Case E3

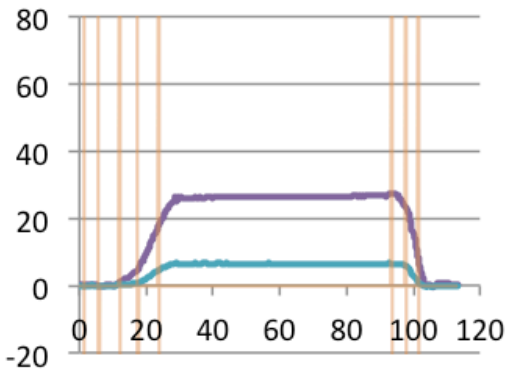

Load Case F3

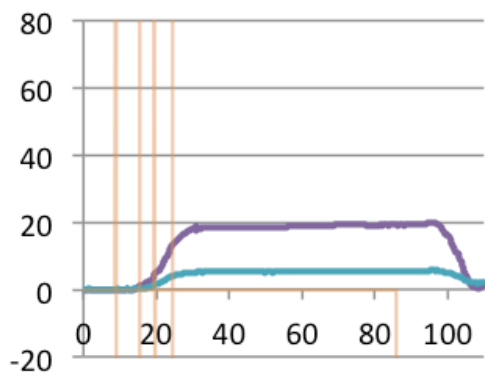

Load Case G3

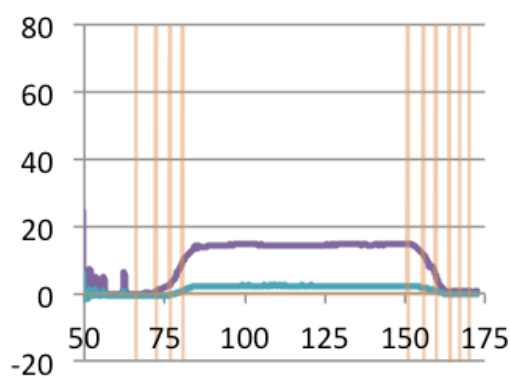

Load Case H3

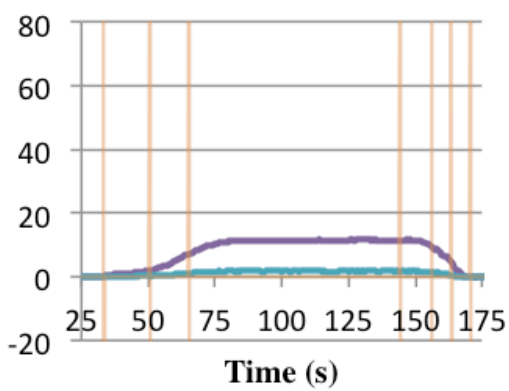

Clicker

Figure 37: Girder 2 Mid-span Strains Plotted Against Time 

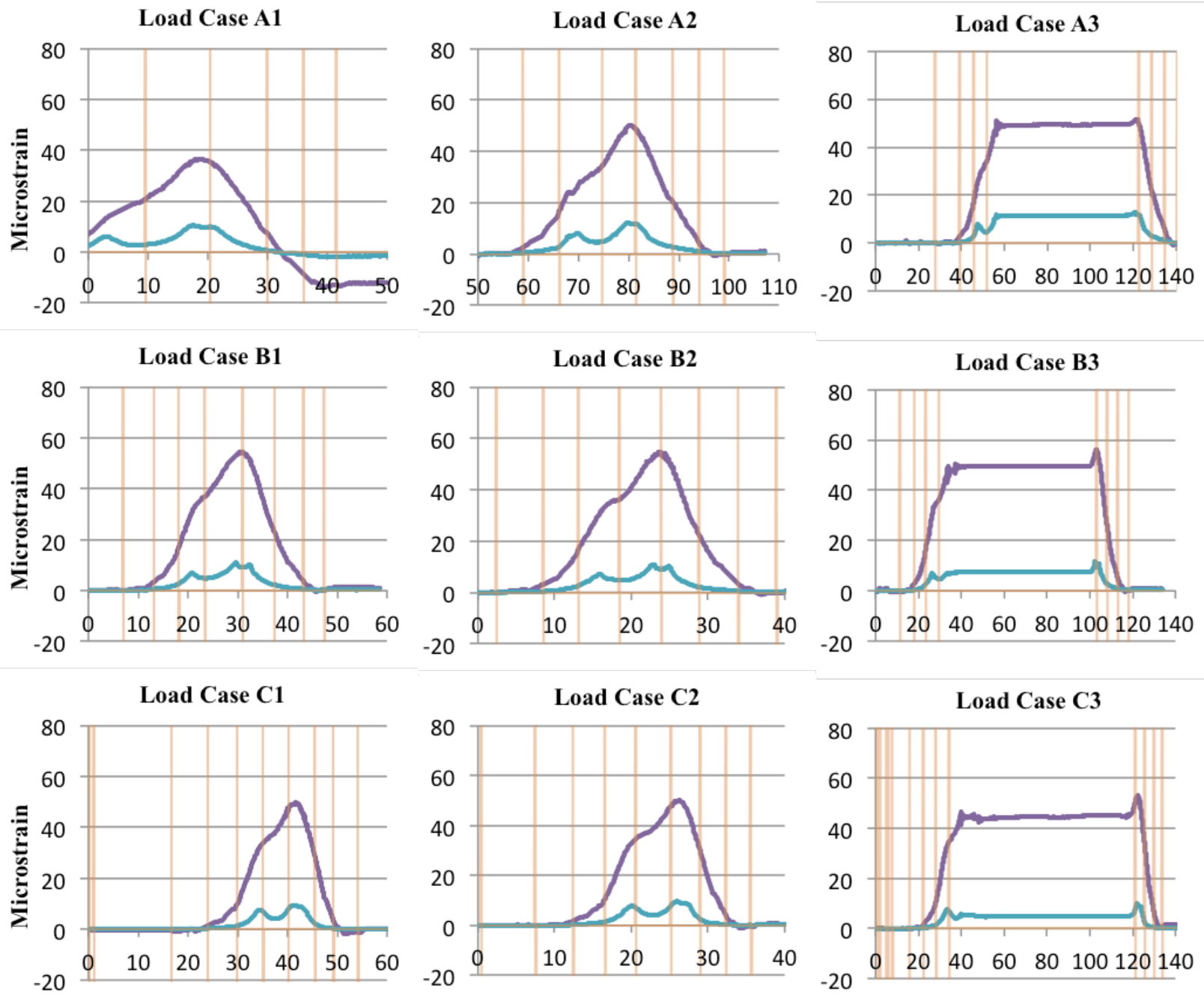

Load Case D1

Load Case D2
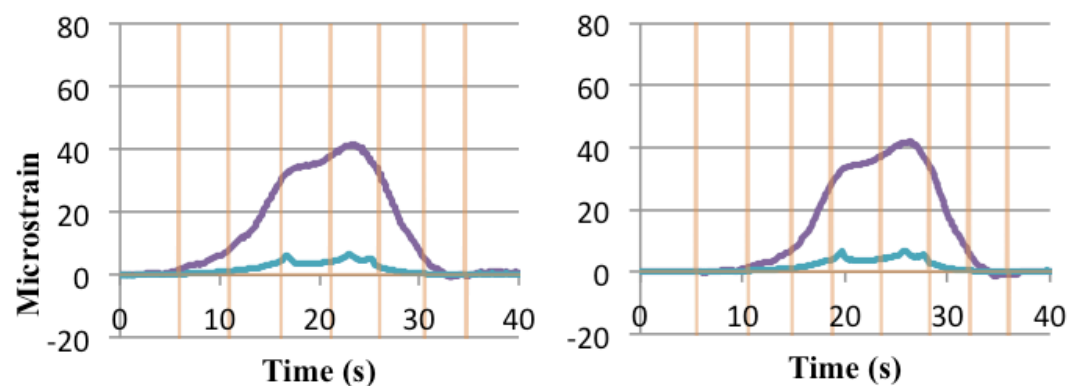

Load Case D3

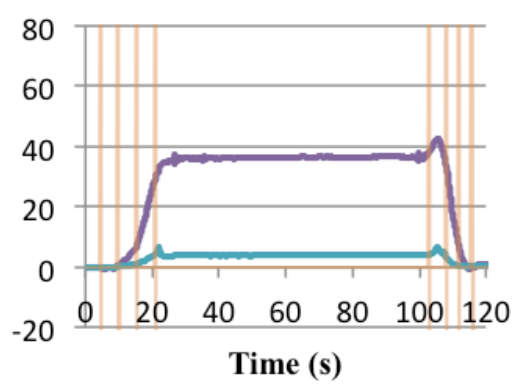

$\longrightarrow$ EXT - B Fl $\longrightarrow$ EXT - U Web Clicker 


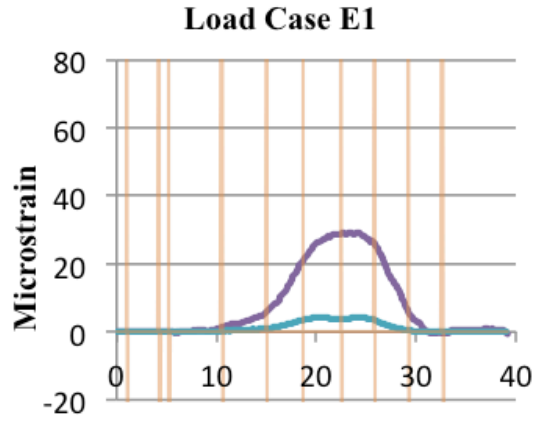

Load Case F1

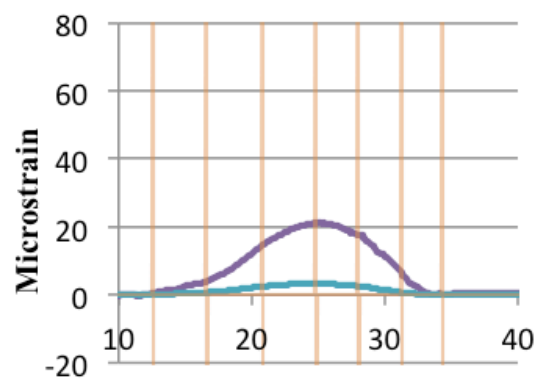

Load Case G1

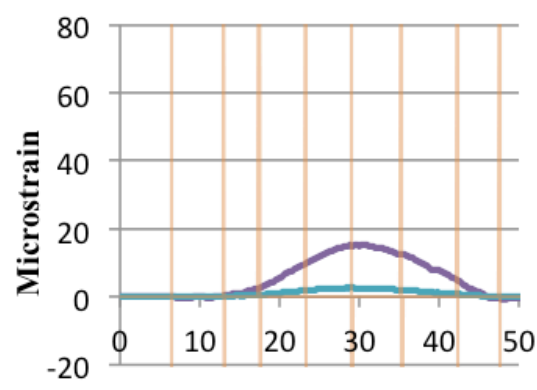

Load Case H1

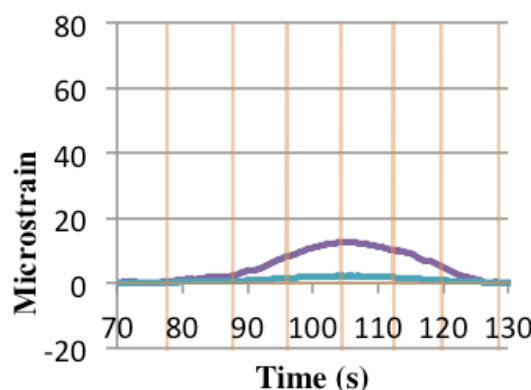

Time (s)
Load Case E2

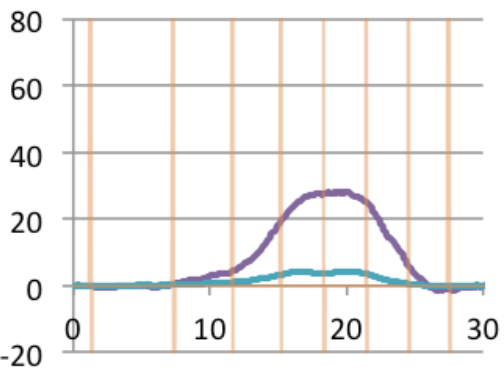

Load Case F2

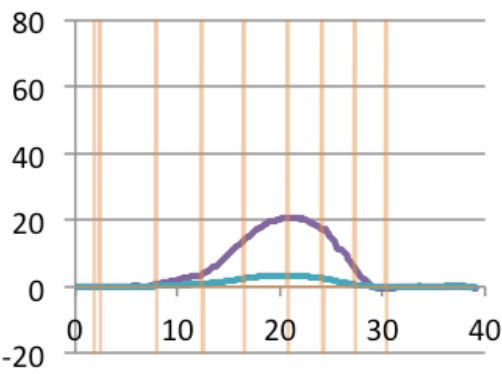

Load Case G2

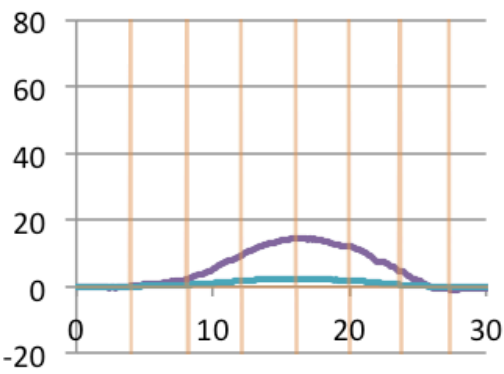

Load Case $\mathrm{H} 2$

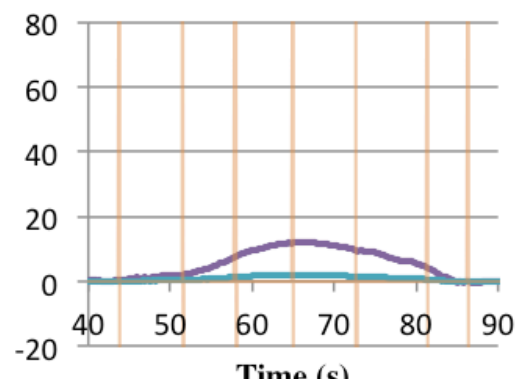

Time (s)
Load Case E3

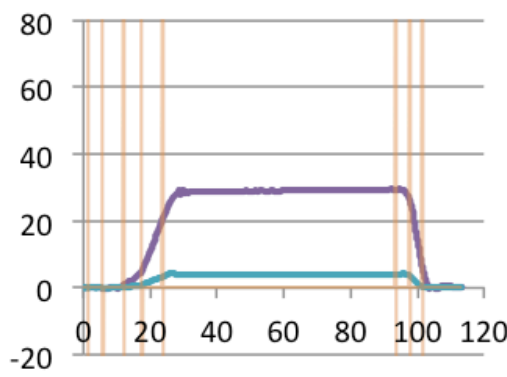

Load Case F3

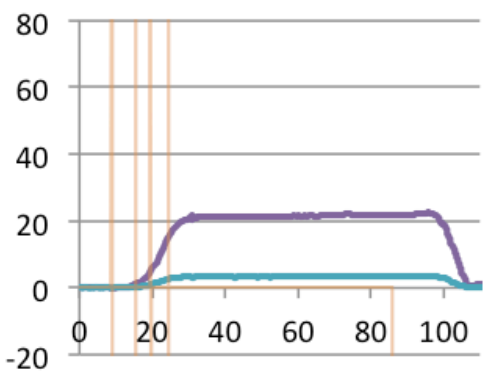

Load Case G3

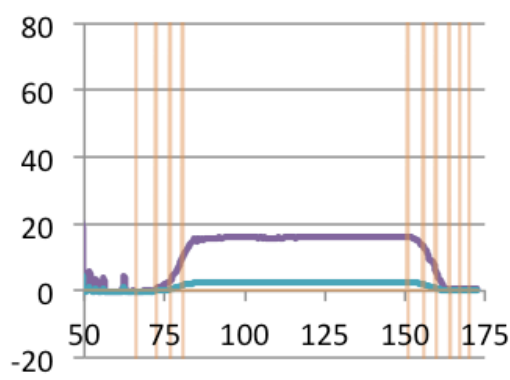

Load Case H3

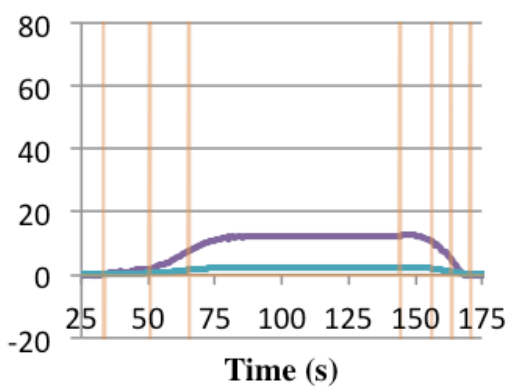

Clicker

Figure 38: Girder 3 Mid-span Strains Plotted Against Time 

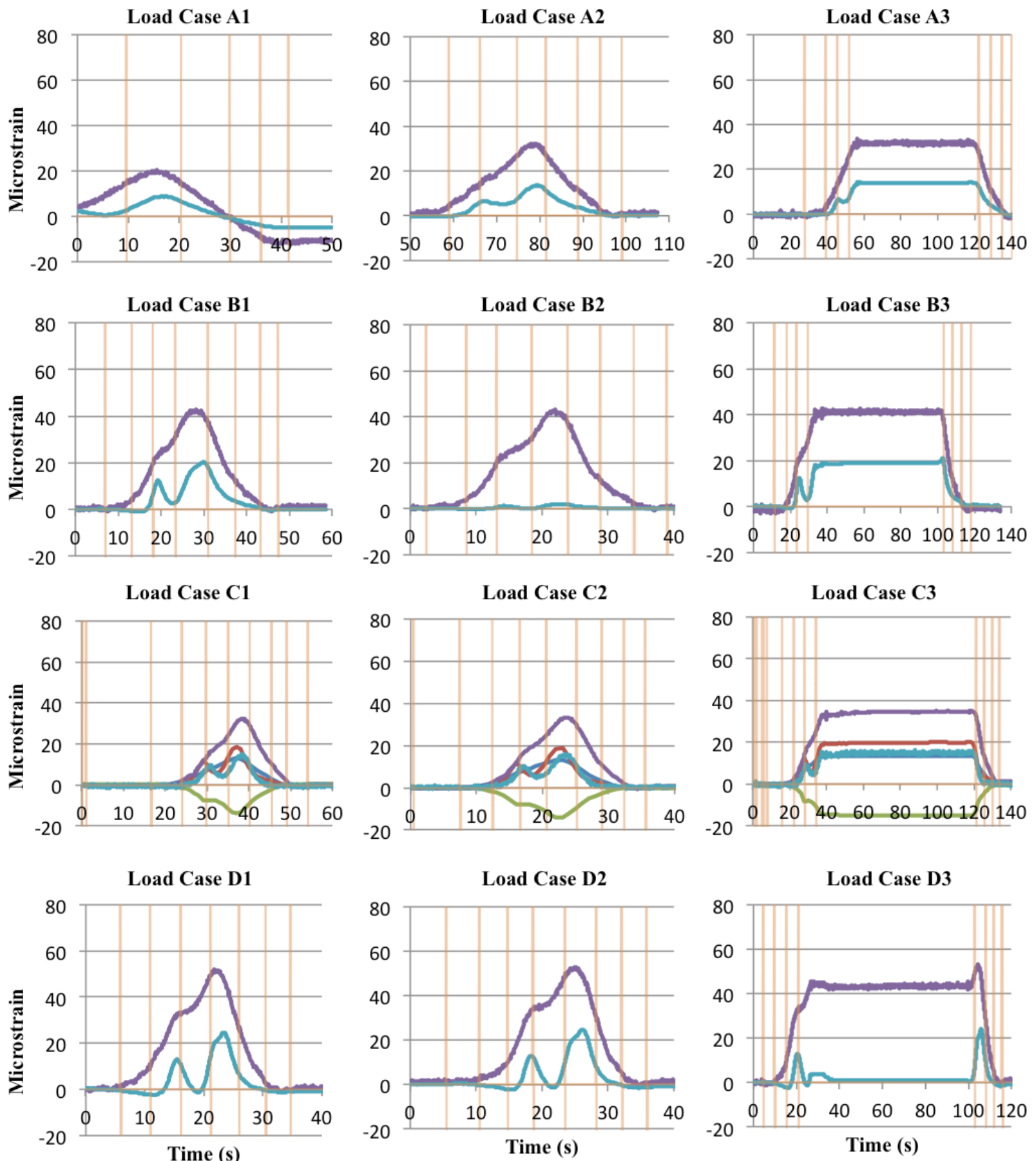

$\longrightarrow$ EXT - B Fl $\longrightarrow$ EXT - U Web $\longrightarrow$ Clicker 

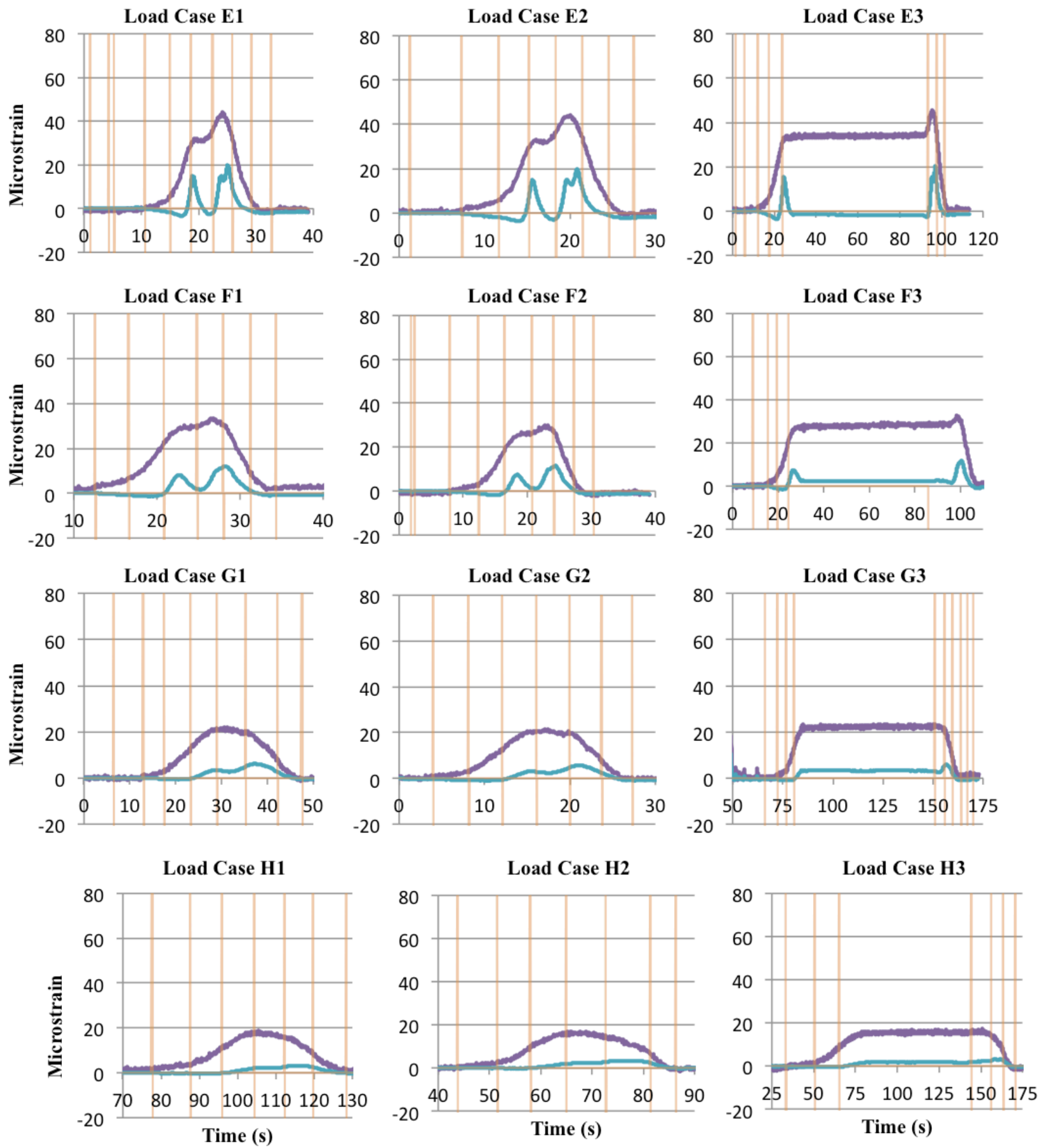

$$
\longrightarrow \text { EXT - B Fl } \longrightarrow \text { EXT - U Web C Clicker }
$$

Figure 39: Girder 4 Mid-span Strains Plotted Against Time 


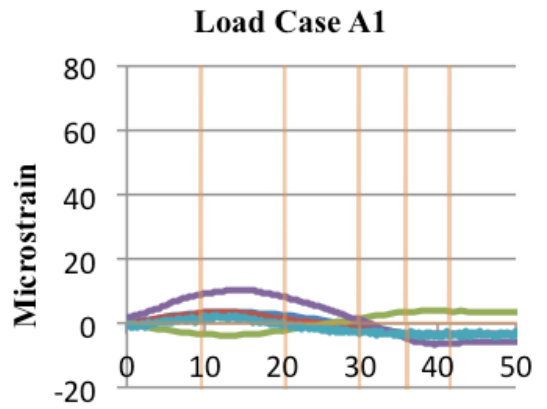

Load Case B1

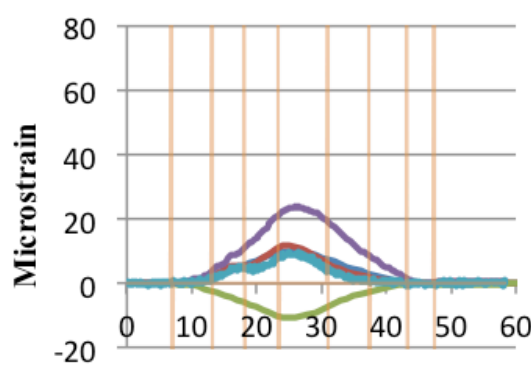

Load Case C1

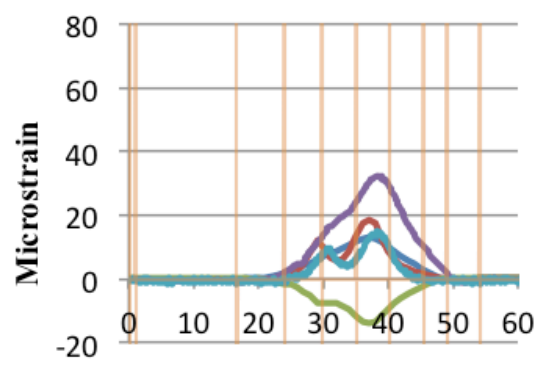

Load Case D1

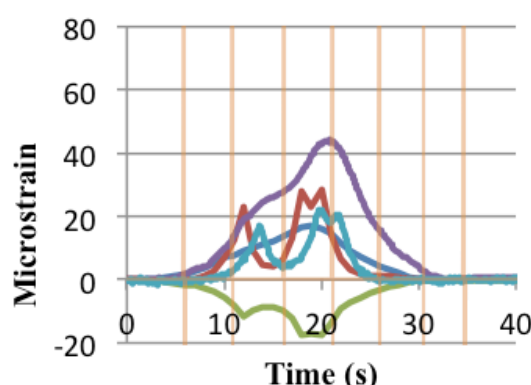

$\longrightarrow$ VWG - T $\longrightarrow$ VWG - CB
Load Case A2

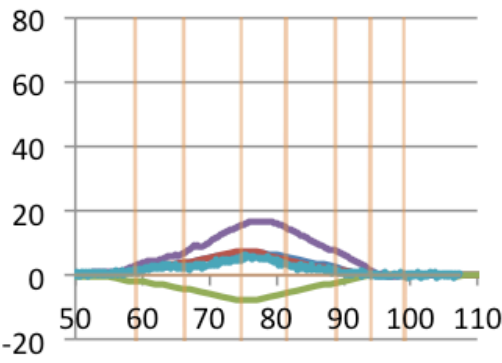

Load Case B2

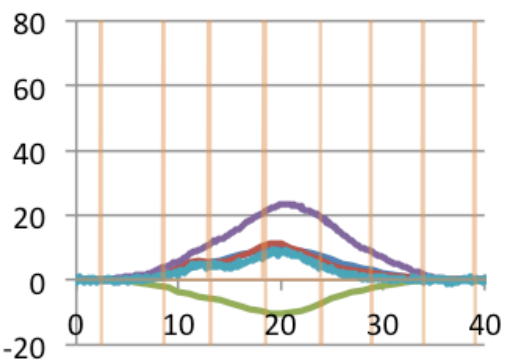

Load Case C2

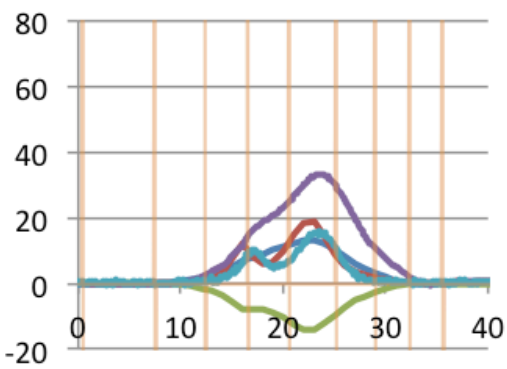

Load Case D2

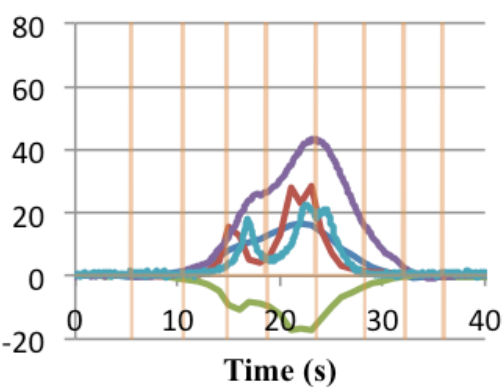

Load Case A3

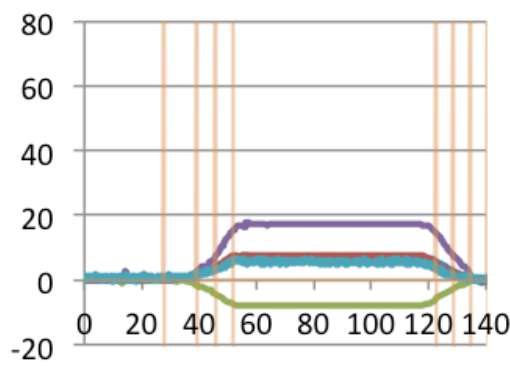

Load Case B3

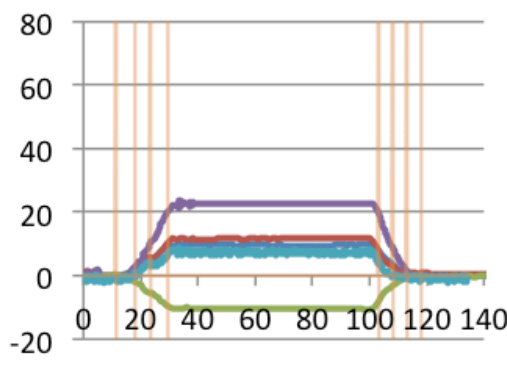

Load Case C3

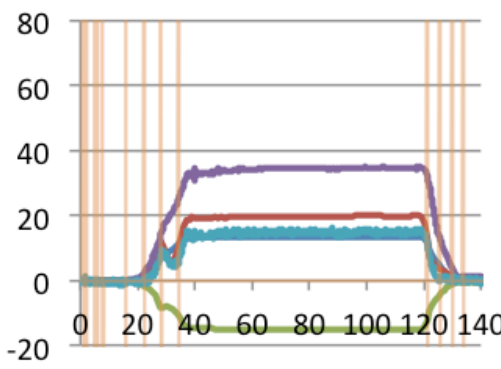

Load Case D3

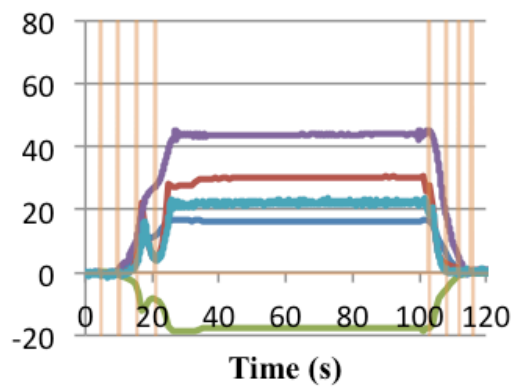

Time (s)

$\longrightarrow$ EXT - B Fl $\longrightarrow$ EXT - U Web $\longrightarrow$ VWG - D - Clicker 

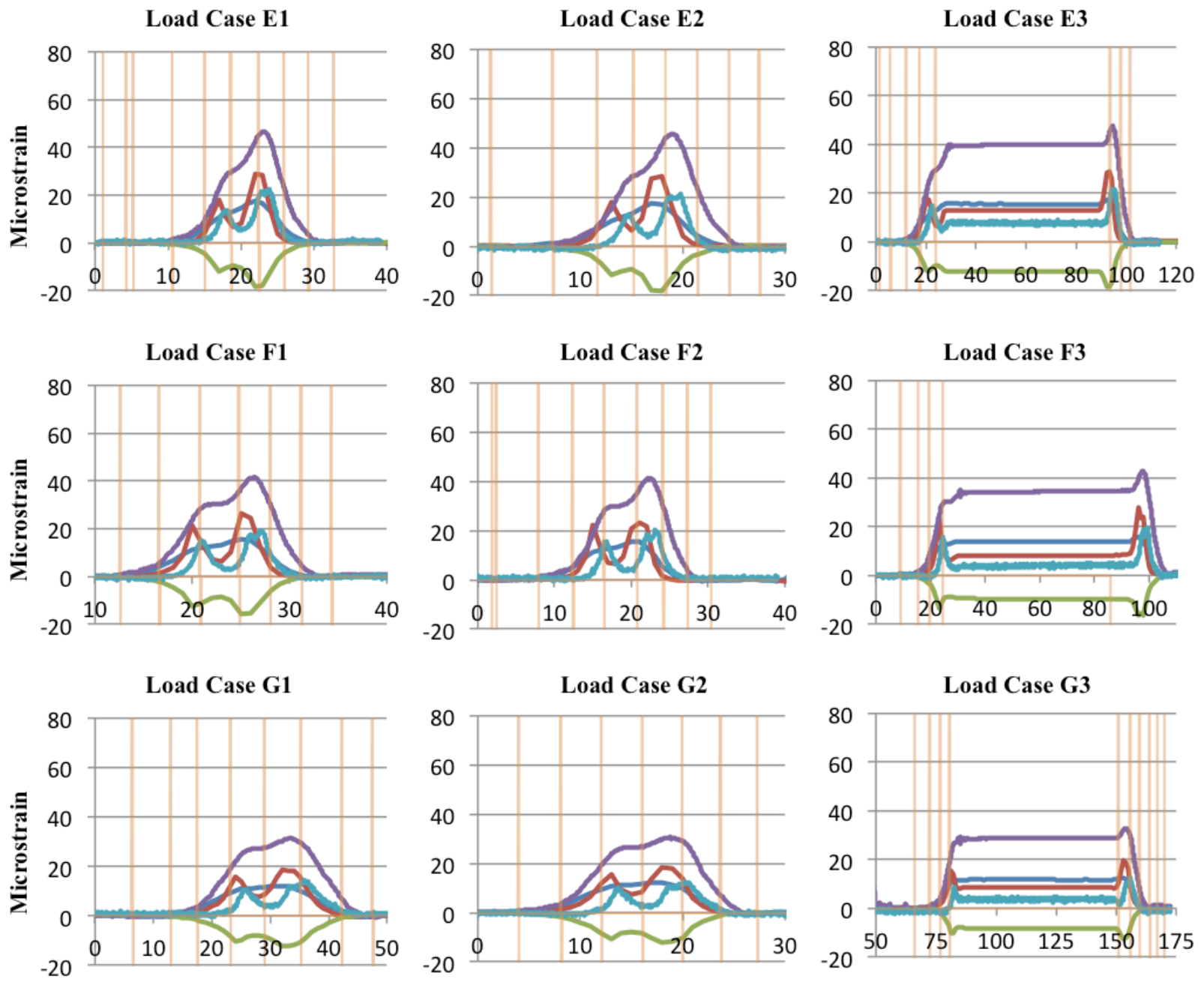

Load Case H1

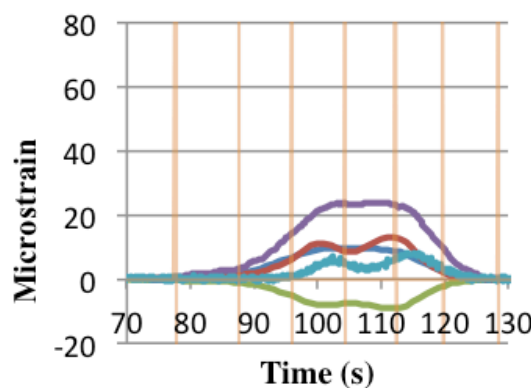

Time (s)
Load Case H2

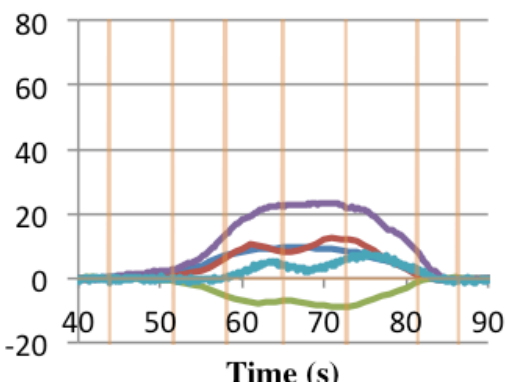

Time (s)
Load Case H3

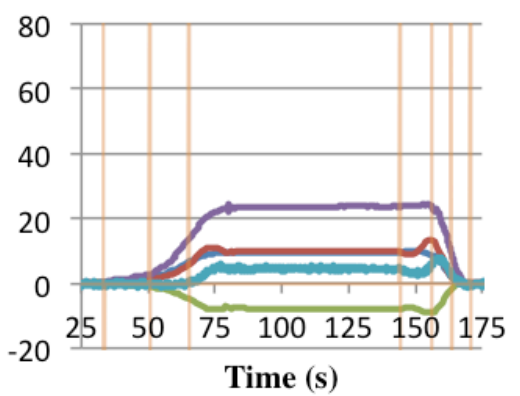

Time (s)

$\longrightarrow$ VWG - T $\longrightarrow$ VWG - CB $\longrightarrow$ EXT - B Fl $\longrightarrow$ EXT - U Web $\quad$ VWG - D $\quad$ Clicker

Figure 40: Girder 5 Mid-span Strains Plotted Against Time 


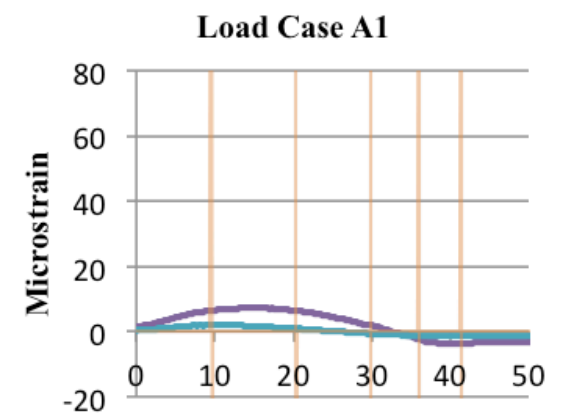

Load Case B1

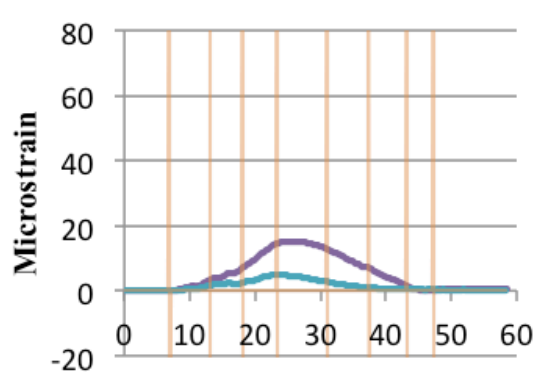

\section{Load Case C1}

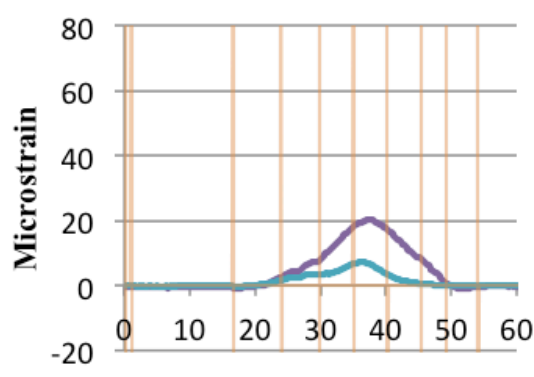

Load Case D1

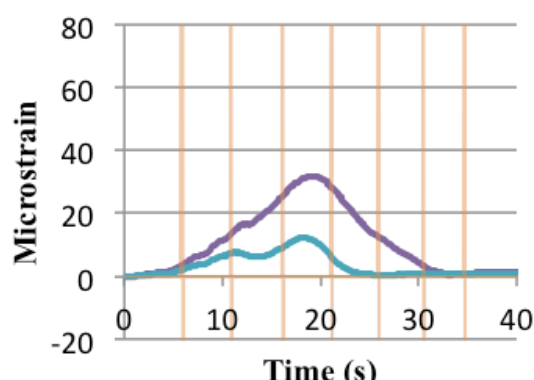

Time (s)

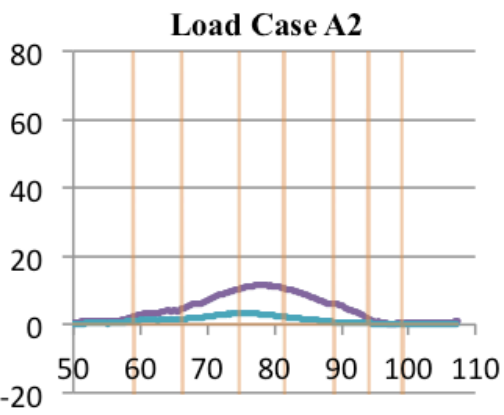

Load Case B2

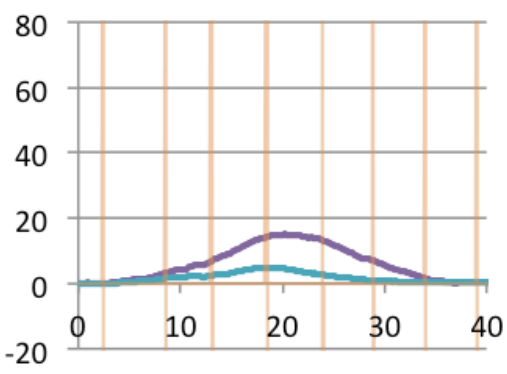

Load Case C2

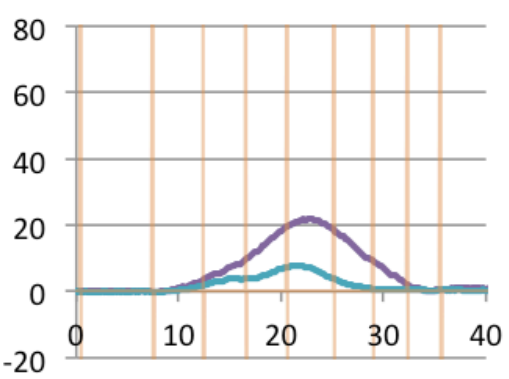

Load Case D2

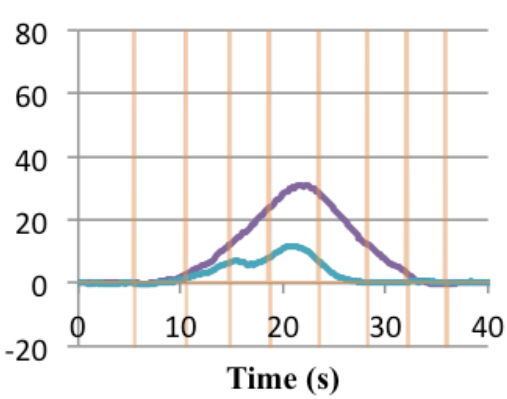

$\longrightarrow$ EXT - B Fl $\longrightarrow$ EXT - U Web

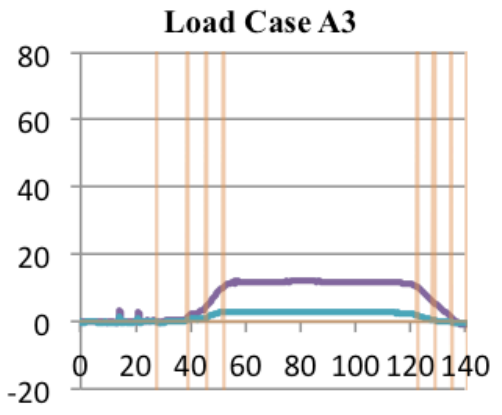

Load Case B3

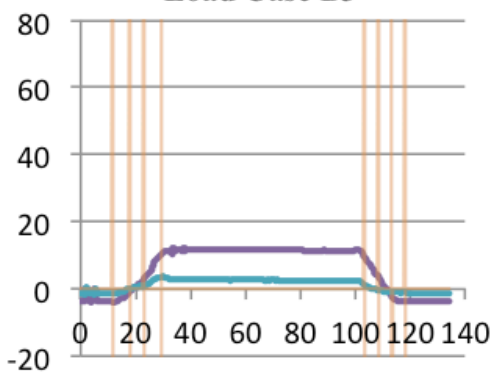

\section{Load Case C3}

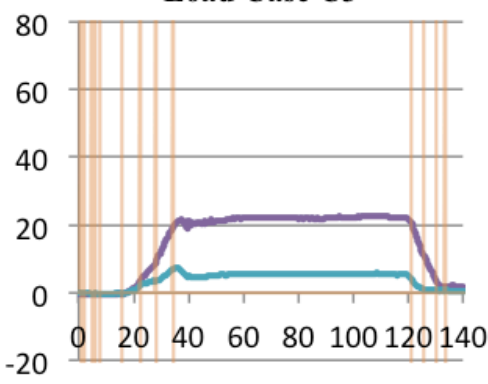

Load Case D3

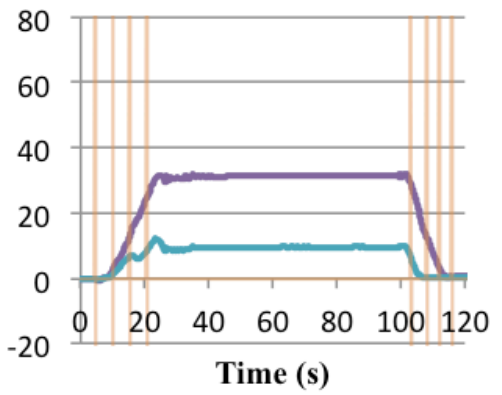

Clicker 
Load Case E1

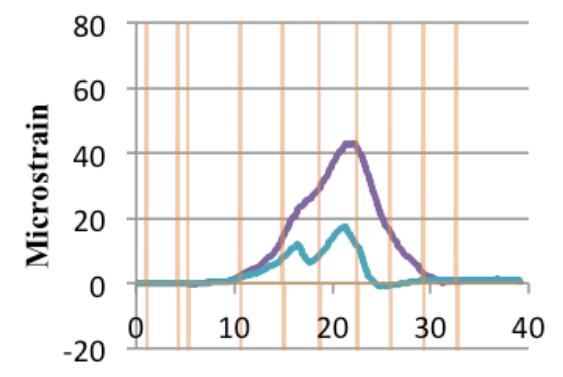

Load Case F1

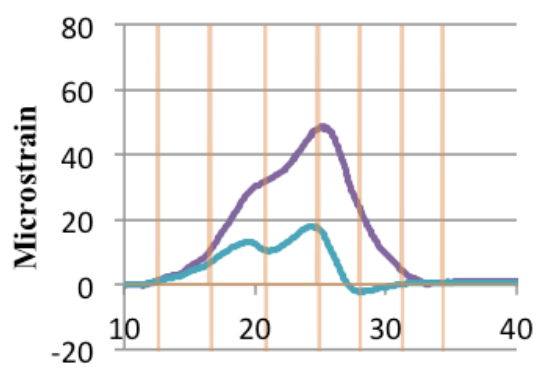

Load Case G1

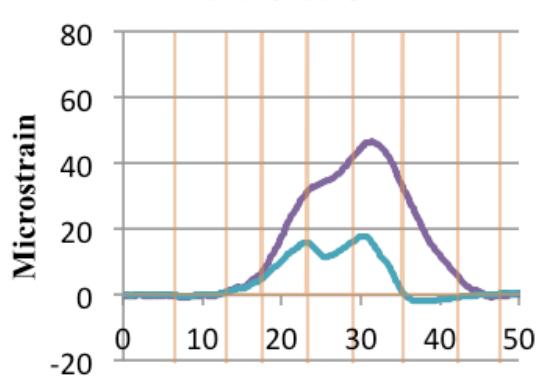

Load Case H1

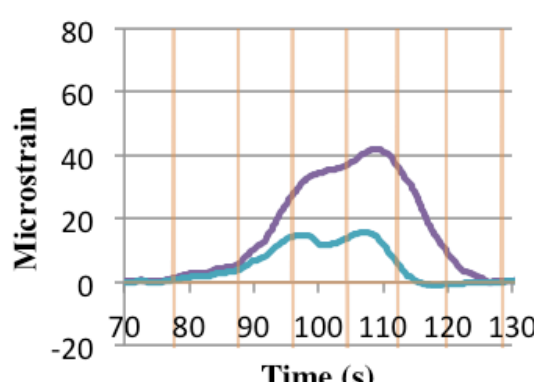

Time (s)
Load Case F2

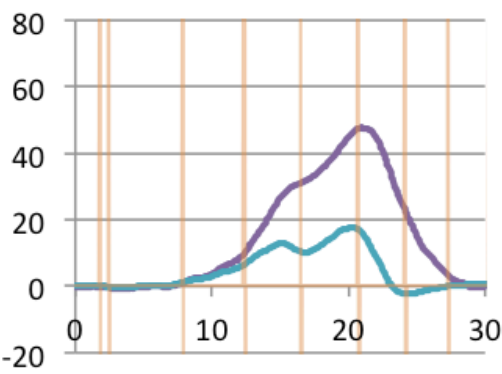

Load Case F2

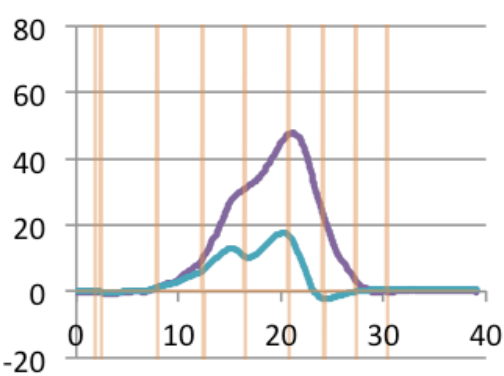

Load Case G2

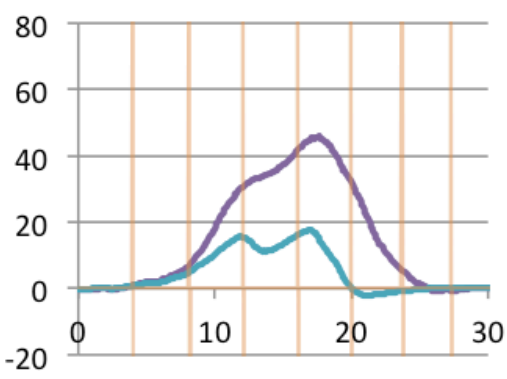

Load Case $\mathrm{H2}$

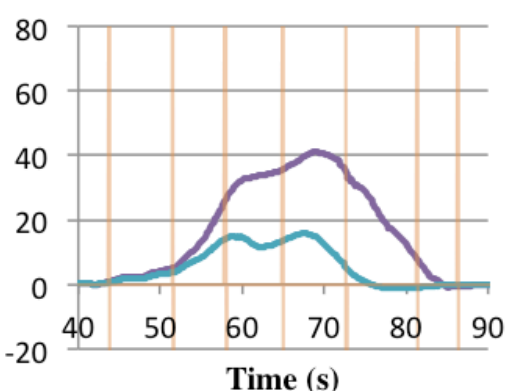

Time (s)

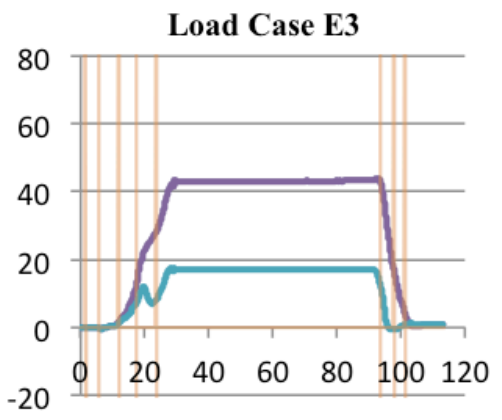

Load Case F3

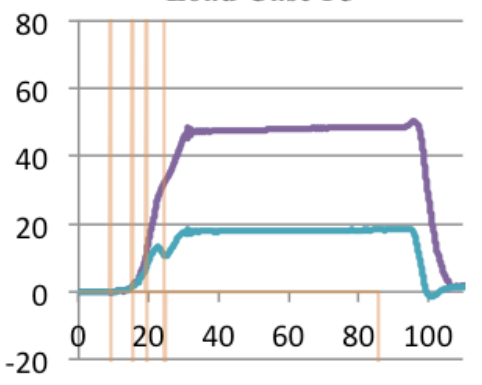

Load Case G3

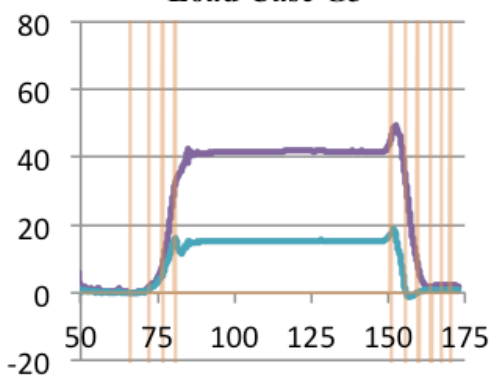

Load Case H3

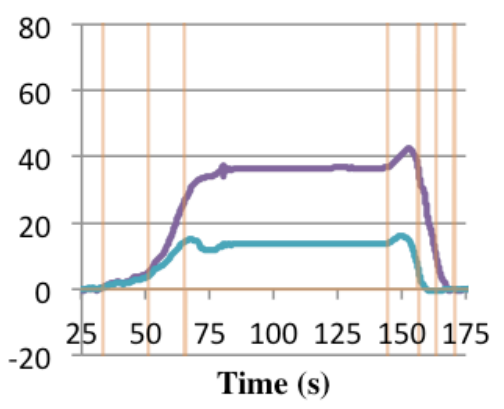

Clicker

Figure 41: Girder 6 Mid-span Strains Plotted Against Time 

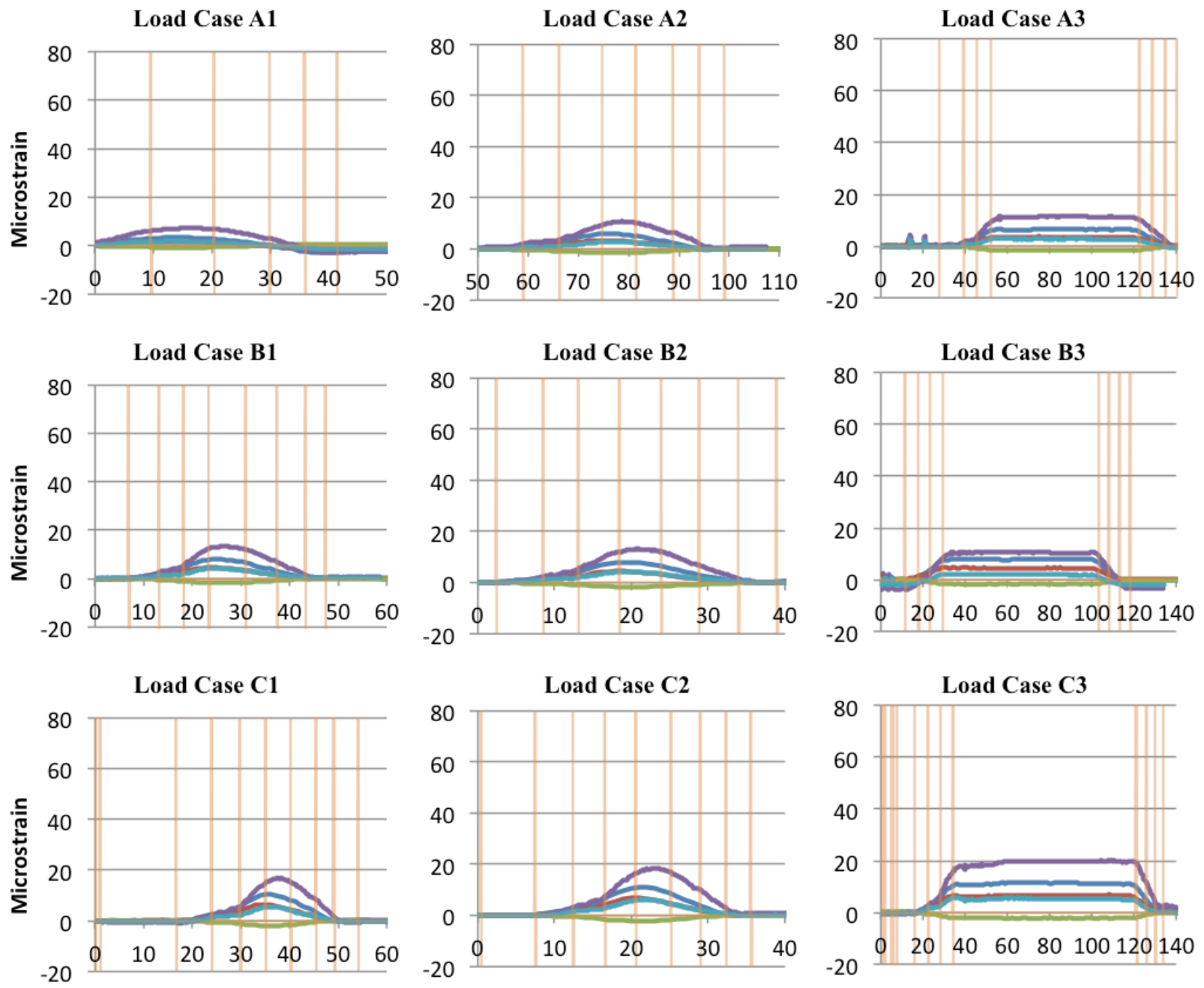

Load Case D1

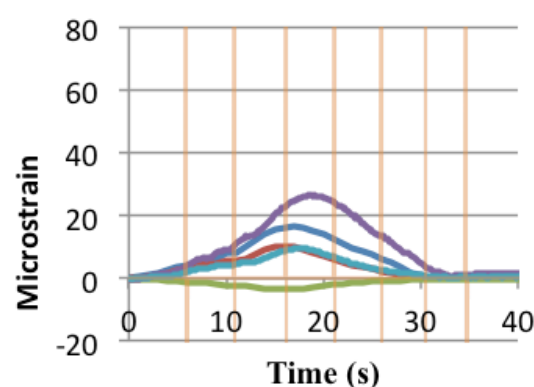

Time (s)
Load Case D2

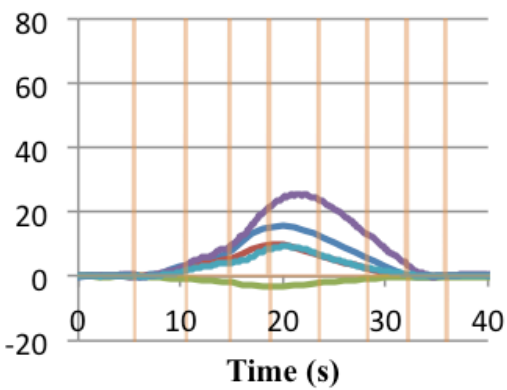

Load Case D3

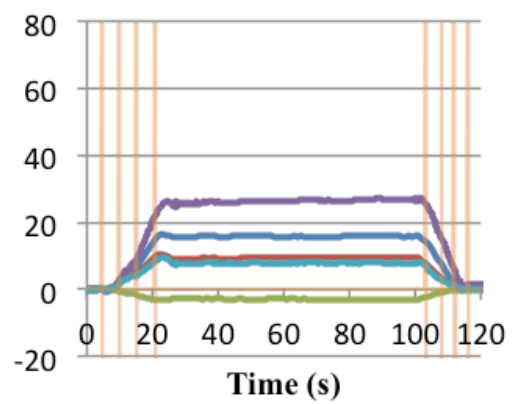
Time (s)

—VWG - T - VWG - CB - EXT - B Fl - EXT - U Web - VWG - D - Clicker 

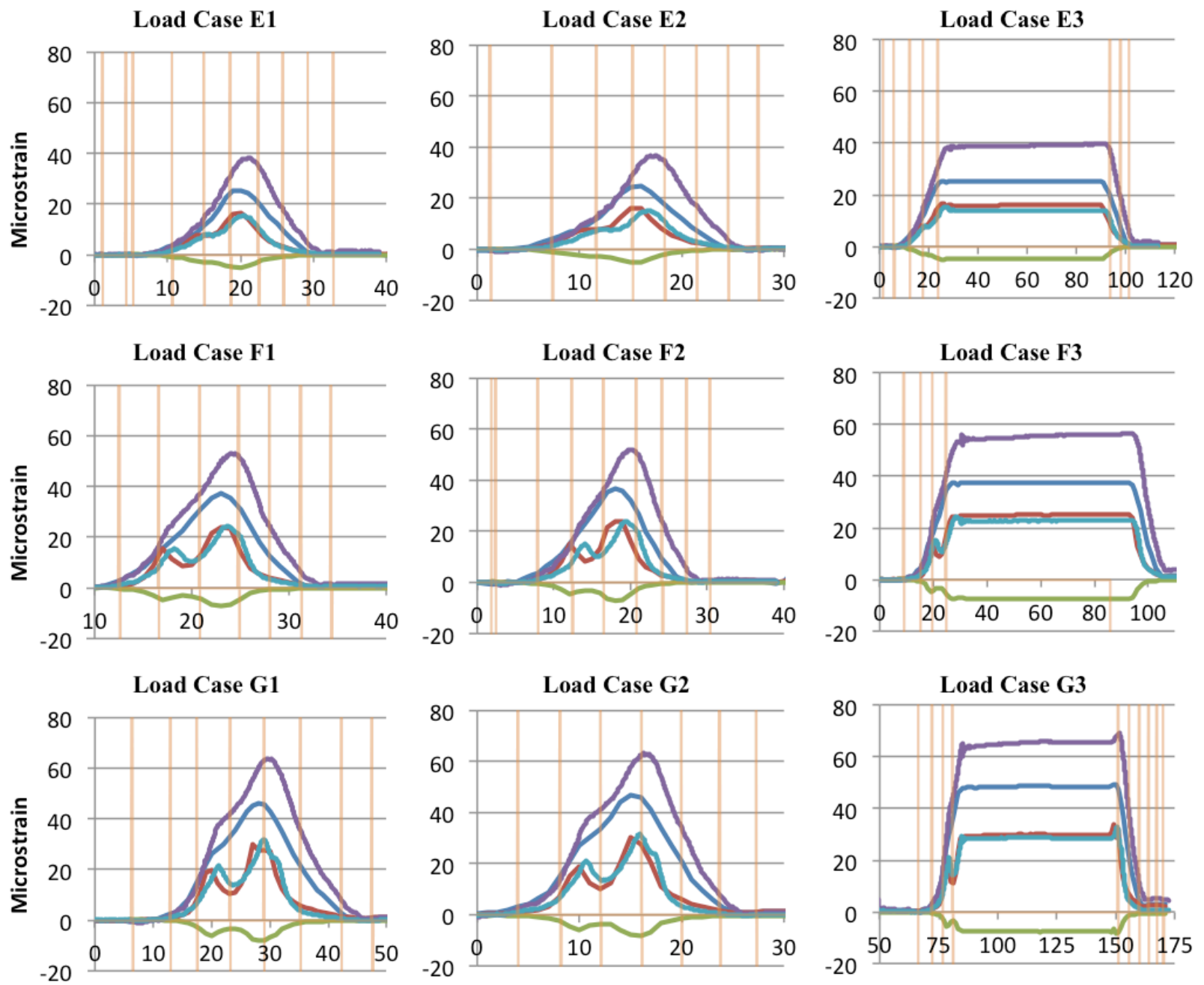

Load Case H1

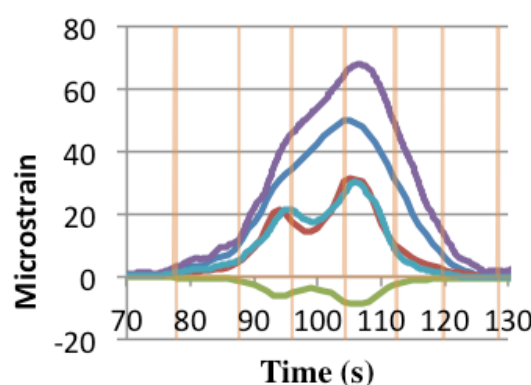

Time (s)
Load Case H2

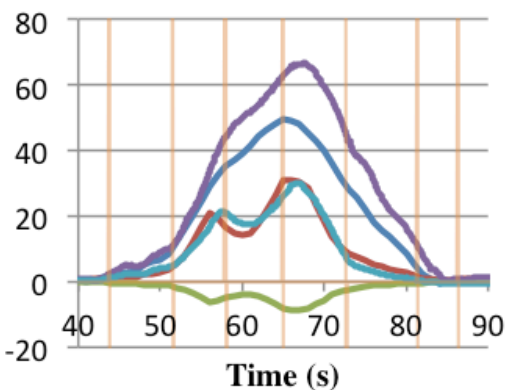

Load Case H3

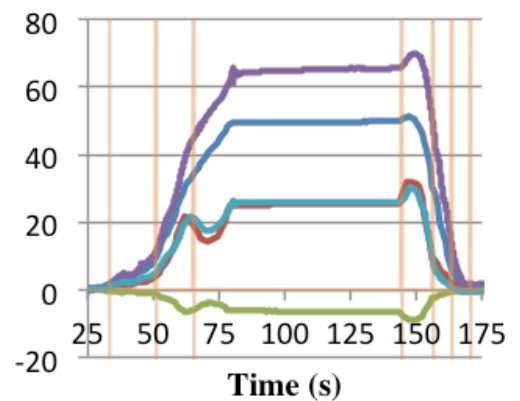

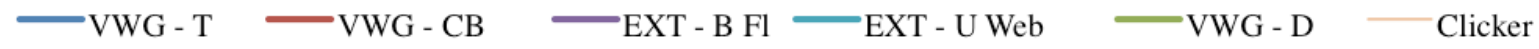

Figure 42: Girder 7 Mid-span Strains Plotted Against Time 

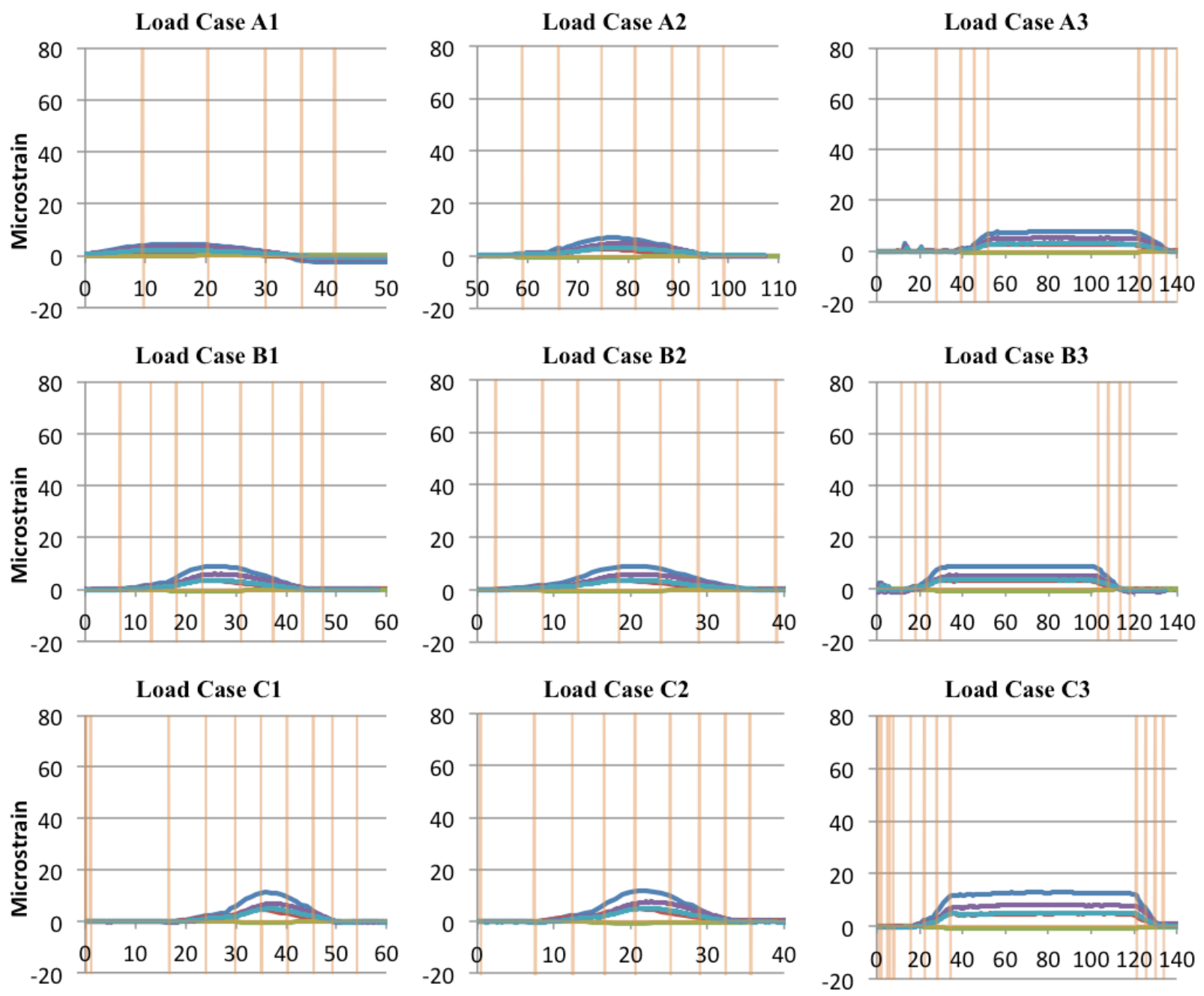

Load Case D1
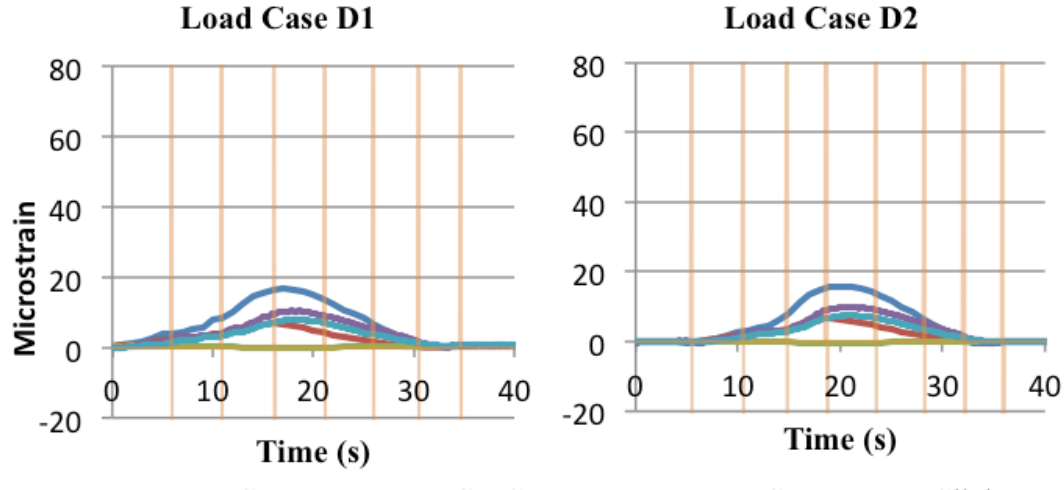

Load Case D3

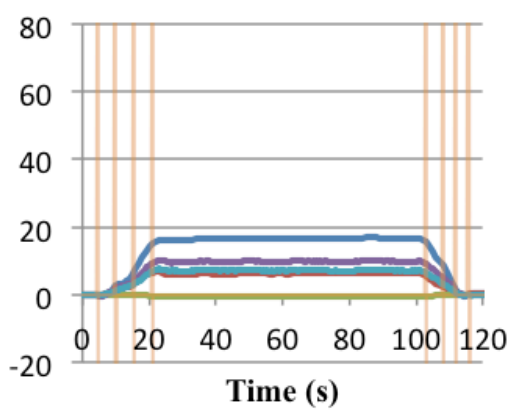

$\longrightarrow$ VWG - T VWG - CB

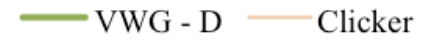

$\longrightarrow$ EXT - B Fl $\longrightarrow$ EXT - U Web 

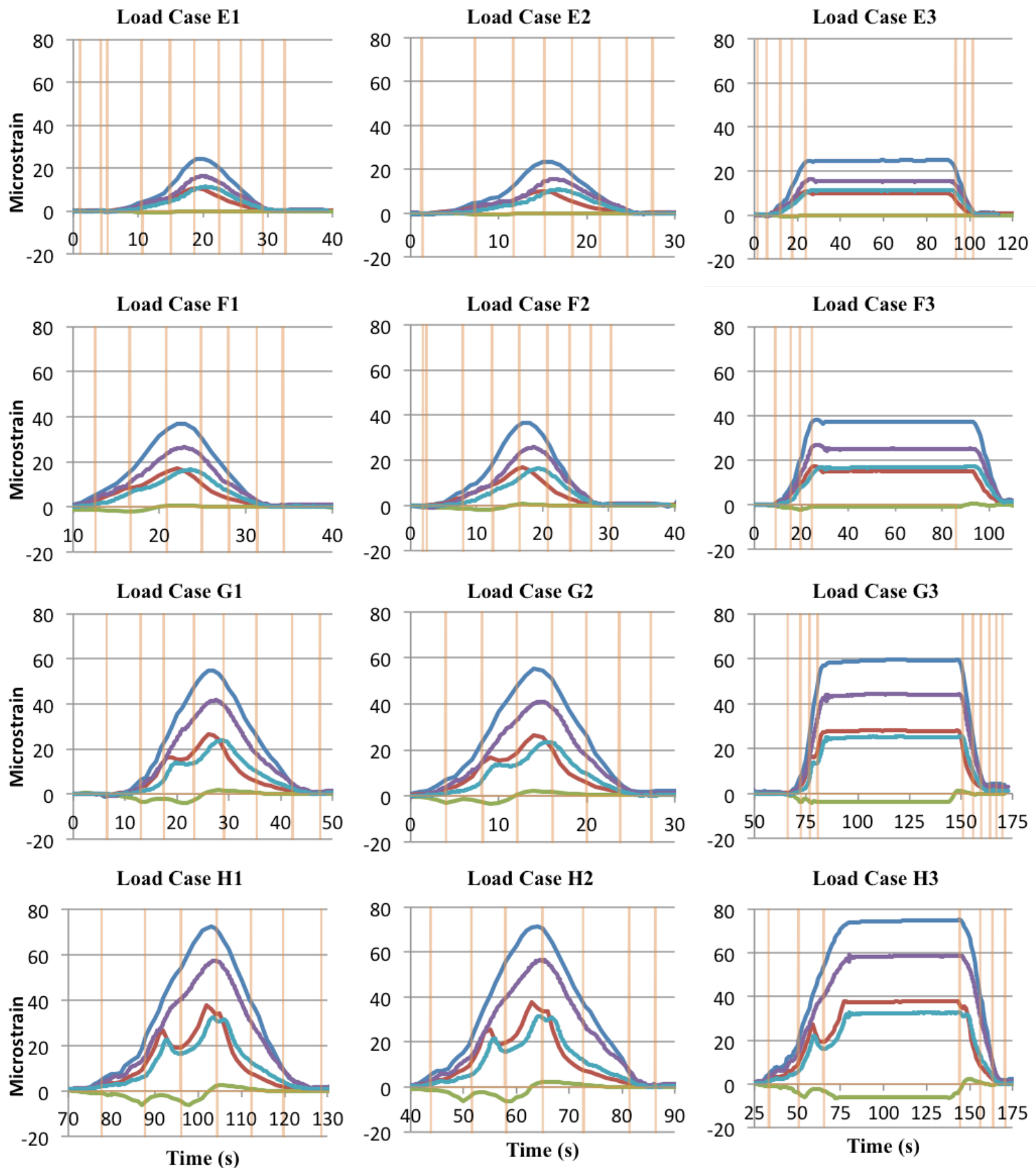

—VWG - T —VWG - CB

- VWG - D C Clicker

EXT - B Fl —EXT - U Web

Figure 43: Girder 8 Mid-span Strains Plotted Against Time 


\section{APPENDIX B: Quarter-span Strains}
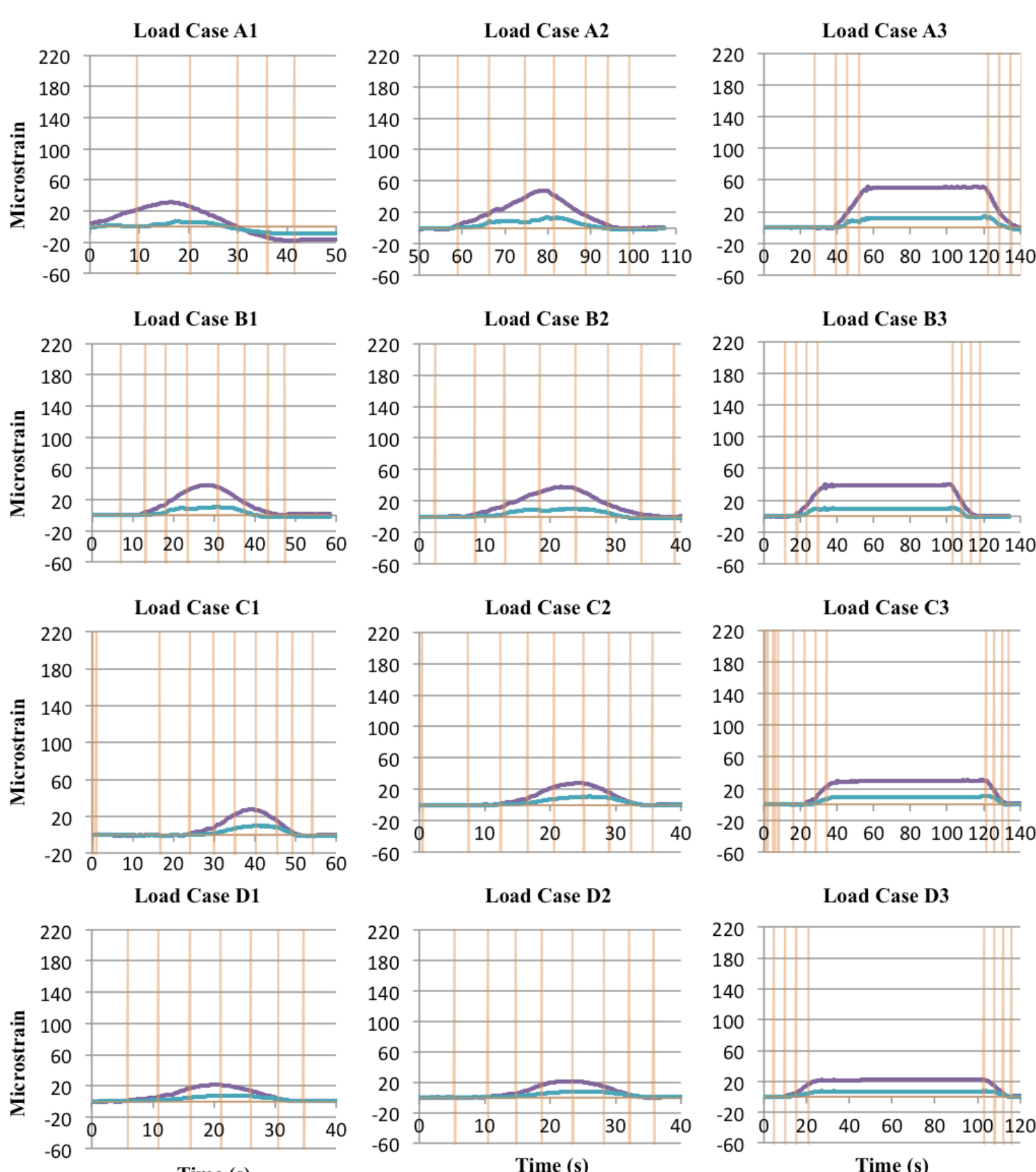

Load Case D2

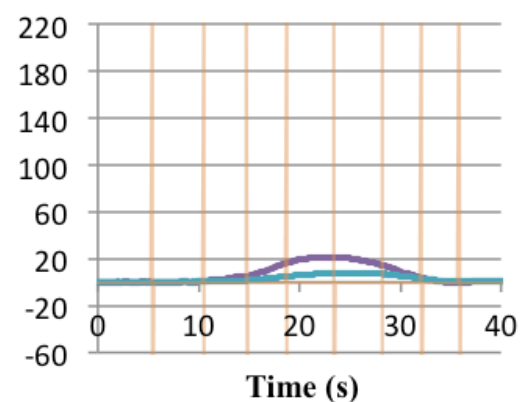

Time (s)

$\longrightarrow$ EXT - B Fl $\longrightarrow$ EXT - U Web
Load Case D3

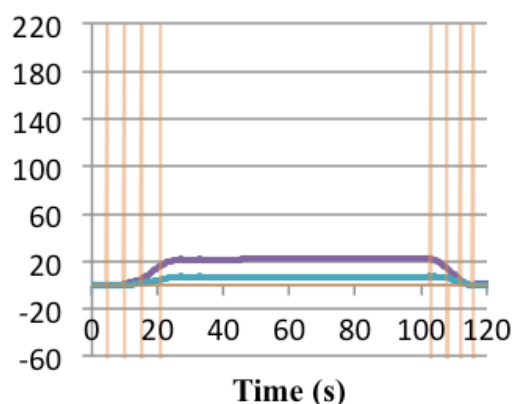

Clicker 

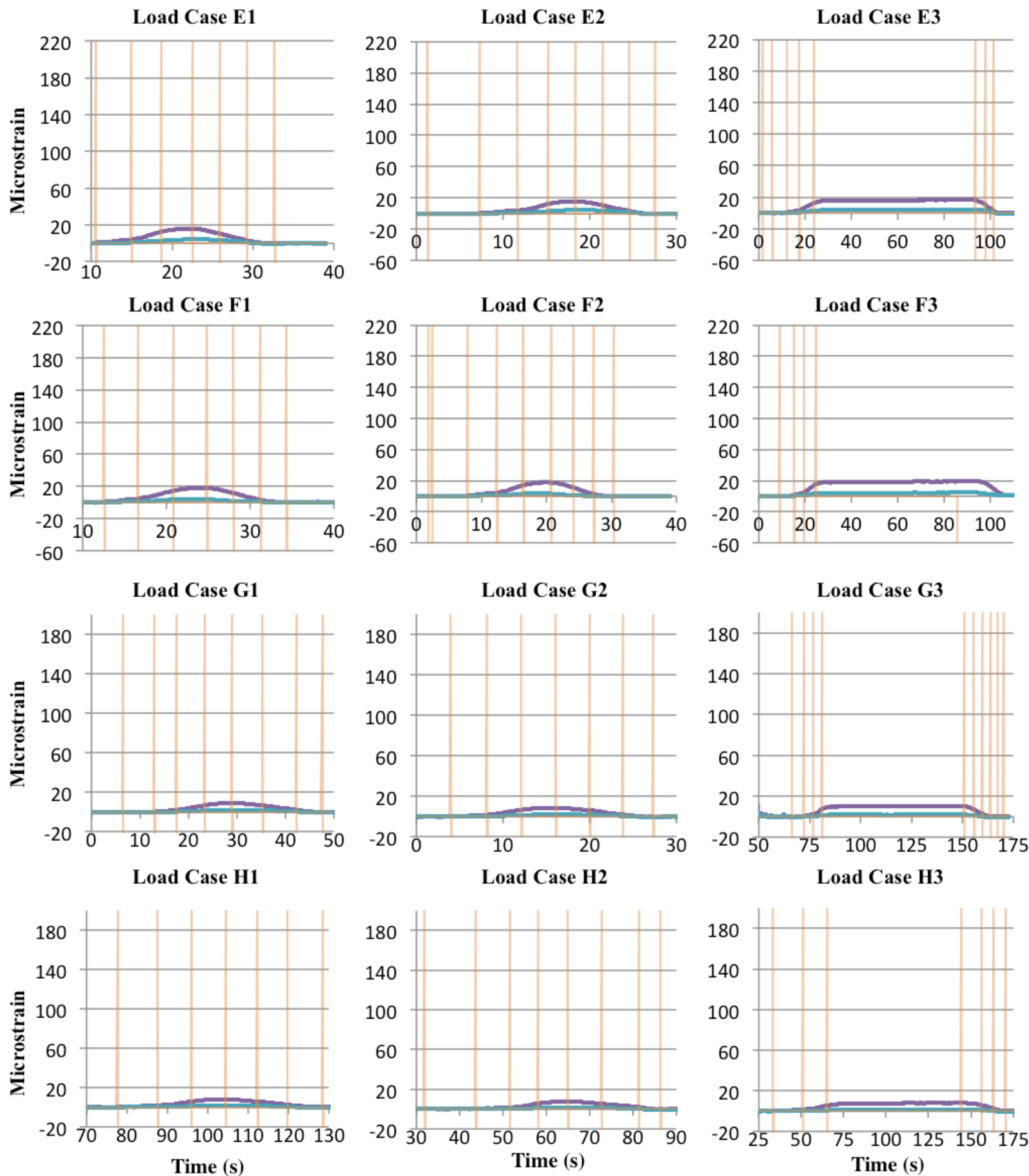

$\longrightarrow$ EXT - B Fl $\longrightarrow$ EXT - U Web

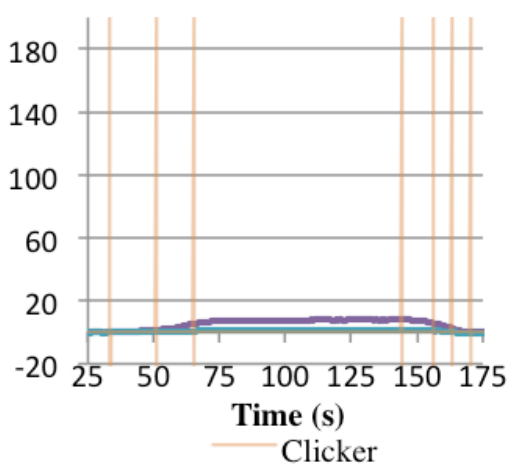

Figure 44: Girder 1 Quarter-span Strains Plotted Against Time 

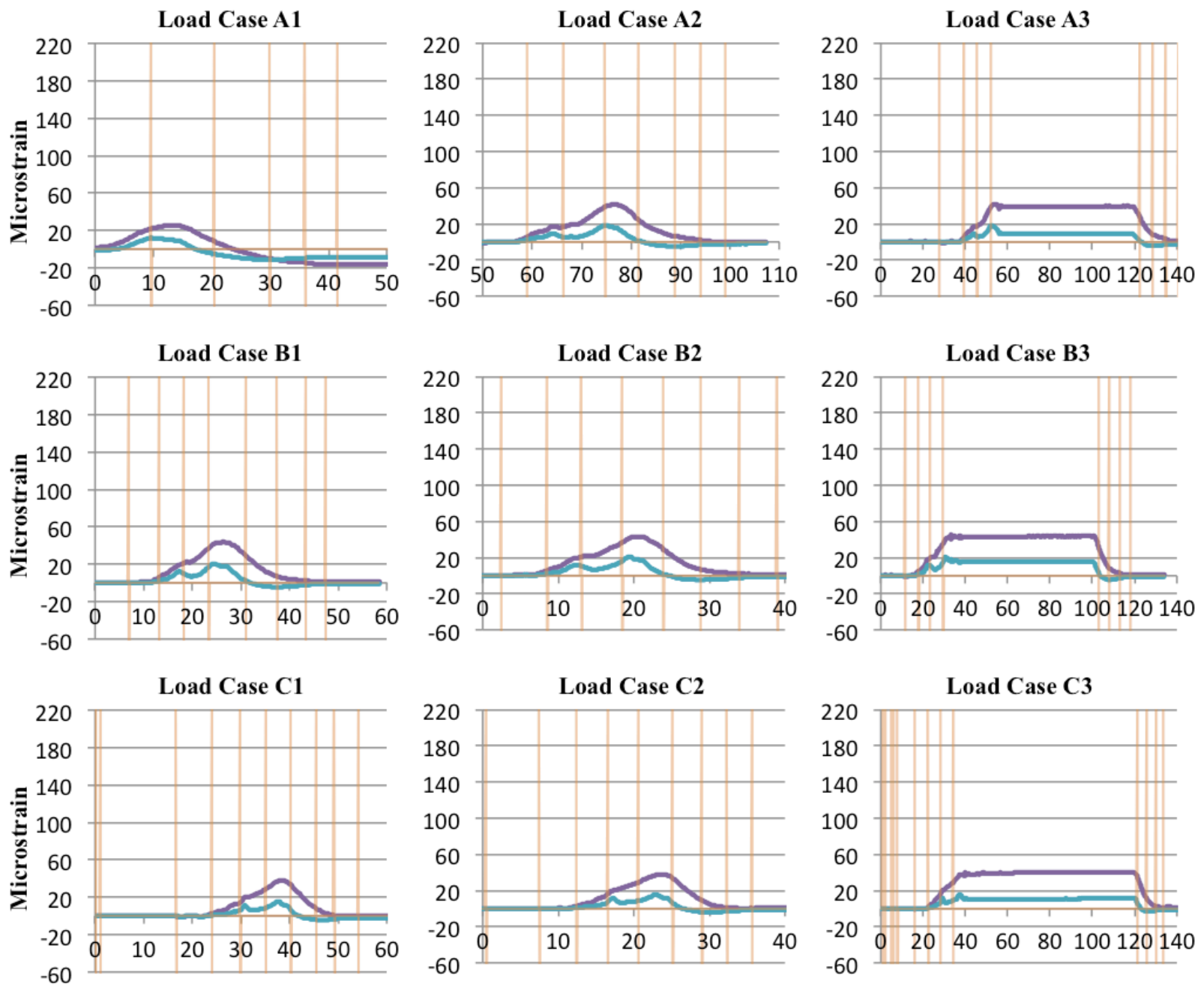

Load Case D1

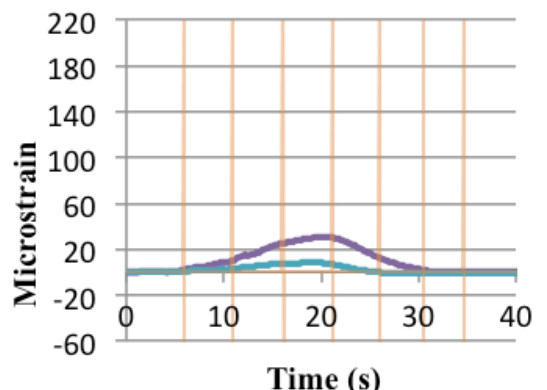

Time (s)
Load Case D2

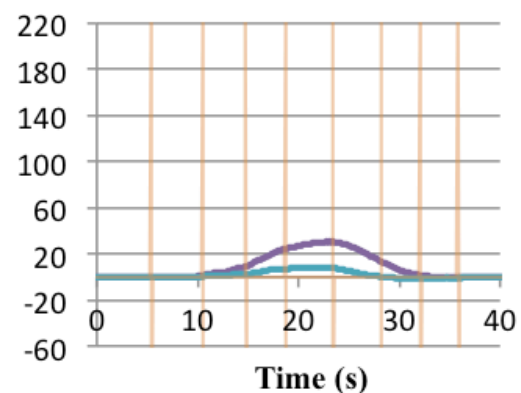

Time (s)
Load Case D3

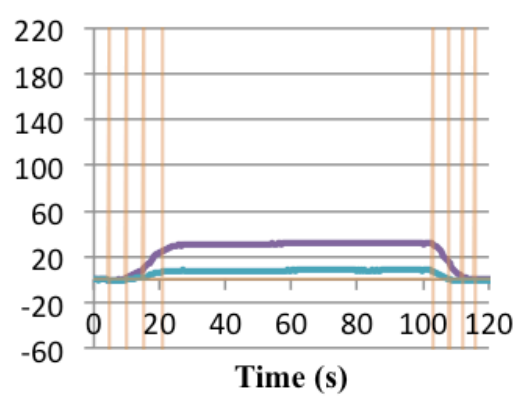

Clicker 

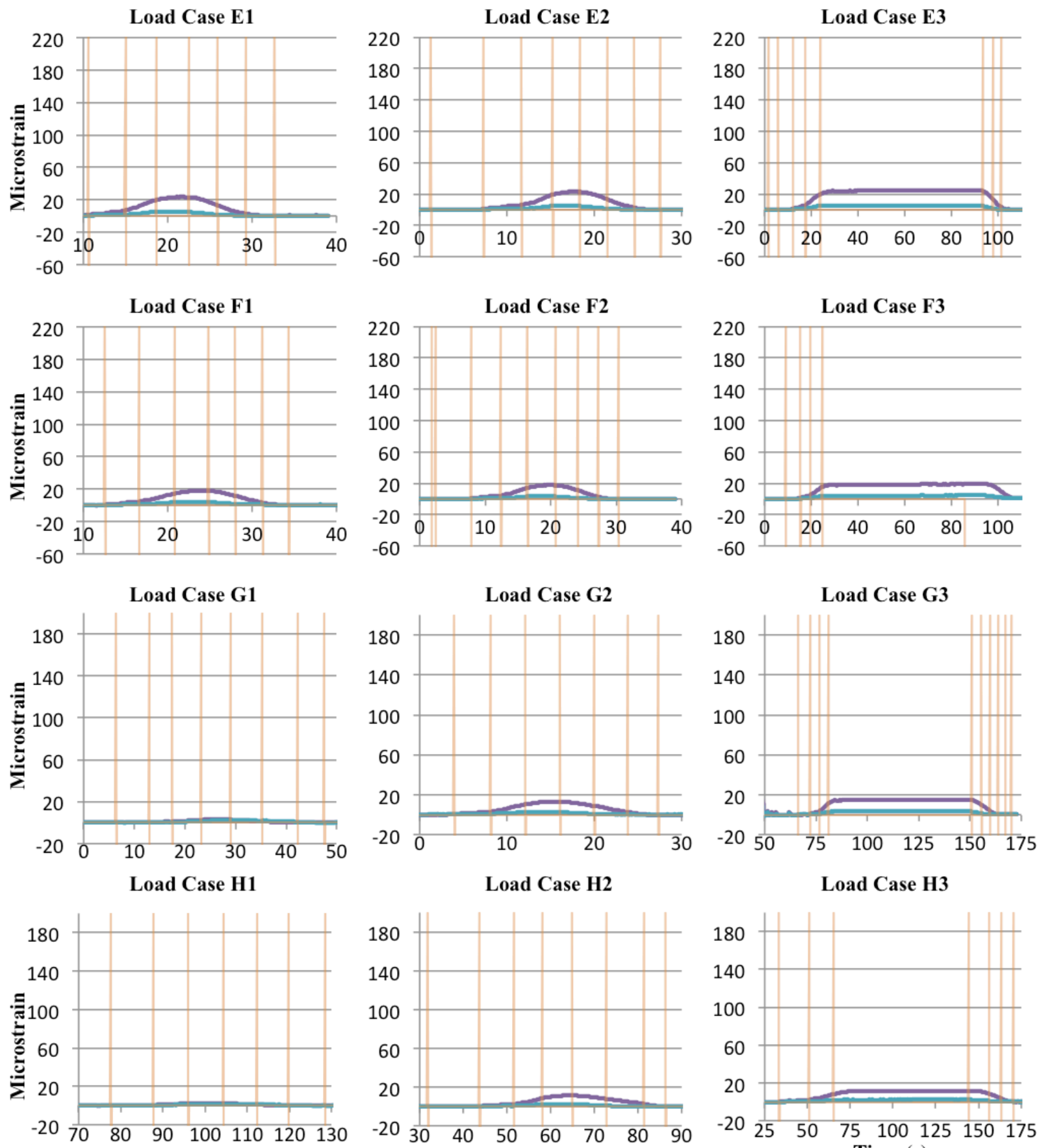

Time (s)
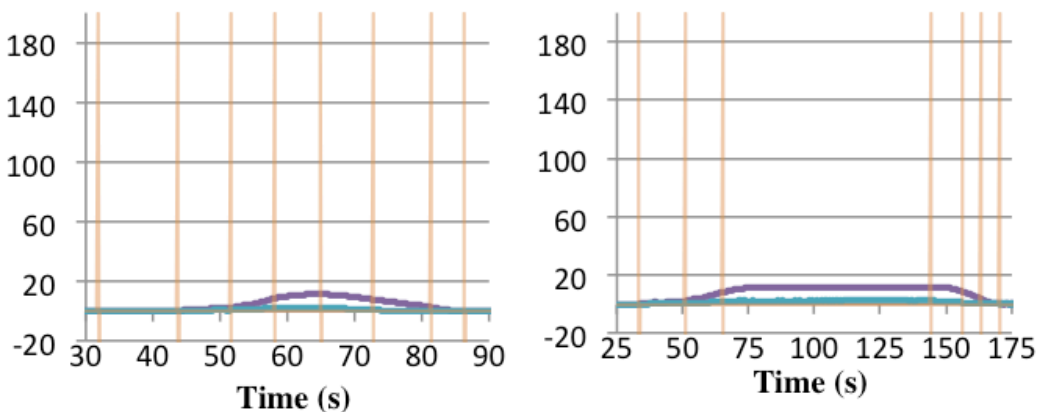

$\longrightarrow$ EXT - B Fl $\longrightarrow$ EXT - U Web $\longrightarrow$ Clicker

Figure 45: Girder 2 Quarter-span Strains Plotted Against Time 

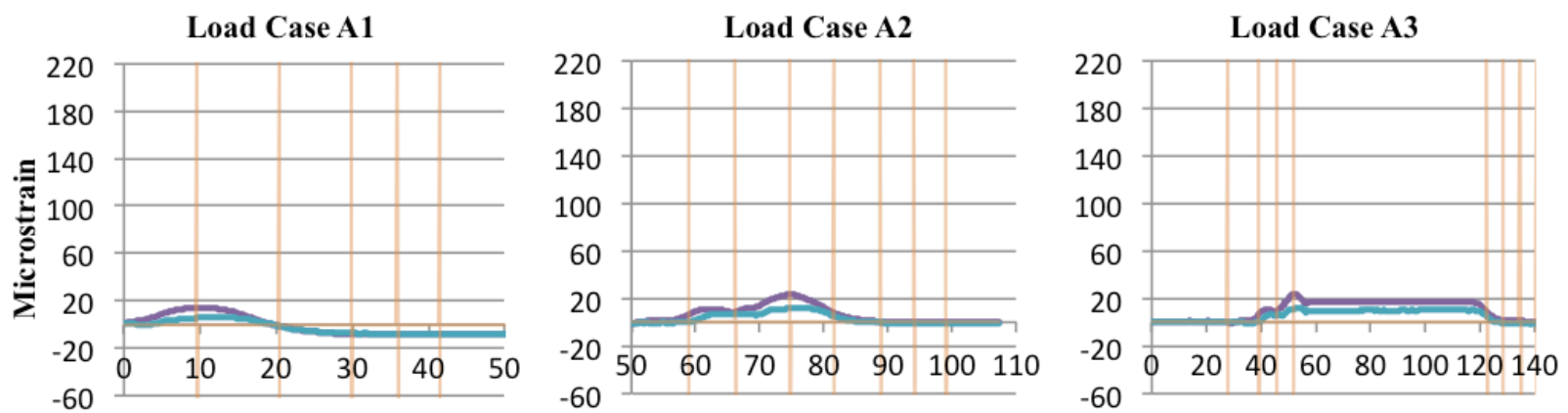

Load Case B1

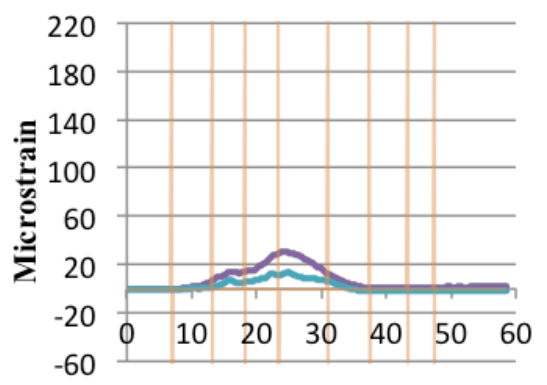

Load Case B2

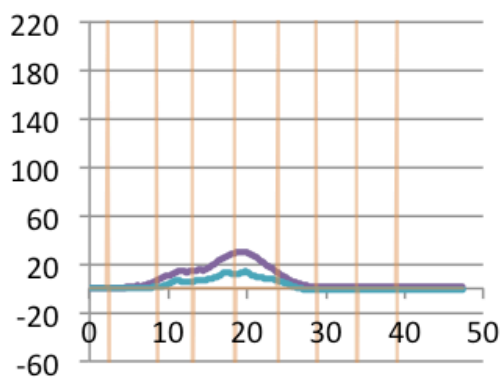

Load Case B3
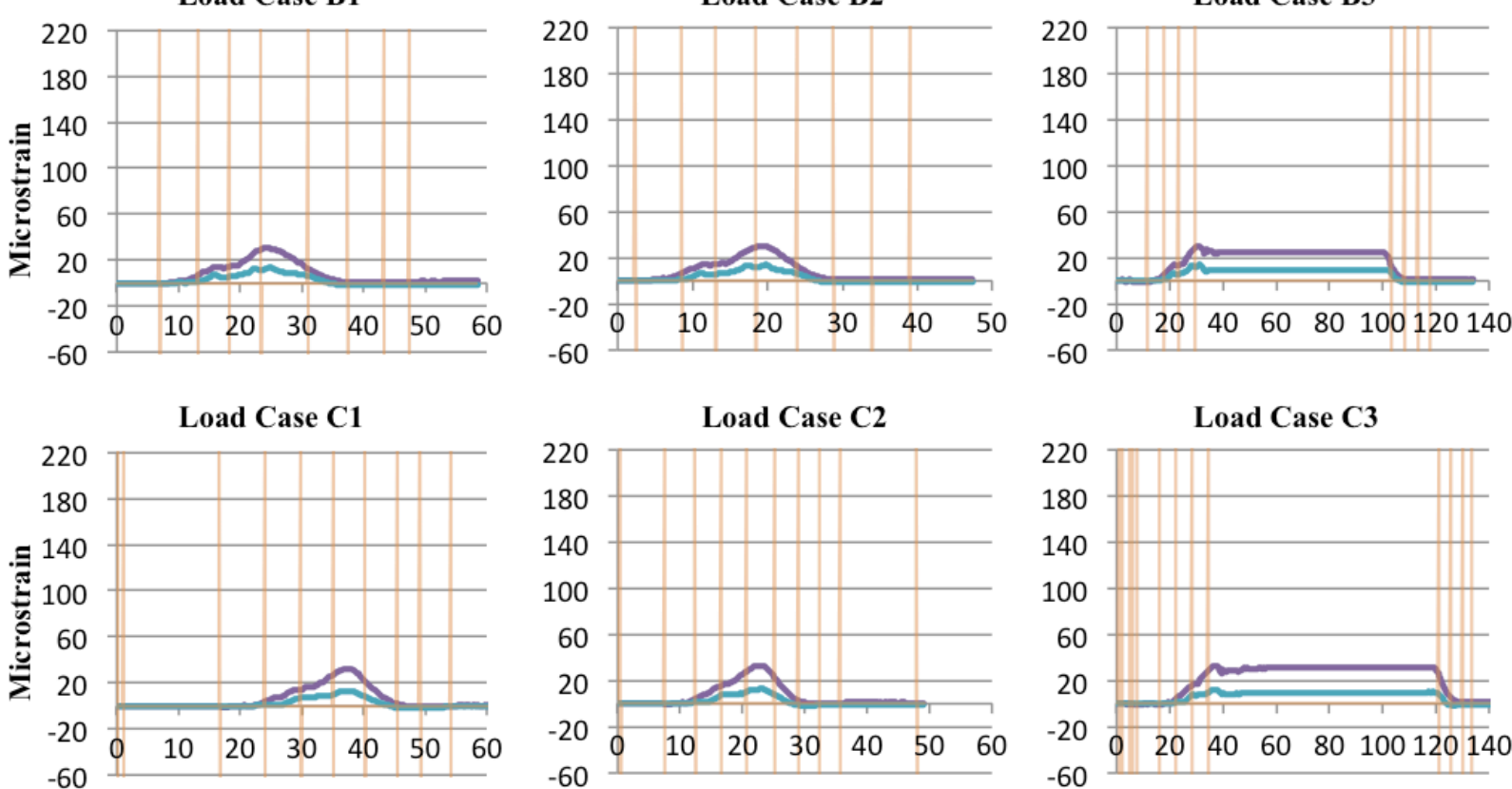

Load Case D1

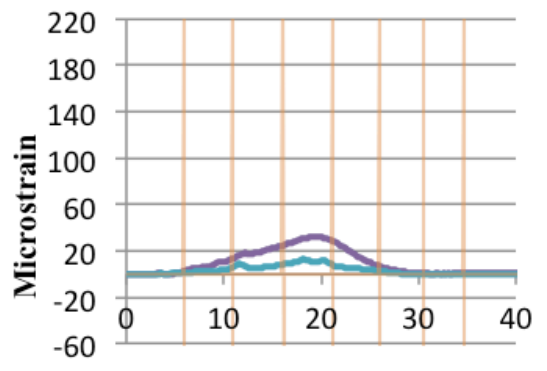

Time (s)
Load Case D2

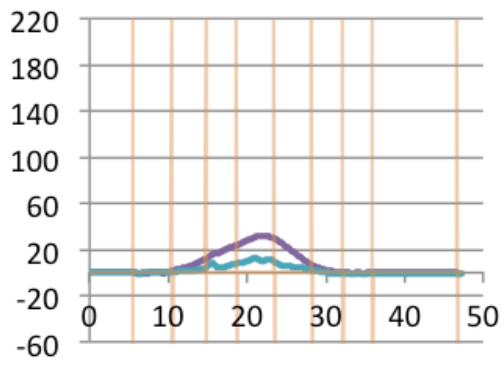

Time (s)

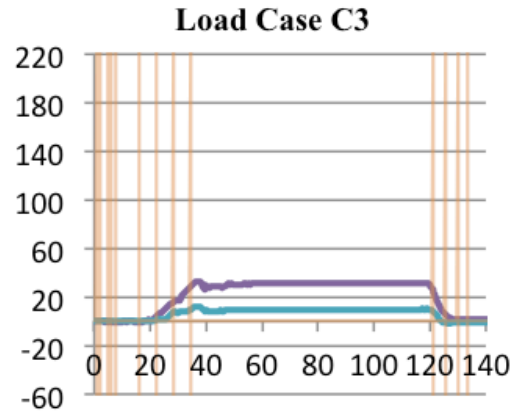

Load Case D3

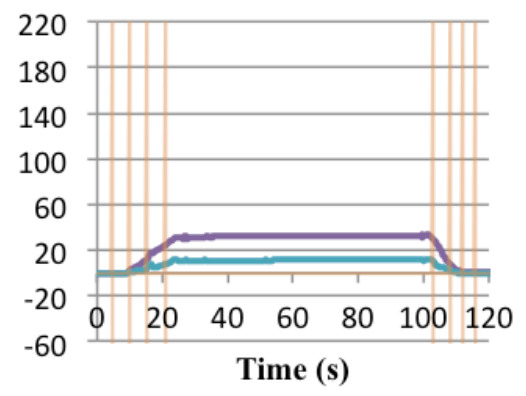

Clicker 

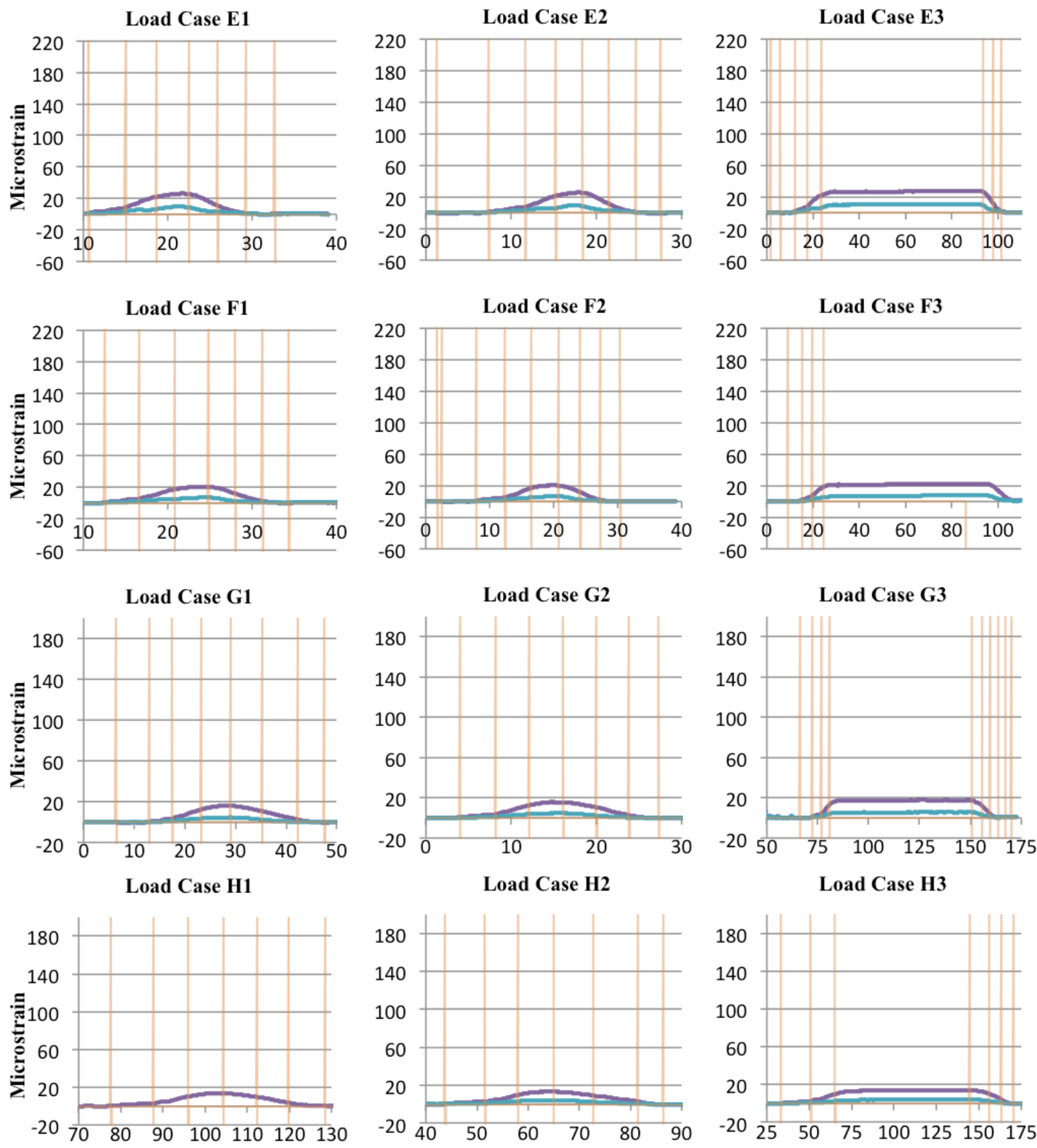

Time (s)

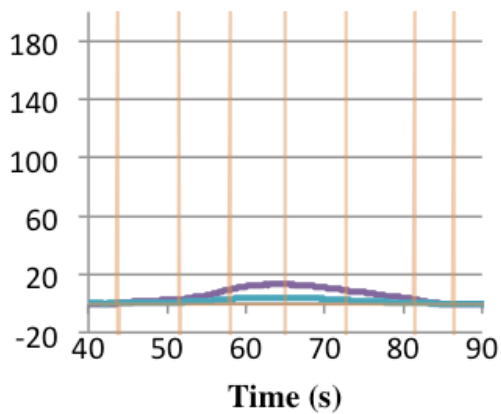

EXT - B Fl - EXT - U Web

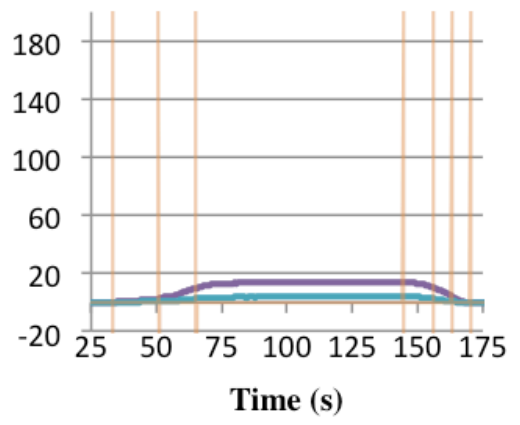

Clicker

Figure 46: Girder 3 Quarter-span Strains Plotted Against Time 

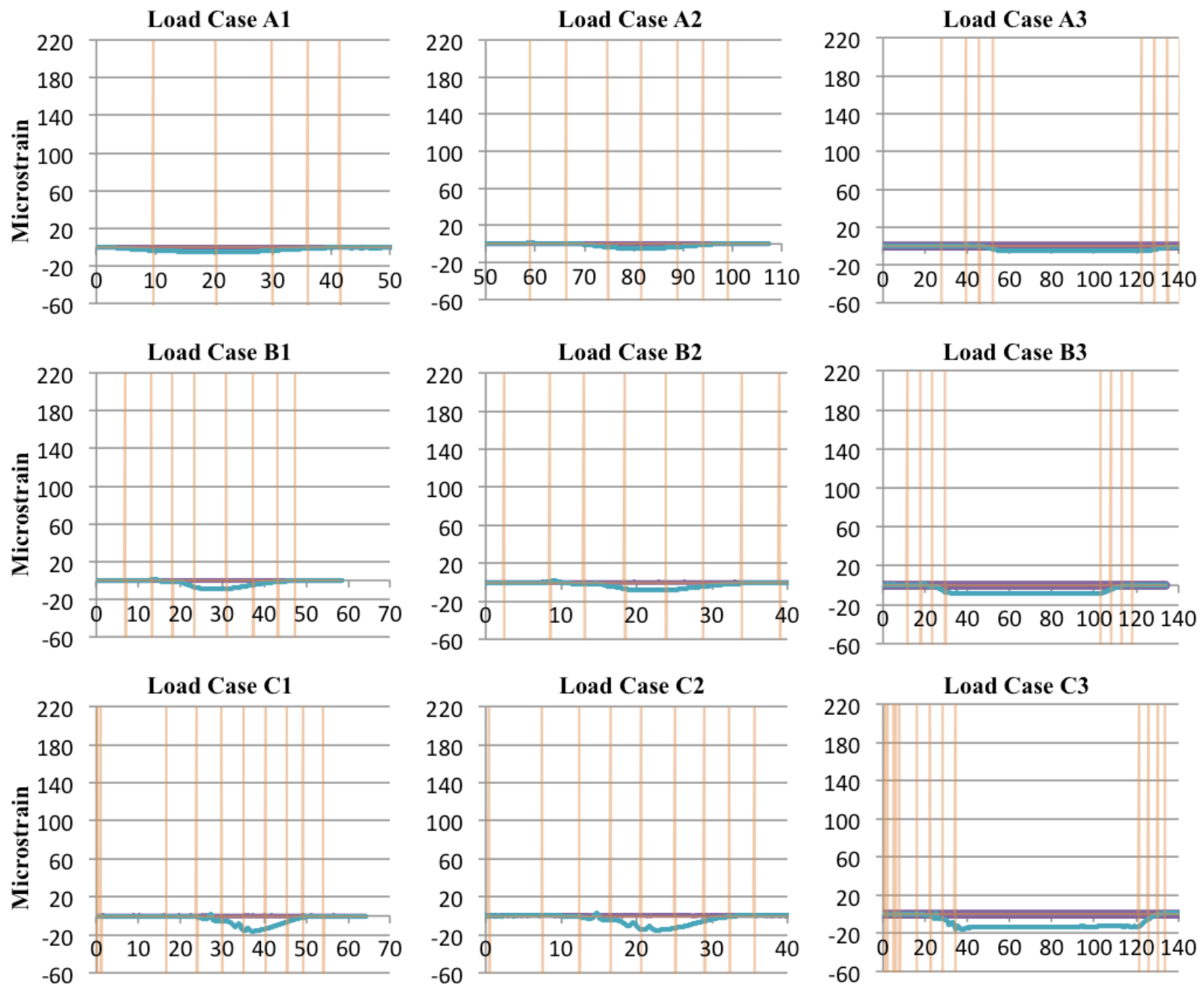

Load Case D1

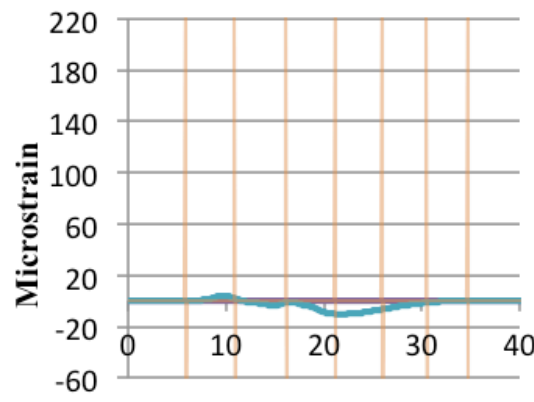

Time (s)

Load Case D2

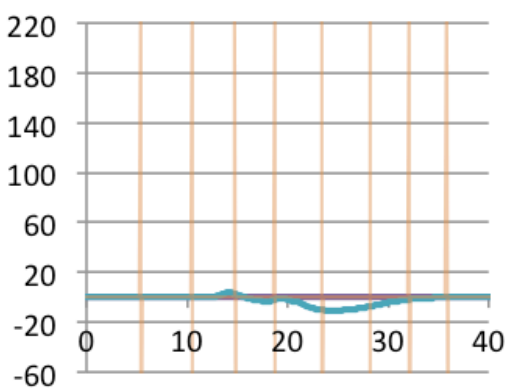

Time (s)

$\longrightarrow$ EXT - B Fl $\longrightarrow$ EXT - U Web
Load Case D3

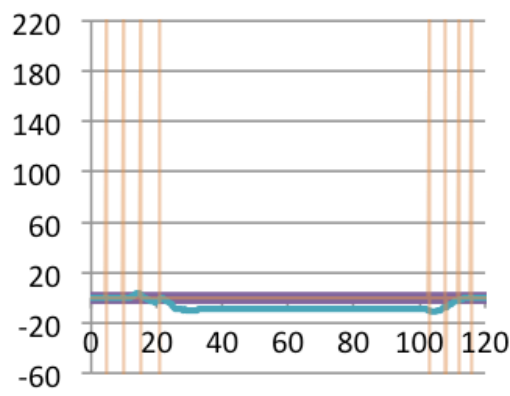

Time (s)

Clicker 

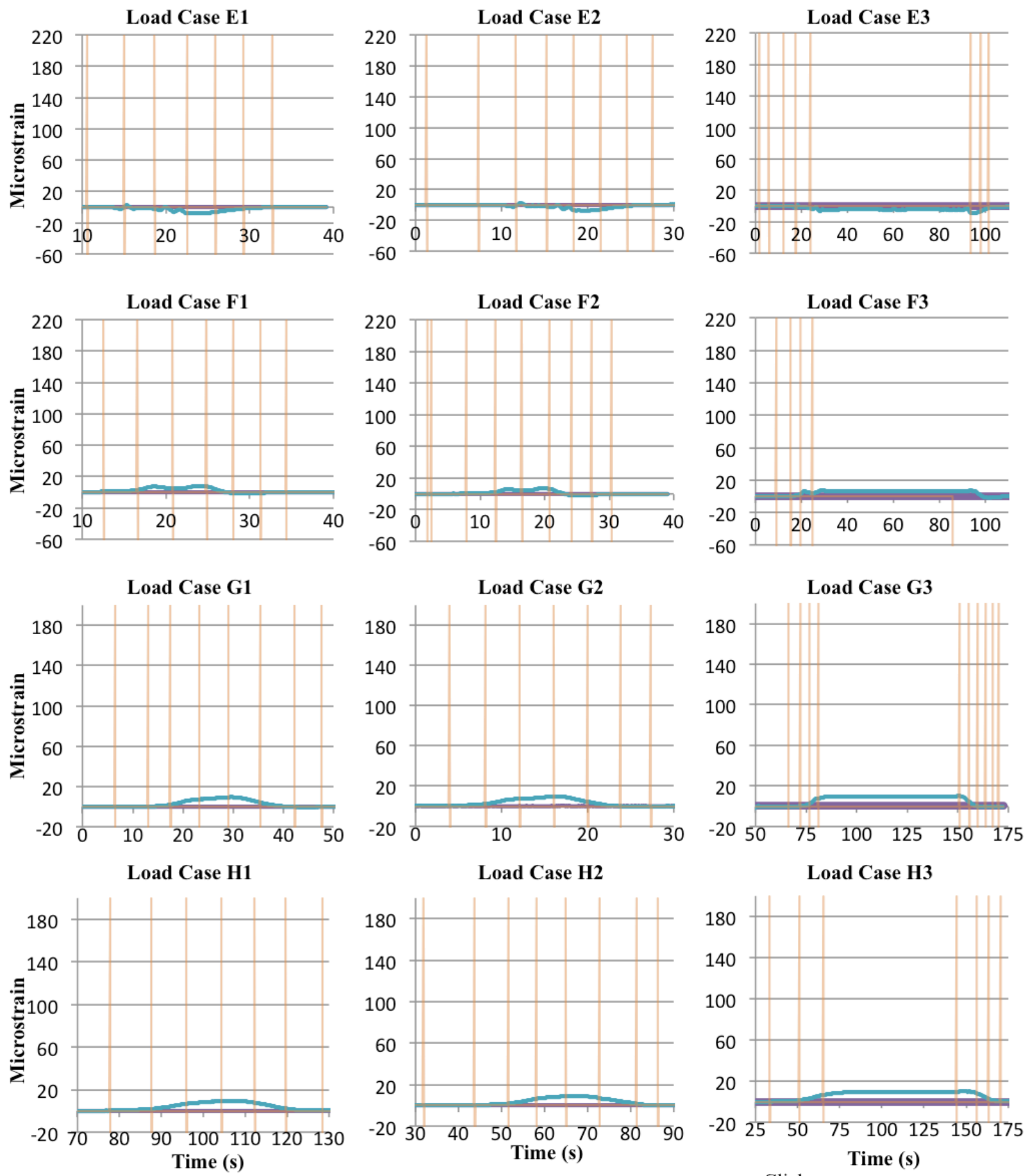

Figure 47: Girder 4 Quarter-span Strains Plotted Against Time 

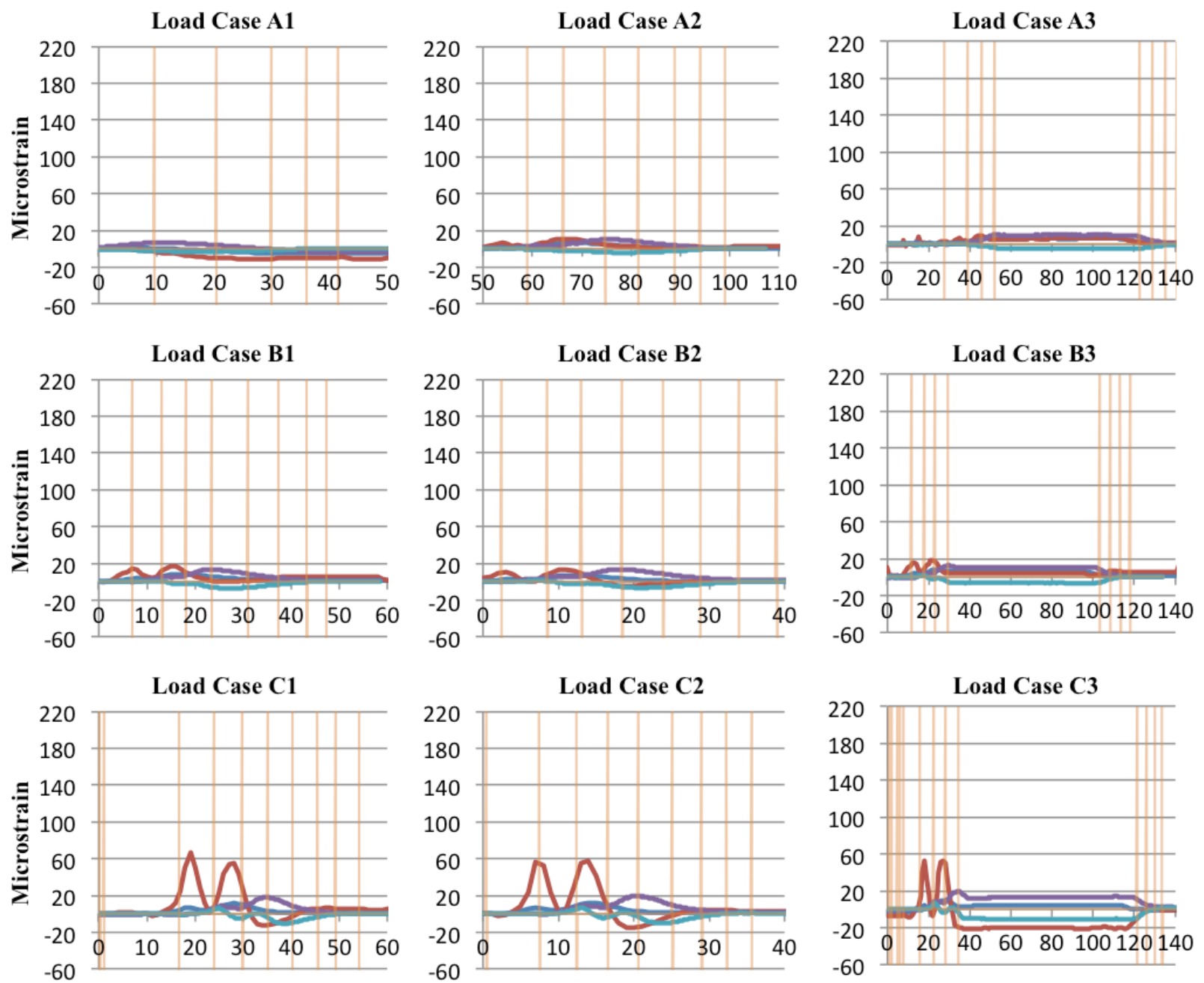

Load Case D1

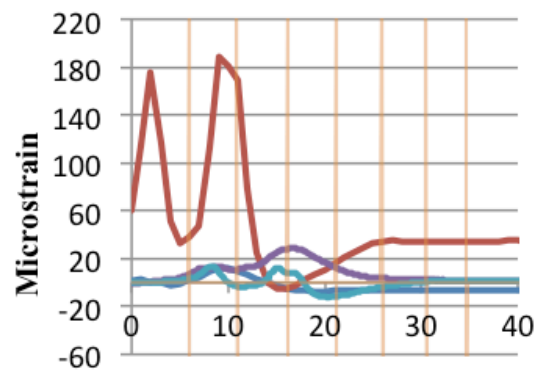

Time (s)
Load Case D2

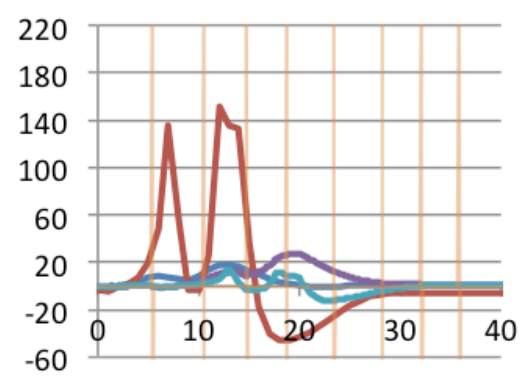

Time (s)
Load Case D3

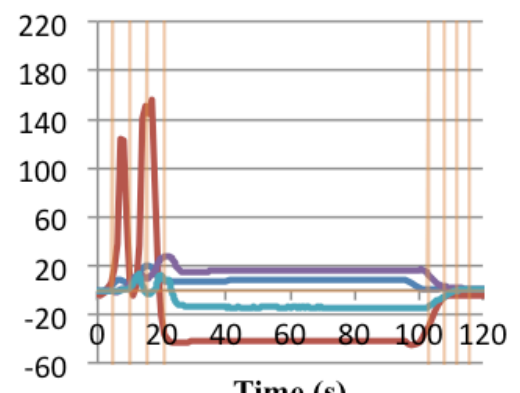

Time (s)

VWG - T $\longrightarrow$ VWG - CB

Clicker 

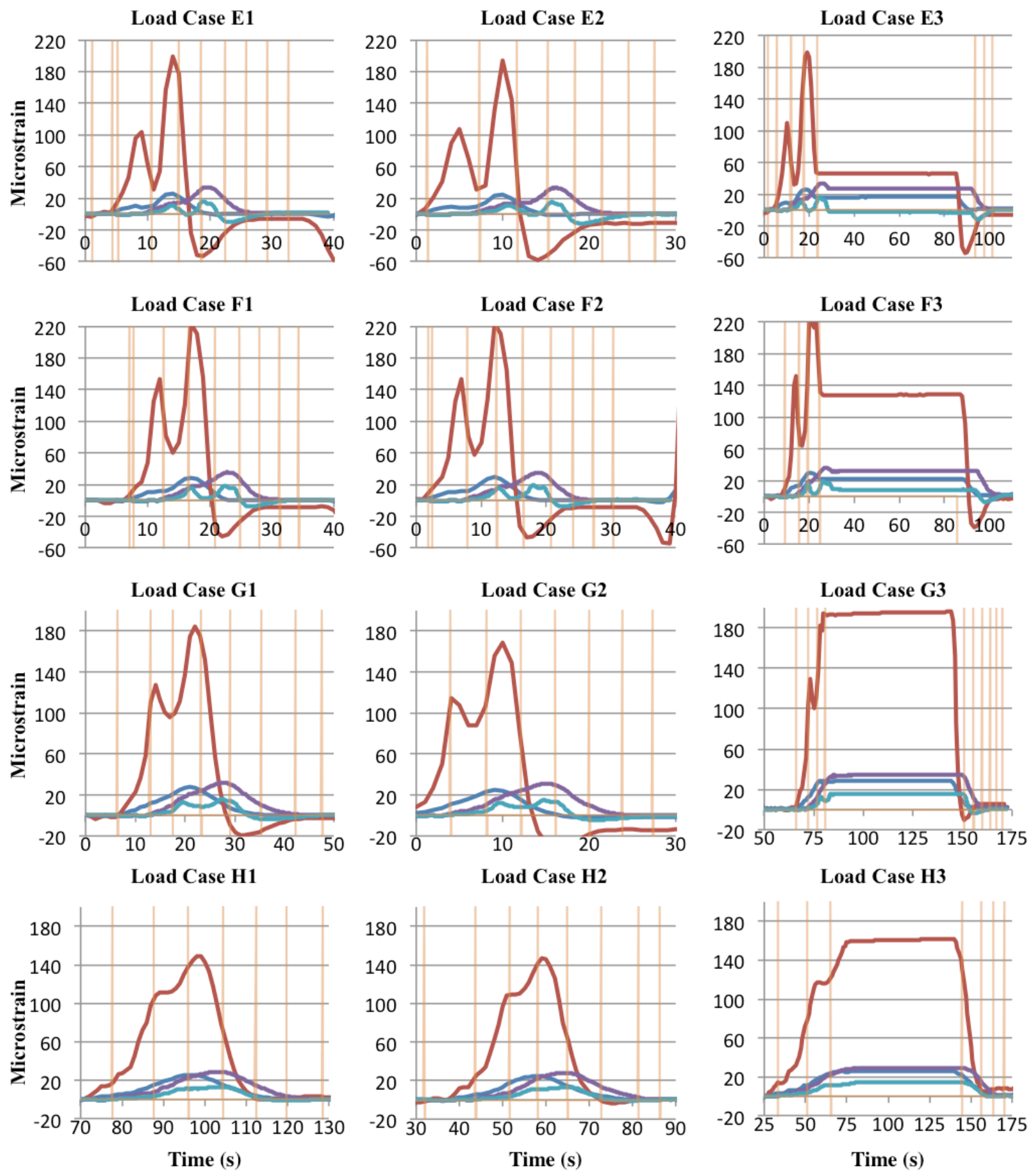

WWG - T WWG - CB - EXT - B Fl EXT - U Web Clicker

Figure 48: Girder 5 Quarter-span Strains Plotted Against Time 

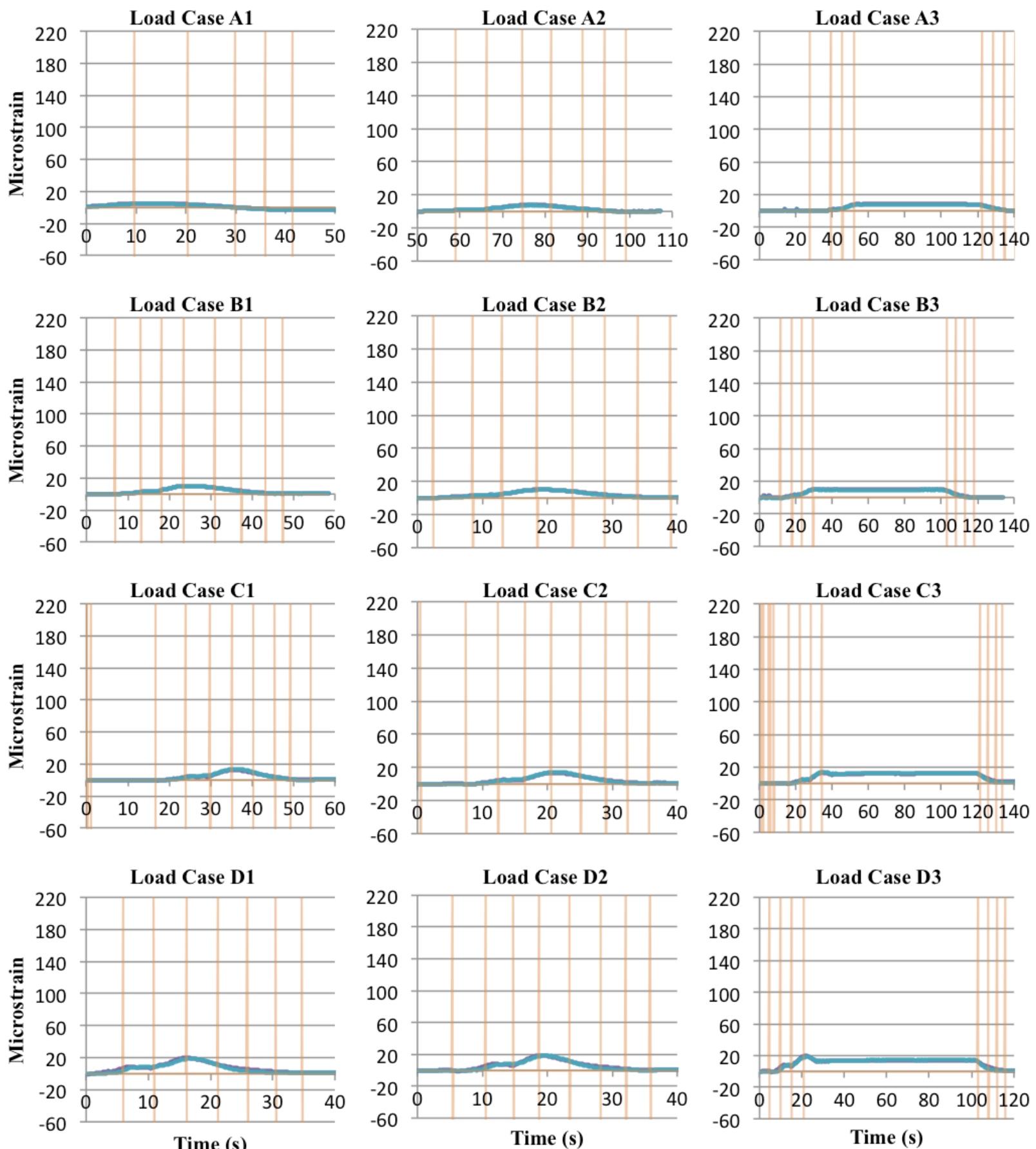

$\longrightarrow$ EXT - B Fl EXT - U Web $\longrightarrow$ Clicker 

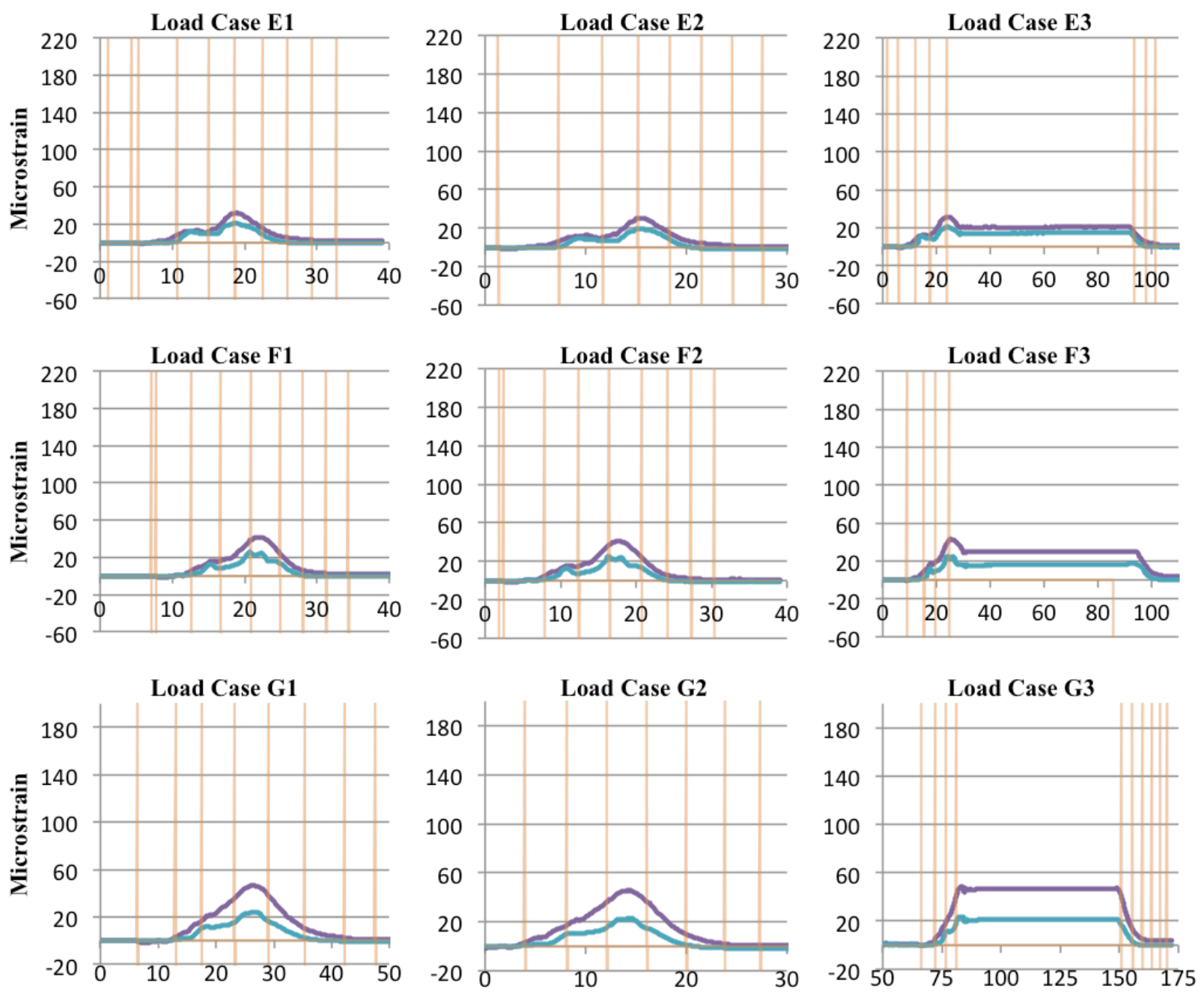

Load Case H1

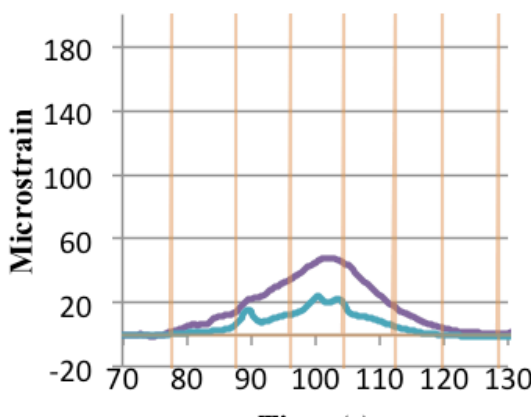

Time (s)
Load Case $\mathrm{H} 2$

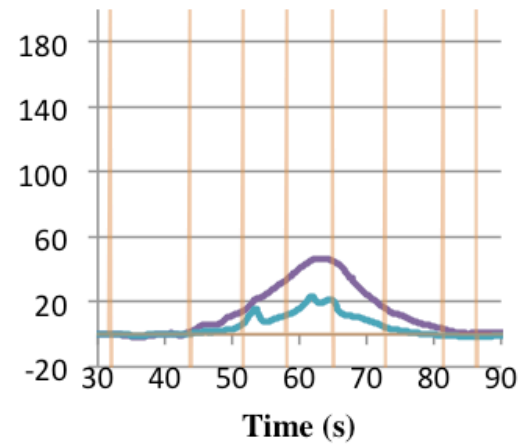

EXT - B Fl EXT - U Web
Load Case H3

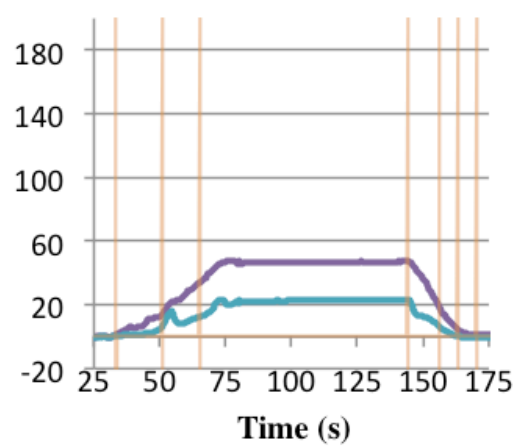

Clicker

Figure 49: Girder 6 Quarter-span Strains Plotted Against Time 
Load Case A1

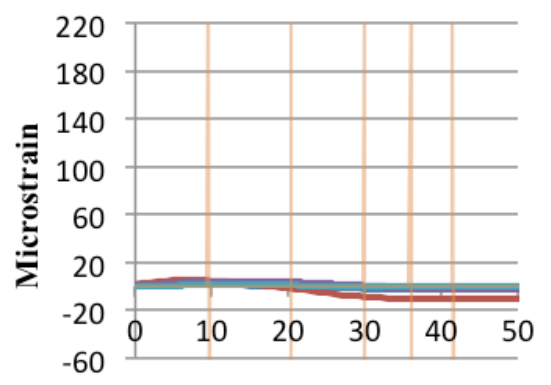

Load Case B1

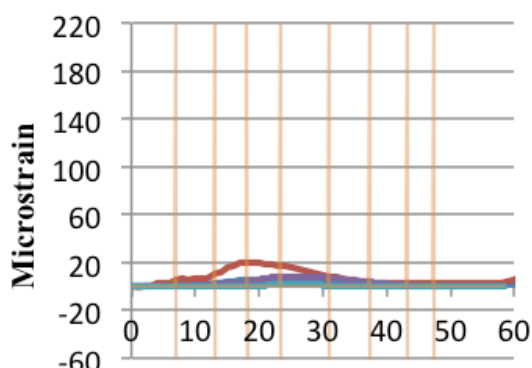

Load Case C1

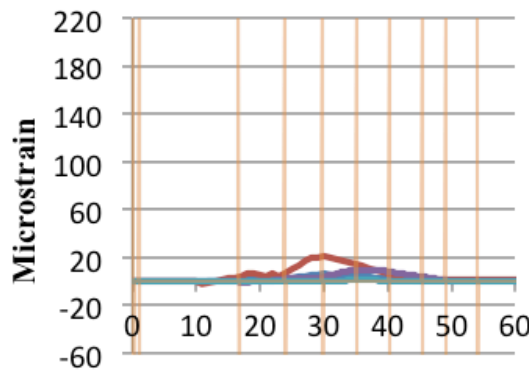

Load Case D1

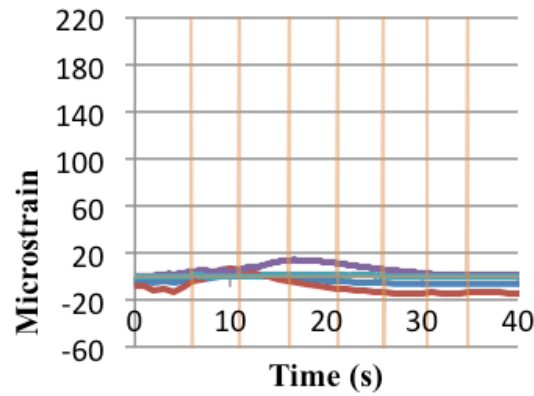

VWG - T $\longrightarrow$ VWG - CB
Load Case A2

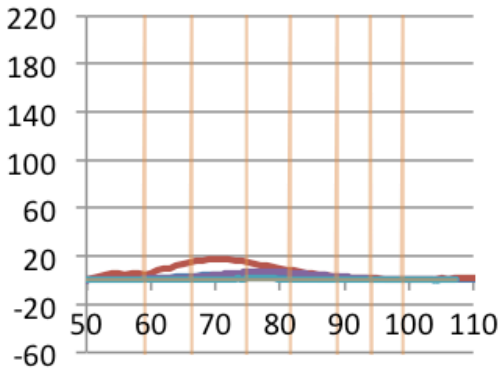

Load Case B2

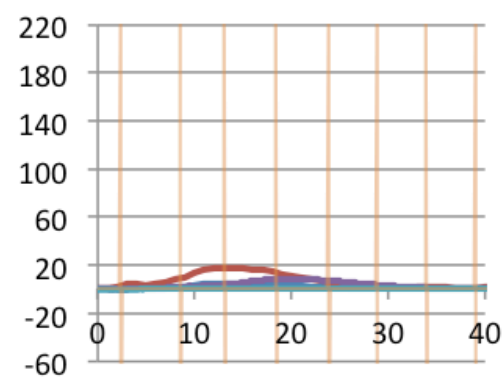

Load Case C2

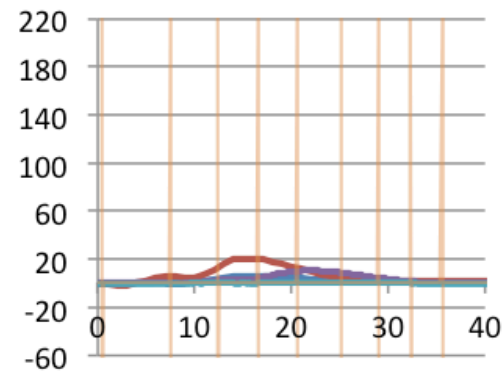

Load Case D2

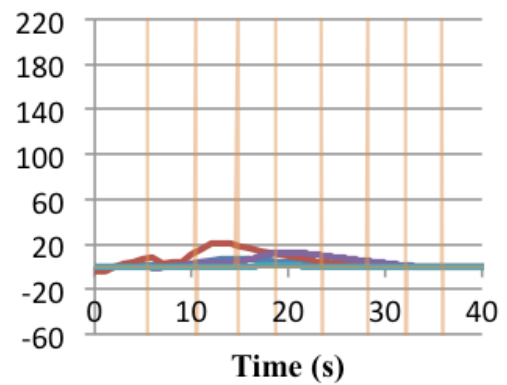

EXT - B Fl —EXT - U Web
Load Case A3

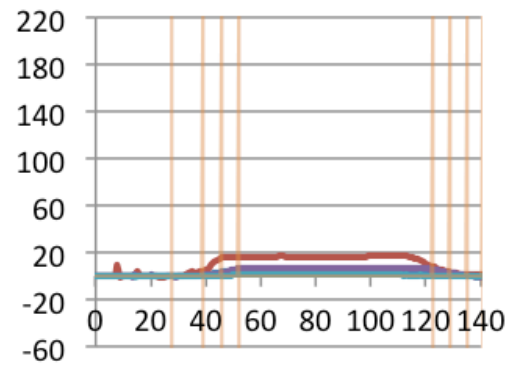

Load Case B3

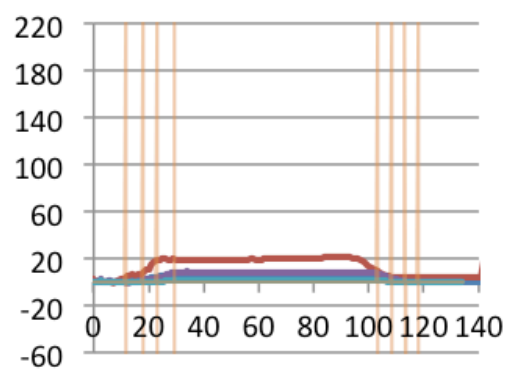

Load Case C3

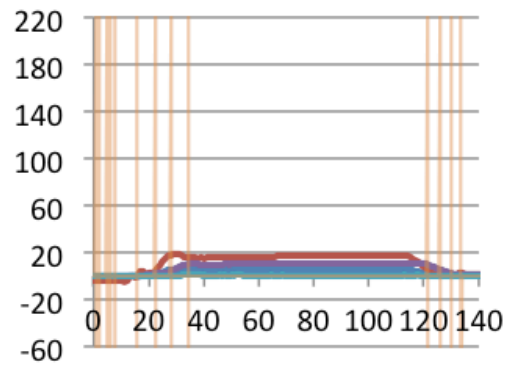

Load Case D3

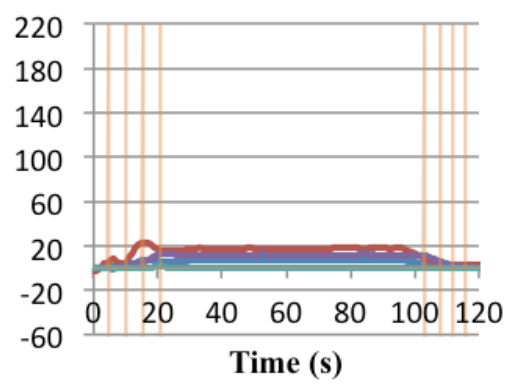

Clicker 
Load Case E1

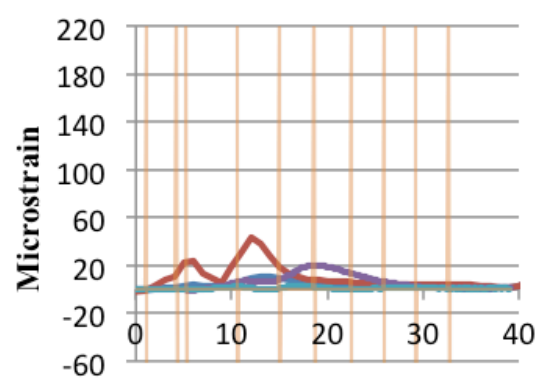

Load Case F1

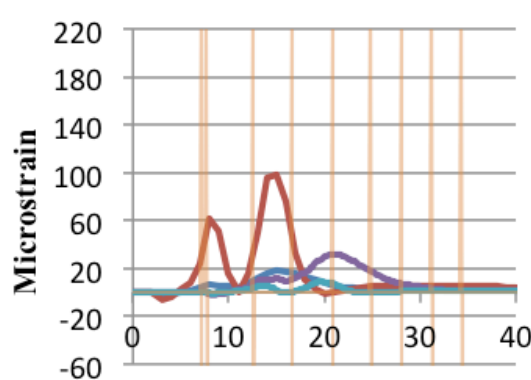

Load Case G1

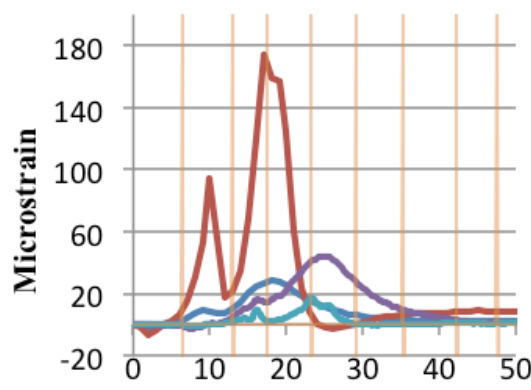

Load Case H1

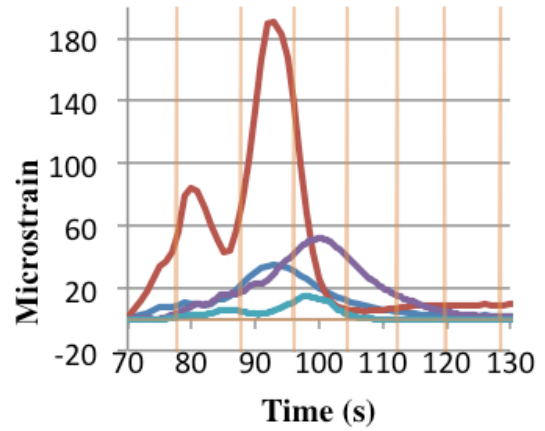

$\longrightarrow$ VWG - T $\longrightarrow$ VWG - CB
Load Case E2

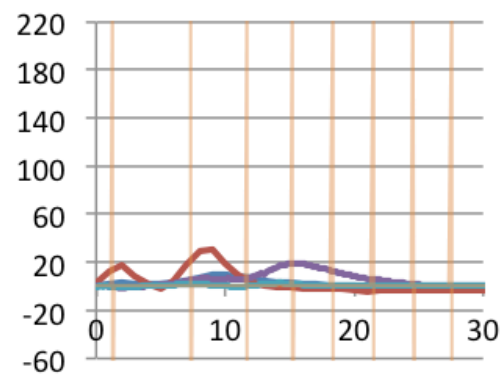

Load Case F2

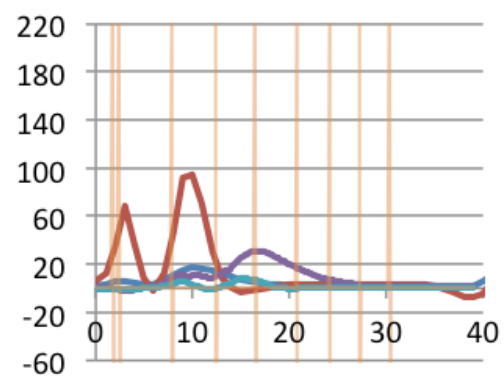

Load Case G2

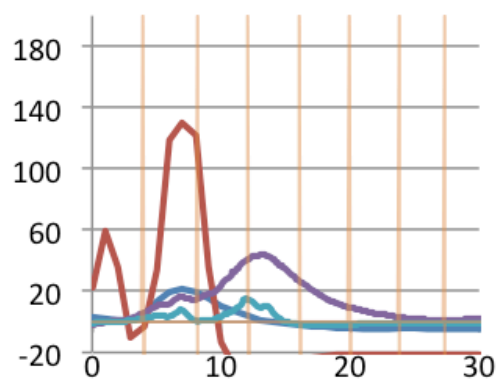

Load Case $\mathrm{H} 2$

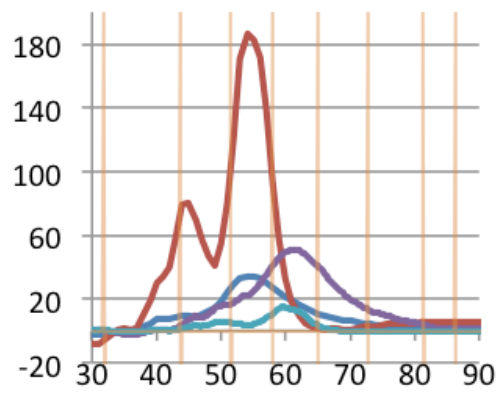

Time (s)
Load Case E3

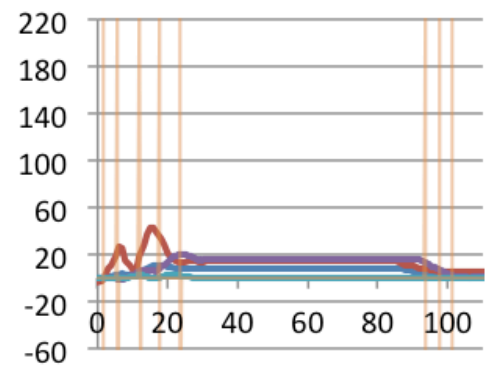

Load Case F3

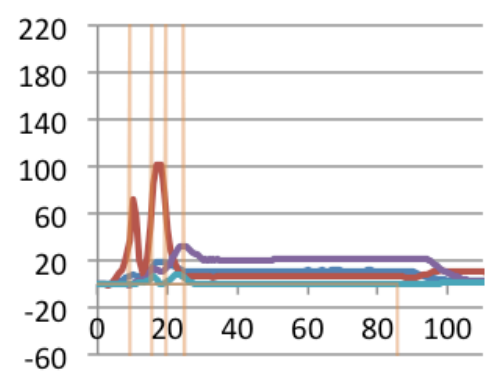

Load Case G3

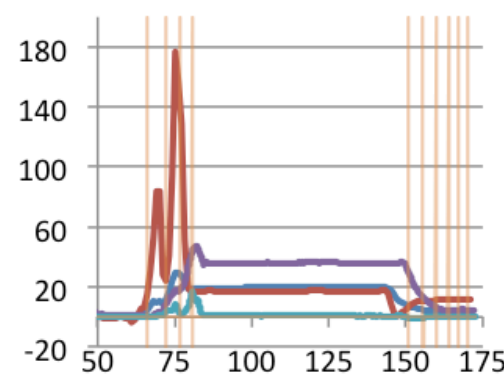

Load Case H3

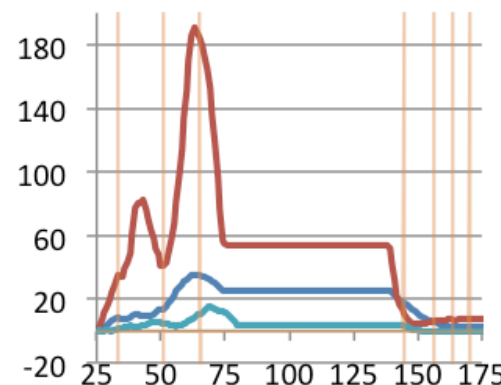

Time (s)

Figure 50: Girder 7 Quarter-span Strains Plotted Against Time 

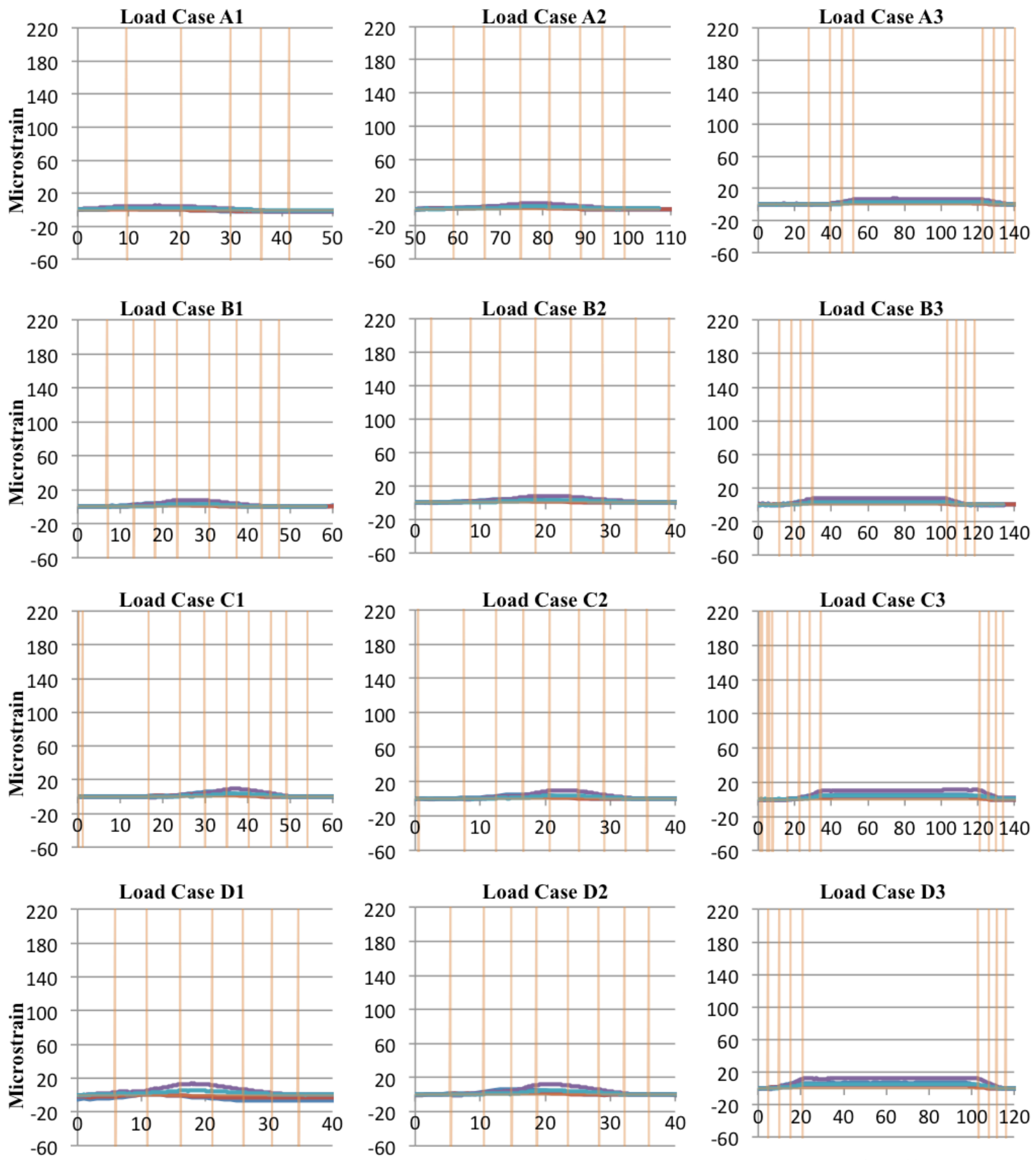

Time (s)

Time (s)

Time (s)

VWG - T - VWG - CB

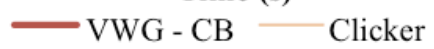

EXT - B Fl —EXT - U Web 

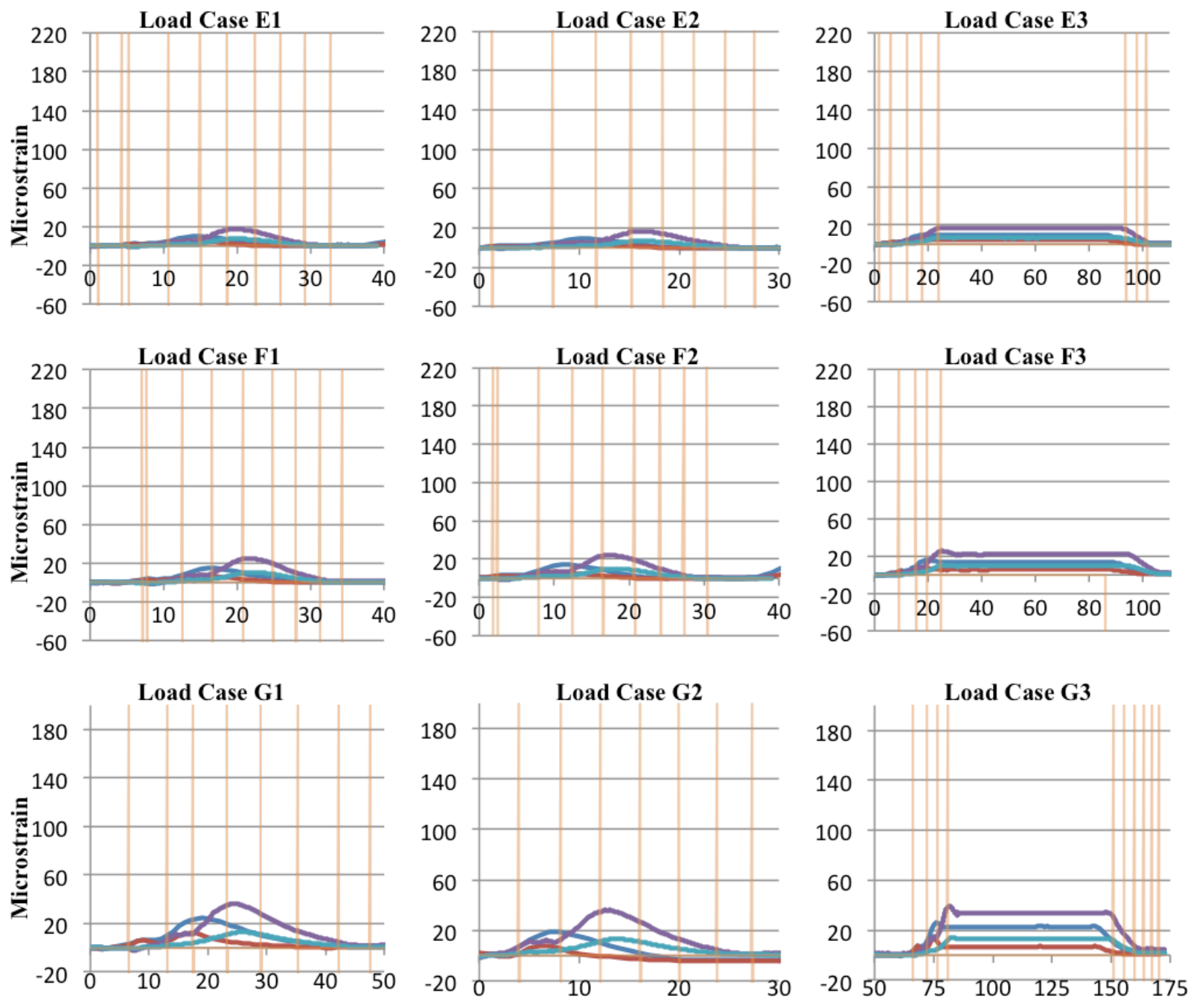

Load Case H1
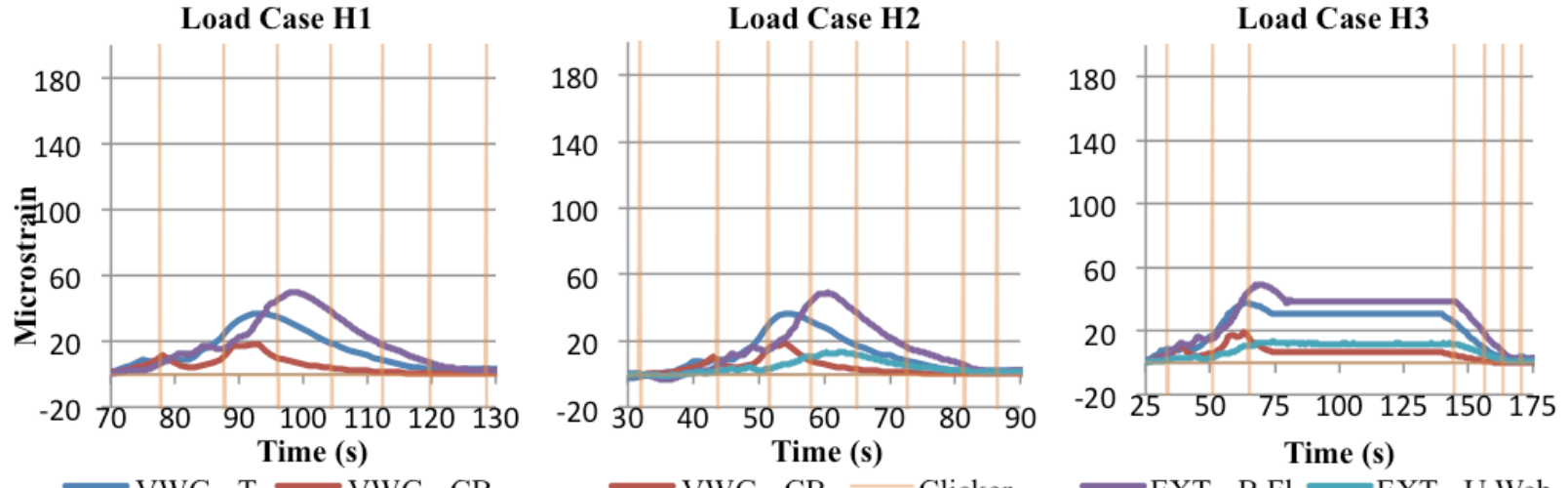

Figure 51: Girder 8 Quarter-span Strains Plotted Against Time 


\section{APPENDIX C: Barrier Strains}

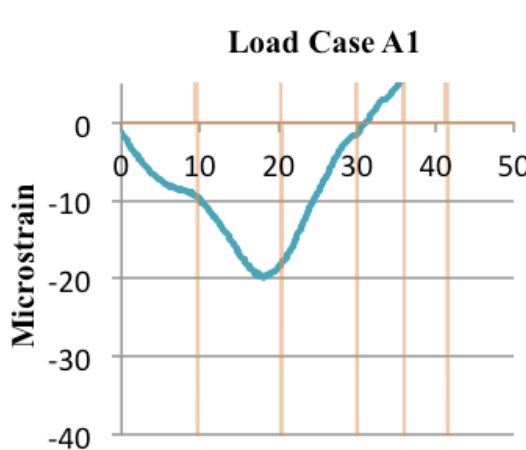

Load Case B1

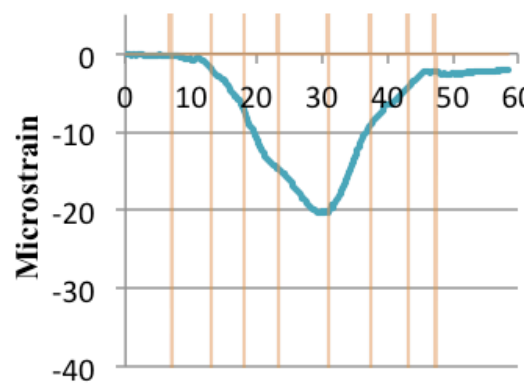

Load Case C1

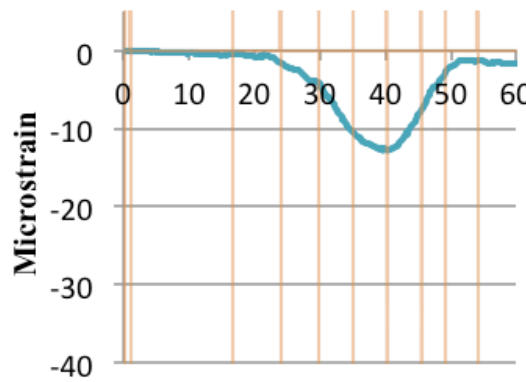

Load Case D1

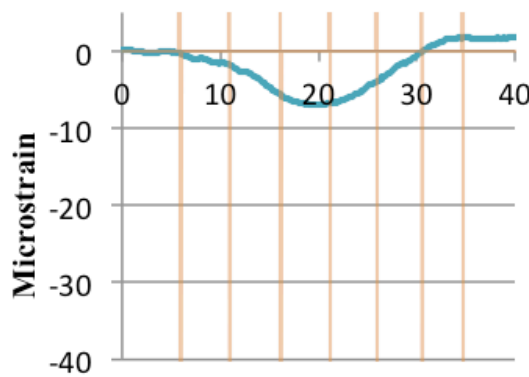

Time (s)
Load Case A2

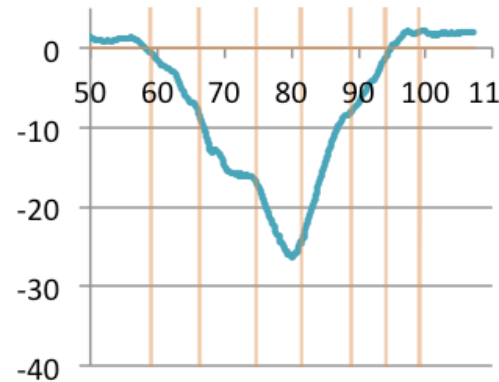

Load Case B2

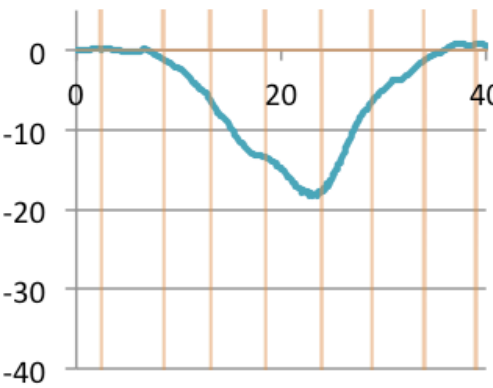

Load Case C2

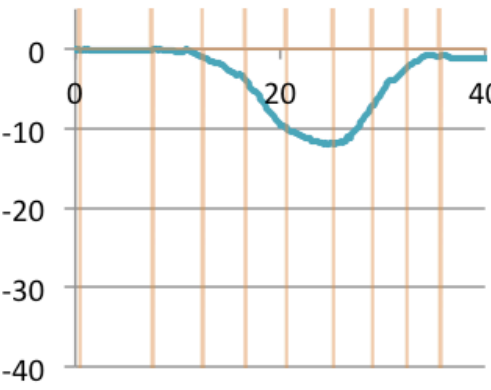

Load Case D2

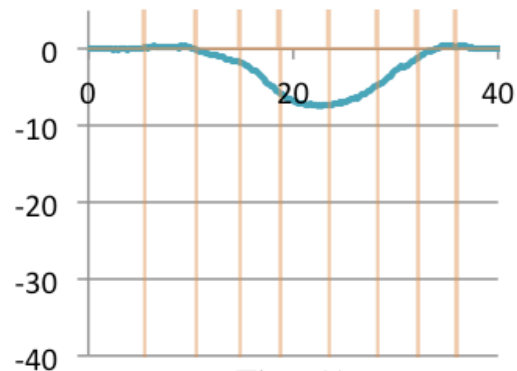

Time (s)
Load Case A3

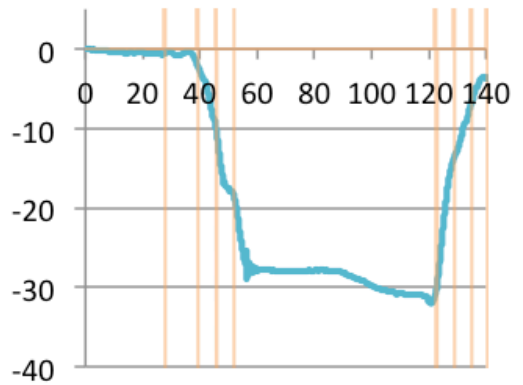

Load Case B3

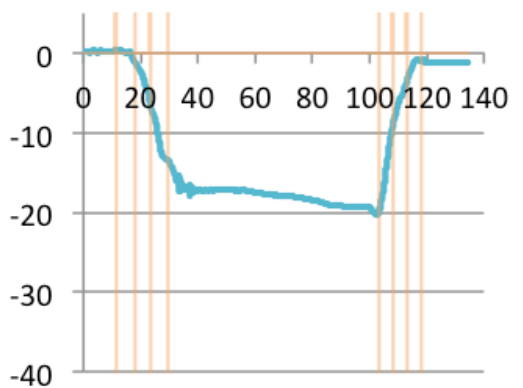

Load Case C3

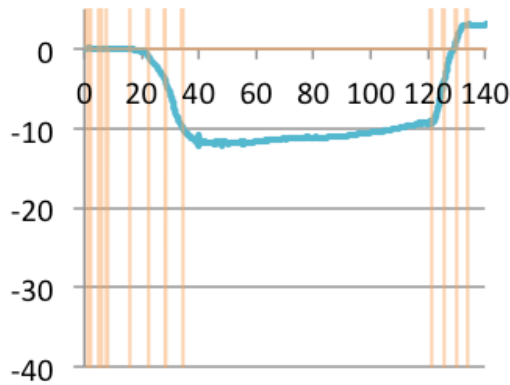

Load Case D3

Clicker 


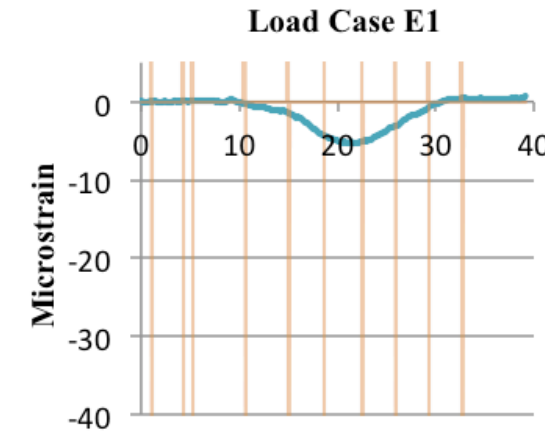

Load Case F1

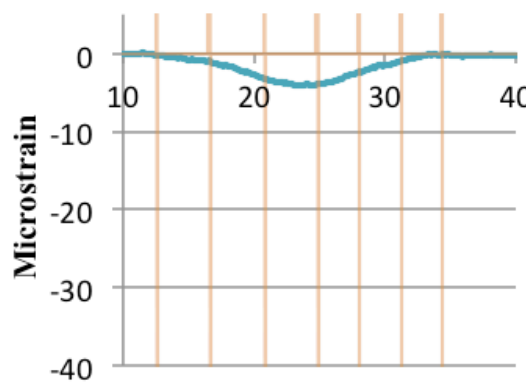

Load Case G1

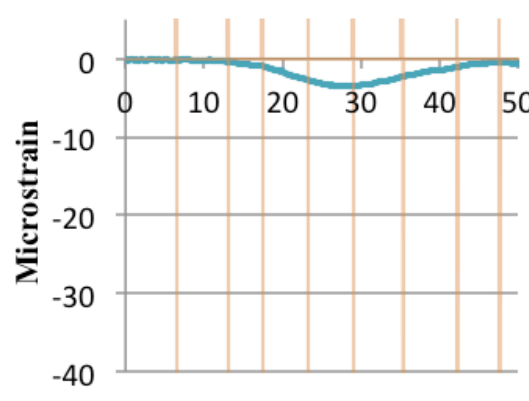

Load Case H1

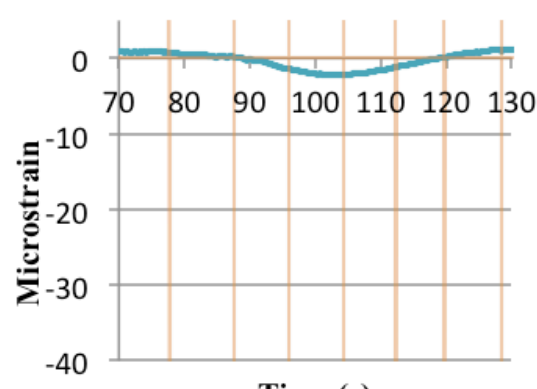

Time (s)
Load Case E2

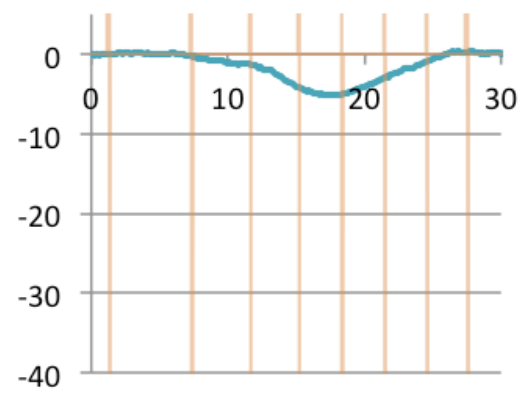

Load Case F2

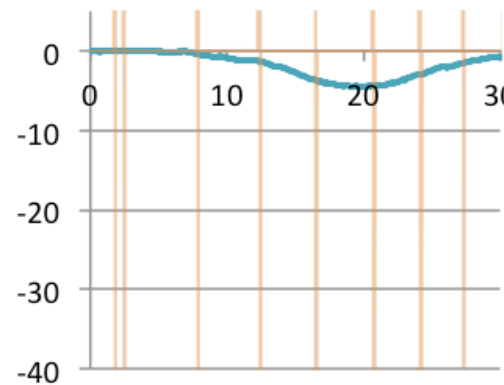

Load Case G2
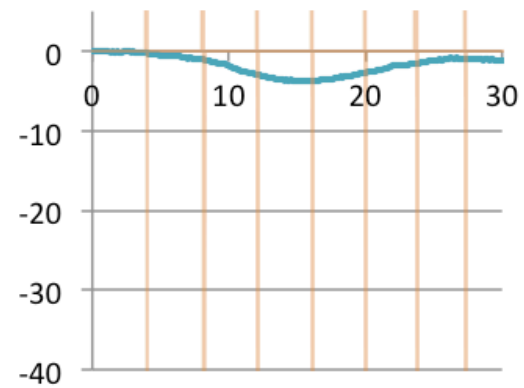

Load Case H2

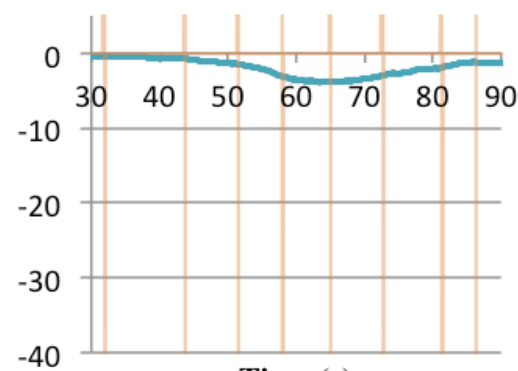

Time (s)
Load Case E3

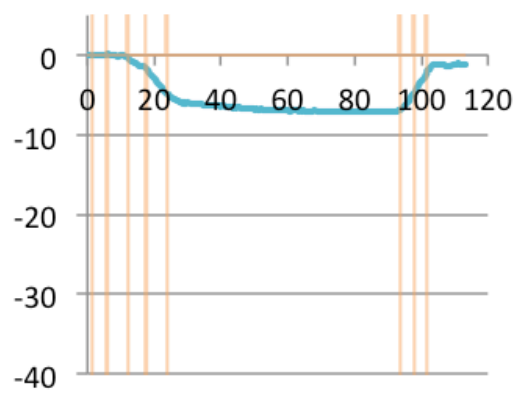

Load Case F3

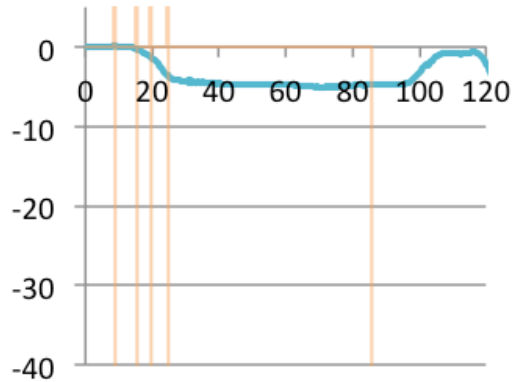

Load Case G3

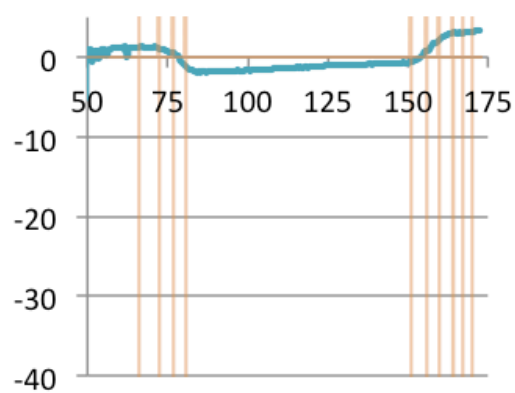

Load Case H3

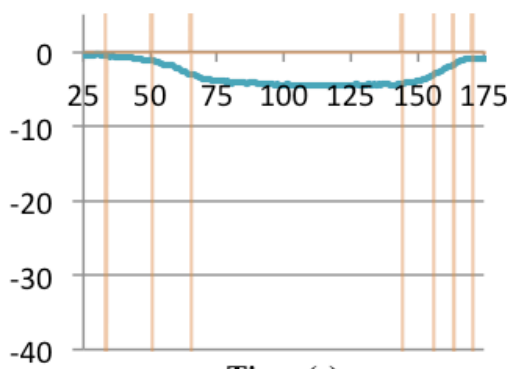

Time (s)

Clicker

Figure 52: North Barrier Strains (Maximum Influence on Girder 1) 


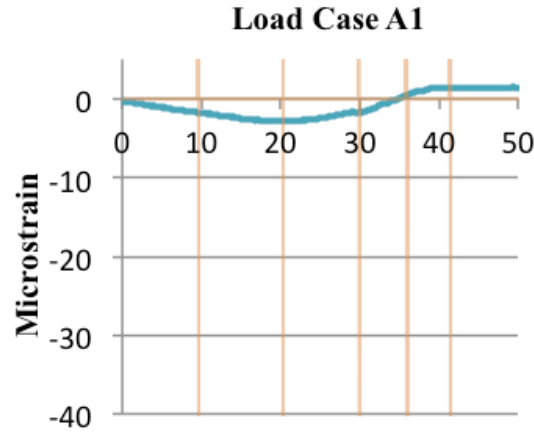

Load Case B1

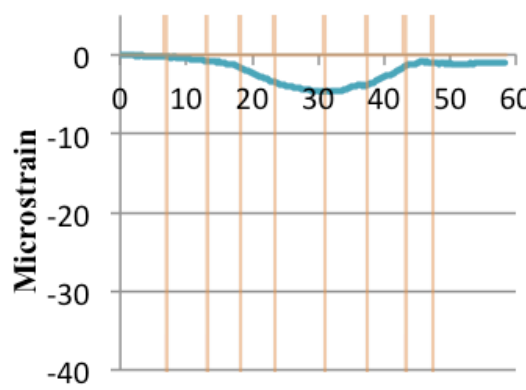

Load Case C1
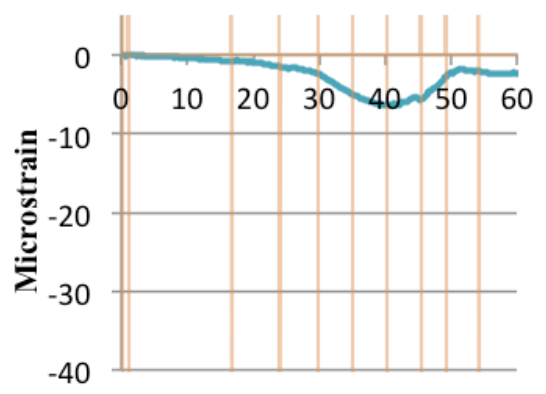

Load Case D1

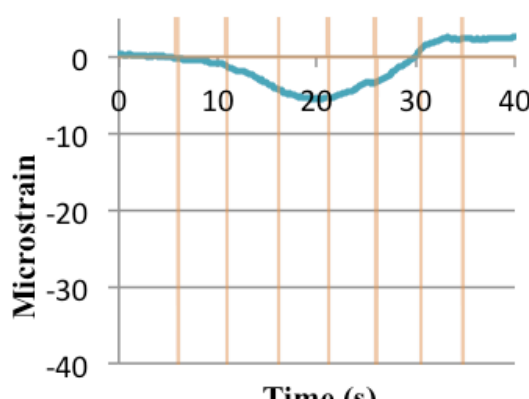

Time (s)
Load Case A2

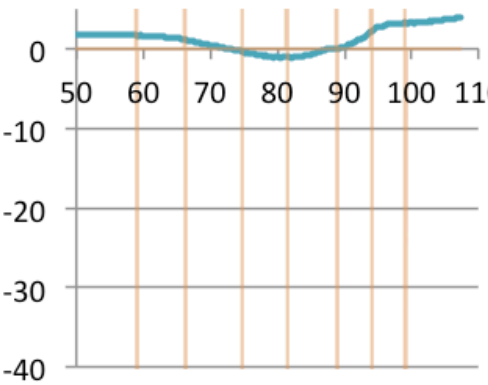

Load Case B2

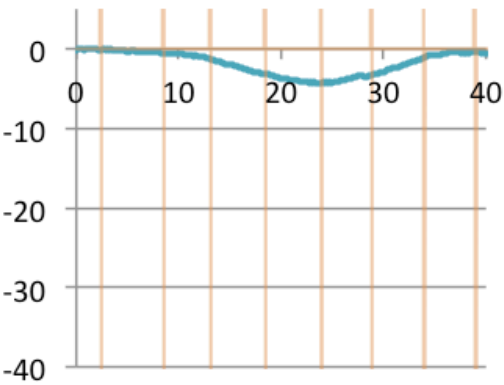

Load Case C2

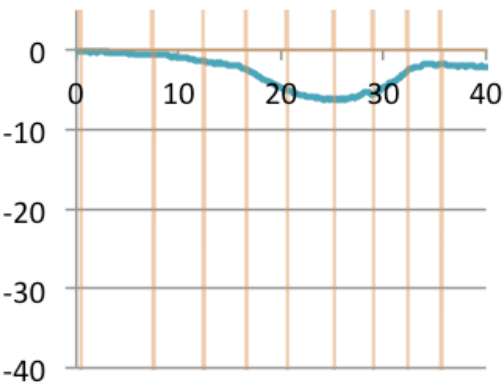

Load Case D2

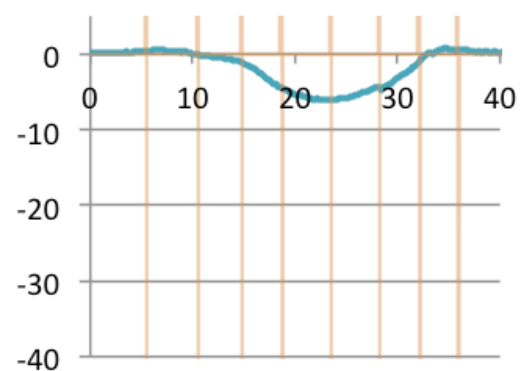

Time (s)

Clicker
Load Case A3

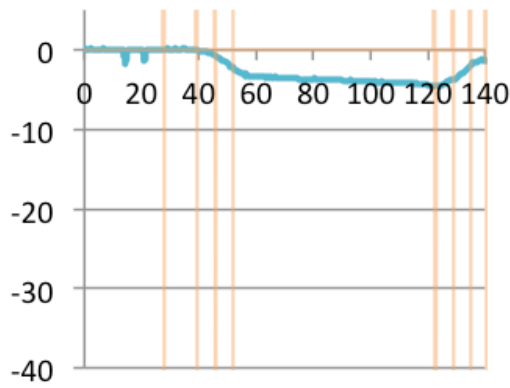

Load Case B3

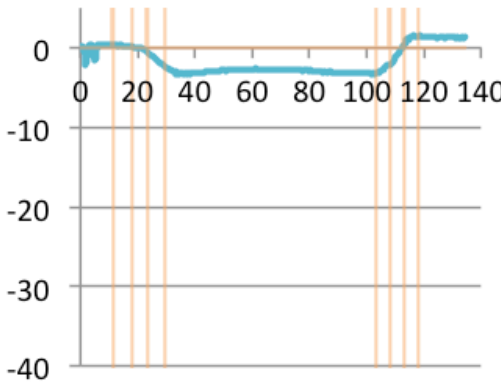

Load Case C3

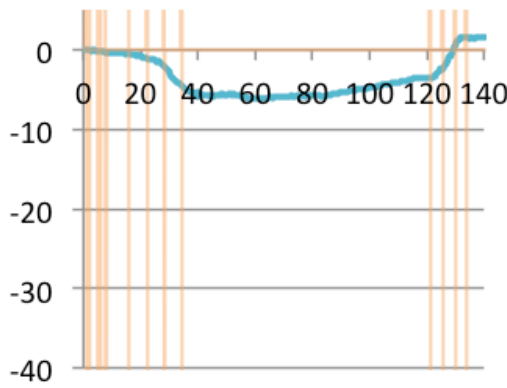

Load Case D3

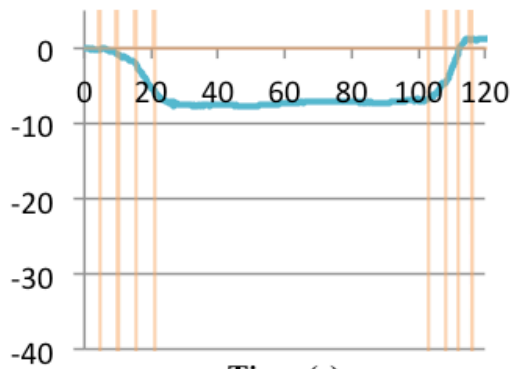

Time (s) 


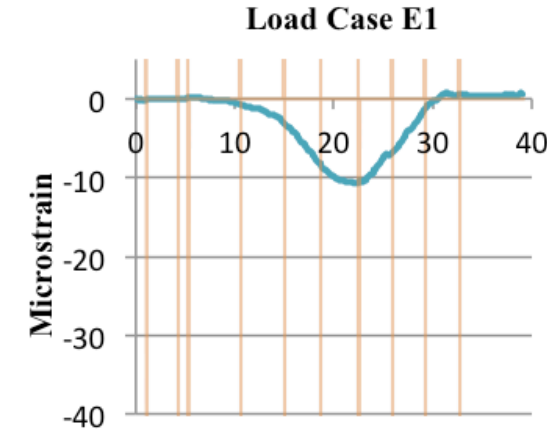

Load Case F1

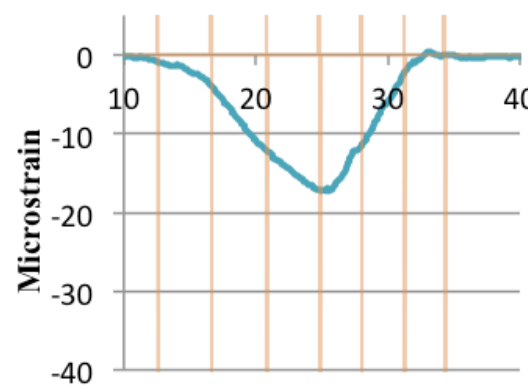

Load Case G1

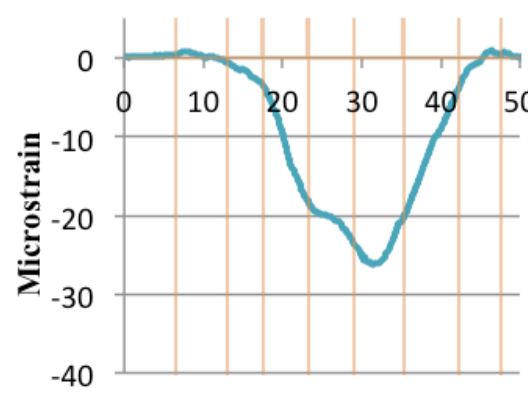

Load Case H1

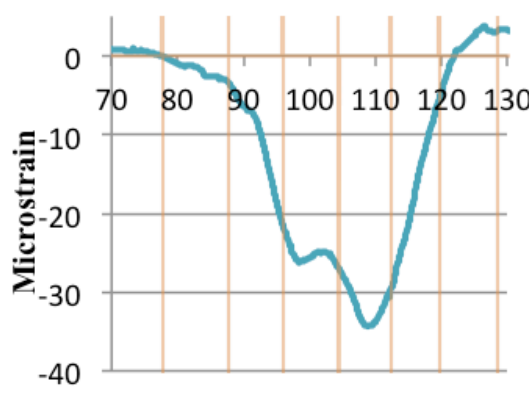

Load Case E2

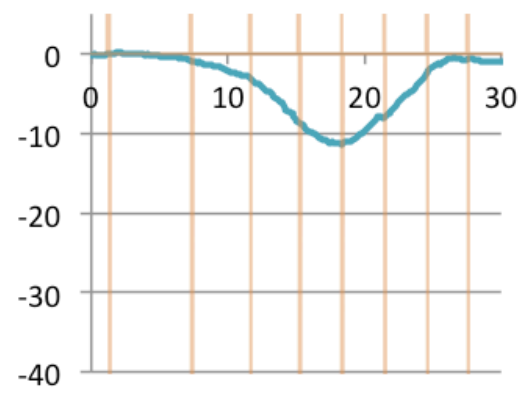

Load Case F2

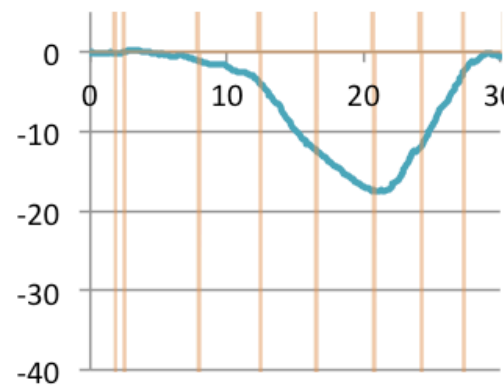

Load Case G2

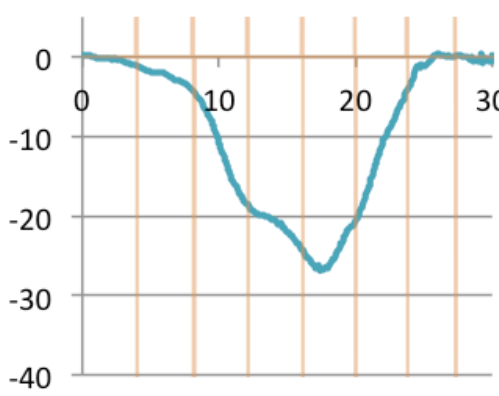

Load Case H2
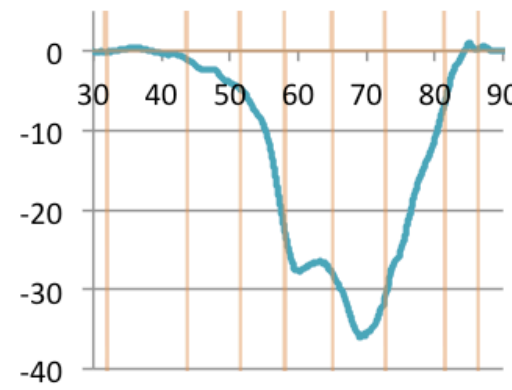

Load Case E3

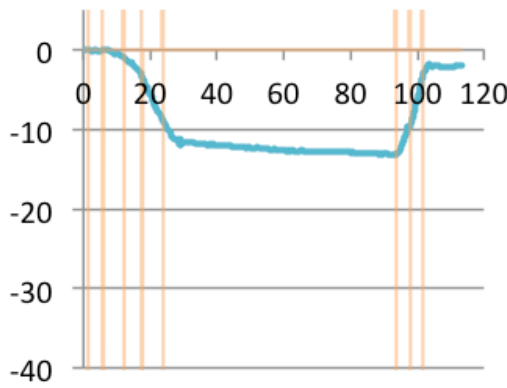

Load Case F3

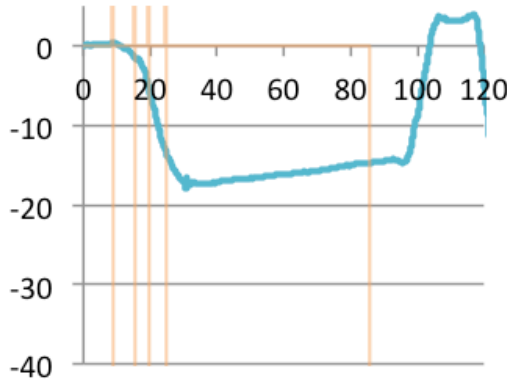

Load Case G3

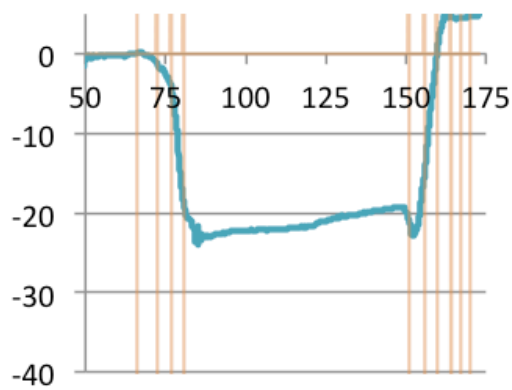

Load Case $\mathrm{H3}$

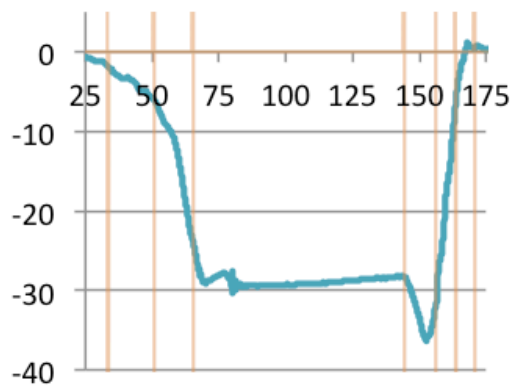

Figure 53: South Barrier Strains (Maximum Influence on Girder 8) 


\section{APPENDIX D: Mid-span Strain Profiles}
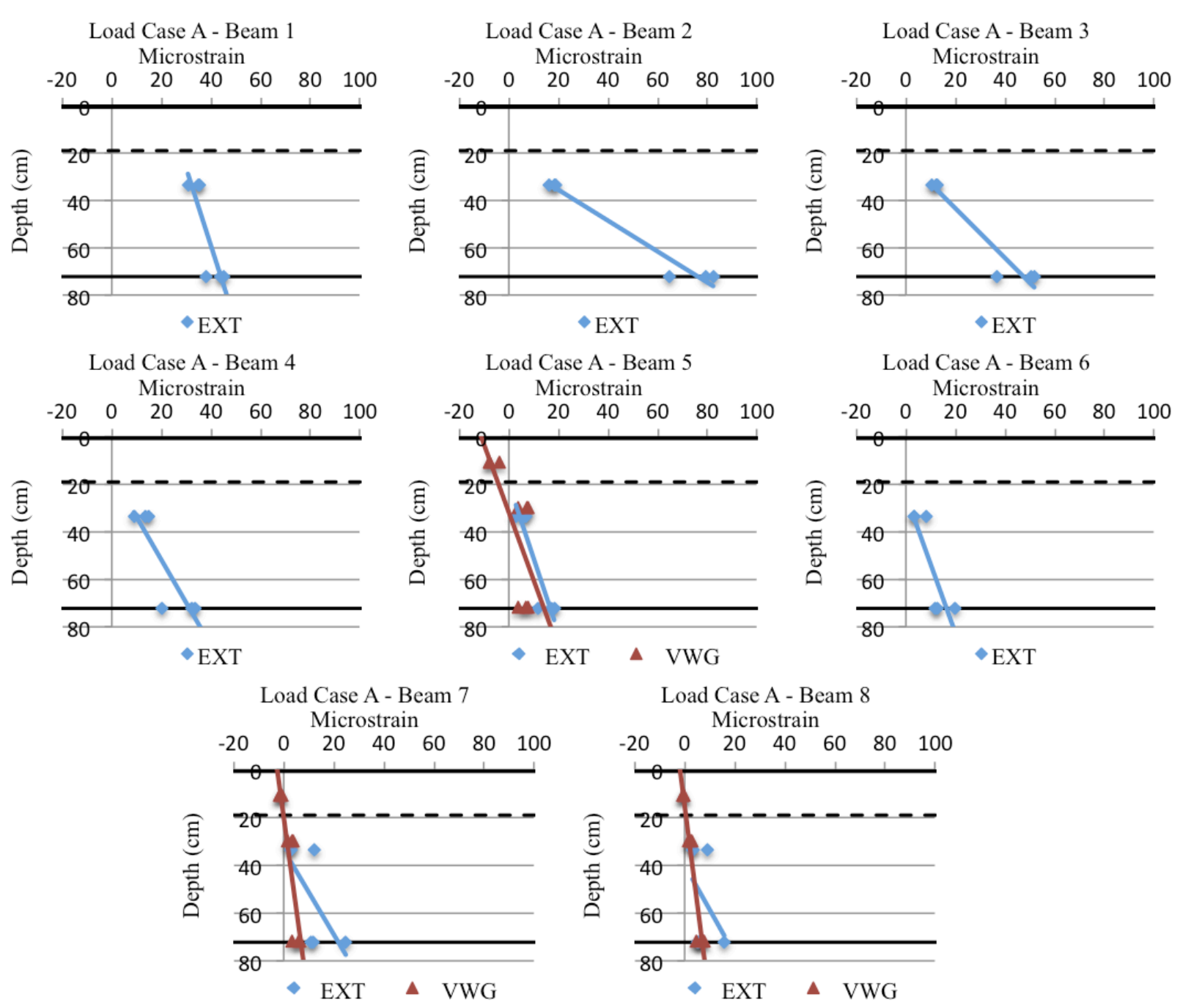

ad Case A - Beam 5

Microstrain
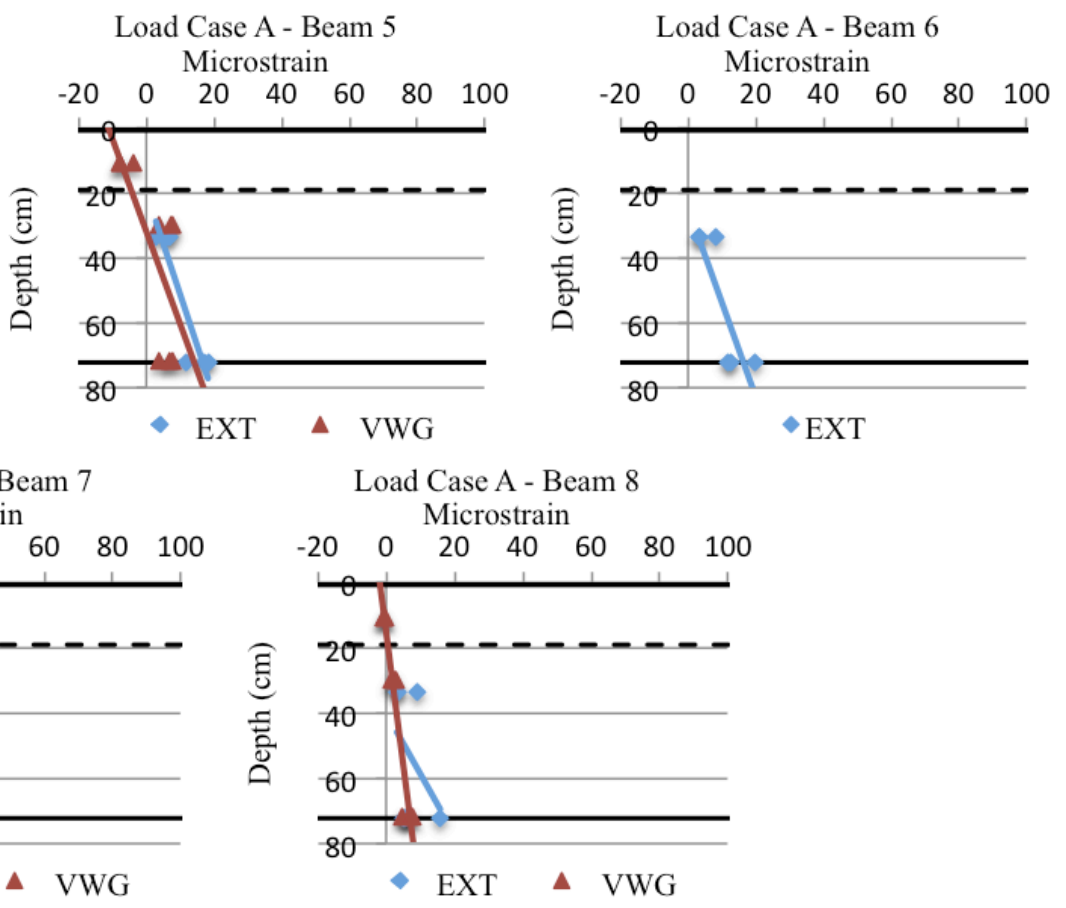

Figure 54: Load Case 'A' Mid-span Strain Profiles 


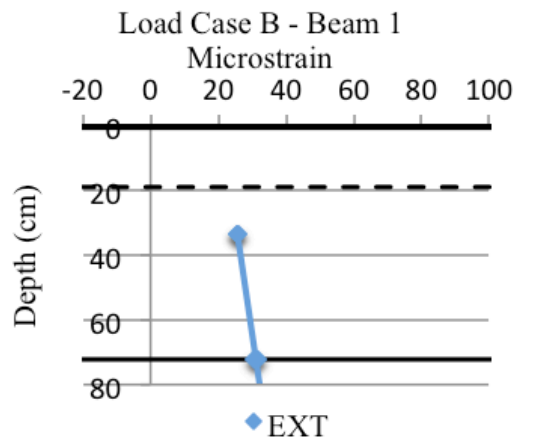

Load Case B - Beam 4

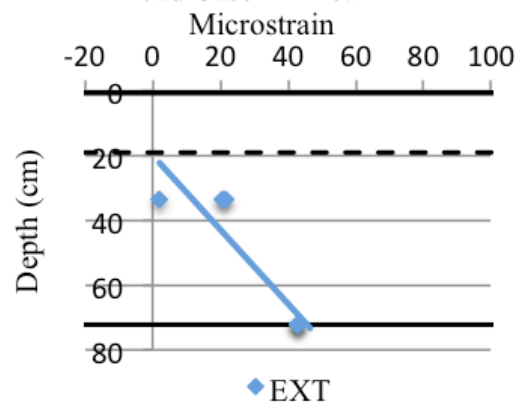

Load Case B - Beam 2

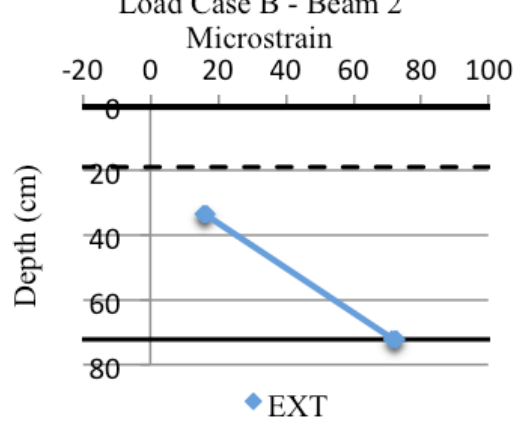

Load Case B - Beam 5

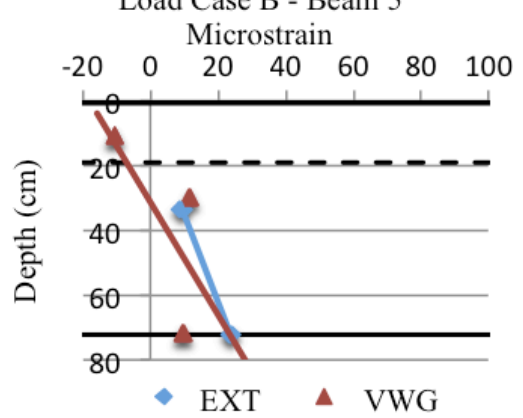

Load Case B - Beam 3

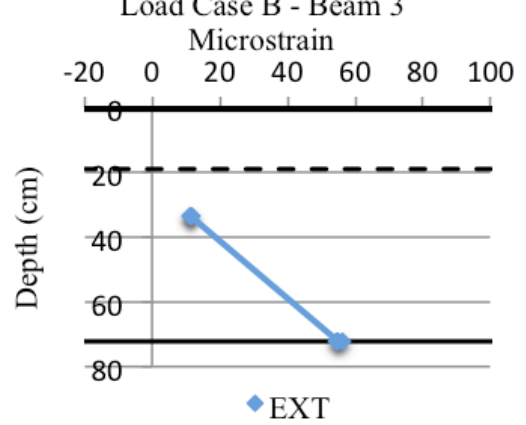

Load Case B - Beam 6

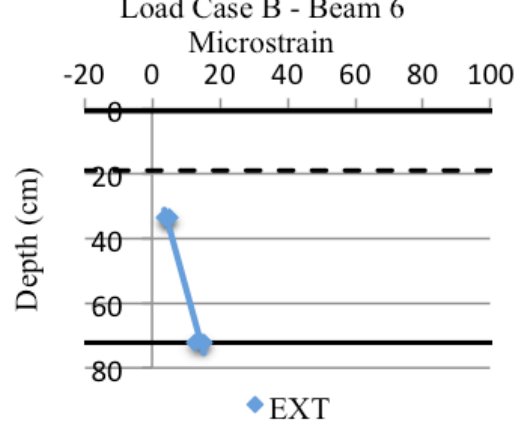

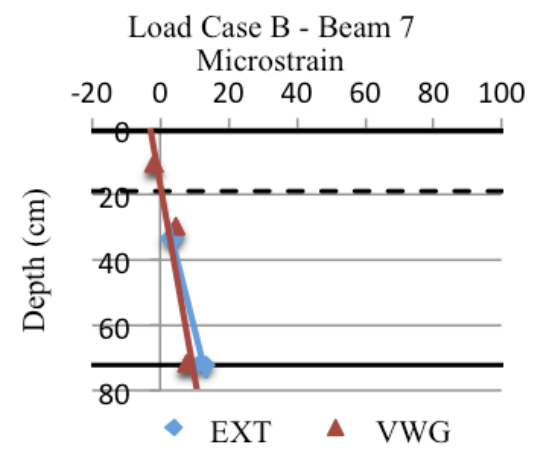

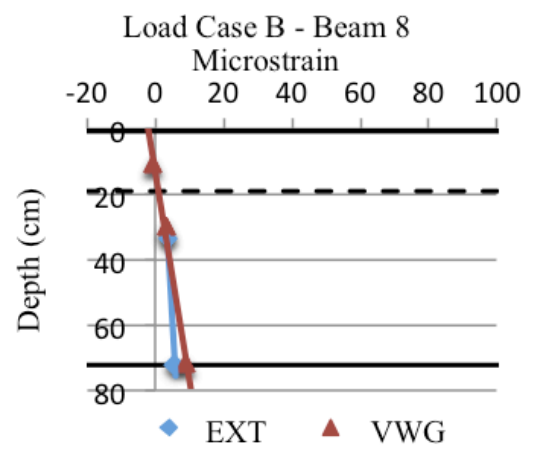

Figure 55: Load Case 'B' Mid-span Strain Profiles 


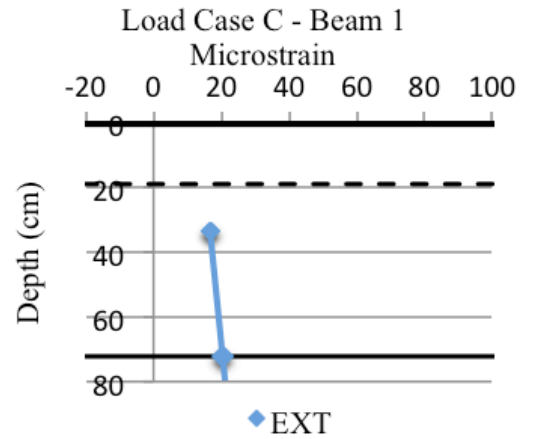

Load Case C - Beam 4

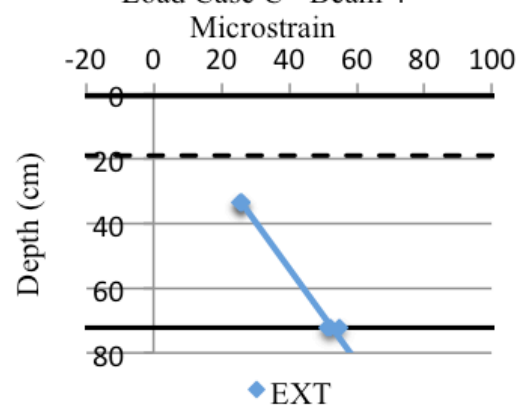

Load Case C - Beam 2

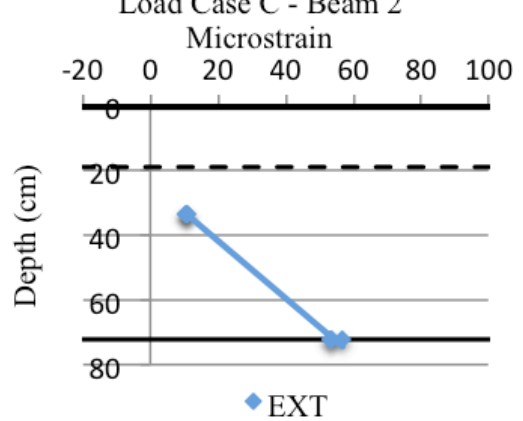

Load Case C - Beam 5

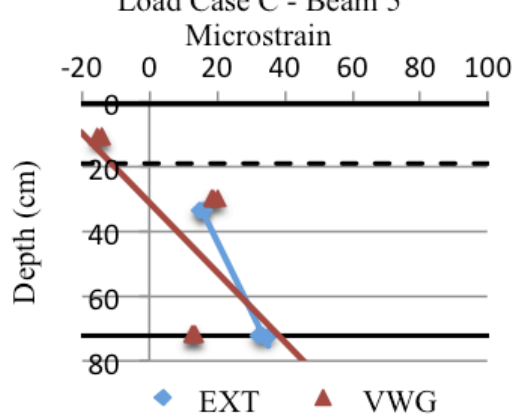

Load Case C - Beam 3

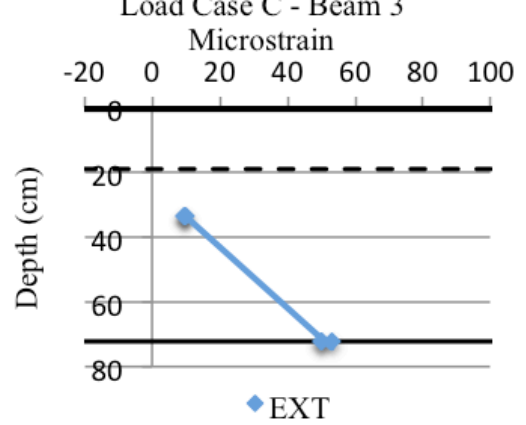

Load Case C - Beam 6

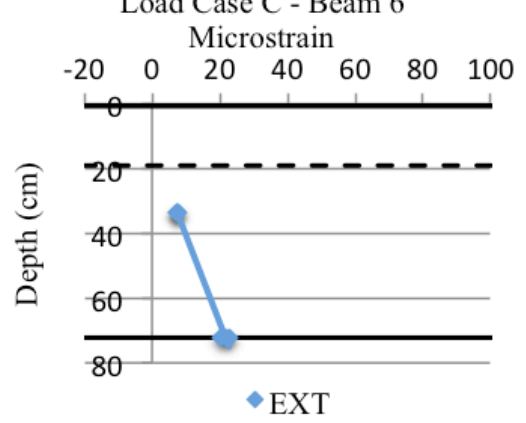

Load Case C - Beam 7

Load Case C - Beam 8
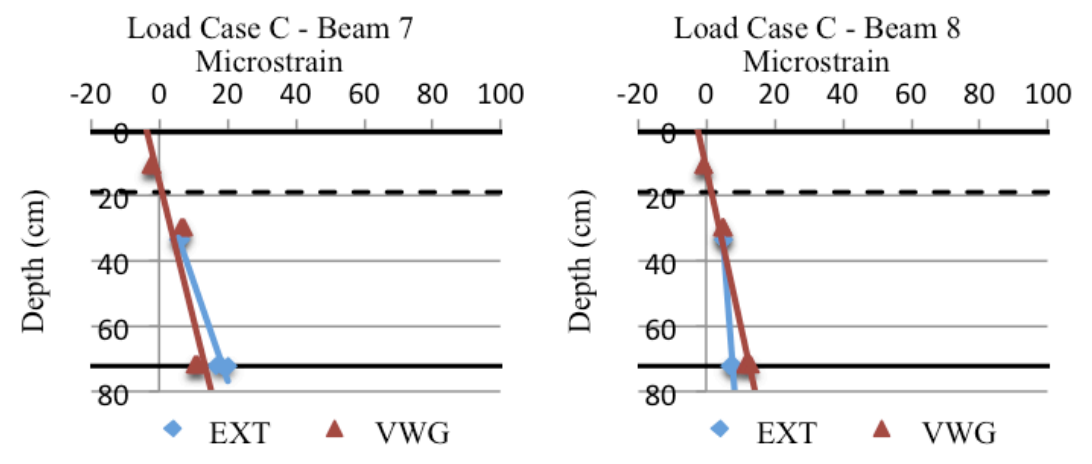

Figure 56: Load Case 'C' Mid-span Strain Profiles 


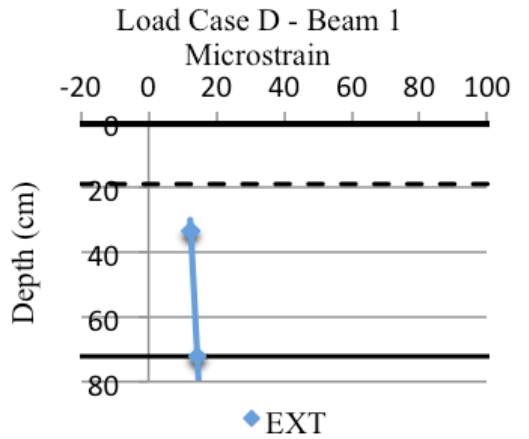

Load Case D - Beam 4

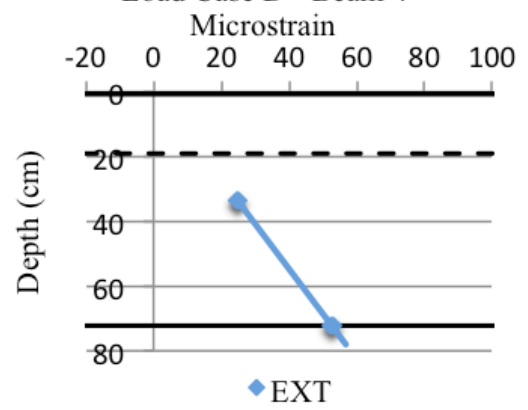

Load Case D - Beam 7 Microstrain

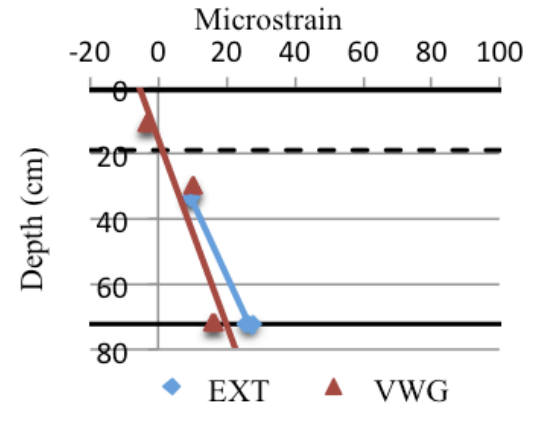

Load Case D - Beam 3

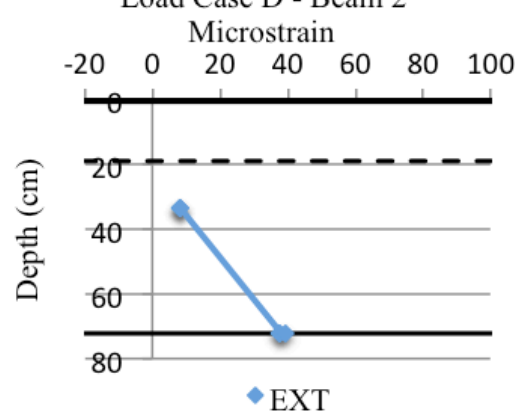

Load Case D - Beam 5

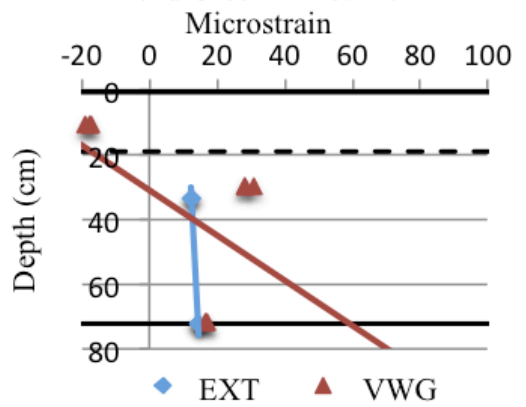
Microstrain

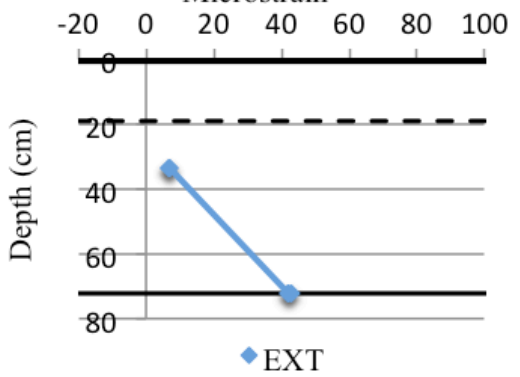

Load Case D - Beam 6

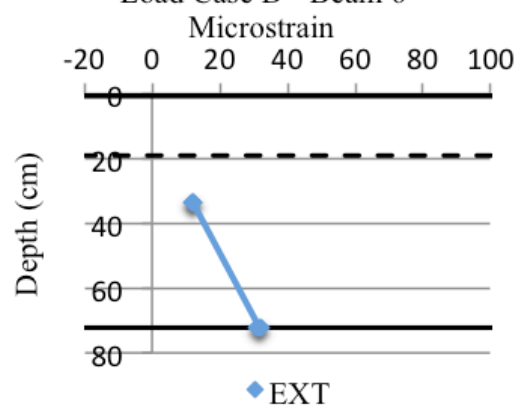

Figure 57: Load Case 'D’ Mid-span Strain Profiles 


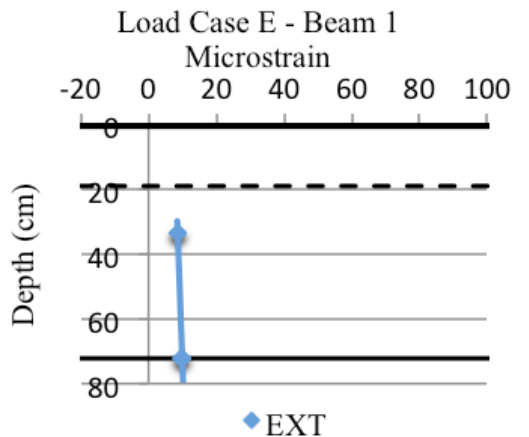

Load Case E - Beam 4

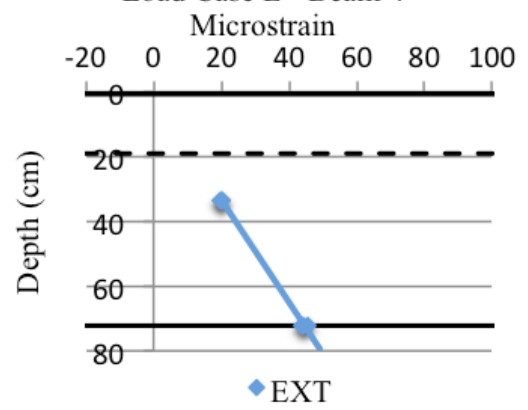

Load Case E - Beam 7 Microstrain

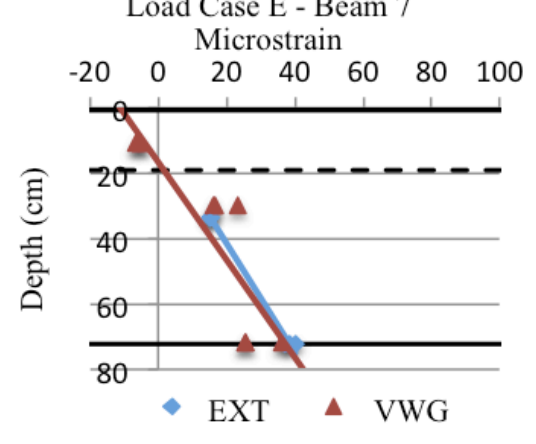

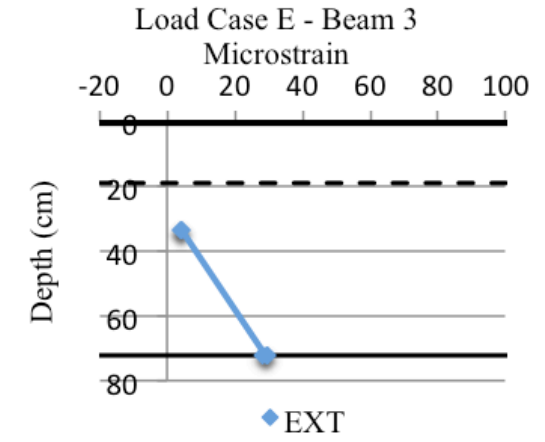

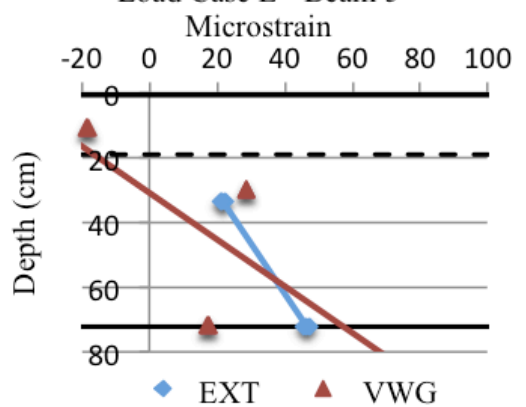

Load Case E - Beam 6

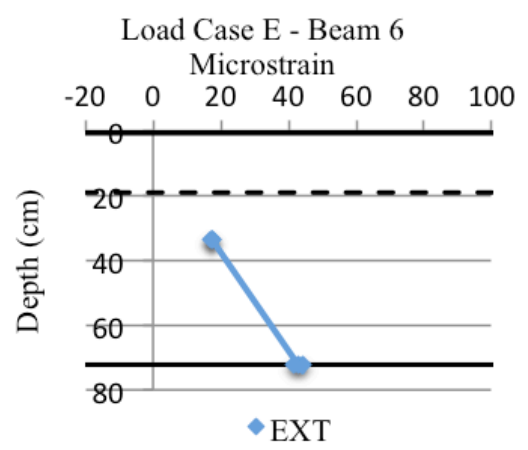

Figure 58: Load Case 'E' Mid-span Strain Profiles 


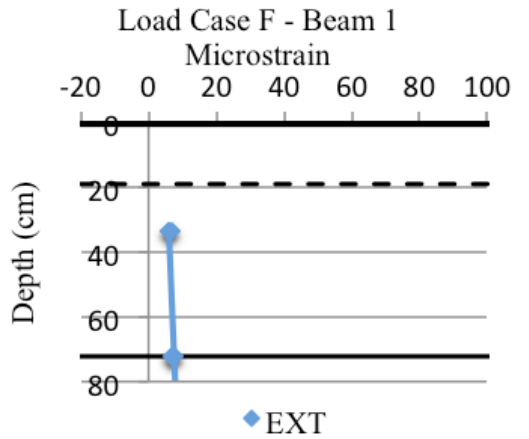

Load Case F - Beam 4

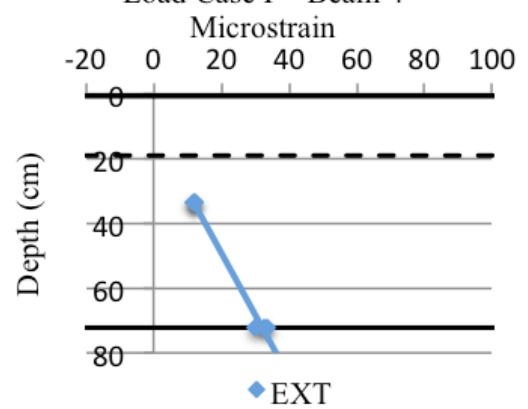

Load Case F - Beam 2

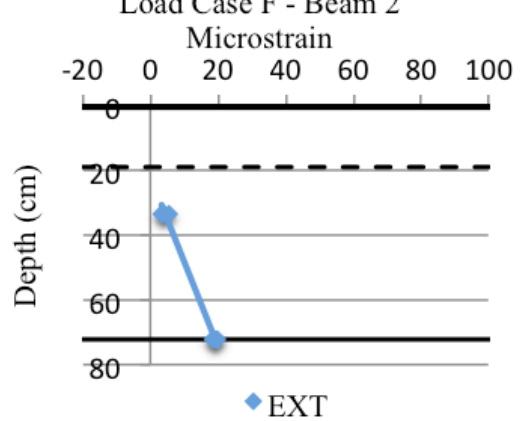

Load Case F - Beam 5

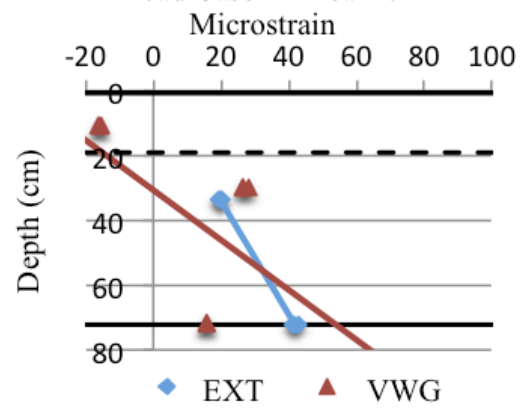

Load Case F - Beam 3

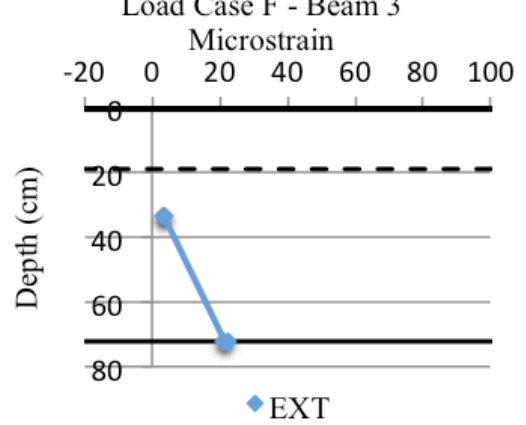

Load Case F - Beam 6

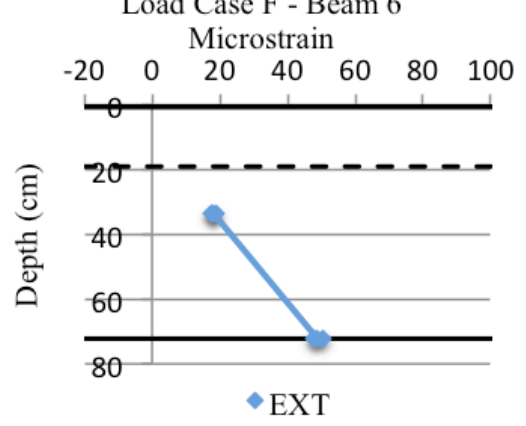

Load Case F - Beam 7 Microstrain
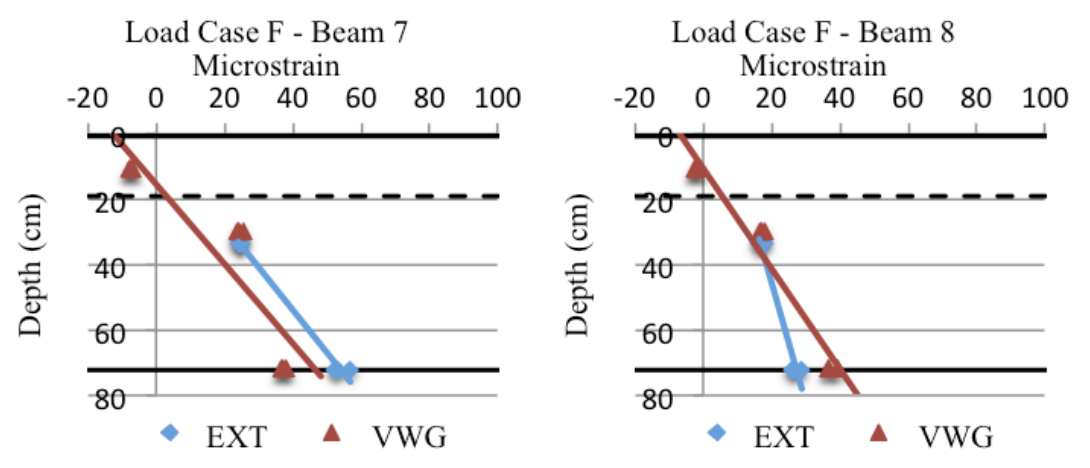

Figure 59: Load Case 'F' Mid-span Strain Profiles 

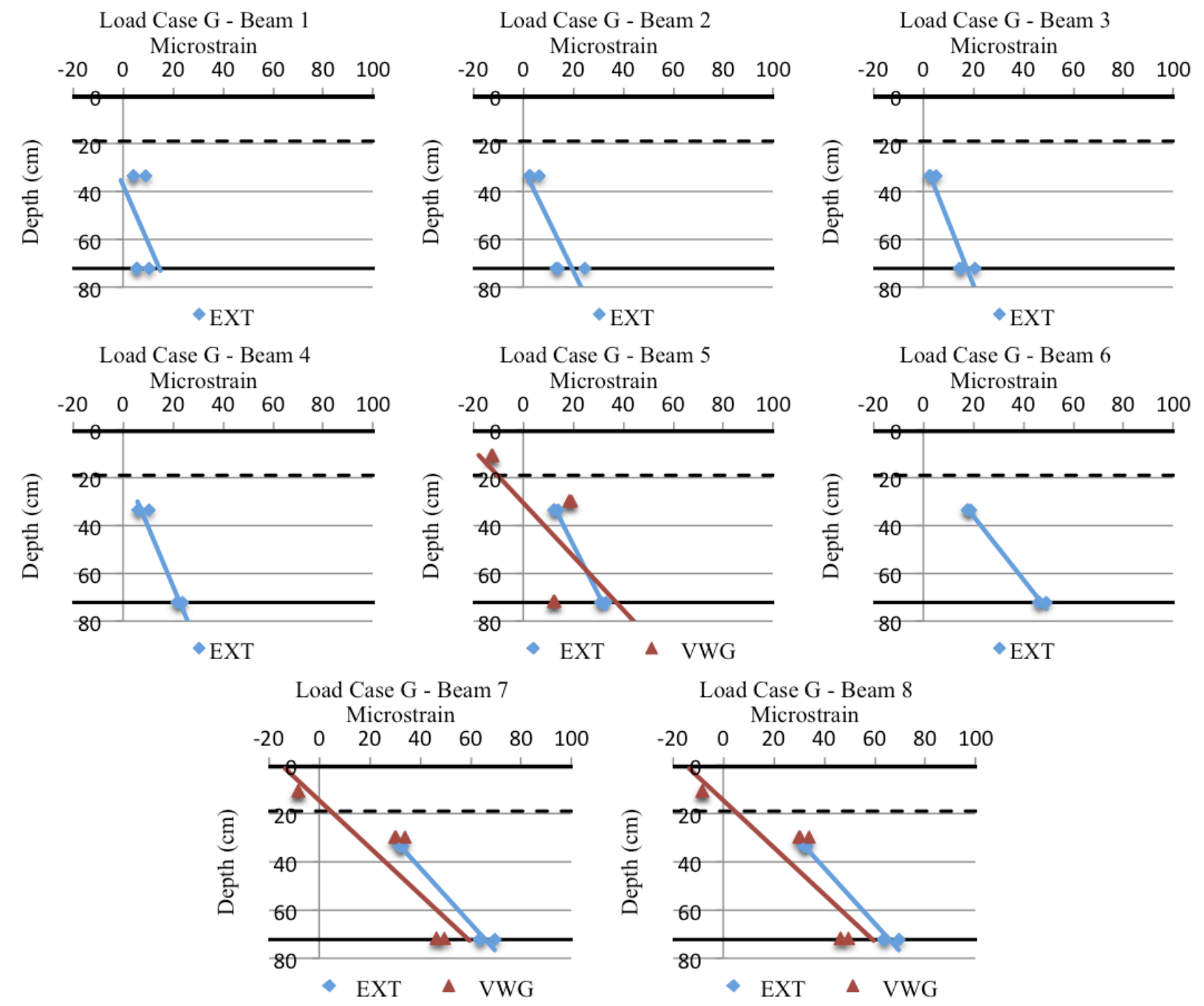

Figure 60: Load Case 'G' Mid-span Strain Profiles 


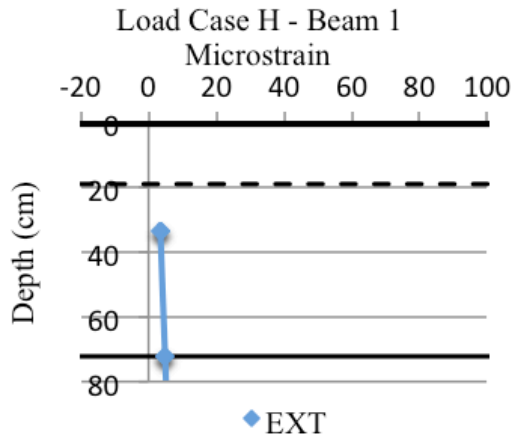

Load Case H - Beam 4

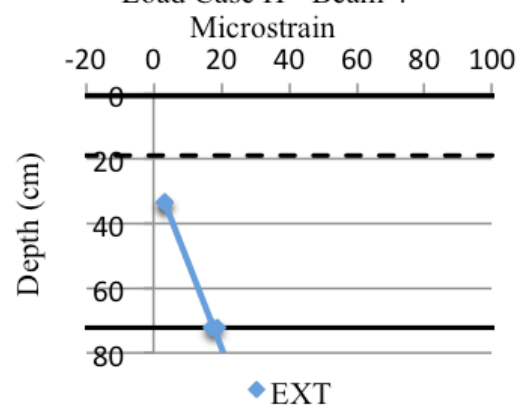

Load Case H - Beam 7 Microstrain

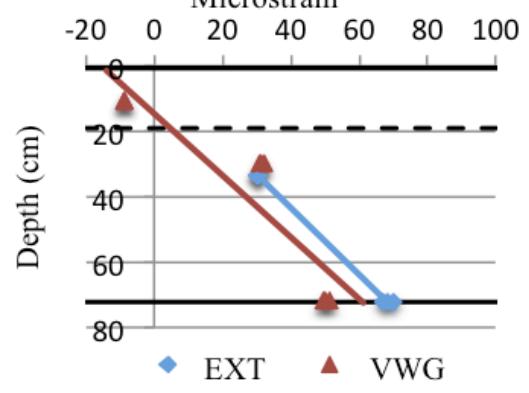

Load Case H - Beam 3
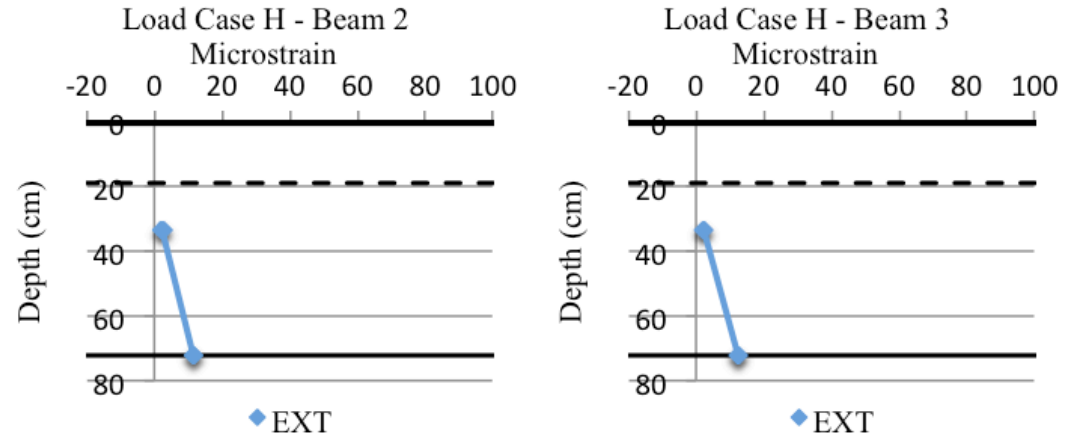

Load Case H - Beam 6
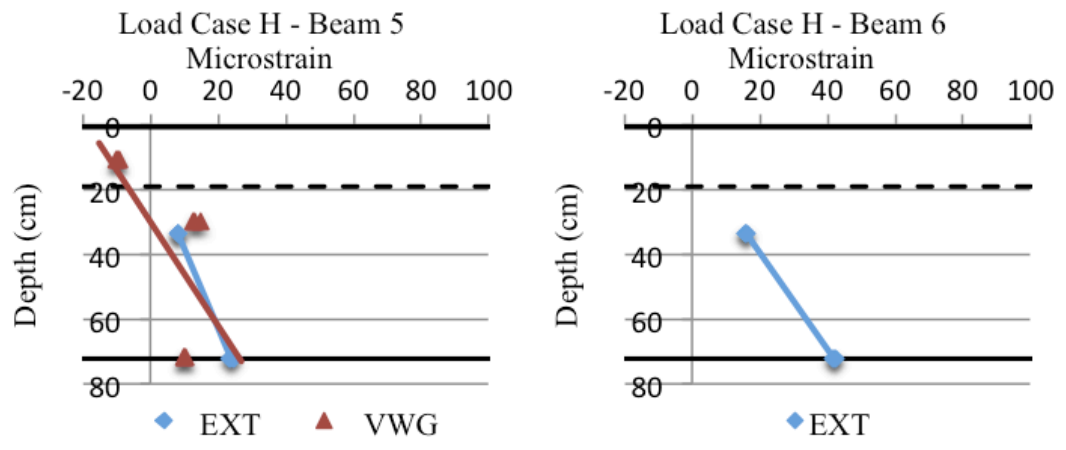

Load Case H - Beam 8

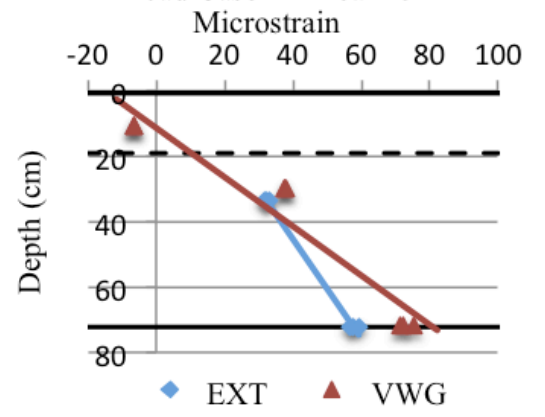

Figure 61: Load Case 'H' Mid-span Strain Profiles 


\section{APPENDIX E: Quarter-span Strain Profiles}

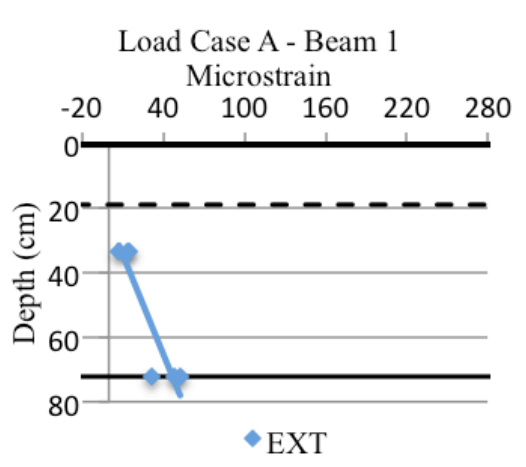

Load Case A - Beam 4

Microstrain

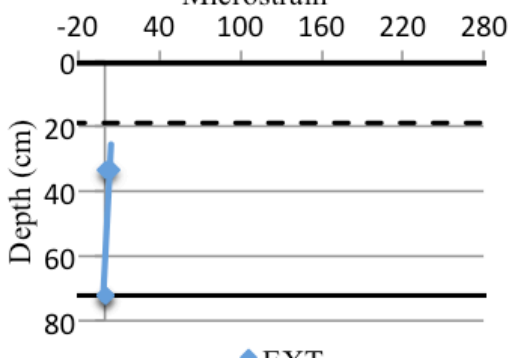

Load Case A - Beam 2

Microstrain

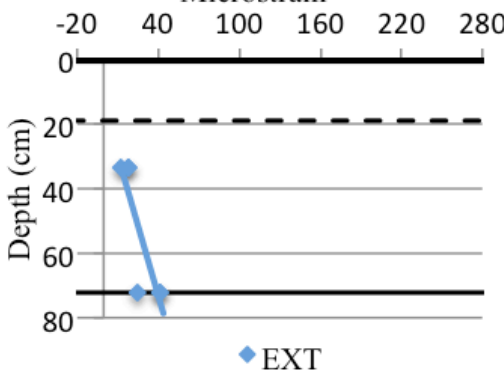

Load Case A - Beam 5

Microstrain

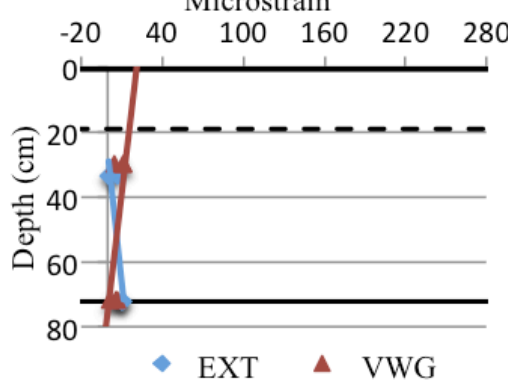

Load Case A - Beam 8

Load Case A - Beam 7

Microstrain

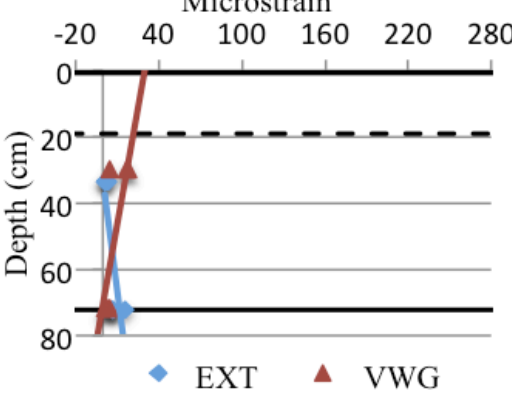

Figure 62: Load Case 'A' Quarter-span Strain Profiles
Load Case A - Beam 3

Microstrain

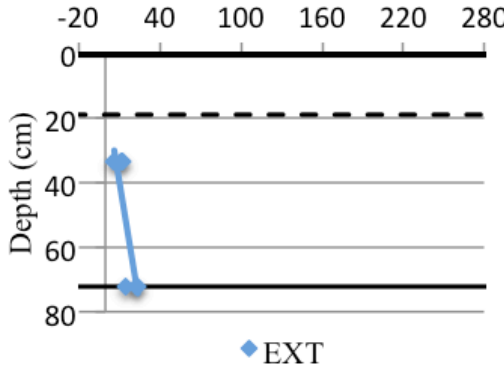

Load Case A - Beam 6

Microstrain

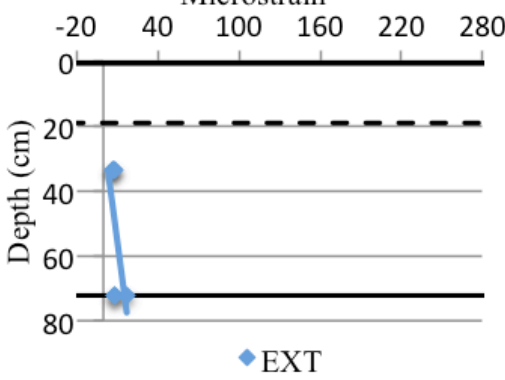

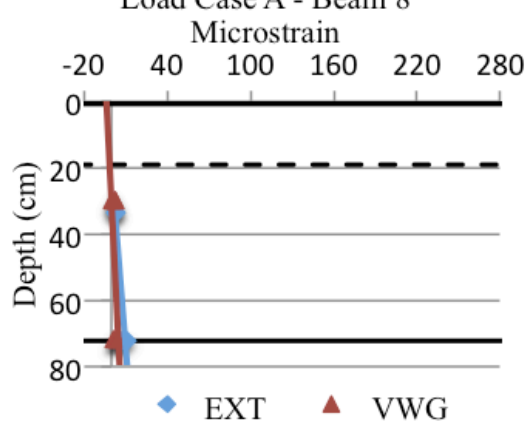




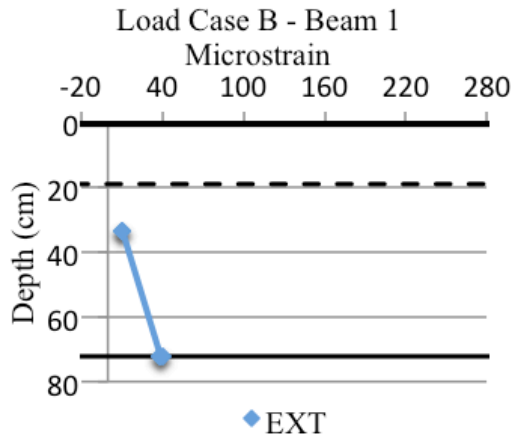

Load Case B - Beam 4

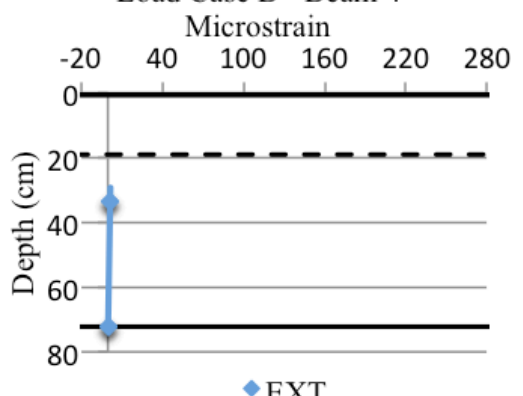

$\bullet$ EXT
Load Case B - Beam 2

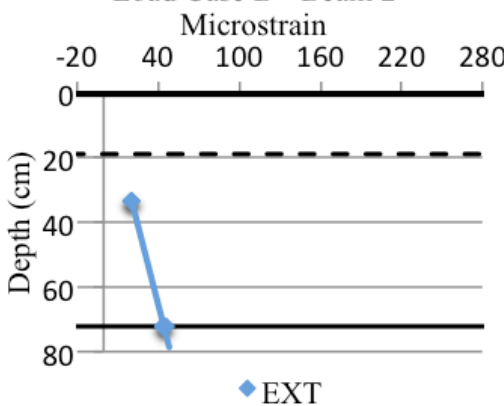

Load Case B - Beam 5

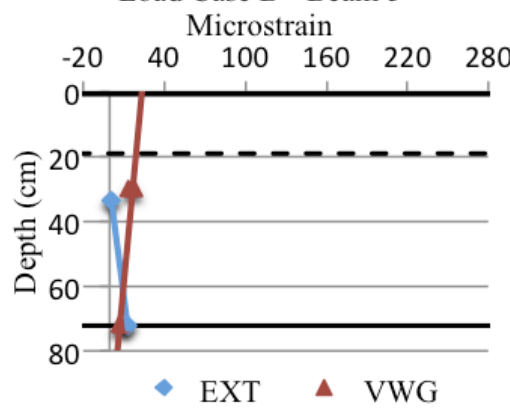

Load Case B - Beam 8

Load Case B - Beam 7

Microstrain
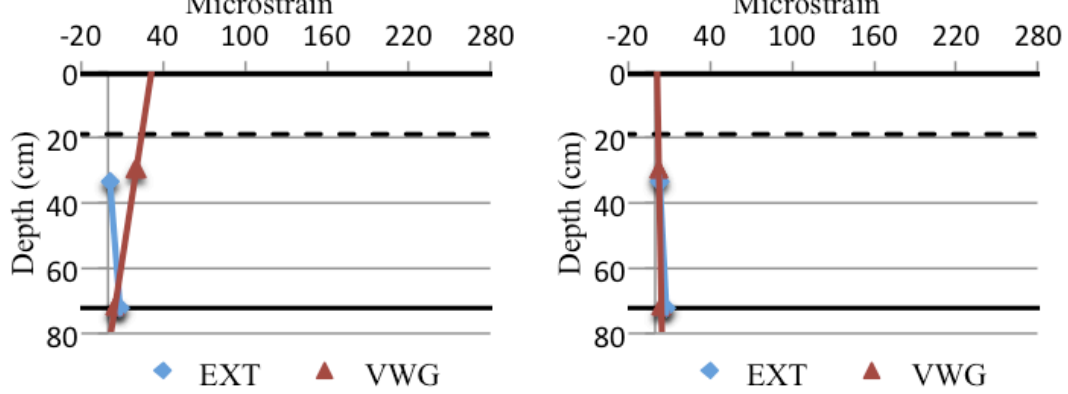

Figure 63: Load Case 'B' Quarter-span Strain Profiles 


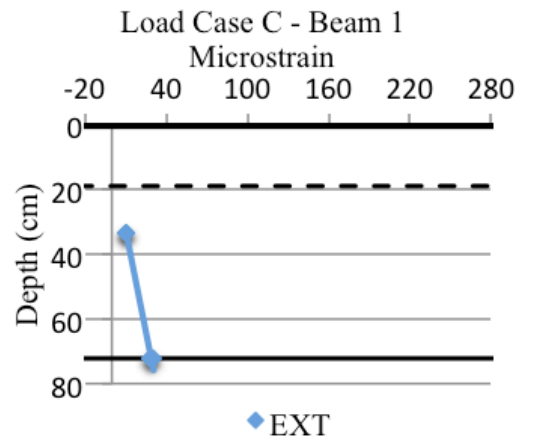

Load Case C - Beam 4

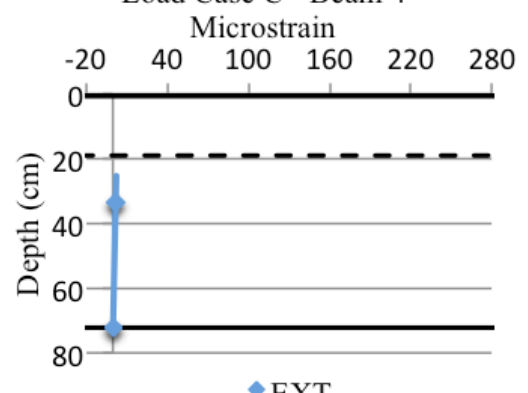

$\bullet$ EXT

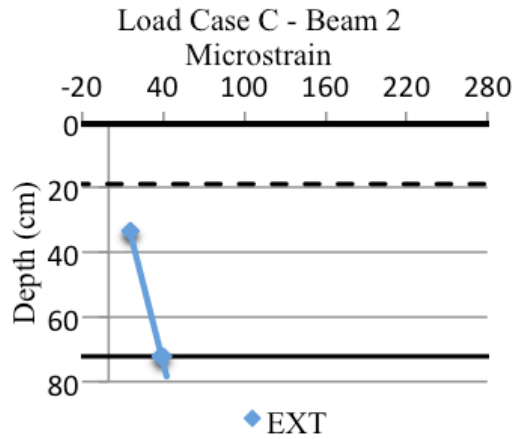

Load Case C - Beam 5

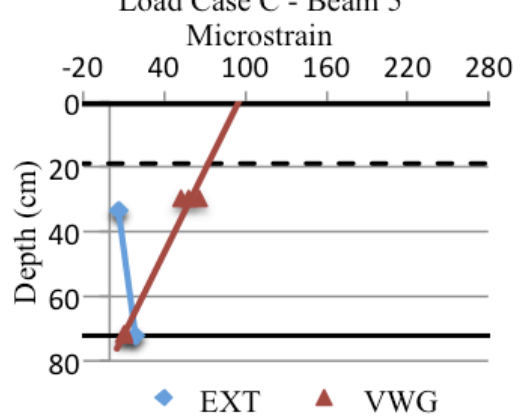

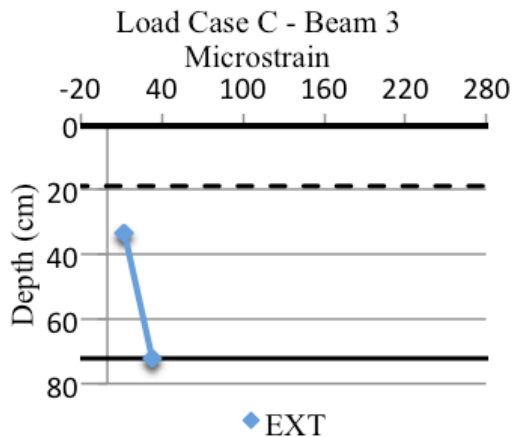

Load Case C - Beam 6

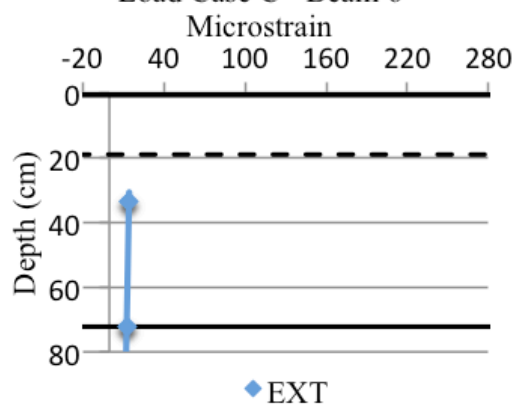

Load Case C - Beam 7

Microstrain

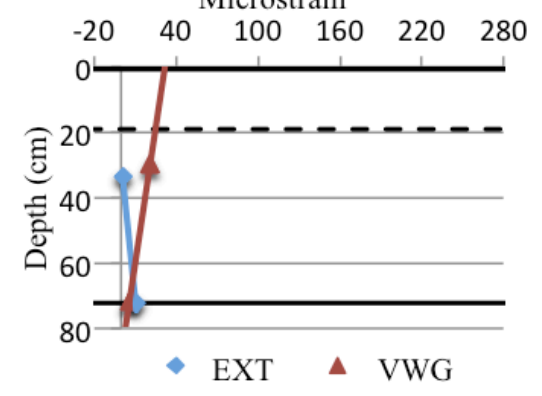

Load Case C - Beam 8

Microstrain

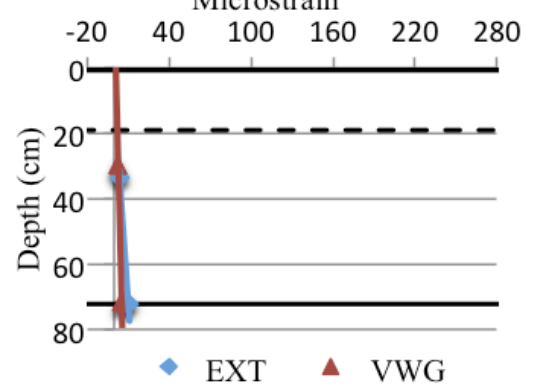

Figure 64: Load Case 'C' Quarter-span Strain Profiles 


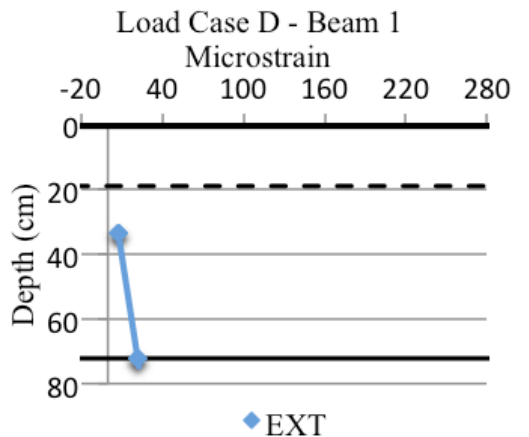

Load Case D - Beam 4

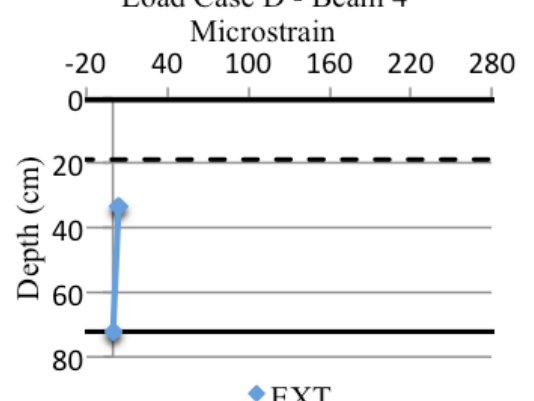

$\bullet$ EXT
Load Case D - Beam 2

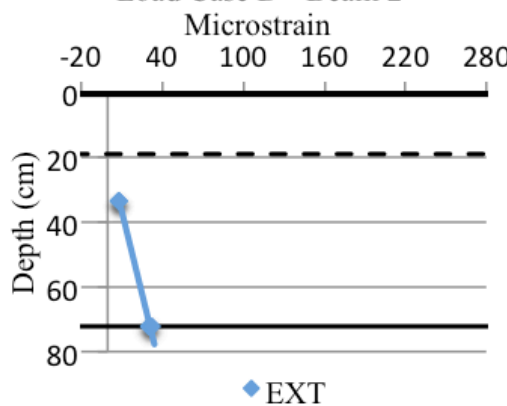

Load Case D - Beam 5

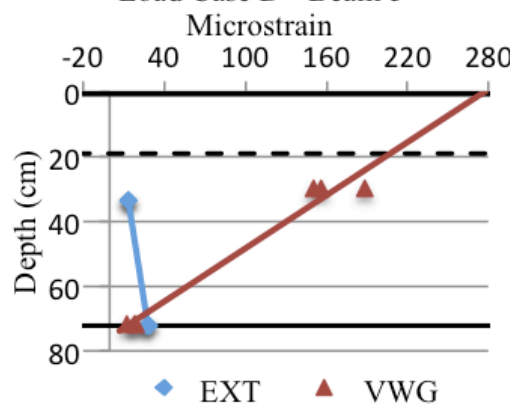

Load Case D - Beam 8

Microstrain
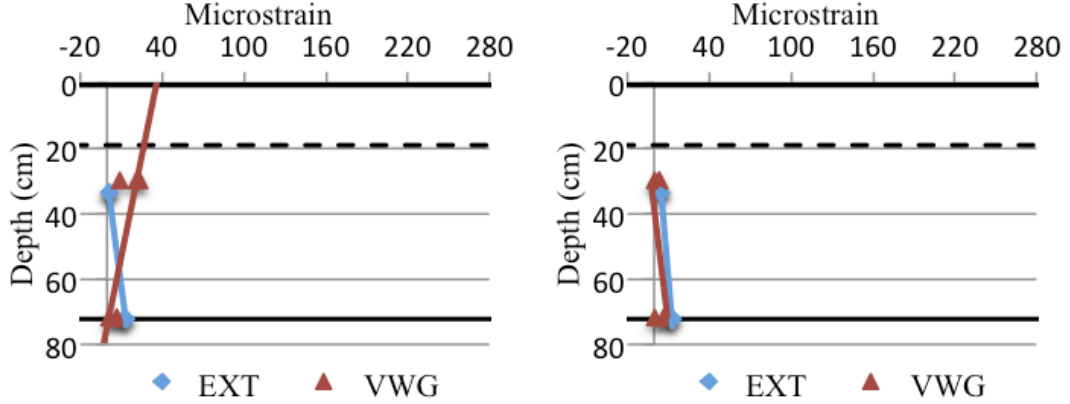

Load Case D - Beam 3

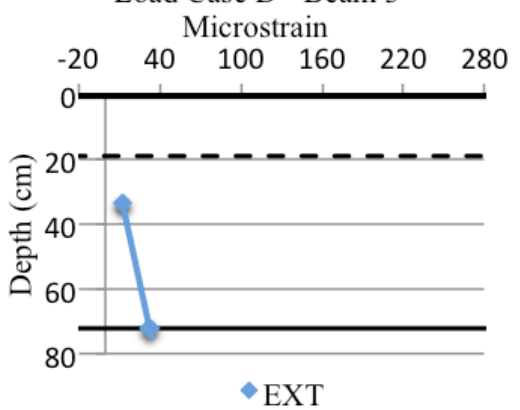

Load Case D - Beam 6

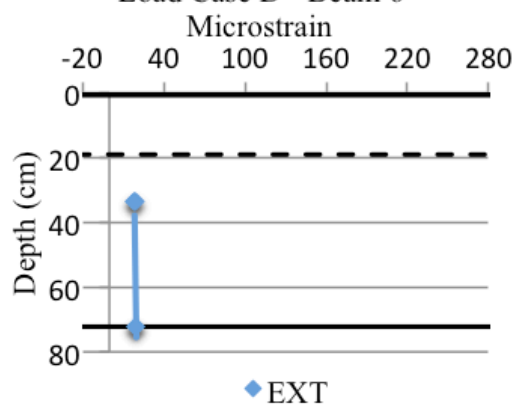

Figure 65: Load Case 'D’ Quarter-span Strain Profiles 


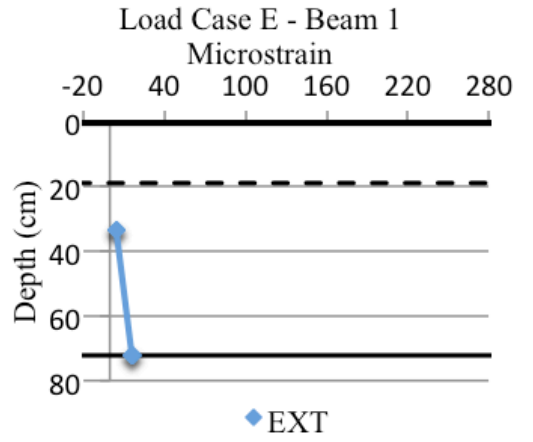

Load Case E - Beam 4

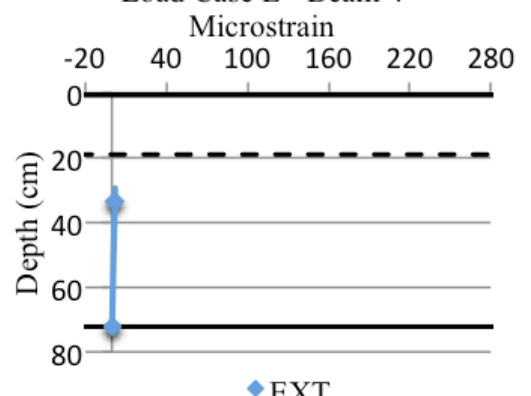

$\bullet$ EXT

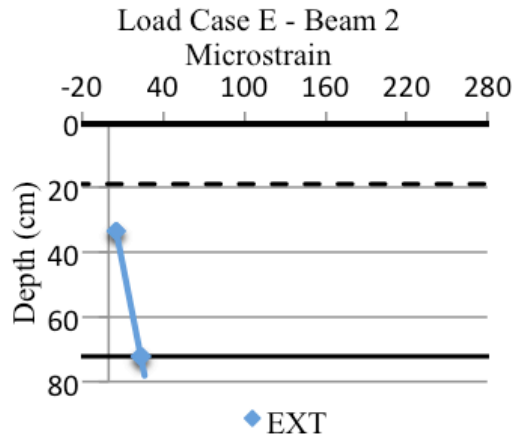

Load Case E - Beam 5

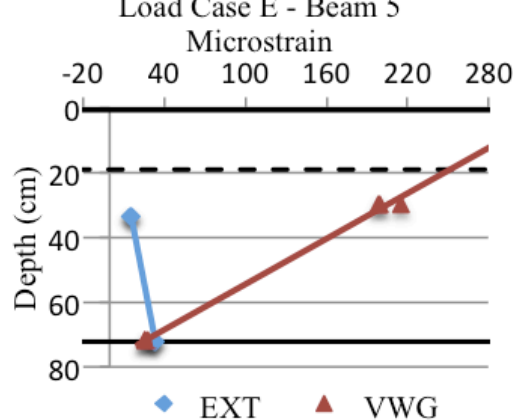

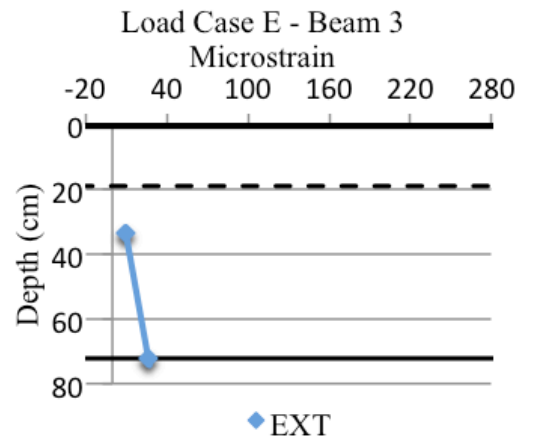

Load Case E - Beam 6

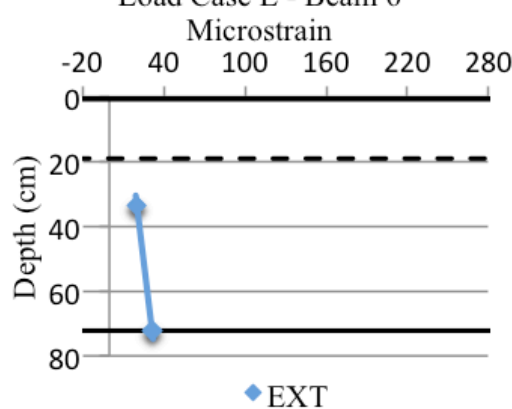

Load Case E - Beam 7

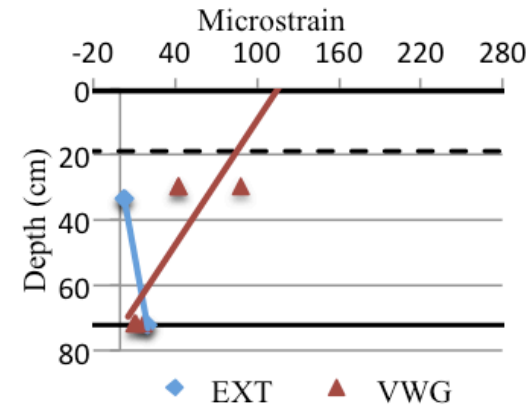

Load Case E - Beam 8

Microstrain

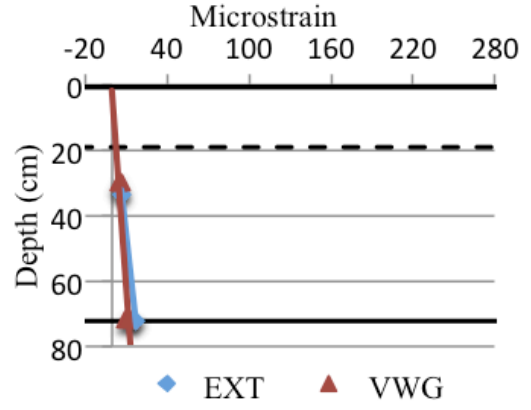

Figure 66: Load Case 'E' Quarter-span Strain Profiles 


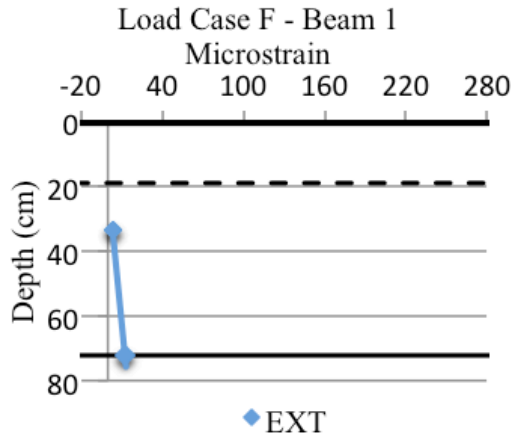

Load Case F - Beam 4

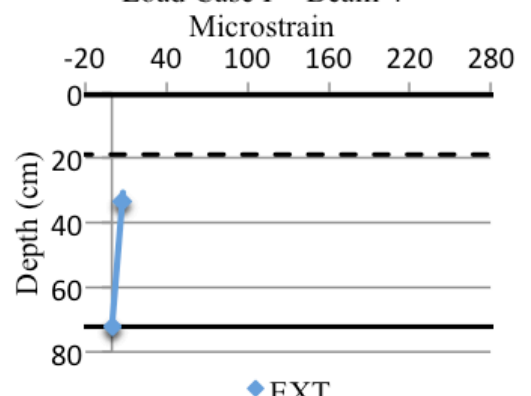

$\bullet$ EXT

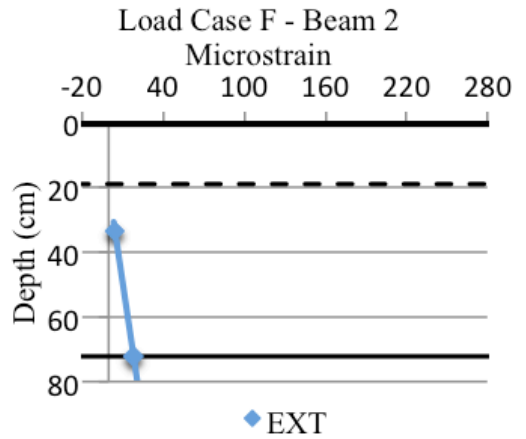

Load Case F - Beam 5

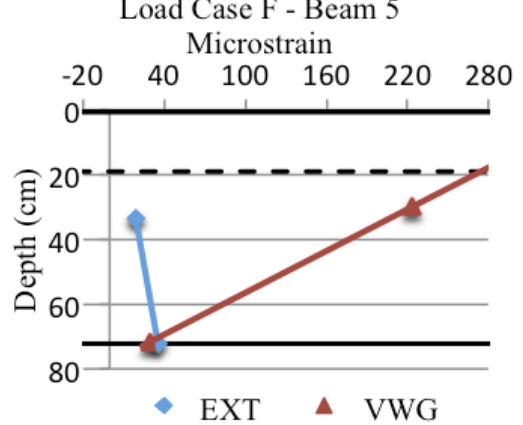

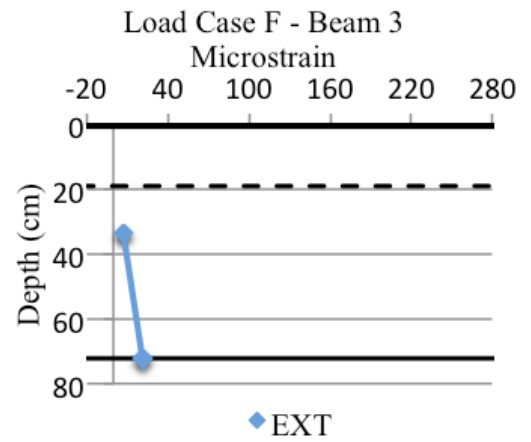

Load Case F - Beam 6

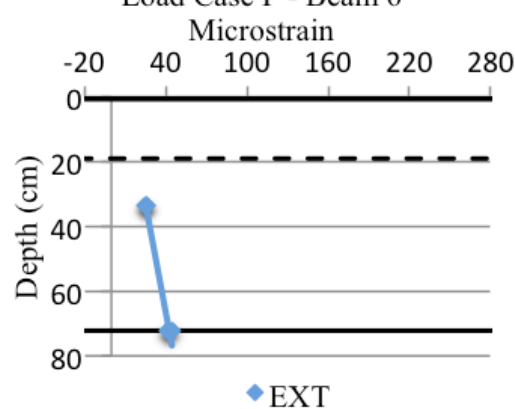

\section{Load Case F - Beam 7}

Microstrain

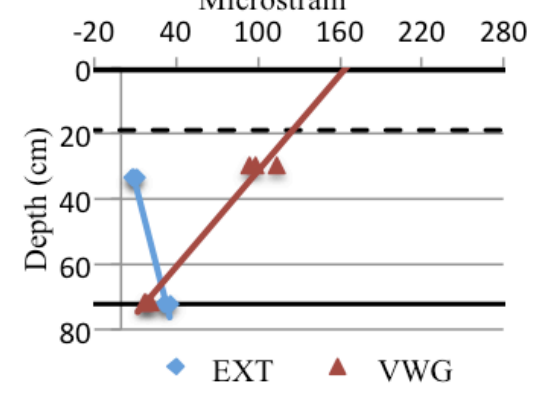

Load Case F - Beam 8

Microstrain

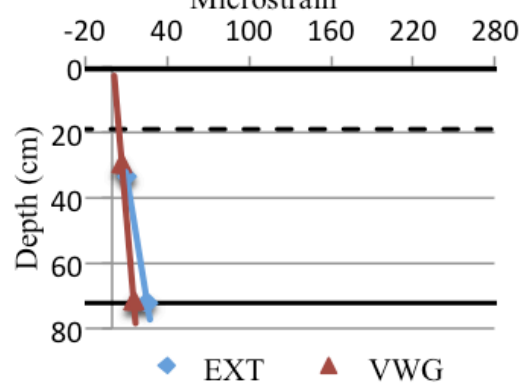

Figure 67: Load Case 'F' Quarter-span Strain Profiles 


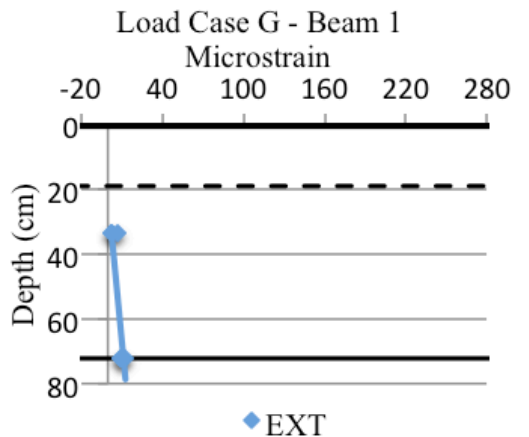

Load Case G - Beam 4

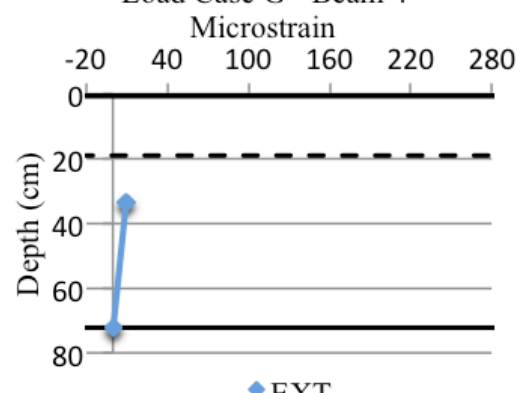

$\bullet$ EXT

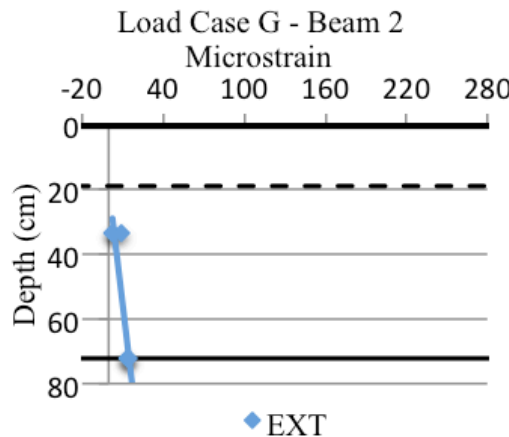

Load Case G - Beam 5

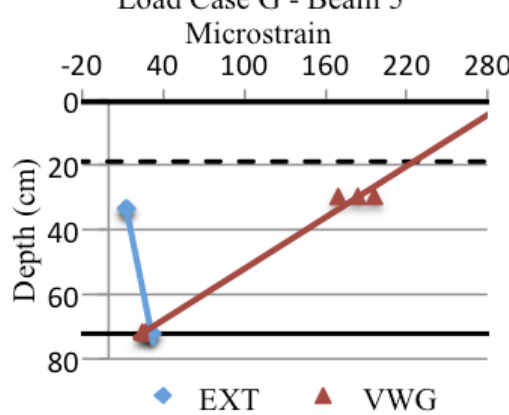

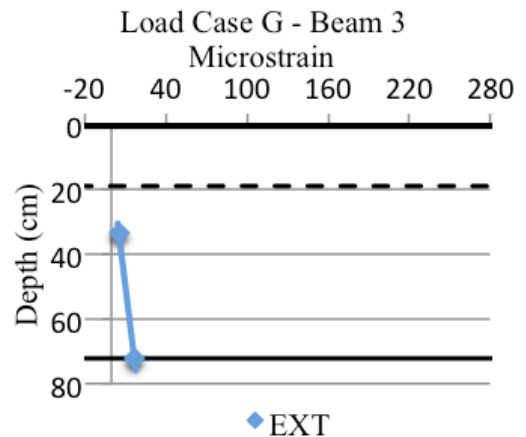

Load Case G - Beam 6

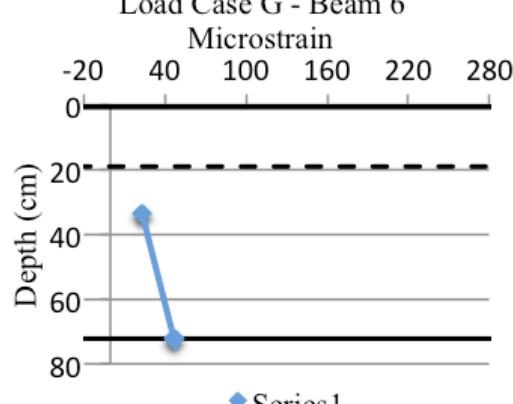

$\rightarrow$ Series 1

Load Case G - Beam 7

Microstrain

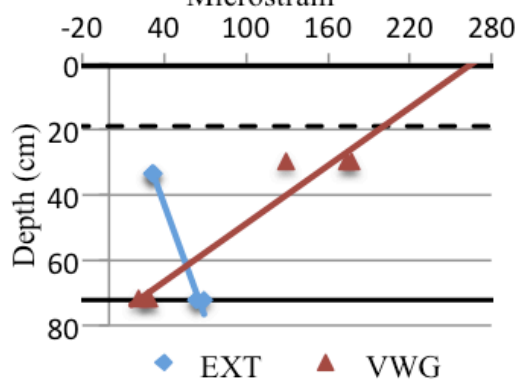

Load Case G - Beam 8

Microstrain

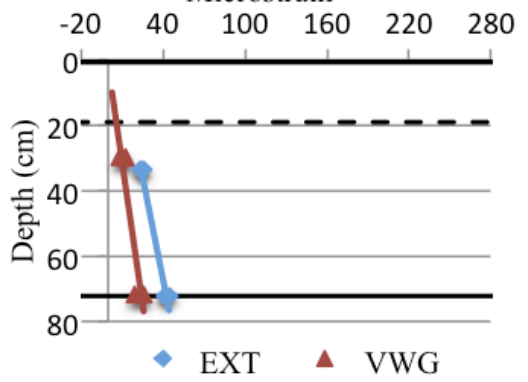

Figure 68: Load Case 'G' Quarter-span Strain Profiles 


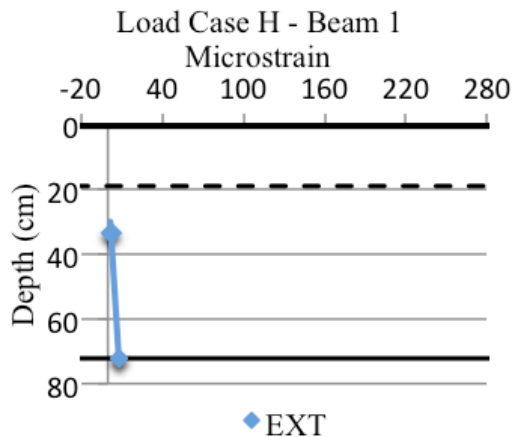

Load Case H - Beam 4

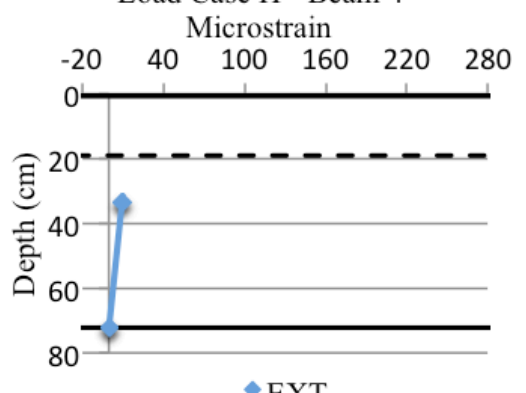

$\bullet$ EXT
Load Case H - Beam 2

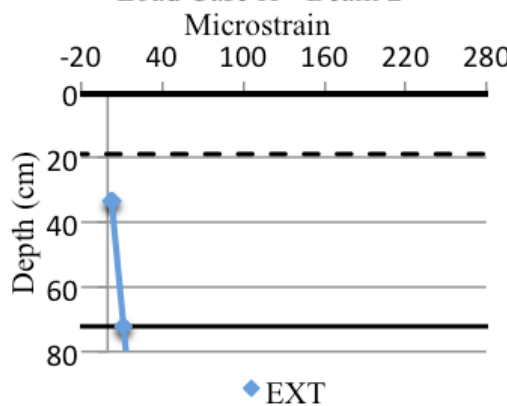

Load Case H - Beam 5

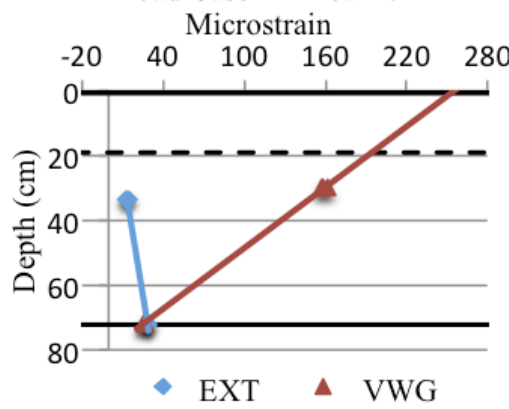

Load Case H - Beam 3

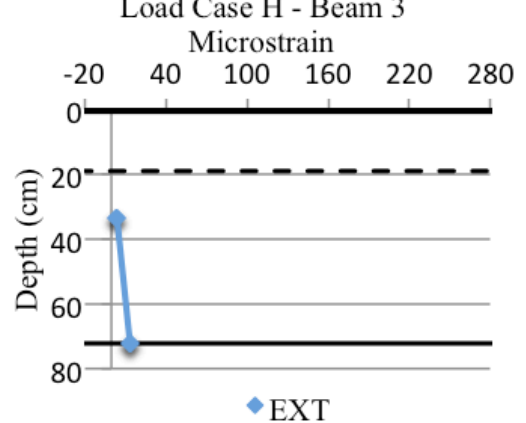

Load Case H - Beam 6

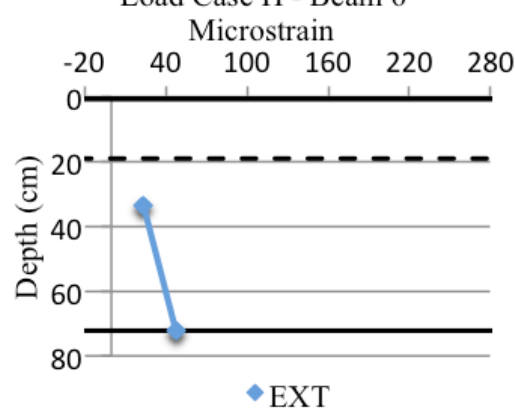

Load Case H - Beam 7

Microstrain

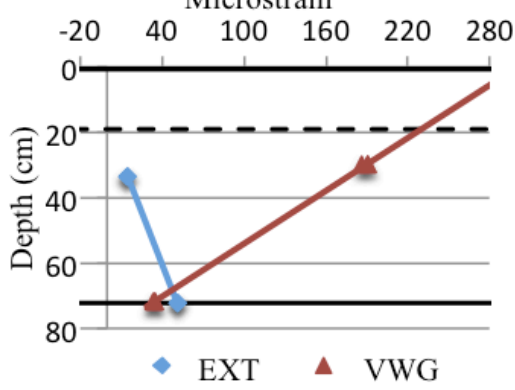

Load Case H - Beam 8 Microstrain

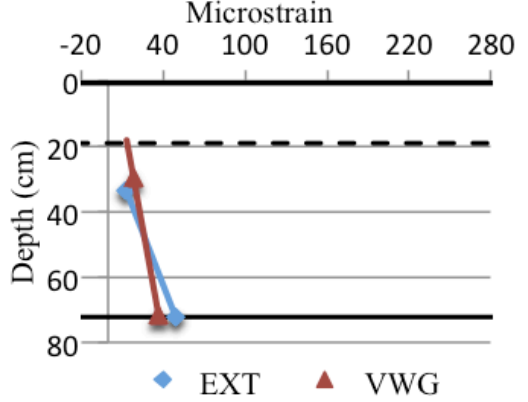

Figure 69: Load Case 'H' Quarter-span Strain Profiles 


\section{APPENDIX F: Dynamic Amplification}

Table 7: Mid-span Dynamic Strain Amplifications

\begin{tabular}{|c|c|c|c|c|c|c|c|c|c|}
\hline & & 1 & 2 & 3 & 4 & 5 & 6 & 7 & 8 \\
\hline Static Load Case 'B' & Max. Strain & 32.7 & 65.3 & 51.3 & 43.0 & 24.2 & 15.7 & 14.6 & 6.5 \\
\hline \multirow[t]{2}{*}{ Dynamic Load Case 'B1' } & Max. Strain & 36.4 & 82.9 & 68.6 & 65.3 & 29.3 & 17.7 & 17.1 & 9.2 \\
\hline & Amplification & $11 \%$ & $27 \%$ & $34 \%$ & $52 \%$ & $21 \%$ & $12 \%$ & $17 \%$ & $41 \%$ \\
\hline \multirow[t]{2}{*}{ Dynamic Load Case 'B2' } & Max. Strain & 41.1 & 99.9 & 79.6 & 63.9 & 33.4 & 22.1 & 19.8 & 11.2 \\
\hline & Amplification & $26 \%$ & $53 \%$ & $55 \%$ & $49 \%$ & $38 \%$ & $40 \%$ & $36 \%$ & $72 \%$ \\
\hline Static Load Case 'D' & Max. Strain & 15.2 & 40.9 & 39.6 & 46.1 & 43.8 & 30.1 & 25.7 & 9.6 \\
\hline \multirow[t]{2}{*}{ Dynamic Load Case 'D1' } & Max. Strain & 17.1 & 42.4 & 39.6 & 46.1 & 43.8 & 30.1 & 25.7 & 9.6 \\
\hline & Amplification & $12 \%$ & $4 \%$ & $13 \%$ & $26 \%$ & $9 \%$ & $34 \%$ & $37 \%$ & $81 \%$ \\
\hline \multirow[t]{2}{*}{ Dynamic Load Case 'D2' } & Max. Strain & 17.0 & 44.1 & 44.5 & 62.4 & 50.7 & 41.7 & 35.7 & 15.9 \\
\hline & Amplification & $12 \%$ & $8 \%$ & $13 \%$ & $35 \%$ & $16 \%$ & $38 \%$ & $39 \%$ & $65 \%$ \\
\hline
\end{tabular}

Table 8: Quarter-span Dynamic Strain Amplifications

\begin{tabular}{|c|c|c|c|c|c|c|c|c|c|}
\hline & & 1 & 2 & 3 & 4 & 5 & 6 & 7 & 8 \\
\hline Static Load Case 'B' & Max. Strain & 44.7 & 47.5 & 26.4 & -- & 12.7 & 10.7 & 9.1 & 8.6 \\
\hline \multirow[t]{2}{*}{ Dynamic Load Case 'B1' } & Max. Strain & 48.1 & 49.2 & 29.8 & -- & 11.8 & 9.8 & 11.2 & 9.6 \\
\hline & Amplification & $8 \%$ & $4 \%$ & $13 \%$ & -- & $-7 \%$ & $-8 \%$ & $23 \%$ & $11 \%$ \\
\hline \multirow[t]{2}{*}{ Dynamic Load Case 'B2' } & Max. Strain & 50.9 & 48.9 & 27.8 & -- & 12.6 & 12.3 & 12.8 & 11.5 \\
\hline & Amplification & $14 \%$ & $3 \%$ & $5 \%$ & -- & $-1 \%$ & $15 \%$ & $41 \%$ & $33 \%$ \\
\hline Static Load Case 'D' & Max. Strain & 24.3 & 35.0 & 35.0 & -- & 16.2 & 13.5 & 11.8 & 11.8 \\
\hline \multirow[t]{2}{*}{ Dynamic Load Case 'D1' } & Max. Strain & 26.9 & 38.4 & 42.1 & -- & 37.4 & 25.9 & 20.2 & 18.3 \\
\hline & Amplification & $11 \%$ & $10 \%$ & $20 \%$ & -- & $132 \%$ & $92 \%$ & $72 \%$ & $55 \%$ \\
\hline \multirow[t]{2}{*}{ Dynamic Load Case 'D2' } & Max. Strain & 29.5 & 40.2 & 44.5 & -- & 33.8 & 24.2 & 20.4 & 18.9 \\
\hline & Amplification & $21 \%$ & $15 \%$ & $27 \%$ & -- & $109 \%$ & $79 \%$ & $74 \%$ & $60 \%$ \\
\hline
\end{tabular}

